Distribution Category:

Phys ics - Nuclear

(UC-34C)

ANL-83-14

ANL- -83-14

DE83 008918

ARGONNE NATIONAL LABORATORY

9700 South Cass Avenue

Argonne, Illino is 60439

\title{
AN EVALUATION OF STRUCTURAL INTEGRITY OF IPNS-I AND ZING-P' TARGETS
}

by

J. Carpenter, H. Ahmed, B. Loomis,

J. Ball, T. Ewing, * J. Bailey, and $A$. F. D'Souza $\star \star$

\section{noThes}

Pontrons of rmis AEPent ane ulectuc.

It has bean repreduced from the best availate copy to permit the broadest possible avallability.

\section{December 1982}

\section{DISCLAIMER}

This report was prepared as an account of work sponsored by an agency of the United States Government. Neither the United States Government nor any agency thereof, nor any of their employees, makes any warranty, express or implied, or assumes any legal liability or responsibility for the accuracy, completeness, or usefulness of any information, apparatus, product, or process disclosed, or represents that its use would not infringe privately owned rights. Reference herein to any specific commercial product, process, or service by trade name, tredemark, manufacturer, or otherwise does not necessarily constitute or impiy its endorsement, recommendation, or favoring by the United States Government or any agency thereof. The views and opinions of authors expressed herein do not necessarily state or reflect thowe of the United States Government or any agency thereof.

* ETA Engineering, Inc., Westmont, Illinois.

**Illinois Institute of Technology, Cinicago, Illinois. 
2 


\section{IPNS - I RADIATION EFFECTS TA.RGET ASSEMBLY}

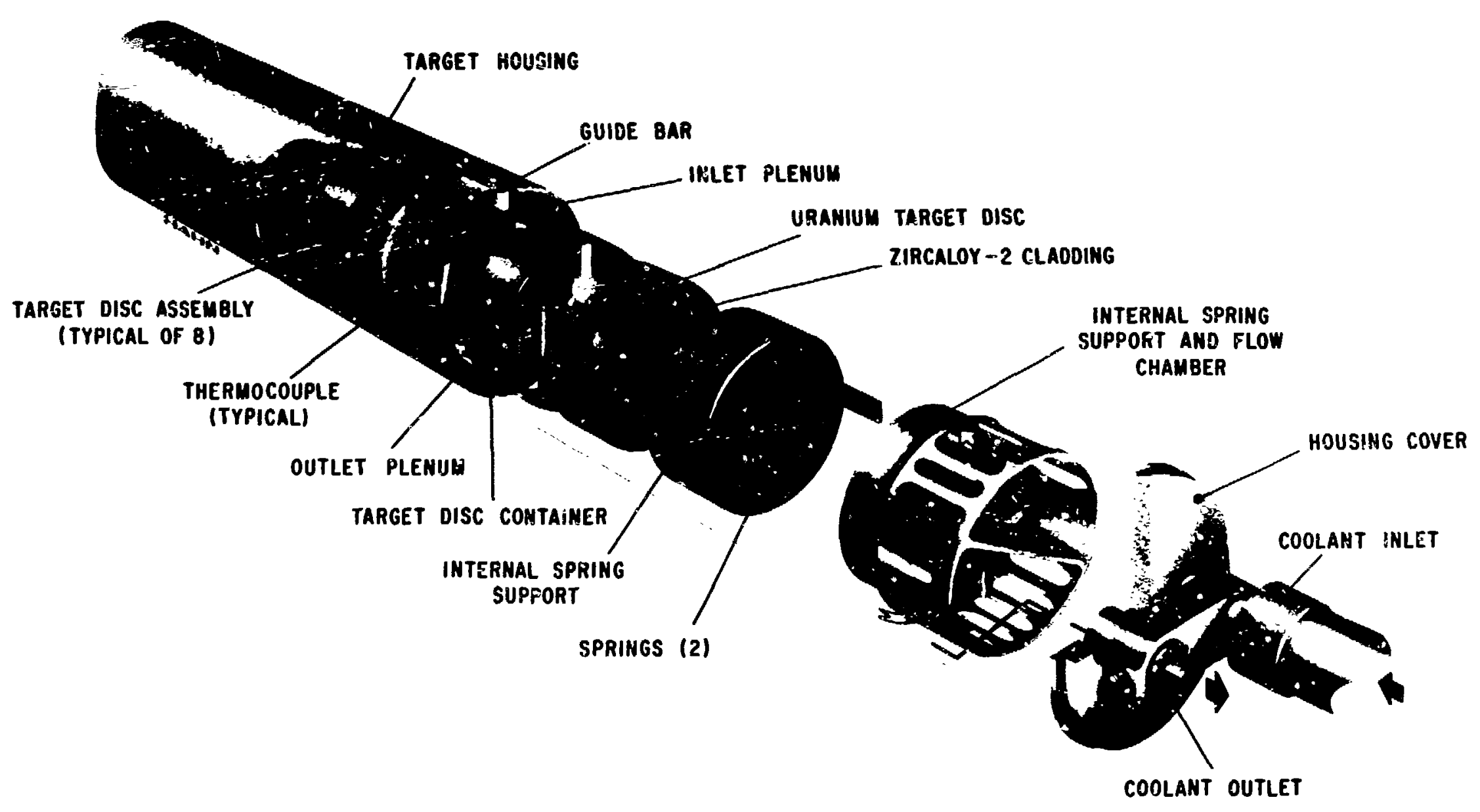




\section{Acknowledgments}

The authors acknowiedqe the contributions of several individuals toward the successful completion of this analysis and the documentation of the resuits: Dr. Henry Thresh, Messrs. Albert Hins and Gary Foqle, for their work in developing the fabrication techniques and procedures, Harry Cern and Elwood Hahn for their contributions tuward the graphics in this report, Ms. C. Landis for her patience and dedication in preparing the manuscript and Mr. Max Weber for his editorial expertise. 
TABLE OF CONTENTS

Page

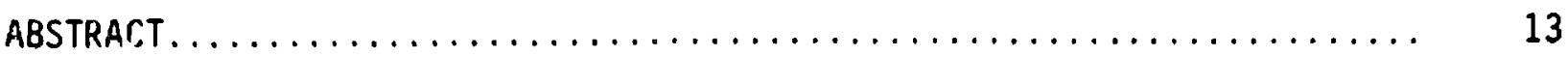

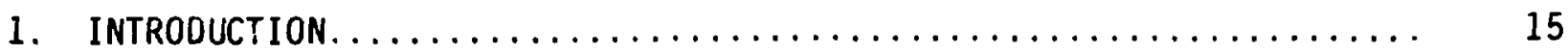

2. ESTIMATE OF THE NEUTRON FLUX DISTRIBUTION AND BURNUP............ 19

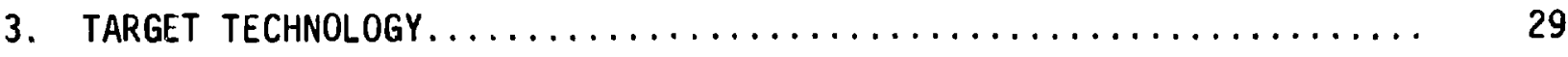

3.1. Target Geometry.............................. 29

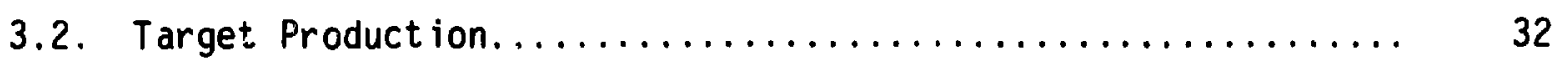

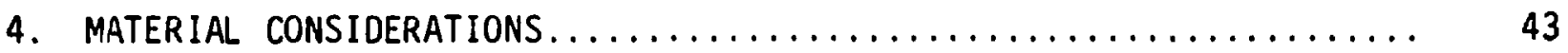

4.1. Heat-Treatment Effects $\ldots \ldots \ldots \ldots \ldots \ldots \ldots \ldots \ldots \ldots . \ldots \ldots, 43$

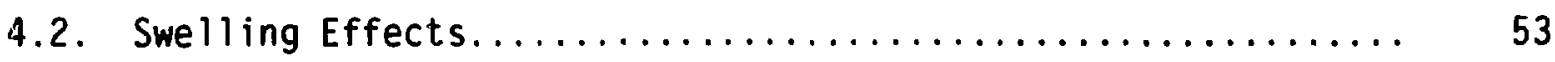

4.2.1. Swelling of Uranium Disc (MAT $=1) \ldots \ldots \ldots \ldots \ldots \ldots$

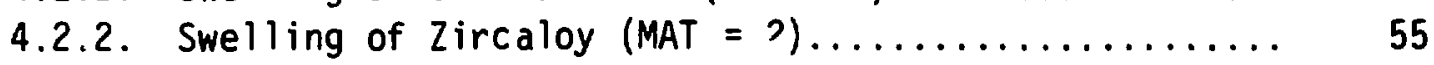

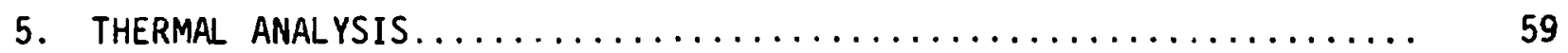

5.1. Zing-P' Experimental Verification.................. 59

5.1.1. Heat-Genewation Rate Distribution.............. 60

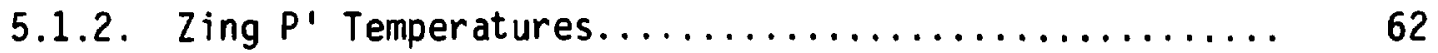

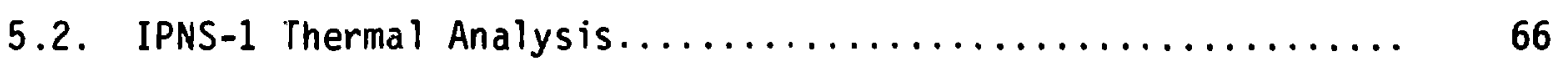

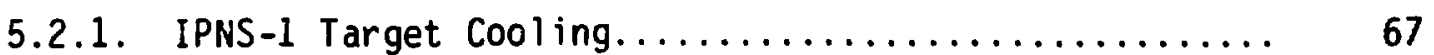

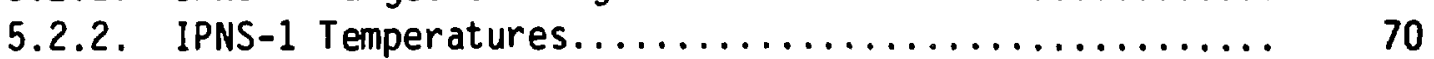

6. TARGET MATERIAL STRESS............................... 77

6.1. Zing-P' Target Stress........................... 77

6.1.1. One-Microampere Proton Current................ 79

6.1.2. Ten-Microampere Proton Current................ 82

6.2. IPNS-1 Target Stress........................... 87

6.3. Fat igue Failure................................... 90

APPENDIXES:

A. Hydraul ic Study of Flow Center and Pressure Profiles in

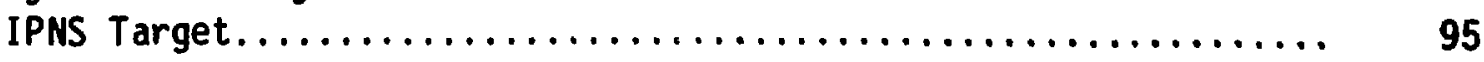

1. Methodology.................................... 95

2. Mode 1. Normal Operation at the Design Conditions......... 103 
TABLE OF CONTENTS

Page

3. Mode 2. Operation with Blocked Channel.............. 103

4. Mode 3. Operation with Broken Spring................. 107

B. Two-Phase Flow Instability in IPNS $-1 \ldots \ldots \ldots \ldots \ldots \ldots \ldots . \ldots . \ldots . \ldots . \ldots 129$

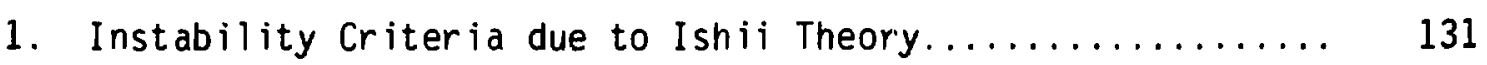

2. Instability Criterion due to Saha Theory.............. 134

C. Heat-Transfer Coefficients.......................... 139

1. Zing-P' Target.................................. 139

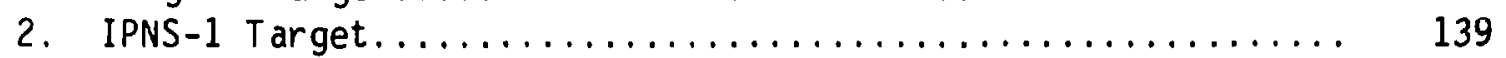

2.1. One-Convective Zone Model.................... 140

2.2. Two-Convect ive-Zone Model................. 141

2.3. Five-Channel Geometry; Two-Convect ive Zones, Reduced Flow Model (20\% Flow)....................... 149

3. Blocked Center Channel Accident.................... 151

D. Materials Physical and Mechanical Properties............... 159

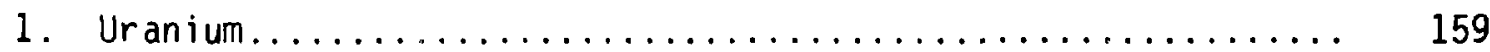

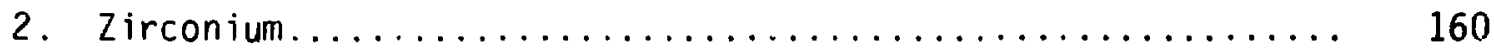

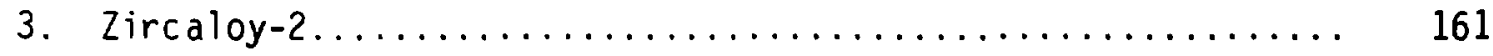


LIST OF FIGURES

No.

Title.

$\underline{\text { Page }}$

2.1. Target Neutron Flux: Diffusion Theory................. 22

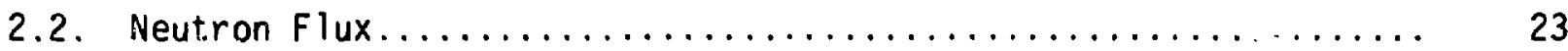

2.3. Uranium-2:38 Neutron-absorption Cross Section $\left(\sigma_{a}\right)$ and Neutrorabsorption Cross Section Weighted by IPNS Target Neutron-energy Distribution $\left(f(E) \times \sigma_{a}\right)$ versus Neutron Energy............. 26

3.1. Zing-P' Uranium Target Assembly................... jú

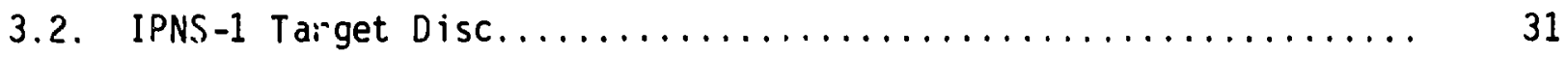

3.3. Design of Zircaloy-2 Interface in the Weld Zone............. 35

3.4. Zircaloy-Uranium Interface after HIP Bonding.............. 36

3.5. Microstructure of Uranium after HIP Bonding............. 37

3.6. Zircaloy-2 Clad Uranium Disc with Thermocouple Well......... 38

4.1. Zing $P^{\prime}$ Target Displacement due to Heat-treatment Effect...... 47

4.2. Zing $P^{\prime}$ Target Maximum Principal Stress Distribution - Heat

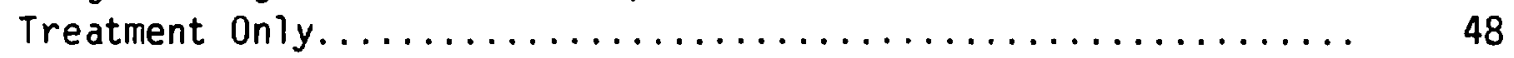

4.3. Minimum Principal Stress Distribution with Stress Difference of 800 psi between Contour Lines...................... 48

4.4. Principal Shear Stress Distribution with Stress Difference of 4000 psi between Contour Lines..................... 48

4.5. Effective Stress Distribution with Stress Difference of 8000 psi

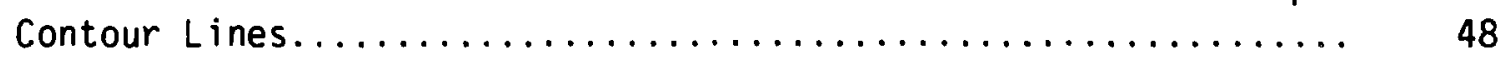

4.6. IPNS-1 Target Displacement during Heat Treatment and Bonding.... 49

4.7. IPNS Target Maximum Principal Stress Distribution due to Heattreatment Effect Only with Stress Difference of 1500 psi between

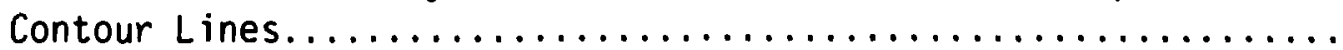

4.8. IPNS-1 Target Minimum Principal Stresses due to Heat-treatment Effect Only with Stress Difference of 8000 psi between Contour

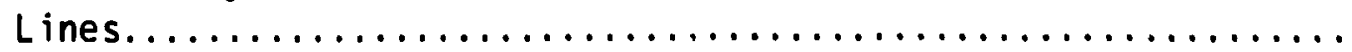

4.9. Maximum Principal Shear Stress Distribution due to Heat treatment Effect Only with Stress Difference of $3000 \mathrm{psi}$ between

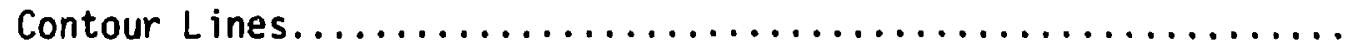

4.10. IPNS-1 Target Effective Stress Distribution due to Heattreatment Effect $0 \mathrm{nly}$ with Stress Difference of 7000 psi between Contour Lines. 


\section{LIST OF FIGURES}

No.

Title

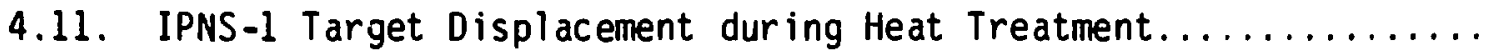

4.12. IPNS-1 Target Radial Stress due to Heat-treatment Effect Only with Stress Difference of 8000 psi between Contour Lines........

4.13. IPNS-1 Target Axial Stress Distribution due to Heat-treatment Effect Only with Stress Difference of $\$ 000$ psi between Contour

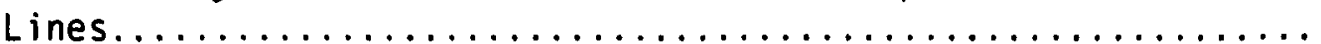

4.14. IPNS-1 Target Hoop Stress Distribution due to Heat-treatment Effect Only with Stress Difference of 8000 psi between Contour

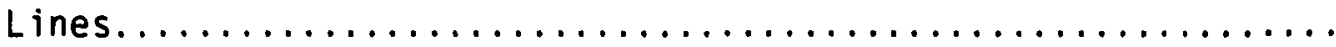

4.15. IPNS Target-Maximum Principal Stress Distribution due to Heat Treatment Effect Only with Stress Difference of 1500 psi between

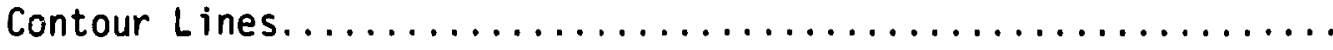

4.16. IPNS-1 Target Minimum. Principal Stress Distribution due to Heat-treatment Effect Only with Stress Difference of 800 psi

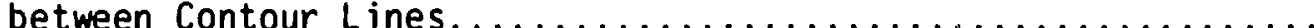

4.17. IPNS-1 Target Maximum Principal Shear Stress Distribution due to Heat Treatment Effect Only with Stress Difference of $4000 \mathrm{psi}$

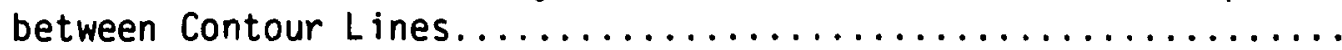

4.18. IPNS-1 Target-effective Stress Distribution due to Heattreatment Effect Only with Stress Difference of 8000 psi between

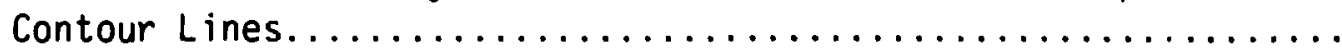

5.1. Interpolation Schemes............................. 63

5.2. Zing P' Temperature Distribution; Fuji Fit............... 64

5.3. Zing $P^{\prime}$ Temperature Distribution; Aztec Fit.............. 65

5.4. IPNS-1 iarget-cool ing Channel Geometries................. 68

5.5. Two-convective-zone Temperature Distributions for Five- and Seven-channel Geometries with Full Flow....................

5.6. One-convect ive-zone Temperature Distributions for Five- and Seven-channel Geometries with Full Flow....................

5.7. Reduced-flow Temperature Distributions for Five-channel

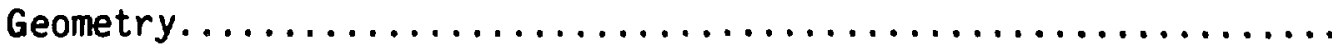

5.8. Temperature Distribution in Five-channel Geometry with Blocked-

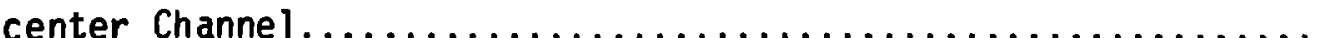

6.1. Zing $P^{\prime}$ Taryet-deflected Shape due to Power Cycle; $0.981 \mu \mathrm{A}$

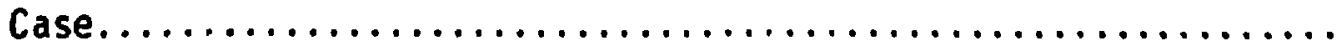


LIST OF FIGURES

No.

Title

Page

6.2. Zing $P^{\prime}$ Target-radial Stress Distribution due to Power Cycle;

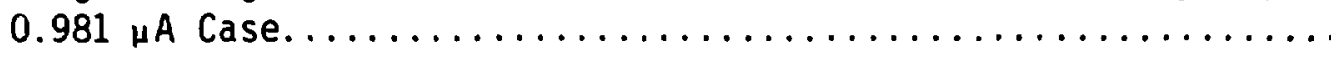

6.3. Axial Stress Distribution Stress Difference of 1000 psi between

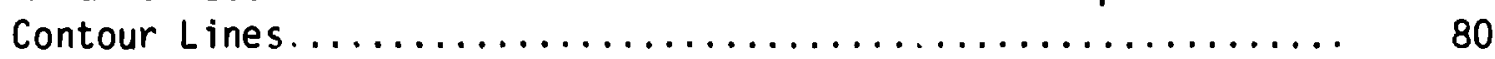

6.4. Hoop Stress Distribution with Stress Differences of 1000 psi

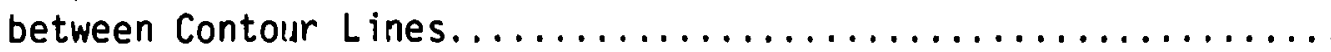

6.5. Zing $P^{\prime}$ Target-maximum Principal Stress Distribution due to Power Cycle with Stress Difference of 1000 psi between Contour

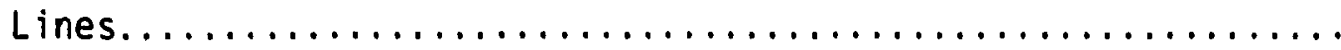

6.6. Minimum Principal Stress Distribution with Stress Difference of

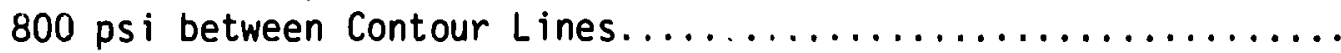

6.7. Principal Shear Distribution with Stress Difference of 250 psi between Contour Lines............................. 81

6.8. Zing $P '$ Target Effective Stress Distribution due to Power Cycle. 83

6.9. Zing P' Target-deflected Shape due to Power Cycle; 10-uA Case... 83

6.10. Zing $P^{\prime}$ Target-radial Stress Distribution due to Power Cycle;

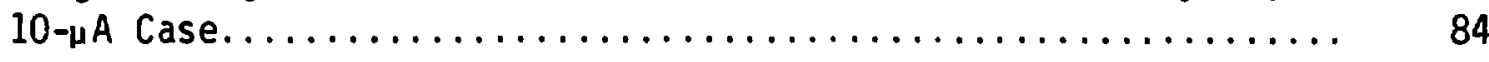

6.11. Axial Stress Distribution with Stress Difference of 8000 psi

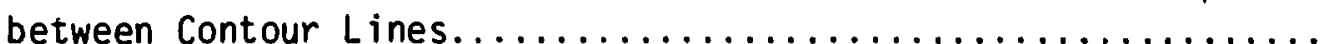

6.12. Hoop Stress Distribution with Stress Difference of 10,000 psi

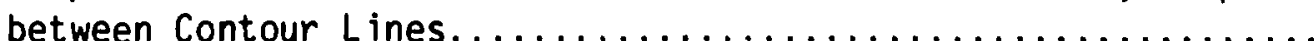

6.13. Zing $P^{\prime}$ Target-maximum Principal Stress Distribution due to

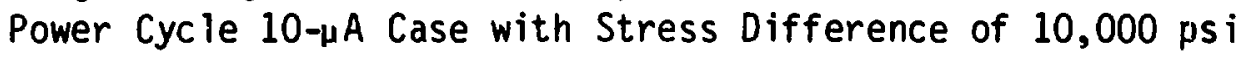

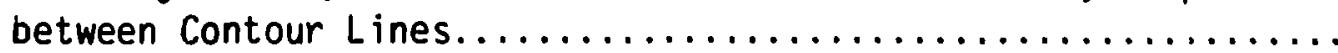

6.14. Minimum Principal Stress Distribution with Stress Difference

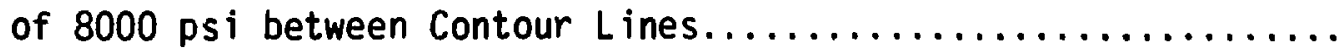

6.15. Principal Shear Stress Distribution with Stress Difference of

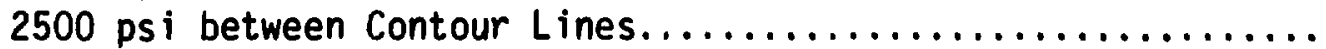

6.16. Zing $P^{\prime}$ Target-effective Stress Distribution due to Power Cycle with Stress Difference of 5000 psi between Contour Lines........

6.17. IPNS-1 Target-deflected Shape due to Power Cycle............ 88

6.18. Radial Stress Distribution......................... 88

6.19. Axial Stress Distribution.......................... 88 


\section{LIST OF FIGURES}

No.

$\underline{\text { Title }}$

Page

6.20. Hoop Stress Distribution........................ 88

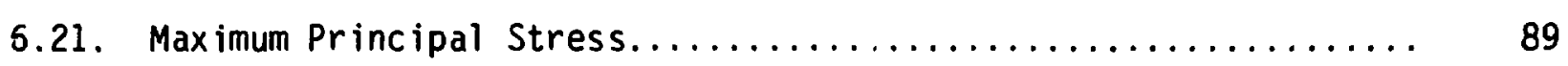

6.22. Minimum Principal Stress Distribution................... 89

6.23. Principal Shear Stress Distribution................... 89

6.24. IPNS-1 Target-effective Stress Distribution due to Power Cycle.. 89

6.25. Design Curve for Unirradiated Zircaloy-2, 3 , or $4 \ldots \ldots \ldots \ldots \ldots$.

6.26. Design Curve for Irradiated Zircaloy $-2,3$, or $4 \ldots \ldots \ldots \ldots \ldots . . . .62$

A.1. Disc Geometry................................. 96

A.2. Layout of Pipe Lines............................. 99

A.3. Resistance in Pipe due to Sudden Enlargements and Contractions.. 104

A.4. Flow and Pressure Profile.......................... 105

A.5. Velocity Distributior........................... 106

A.6. Flow and Pressure Distribution when Channel in First Disc is

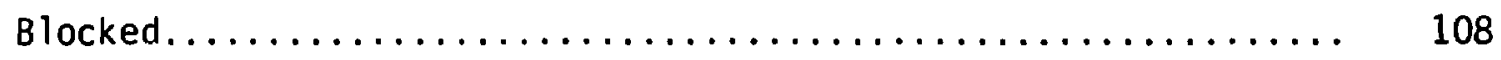

A.7. Velocity Distribution when 5/16-in. $\times 3-1 / 8-i n$. Channel in First

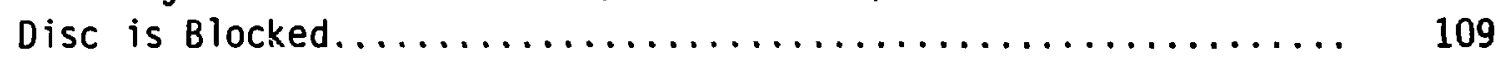

A.8. Flow and Pressure Distribution when 1/2-in. $\times$ 3-7/8-in. Channel in First Disc is Blocked............................ 110

A.9. Velocity Distribution when 1/2-in. $\times 3-7 / 8-i n$. Channel in First

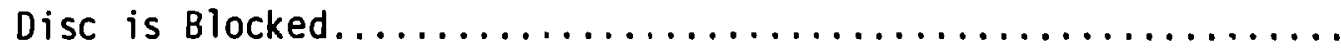

A.10. Flow and Pressure Distribution when 1/2-in. $\times 4$-in. Channel in

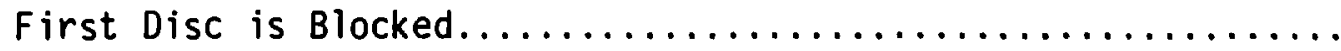

A.11. Velocity Distribution when 1/2-in. $x$ 4-in. Channel in First Disc

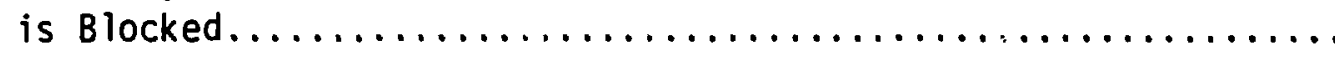

A.12. Flow and Pressure Distribution when All Channels in Last DisC

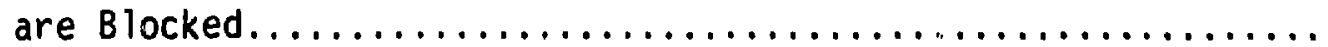

A.13. Velocity Distribution when All Channels in Last Disc are Blocked.

A.14. Flow and Pressure Distribution with 1/4-in. Diameter Hole

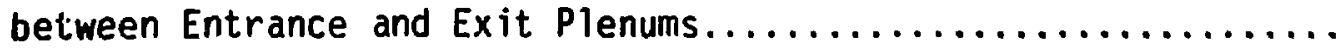

A.15. Velocity Distribution with 1/4-in. Diameter Hole between Entrance and Exit Plenums. 
LIST OF FIGURES

No.

$\underline{\text { Title }}$

Page

A.16. Cross-sectional Area of Gap.

A.17. Flow and Pressure Distribution with 1/4-in. Gap at Front of First Disc.................................... 120

A.18. Velocity Distribution wich 1/4-in. Gap at Front cf First Disc... 121

A.19. Flow and Pressure Distribution with 1/4-in. Gap at Front of

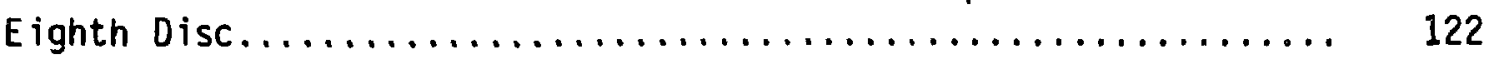

A.20. Velocity Distribution with 1/4-in. Gap at Front of Eighth Disc.. 123

A.21. Flow and Pressure Profile for $40 \%$ Flow................... 124

A.22. Velocity Distribution for $40 \%$ Flow.................... 125

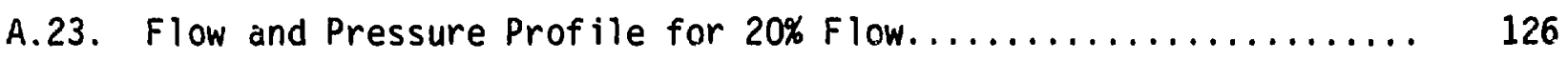

A.24. Velocity Distribution for $20 \%$ Flow................... 127

C.1. One-convective-zone Mode1........................ 142

C.2. Two-convect ive-zone Model........................ 143

C.3. Blocked Center Channel Case; Three-zone Geometry............. 153

C.4. Critical Heat Flux in IPNS-1 Target with Reduced Flows......... 156

C.5. Typical Eoiling Data for Subcooled Forced Convection--Heat Flux vs. Temperature Difference between Surface and Fluid Bulk...... 


\section{LIST OF TABLES}

No. $\quad \underline{\text { Title }}$ Page

2.1. Neutron Production in IPNS -1 Target........................ 21

3.1. Tensile Properties of Zirconium-Uranium Alloys Annealed at $24 \mathrm{hr}$

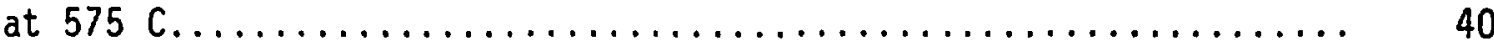

4.1. Computer program for Adjustment of Mean Coefficient of Expansion. 45

4.2. Computer Program for Adjustment of Mean Coefficient of Thermal

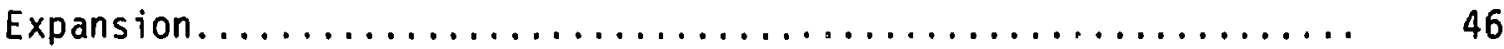

5.1. HETC/VIM Thermal Energy Deposition for Zing-P' Target with

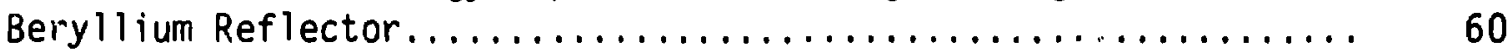

5.2. Comparison of Zing-P' Theoretical and Experimental Results...... 62

5.3. HETC/VIM Thermal Energy Deposition for IPNS-1 Target with

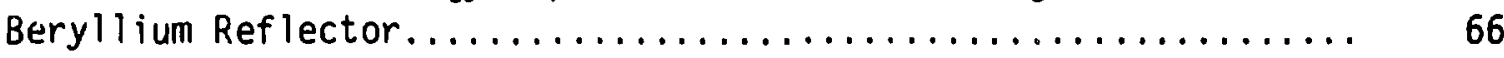

5.4. Maximum Interior Target lemperature and Channel-Wall

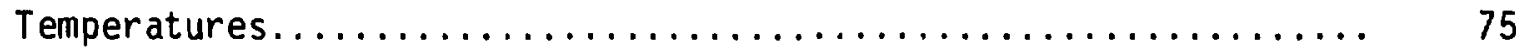

A.1. Channel Pararieter Values............................ 97

A.2. Pipeline Parameters............................... 100

B.1. Calculated Values of Physical Constants................. 130

B.2. Calculated Values of Physical Constants.................. 131

B.3. Two-Phase Flow Physical Properties.................... 132

B.4. Heat Transfer Properties of Fluid..................... 133

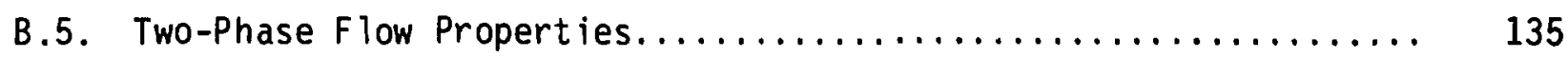

C.1. Five-Channel Geometry; One-Convective-Zone Model............. 144

C.2. Seven-Channel Geometry; One-Convect ive-Zone Model............ 145

C.3. Five-Channel Geometry; Two-Convect ive-Zones, Full-flow Model.... 145

C.4. Seven-Channel Geometry; Two-Convect ive-Zones, Flow Model........ 147

C.5. Five-Channel Geometry; Two-Convect ive-Zones, Flow Model......... 148

C.6. Five-Channel, Two-Convective Reduced Flow Mode 1.............. 152

C.7. Seven-Channel; Blocked Center Channel................... 154 
AN EVALUATION OF STRUCTURAL INTEGRITY OF

IPNS-I AND ZINGG-P' TARGETS

by

J. Carpenter, H. Ahmed, B. Loomis,

J. Ball, T. Ewing, J. Bailey,

and A. F. D'Souza

\begin{abstract}
This report discusses the design, production, and evaluation of clad uranium-alloy targets that function as spallation neutron sources in the ZING-P' and IPNS-I facilities with a pulsed $(10-30 \mathrm{~Hz}), 500-\mathrm{MeV}$ proton beam. The methodology and resuits of theoretical nuclear-particle transport, heat transport, and stress analyses that were used in the development of a design for the targets are described. The production of a zirconium-clad uranium-alloy cylinder for ZING-P' and Zircaloy-2-clad uranium alloy discs for IPNS-I is discussed with particular attention to the procedural details. The theoretical analyses were verified by measuring the thermal and mechanical response of the clad uranium under conditions designed to simulate the operations of the pulsedneutron sources.
\end{abstract}




\section{INTRODUCTION}

The goals of the Intense Pulsed Neutron Source (IPNS) program at Argonne National Laboratory are the construction, operation, and scientific utilization of an intermediate-intensity, pulsed spallation neutron source for fast-neutron radiation damage and slow-neutron scattering research. Simultaneously, the goal is to lay the technical and scientific groundwork for eventual construction of higher-intensity facilities. Pulsed sources provide intense bursts of neutrons in very narrow pulses at a repetition rate sufficient to provide high data rates in the experiments. Pulsed operation, combined with the high rate of neutron production per unit of deposited heat, avoids many of the limitations of steady reactorbased sources, such as the high time-average heat-generation rates, while use of noncritical target assemblies avoids reactor licensing problems.

Earlier, Argonne built and operated two prototype pulsed spallation neutron scurces, ZING-P and ZING-P'; these provided data and experience for the design of IPNS-I. A larger facility (IPNS-II) was conceptually designed, but has not been constructed.

In IPNS-I the Rapid Cycling Synchrotron (RCS) accelerates a pulsed beam (frequency $30 \mathrm{~Hz}$, average current $10 \mu \mathrm{A}$ ) of protons to medium energy $(500 \mathrm{MeV})$. The protons strike a heavy metal target, e.g., uranium, tungsten, tantalum, etc., producing bursts of neutrons by a process called "spallation." Uranium targets are used in IPNS-I because these produce the highest neutron yield. A uranium target in ZING-P' provided fundamental experience.

Thermal gradients in the targets, that are made more complex by the nonuniform distribution of protons in the beam and the resulting nonuniformities in the power-density distribution, give rise to significant thermal stresses in the target and target-cladding material. This report addresses the stress problems and their consequences. Since accelerators operate somewhat irregularly with the beam going on and off momentarily some 20-30 times per day, these stress cycles are repeated many times in the 
intended lifetime of a target; the cyclic thermal stress in the cladding may lead to fatigue failure, which has been identified as the most important potential failure mechanism in the IPNS-1 targets. The swelling effects due to radiation damage, accumulated fission products and cyclic stress must be controlled; consideration of these effects led to the choice of a "Savannah River" (low iron, carbon, and aluminum) alloy of uranium and limitation of the operating temperature. Developments that led to the successful IPNS-I clad-uranium target are the subject of this report.

The design of the IPNS-I target is the result of a one-year effort involving theoretical nuclear particle and heat transport, stress analyses, prototypical target operation, and experimental verification of the thermal and mechanical responses of Zircaloy-2 and zirconium-clad uranium targets in the pulsed source environment. This report presents the analyses and experimental results associated with this design effort.

The phases of the IPNS target design effort may be characterized as follows:

1. Design of the ZING-P' prototypic target--a solid uranium cylinder diffusion bonded to $0.060 \mathrm{in}$. of zirconium cladding.

2. Nuclear, thermal, and stress analyses of the ZING-P' target.

3. Operation of the ZING-P' target at several levels of beam power and proton energies to experimentally confirm and supplekient analytical results.

4. Design of the IPNS-I target consisting of several discs of uranium, each diffusion-bonded to a cladding of Zircaloy-2.

5. Nuclear, thermal, and stress analyses of the IPNS-1 target.

6. Preliminary operation of the IPNS-1 target to experimentally confirm analytical results.

The thermal and stress analyses have been geared to structural integrity investigations of the ZING-P' and IPNS-I targets. Occasionally, obstacles were encountered in achieving the theoretical objectives. For example, the available information on the material properties used in the calculation of the energy deposition, temperature distribution, and 
stresses was incomplete and had to be supplemented by ZING-P' experimental results, other experiments conducted at Argonne National Laboratory, and recent developments appearing in the literature.

Much of the initial analys is performed is reported in Refs. [1.1-1.3]. However, experience with ZING-P' target experiments indicated the energy deposition in the target is somewhat different than assumed in Refs. [1.11.3]. Analytical and design guidelines are generally based on the ASME Nuclear Vessel Code, Ref. [1.4], wherever applicable. Information on material properties used in the analysis is based on available data from Refs. [1.4-1.9].

The stress analyses reported here use the linear-elastic finiteelement method of analysis. Cyclic temperature variations that occur with each proton pulse are quite small ( $\left.\leqslant 1^{\circ} \mathrm{F} / \mathrm{pulse}\right)$ so that a quasi-static analysis is applicable. For thermal ratchetting and fatigue behavior of the materials, simplified techniques based on elastic analys is are used to determine safe operating power levels for the ZING-P' and IPNS-I targets. Creep, swelling, and plasticity effects have not been investigated in detail because of the very linited body of available data on properties and because of cost limitations. However, qualitative evaluations of these effects indicate that none of these are life-time limiting.

For the ZING-P' target, the following different cases of stress were invest igated:

Case 1: The prestress condition arising from annealing of the target at $932^{\circ} \mathrm{F}$ followed by assumed rapid cooling to $70^{\circ} \mathrm{F}$.

Case 2: A target power level corresponding to $1 \mu \mathrm{A}$ of p:oton beam current--the level at which ZING-PI experiments were performed.

Case 3: A target power level corresponding to a proton beam current of $10 \mu \mathrm{A}$ scaled up from Case 2. This high-power case was calculated to verify the proportionality of results between the 1- and 10- $\mathrm{A}$ cases. Limits for ZING-P' operation targets were chosen based on maximum stress and temperature limits. 
For the IPNS-1 target, which is composed of eight discs of $2.5 \mathrm{~cm}$ thickness each cooled on the outer boundary, the calculations are performed for the following different cases:

Case 4: The prestressed condition arising from the heat treatment of the target disc at a $932^{\circ} \mathrm{F}$ zero stress level followed by an assumed rapid cooling to $70^{\circ} \mathrm{F}$.

Case 5; The limiting target power level determined from the allowabie stresses in the target based on fatigue characteristics of the materials.

The results for Cases 1 and 4 are presented in Chapters 3 and 4 . In Chapter 5 the thermal analysis is presented with extensive experimental verifications. The results for Cases 2,3 , and 5 are presented in chapter 6 .

\section{References}

[1.1]. Pan, Y. C. to Ball, J. R., IPNS-I Target Disc Thermal and Stress Analys is - ENG/DE/7028, August 17, 1978.

[1.2]. Ahmed, H. and Bailey, J. to J. Ball, Thermal and Stress Analys is Zing P' Target - Single Pellet Concept - ENG/DE/7660, March 28, 1979.

[1.3]. Loomis, B. to J. Ball, Evaluation of Target Material and Power Source for Zing $\mathrm{P}^{\prime}$ Target.

[1.4]. ASME Nuclear Vessel Code - Section III - Code-Case 1592 (1979).

[1.5]. Miller, G. L., Zirconium - Metallurgy of the Rarer Metals - 2, Acadeinic Press Inc., Publishers, New York, 1957.

[1.6]. Tebo, F. J., Selected Physical Property Value of Various Materials.

[1.7]. Gittus, J. H., Uranium - Metallurgy of the Rarer Metals-8, Butterworths, Washington, 1963.

[1.8]. Scheme1, J. H., ASTM Manual on Zirconium and Hafnium, ASTM-STP-639, 1977.

[1.9]. Douglass, D. L., The Physical Metallurgy of Zirconium "Atomic Energy Review," Vol. 1, No. 4, International Atomic Energy Agency, Vienna, 1963. 


\section{ESTIMATES OF THE NEUTRON FLUX DISTRIBUTION AND BURNUP}

\subsection{Neutron Flux Distribution}

Neutrons are produced in the uranium target during axial bombardment with 500-MeV protons by spallation and fast-fission reactions. The target neutron energies range up to $500 \mathrm{MeV}$, with a most probable energy of about $1 \mathrm{MeV}$. The greatest neutron production in uranium occurs at an axial depth in the target of approximately $5 \mathrm{~cm}$ [2.1]. By contrast, the highest target temperatures occur in the first disk $(0-2.5 \mathrm{~cm}$ axial depth). However, for conservatism, the thermal anaiys is assumes the worst-case tempeiature distribution coincident with the worst-case neutron swelling.

HETC/MORSE computed values of neutron production rate in uranium corresponding to $22 \mu \mathrm{A}=1.37 \times 10^{14}$ protons $/ \mathrm{sec}$ at $500 \mathrm{MeV}$ are tabulated in Table 2.1. These values are computed from the neutron/proton production values in Table 12 of Ref. [2.1] by multiplication with $1.37 \times 10^{14} \mathrm{p} / \mathrm{s}$ and dividing by the target volume associated with each axial radial zone.

Using the neutron production rates as a source term, estimates of the neutron flux distribution are computed using two approaches: neutrondiffusion theory and a Green's function solution of the transport equation. Provided the sources are isotropic (fission and spallation sources are essentially isotropic) and the angular flux is only weakly dependent on angle, the time-average neutron flux is given approximately by the onespeed neutron diffusion equation [2.2]

$$
-\nabla \cdot D(\underline{r}) \underline{\nabla_{\phi}}+\Sigma_{R}(\underline{r}) \phi(\underline{r})=S(\underline{r})
$$

where $S$ is the source term, $D$ is the diffusion coefficient, and $\Sigma_{R}$ is the macroscopic-removal cross section. In the present problem, the source term varies only slowly in the axial direction over several neutron mean-free paths (between $Z=1.8$ and $Z=8.4 \mathrm{cin}$ in Table 2.1) compared to the radial variation. Hence, the diffusion equation may be further simplified by neglecting the axial variation of the flux $\phi$ in the vicinity of $Z=5 \mathrm{~cm}$ to yield 


$$
-D \frac{d^{2} \phi}{d r^{2}}+\frac{1}{r} \frac{d \phi}{d r}+\varepsilon_{R} \phi(r)=s(r) \text {. }
$$

The corresponding discretized radial equation may be written [2.1] as

$$
-D\left[\frac{\phi_{i+1}-2 \phi_{i}+\phi_{i-1}}{\Delta^{2}}+\frac{\phi_{i+1}-\phi_{i-1}}{2 r_{i} \Delta}\right]+\Sigma_{R} \phi_{i}-s_{i}=0, i=1,2, \ldots, 5 \text {. (2.2) }
$$

Here, the index $i$ references the five radial regions at which the source value $S_{i}$ is given (see Tahle 2.1).

The diffusion-theory radial flux at $Z=5.1 \mathrm{~cm}$ is shown in Fig. 2.1. For this calculation, fast-flux constants [2.2] of $D=1.16 \mathrm{~cm}^{-1}$ and $\varepsilon_{R_{1}}=$ $0.100 \mathrm{~cm}$ for ${ }^{238} \mathrm{U}$ have been used, and the boundary condition $\phi_{\phi}=6 \times 10^{12}$ $\mathrm{n} / \mathrm{s}-\mathrm{cm}^{2}$ at the cylindrical surface (from [2.1], Table 13) has been applied. The flux is converted to a fluence by multiplication by the cycle duration of $0.1 \mu \mathrm{sec}$.

The diffusion approximation implies that the collision rate in a high neutron-density region will be higher than in a low-density region and will give rise to a diffusion of neutrons from high-to low-density regions. Implicitly, an average neutron is assumed to undergo numerous scatierings before being absorbed or escaping the target. Because of the small diameter of the IPNS-1 target cylinder (approximately four scattering mean-free paths). this condition is only marginally satisfied. It is thus useful to contrast the diffusion-theory (high-scattering) case with the opposite extreme: neutron transport in a medium that scattering can be ignored (i.e., purely absorbing). In the case of isotropic sources in a medium characterized by a uniform absorption cross section $\Sigma_{a}$, the steady-state Green'sfunction solution of the transport equation may be expressed

$$
\phi(\underline{r})=\int d^{3} r^{\prime} \frac{\exp \left(-\Sigma_{a}\left|\underline{r}-\underline{r}^{\prime}\right|\right)}{4 \pi\left|\underline{r}-\underline{r}^{\prime}\right|^{2}} s\left(\underline{r}^{\prime}\right)
$$

In the present problem, the above result may be rewritten in a form more amenable to numerical solution: 


$$
\begin{aligned}
& \phi(r, z=5.1 \mathrm{~cm})=\iiint r^{\prime} d r^{\prime} d \theta^{\prime} d z^{\prime} s\left(r^{\prime}, z^{\prime}\right) \\
& \exp \left[-\Sigma a\left(r^{\prime 2}+r^{2}+z^{2}-2 r r^{\prime} \cos \theta^{\prime}\right)^{1 / 2}\right] \vdots \\
& 4 \pi\left(r^{\prime 2}+r^{2}+z^{\prime 2}-2 r r^{\prime} \cos \theta^{\prime}\right) .
\end{aligned}
$$

The result of numerically evaluating the volume integral at 5 radial, 11 axial, and 11 angular points (605 nodes) is given in Fig. 2.2. The pure-absorption results are everywhere about a factor of 2 greater than the diffusion-theory flux. At the cylindrical boundary, the predicted flux in the absence of scattering is $1.8 \times 10^{13} \mathrm{n} / \mathrm{s} \cdot \mathrm{cm}^{2}$. This is three times higher than the expected boundary flux of $6 \times 10^{12} \mathrm{n} / \mathrm{s} \cdot \mathrm{cm}^{2}$ ([2.1], Table 13). The pure-absorption case is thus an inadequate description of neutron transport in the IPNS-1 target, and the diffusion-theory result, despite its numerous simplifying assumptions, appears to be the best solution.

Table 2.1. Neutron Production in IPNS-1 Target [2.2] $\left(22-\mu \mathrm{A}, 500-\mathrm{MeV}\right.$ protons, $\left.\mathrm{T}=400^{\circ} \mathrm{C}\right)$

\begin{tabular}{lccccc}
\hline \multirow{2}{*}{ Axial } & Radial & \multicolumn{2}{c}{$10^{13} \mathrm{n} / \mathrm{s} \cdot \mathrm{cm}^{3}$} & & \\
& $0-1 \mathrm{~cm}$ & $1-2$ & $2-3$ & $3-4$ & $4-5$ \\
\hline $5 \times 10^{-7} \mathrm{~cm}$ & 1.462 & 1.119 & 0.748 & 0.409 & 0.221 \\
1.8 & 4.021 & 2.023 & 0.985 & 0.647 & 0.370 \\
3.5 & 5.171 & 2.537 & 1.544 & 0.945 & 0.530 \\
5.1 & 4.726 & 2.425 & 1.549 & 0.988 & 0.570 \\
6.8 & 4.228 & 2.185 & 1.413 & 0.900 & 0.549 \\
8.4 & 3.719 & 1.959 & 1.217 & 0.770 & 0.478 \\
10.1 & 2.334 & 1.359 & 0.930 & 0.590 & 0.365 \\
11.7 & 1.317 & 0.745 & 0.570 & 0.414 & 0.264 \\
13.4 & 0.939 & 0.574 & 0.398 & 0.312 & 0.223 \\
14.0 & 0.770 & 0.413 & 0.342 & 0.246 & 0.154 \\
14.99998 & 0.297 & 0.213 & 0.210 & 0.171 & 0.115 \\
\hline
\end{tabular}




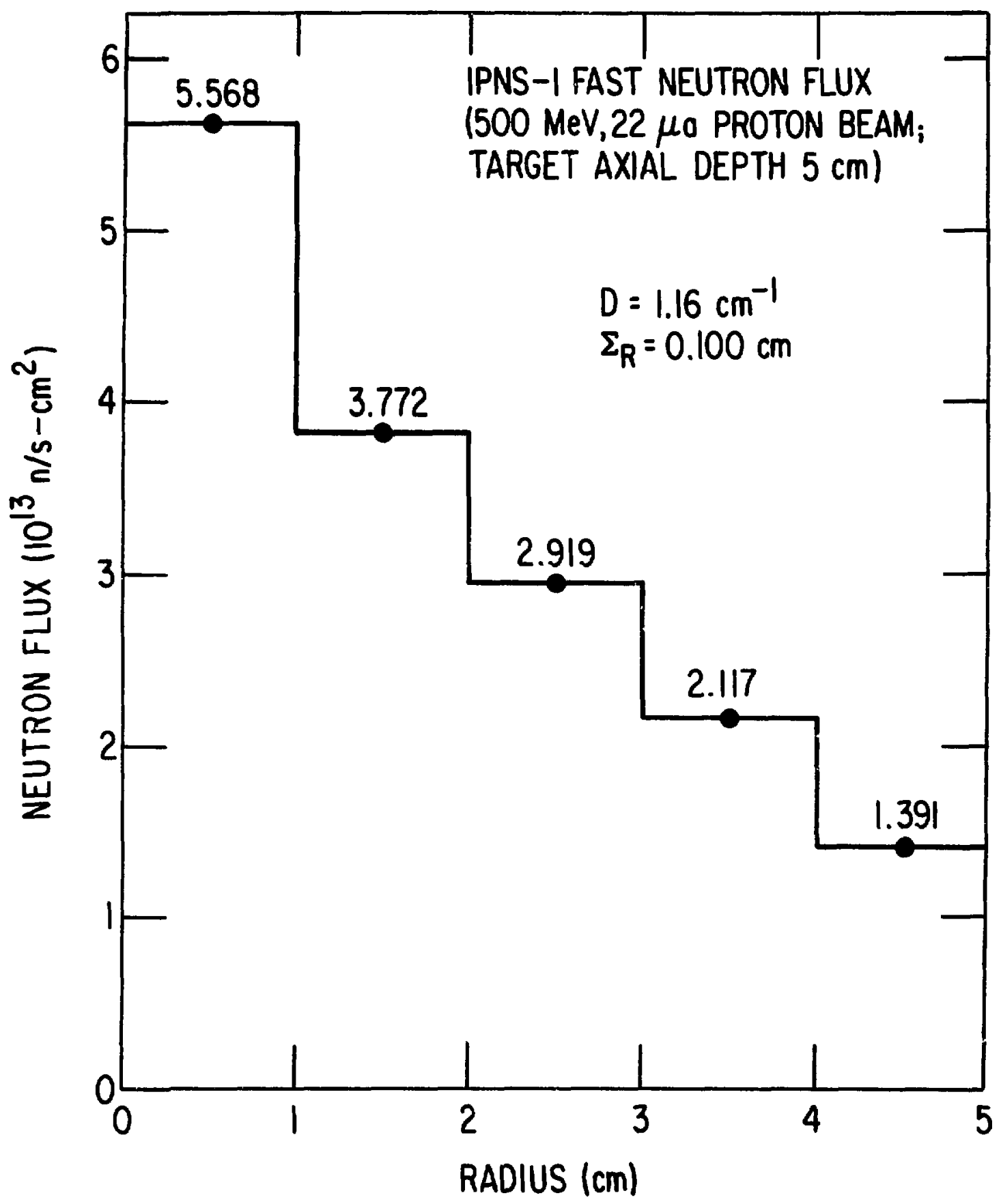

Fig. 2.1. Target Nestron Flux: Diffusion Theory. 


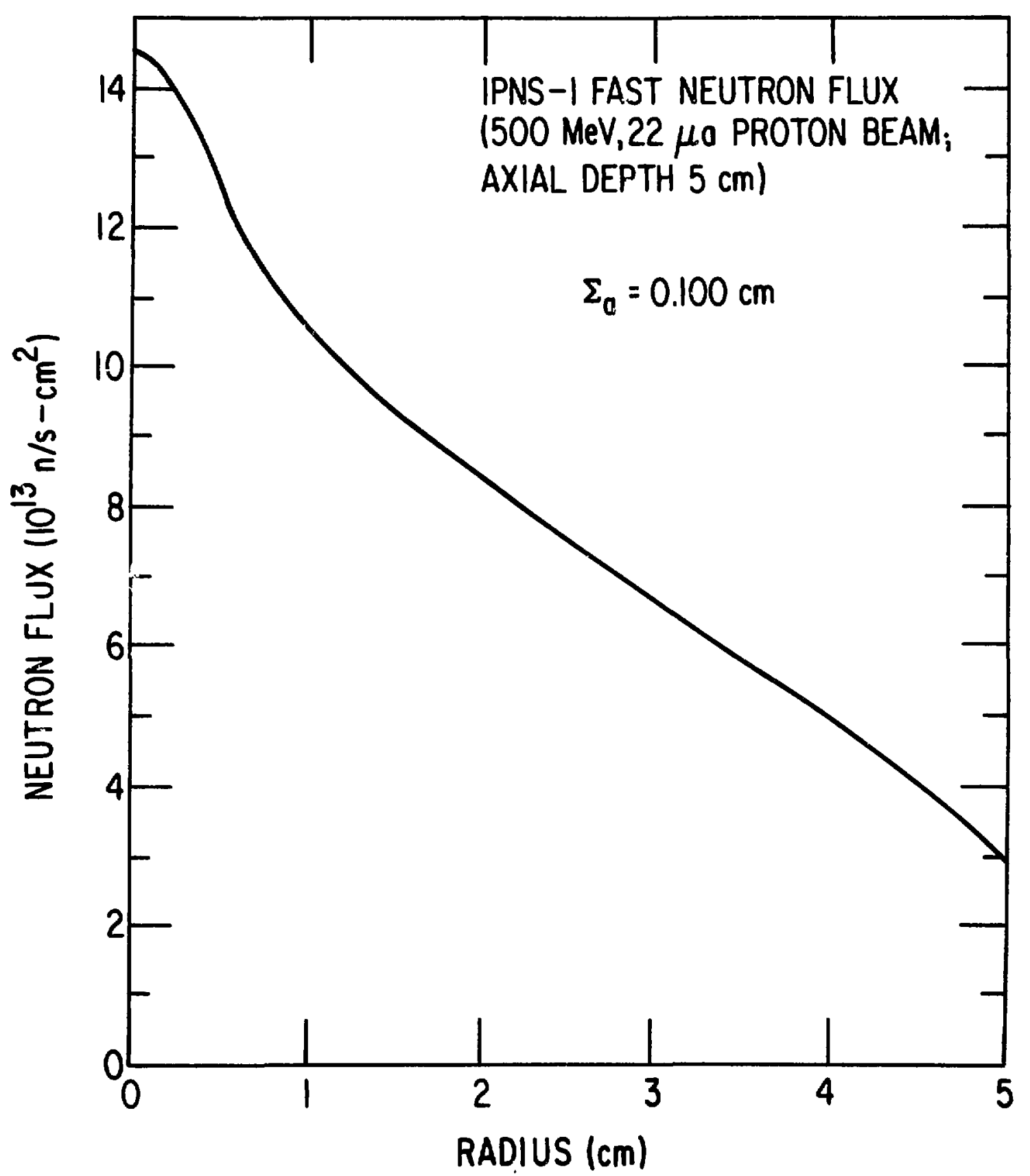

Fig. 2.2. Neutron Flux (Pure Absorbing Medium Case). 


\subsection{Burnup}

Assuming a pure uranium target characterized by an atomic number density $N(\underline{r}, t)$ and one group-absorption cross-section $\sigma_{a}$, the burnup of ${ }^{238} U$ is described by the rate equation

$$
\frac{\partial N}{\partial t}=-N(\underline{r}, t) \sigma_{a} \phi(\underline{r}, t)
$$

Assuming that over the time interval of interest the flux is a constant $\phi_{0}(\underline{r})$, the solution is

$$
N(\underline{r}, t)=N(\underline{r}, 0) \exp \left[-\sigma_{a^{\phi}} \underline{ }_{0} \underline{r} t\right] .
$$
For small times $t \ll \frac{1}{\sigma_{a} \phi_{0}}$, the solution can be expanded to first order
in time, yielding

$$
N(\underline{r}, t)=N(\underline{r}, 0)\left(1-\sigma_{a} \phi_{0}(\underline{r}) t\right)=\ddot{n}_{0}-\Sigma_{a} \phi_{0}(\underline{r}) t,
$$

where $N_{0}$ is the initial uranium atom density $N(\underline{r}, 0)$, assumed independent of position $r$, and $\Sigma_{a}=N_{0} \sigma_{i}$ is the macroscopic cross section for absorption.

The number of uranium atoms depleted per unit volume by time $t$

$\left(t \ll 1 / \sigma_{a} \phi_{a}\right)$ is thus given by the product $\Sigma_{a}$ and the nelliron fluence $\Phi$ :

$$
N_{0}-N(\underline{r}, t)=\Sigma_{a} \phi(\underline{r}) t=\Sigma_{a} \Phi(\underline{r}) \text {. }
$$

This expression is useful for estimating the burnup in the target during, for examples a pulse of the proton beam of duration $t=0.1 \mu \mathrm{sec}$.

\subsection{Evaluation of $\sigma_{a}$}

The one-group absorption cross section is obtained from

$$
\bar{\sigma}_{a}=\frac{\int f(E) \sigma_{a} 238(E) d E}{\int f(E) d E},
$$

where $f(E)$ is the target neutron energy distribution shown graphicaliy 
in Fig. 2.3 [2.1]. Recent values of $\sigma_{a}{ }^{238}(E)$ from ENDF/B [2.4] are used for the evaluation. The ENDF/B cross-sections are available for energies up to $15 \mathrm{MeV}$. Above $15 \mathrm{MeV}$, the available data ware extrapolated. It is assumed that $\sigma_{a}(E)$ smoothly approaches a value of $\pi r_{0}^{2}$ (the nuclear cross-sectional area $\Perp 2.4$ barns for $238 \mathrm{U}$ ) with a $E^{1 / 2}$ dependence in the ectrapolation region. The energy dependence of $\sigma_{a} 238$ weighted by the target neutron-energy distribution (smoothed) is depicted in Fig. 2.3. A numerical evaluation of the integral expression for $\sigma_{a}$ gives

$$
\begin{aligned}
& \begin{aligned}
\bar{\sigma}_{a}{ }^{238}= & \text { one-group target-absorption cross-section } \\
& =1.42 \text { barns }\left(1.42 \times 10^{-24} \mathrm{~cm}^{2}\right) . \\
\text { For a pure } & 238 \mathrm{U} \text { target, the macroscopic cross section } \sigma_{a} \text { is thus } \\
\sigma_{a}=N_{0} \bar{\sigma}_{a} & =0.04783 \times 10^{24} \frac{\text { nuclei }}{\mathrm{cm}^{3}} \times\left(142 \times 10^{-24} \mathrm{~cm}^{2}\right) \\
& =0.0678 \mathrm{~cm}^{-1} .
\end{aligned}
\end{aligned}
$$

At the center of the target, the neutron flux is estimated to be (see Fig. 2.1)

$$
\phi_{0}(r=0)=5.568 \times 10^{13} \mathrm{~s}^{-1} \mathrm{~cm}^{-2} \text {. }
$$

Thus, the burnup at the target center during a $0.1-\mu$ s pulse is approximateiy

$$
\begin{aligned}
& N_{0}-N(r=0, t=0.1 \mathrm{~ms})=\left.\Sigma_{a_{0} \phi_{0} t}\right|_{r=0 . t=0.1 \mu s} \\
& =\left(0.0678 \mathrm{~cm}^{-1}\right)\left(5.568 \times 10^{13} \mathrm{~s}^{-1} \mathrm{~cm}^{-2}\right)(0.1 \mu \mathrm{s}) \\
& =3.8 \times 10^{5} \text { nuclei } / \mathrm{cm}^{3} .
\end{aligned}
$$

The burnup per pulse estimated above is valid for total (accumulated) time $t \ll 1 / \sigma_{a} t_{0} \approx 1.26 \times 10^{10} \mathrm{~s}(400$ years $)$. Since this is well in excess of the target life (not to mention the iffe of the IPNS operating personnel), the burnup per pulse is essentially constant for all time. 


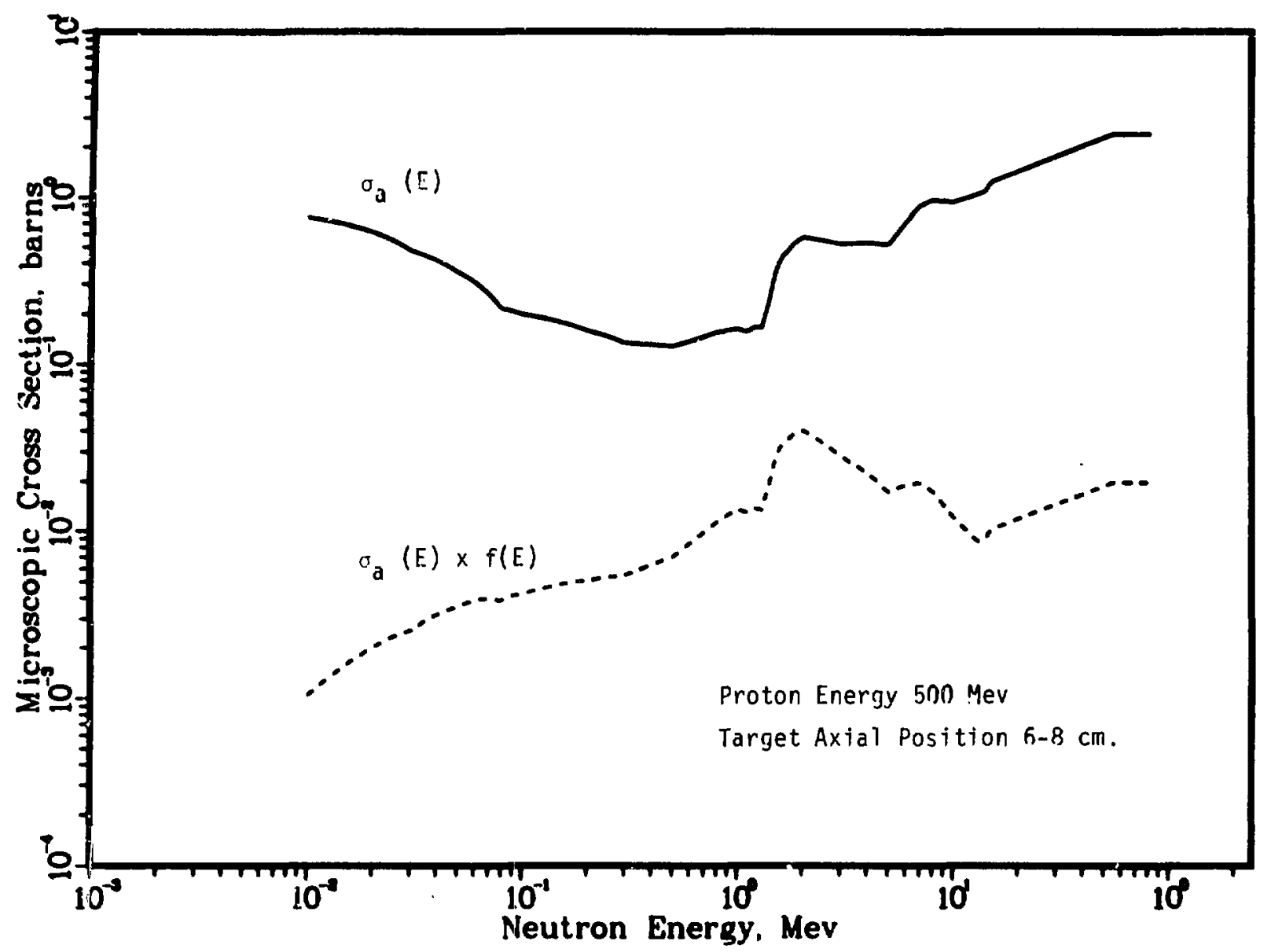

Fig. 2.3. Uranium-238 Neutron Absorption Cross Section $\left(\sigma_{a}\right)$ and Neutron-absorption Cross Section Weighted by IPNS Target Neutron-energy Distribution $\left(f(E) \times \sigma_{a}\right)$ versus Neutron Energy. 


\section{References}

[2.1]. Alsmiller, R. G., referenced in "IPNS - A National Facility for Condensed Matter Research," ANL-78-88, November 1978 (pp. 83-87).

[2.2]. J. J. Duderstadt and L. J. Hamilton, Nuclear Reactor Analysis, John Wiley and Sons, New York (1976).

[2.3]. Reactor Physics Constants, ANL -5800 (1963).

[2.4]. A. Prince, Analysis of High-Energy Neutron Cross-Sections for Fissile and Fertile Isotopes, $\mathrm{pg} .825$ in Second International Conference on Nuc lear Data for Reactors, Vol. II, International Atomic Energy Agency, Vienna (1970). 


\section{TARGET TECHNOLOGY}

A uranium target was considered to have a usable lifetime as a neutron source until either (1) the coolant channels were obstructed sufficiently to reduce coolant flow below an allowable value by dimensional changes of the uranium or (2) unacceptable amounts of highly radioactive products are released from the uranium to the water coolant due to cladding failure. To achieve an acceptable target lifetime ( $>1$ year of operation) before the occurrence of either of these unacceptable effects, we determined from an analys is of potential irradiation-damage effects in uranium that the dimensional configuration and fabrication procedure for the target were of paramount importance [3.1]. These considerations have led to the following design and fabrication considerations:

1. The optimization of the uranium metallurgical structure in the target by control of the uranium processing history and chemistry to minimize irradiation- and thermal-induced dimensional change of the uranium.

2. The utilization of a zirconium or Zircaloy-2 barrier between the uranium and the coolant to prevent release of radioactive products from the target to the coolant.

3. The limitation of the maximum internal uranium temperature to less than $350^{\circ} \mathrm{C}$ during irradiation with protons by optimization of the uranium surface-to-volume ratio to further minimize the irradiation- and thermalinduced dimensional change which exacerbates the residual stress level in the uranium cladding, i.e. zirconium or Zircaloy-2.

4. The use of fabrication techniques that give initial enclosure of the uranium on assembly of the target composite by electron-beam welding and primary containment of the uranium by metallurgical bonding to zirconium or Zircaloy-2 for optimum transfer of heat to the coolant.

\subsection{Target Geometry}

The important dimensional parameters of the ZING-PI and IPNS-I targets are shown in Figs. 3.1 and 3.2, respectively, which adequately limit the maximum internal uranium temperature to less than $350^{\circ} \mathrm{C}$ during the axial impingement of the maximum, anticipated proton current, i.e., $1 \mu A$ for ZING-P and $22 \mu A$ for IPNS-I. 


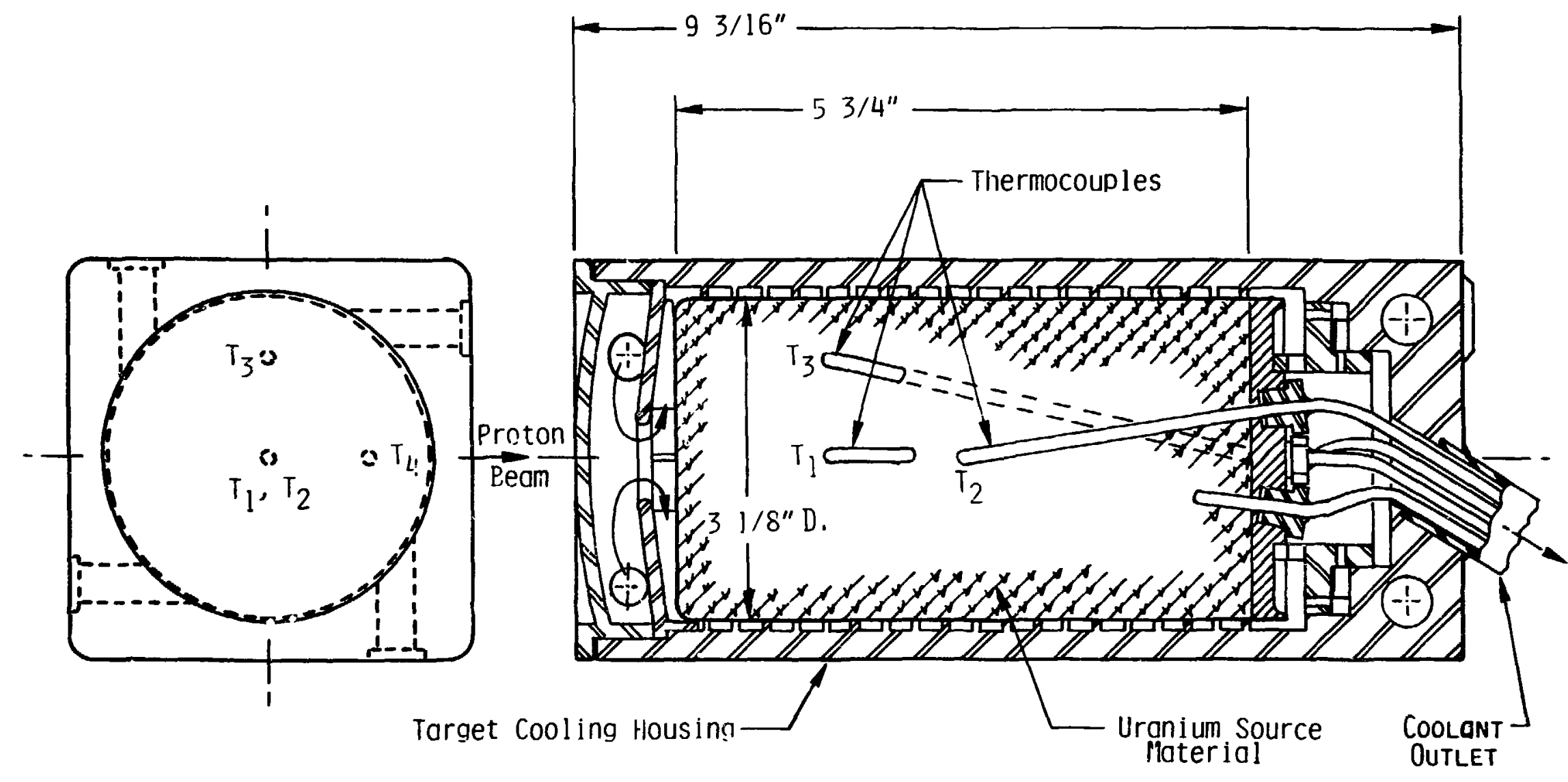

Fig. 3.1. Zing-P' Uranium Target Assembly. 


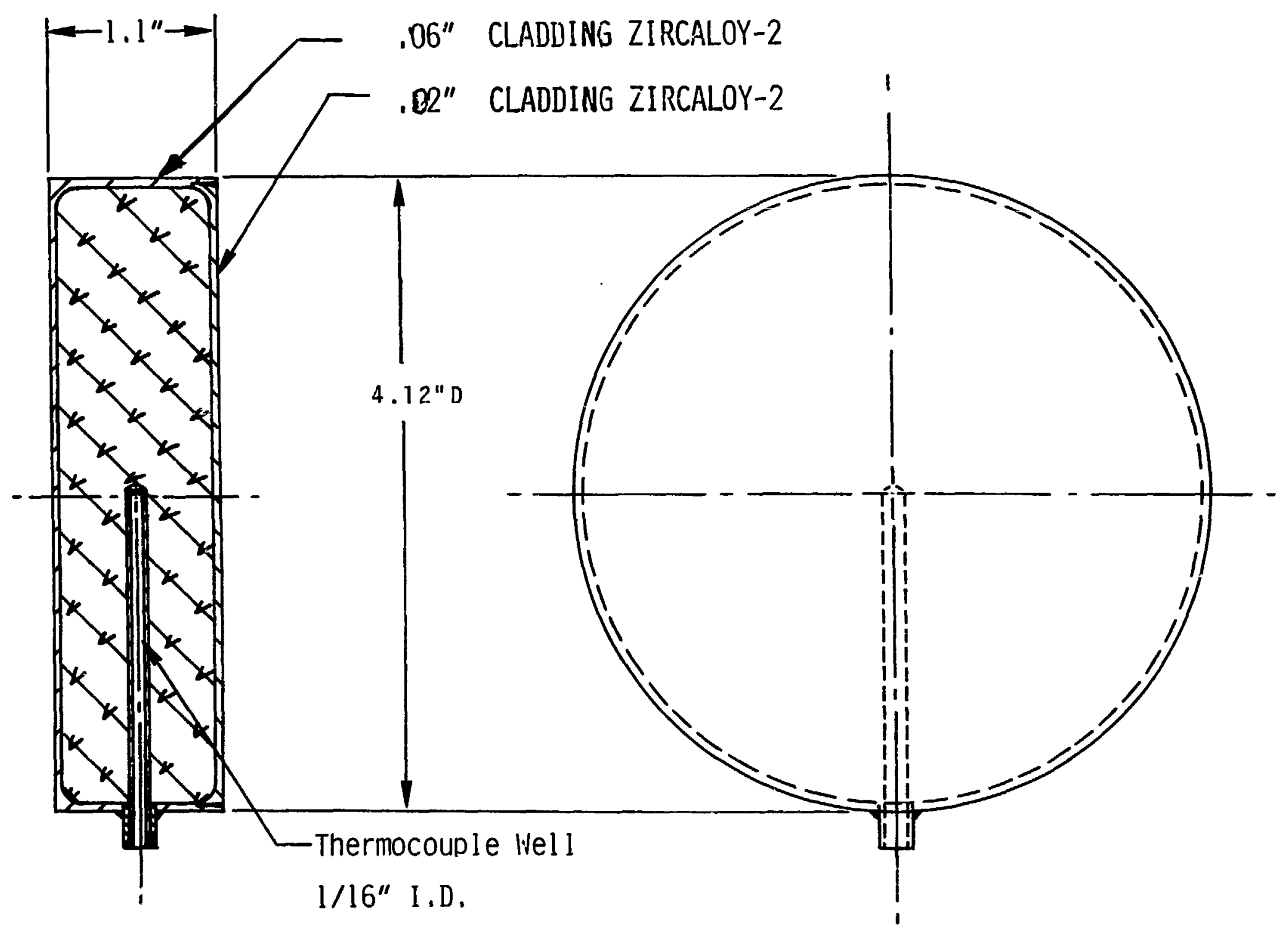

Fig. 3.2. IPNS-I Target Disc (Typical). 
The Zing-P' target was a uranium cylinder with a diameter of $7.9 \mathrm{~cm}$ and a length of $14.6 \mathrm{~cm}$. The proton-impingement surface (front face) and the cylindrical surface of the uranium cylinder were clad, i.e., metallurgically bonded with zirconium having a $0.15-\mathrm{cm}$-wall thickness. The back face of the uranium cylinder was clad with zirconium having a $1.0-\mathrm{cm}$ thickness so that Chromel-Alumel thermocouples with an Inconel sheath could be inserted through the zirconium (back face) into the uranium cylinder as shown in Fig. 3.1.

The IPNS-I target consisted of eight uranium discs. Each disc had a thickness of $2.8 \mathrm{~cm}$ and a diameter of $10.5 \mathrm{~cm}$. The surface of each disc was clad with Zircaloy-2. A design option was to incorporate a Zircaloy-2 thermocouple well into the uranium disc at the midheight plane as shown in Fig. 3.2.

\subsection{Target Production}

Uranium feedstock containing nominally 0.2 wt.\% 235U, 100 ppm carbon, $75 \mathrm{ppm}$ iron, and $55 \mathrm{ppm}$ silicon was melted by induction heating to $1350^{\circ} \mathrm{C}$ in a $y \pm t r i a-c o a t e d$ Magnorite crucible and poured from the crucible bottom into a 7-cm-diam., yttria-coated, graphite mold in a vacuum of $\sim 1.3 \mathrm{~Pa}$. Typically, sufficent feedstock was melted to give a $40-\mathrm{kg}$ ingot. To refine the grain size of the uranium and to increase the diameter of the as-cast ingot, the ingot was remelted in a helium atmosphere $\left(-5.3 \times 10^{4} \mathrm{~Pa}\right)$ by using the ingot as a consumable electrode and cast into an $11-\mathrm{cm} / \mathrm{diam}$., water-cooled copper mold. The resulting ingot was used for the production of the Zing-P' target. In the uranium ingot for the IPNS-I target, the uranium feedstock was enriched with carbon, iron, and silicon by melting the feedstock with uranium-carbon, -iron, and -silicon master alloys. The resulting alloyeduranium ingot contained $450 \begin{aligned} & +100 \\ & -200\end{aligned}$ $\mathrm{ppm}$ silicon. The grain diameter in the uranium was $\approx 0.01 \mathrm{~cm}$ after surface finishing of the ingots.

The uranium ingots were prepared for subsequent cladding with zirconium or Zircaloy-2 by machining to a $0.003-\mathrm{cm}$ surface finish. In the IPNS-I target fabrication, the alloyed ingot was sectioned into 2.8-cm-thick discs. 
Cladding containers for the uranium were machined from forged zirconium or Zircaloy-2 bar stock. Bar stock in the forged condition was chosen as the desired metallurgical structure for the zirconium or Zircaloy-2 to minimize preferential directionality of the grain structure. The container for the ZING $P^{\prime}$ - uranium cylinder was a cylindrical zirconium-cup with a $0.15-\mathrm{cm}-w a l l$ thickness of sufficient depth to allow complete enclosure of the uranium cylinder. The zirconium cylinder was enclosed with the ziconium back-face plate by a circumferential electron-beam weld. The cladding for the IPNS-I target discs consisted of a pair of shallow, cylindrical Zircaloy-2 cups with $0.155-\mathrm{cm}$-wall thickness placed around the uranium disc and closed by a circumferential electron-bean weld at the mid-height $p l a n e$ of the uranium disc. A clearance of $0.005 \mathrm{~cm}$ between the zirconium or Zircaloy-2 and the uranium was used to provide control of penetration during welding and to allow for the differential expansion of the zirconium or Zircaloy-2 and uranium during bonding. Prior to enclosure by welding, a surface-preparation procedure on the uranium and Zircaloy-2 was meticulously performed. The uranium was etched in $50 \%$ $\mathrm{HNO}_{3}$ solution, washed in distilled water, and dried after rinsing in ethanol. Degreased-zirconium or Zircaloy containers and the cleaned-uranium cylinder or discs were transferred into a glovebox containing a helium atmosphere. The uranium and the cladding surfaces to be bonded were rotary-wire brushed and the components were assembled. The electron-beam welding operation in a vacuum of $\sim 1.3 \times 10^{-2} \mathrm{~Pa}$ was initiated without delay.

The design of the zirconium or Zircaloy-2 interfaces to be welded used an overlapping joint (see Fig. 3.3). This design minimized distortion of the zirconit: 1 or Zircaloy-2 and made use of end thrust to suppor: the assemblies in the welding position. Penetration of the weld zone into the uranium results in a two-phase metallurgical weld zone which can crack during the subsequent bonding procedure and in unsatisfactory bonding of the uranium-zirconium or Zircaloy interface. A $50 \%$ weld penetration of the ziconium or Zircaloy-2 wall thickness was sufficient since the subsequent bonding procedure sealed the overlapping portion of the weld joint.

A strong, continuous metallurgical bond between the uranium and the zirconium or Zircaloy-2 container was obtained by subjecting the composite to 
an isostatic helium pressure at high temperature (HIP bonding). A satisfactory HIP bonding schedule consisted of the following procedure:

1. Pressurize the composite to $10^{6} \mathrm{~Pa}(150 \mathrm{psi})$, and heat to $150^{\circ} \mathrm{C}$.

2. Pressurize to $10^{8} \mathrm{~Pa}(15000 \mathrm{psi})$ and heat to $840^{\circ} \mathrm{C}$.

3. Maintain at $840^{\circ} \mathrm{C}$ and $10^{8} \mathrm{~Pa}(15000 \mathrm{psi})$ for $4 \mathrm{hr}$.

4. Cool to $500^{\circ} \mathrm{C}$ and maintain for $1 \mathrm{hr}$ at $10^{8} \mathrm{~Pa}(15,000 \mathrm{psi})$.

5. Cool slowly $\left(\sim 0.5^{\circ} \mathrm{C} / \mathrm{min}\right)$ to ambient temperature.

The integrity of the zirconium (Zing $\mathrm{P}^{\prime}$ ) or Zircaloy (IPNS-I)-uranium bond was determined by propagation of an ultrasonic wave from a 1.3-cm-diam., spherically focused, 10-MHz transducer perpendicular to the zirconium or Zircaloy-uranium interface; "C"-scan recordings were obtained with an immersion scanning system. Nonbonded areas larger than $0.16-\mathrm{cm}$ diameter could be detected with this system. Experience has shown that with the above HIP bonding schedule, $\sim 75 \%$ of the Zircaloy-uranium composites are totally bonded. However, in most cases, the nonbonded areas in a composite could be removed by repeating the HIP bonding schedule. Following the ultrasonic-wave inspection, the faces of the IPNS-I discs were machined to give a $0.05-\mathrm{cm}$ Zircaloy-2 wall thickness.

Figure 3.4 shows typical metallurgical microstructures observed at the Zircaloy-uranium interface and in the uranium following the HIP bonding schedule. Isolated areas of a second phase, which are believed to be the uranium-zirconium delta phase, were infrequently observed along the Zircaloy-uranium interface [3.2]. The uranium microstructure (Fig. 3.5) contains a high density of finely dispersed second-phase particles which are believed to be $U_{6}$ (FeSi) [3.3]. The grain size of the uranium is $>0.01 \mathrm{~cm}$. The preferred orientation of the uranium grains is believed to be the minimum attainable with the composite cooling rate $\left(1^{\circ} \mathrm{C} / \mathrm{min}, 840\right.$ to $500^{\circ} \mathrm{C}$ ) that is attained in the HIP bonding apparatus. An option at this stage of the disc-production procedure was to heat the disc to $725^{\circ} \mathrm{C}$ ( $B$ phase of uranium) and quench in 011 to further randomize the uraniumgrain size. However, this option nvolves some risk of deterioration of the Zircaloy-uranium bond and was determined to be unnecessary. A photograph of a Zircaloy-2-clad uranium disc with a thermocouple well is shown in Fig. 3.6. 

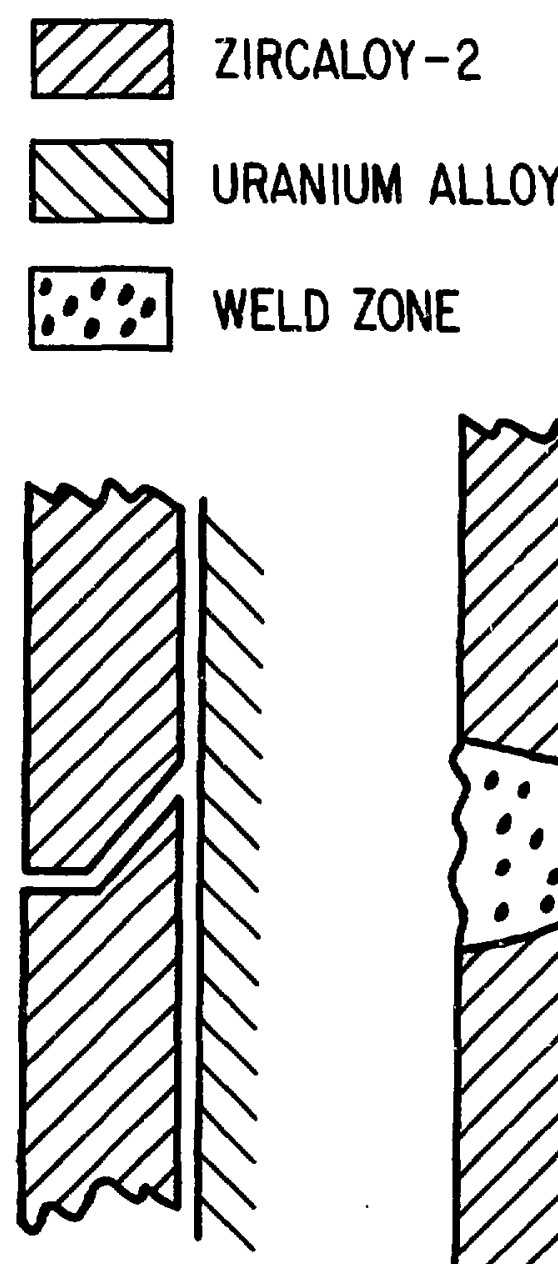

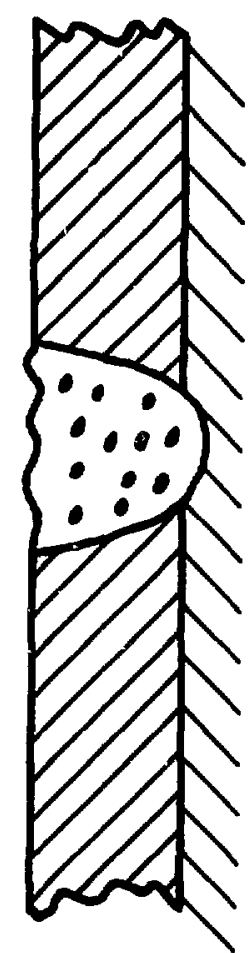

(b)

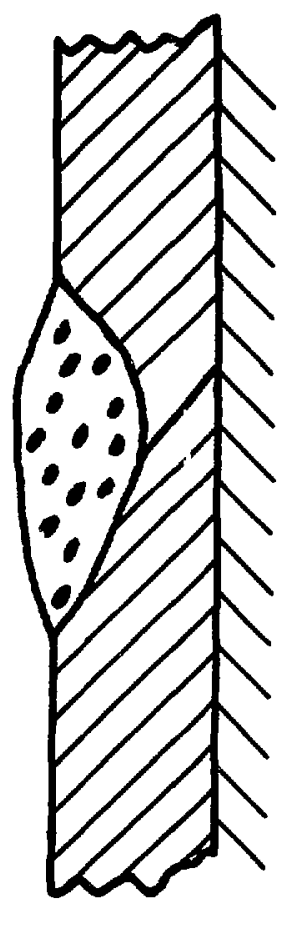

(c)

Fig. 3.3. Design of Zircaloy-2 Interface in the Weld Zone. 


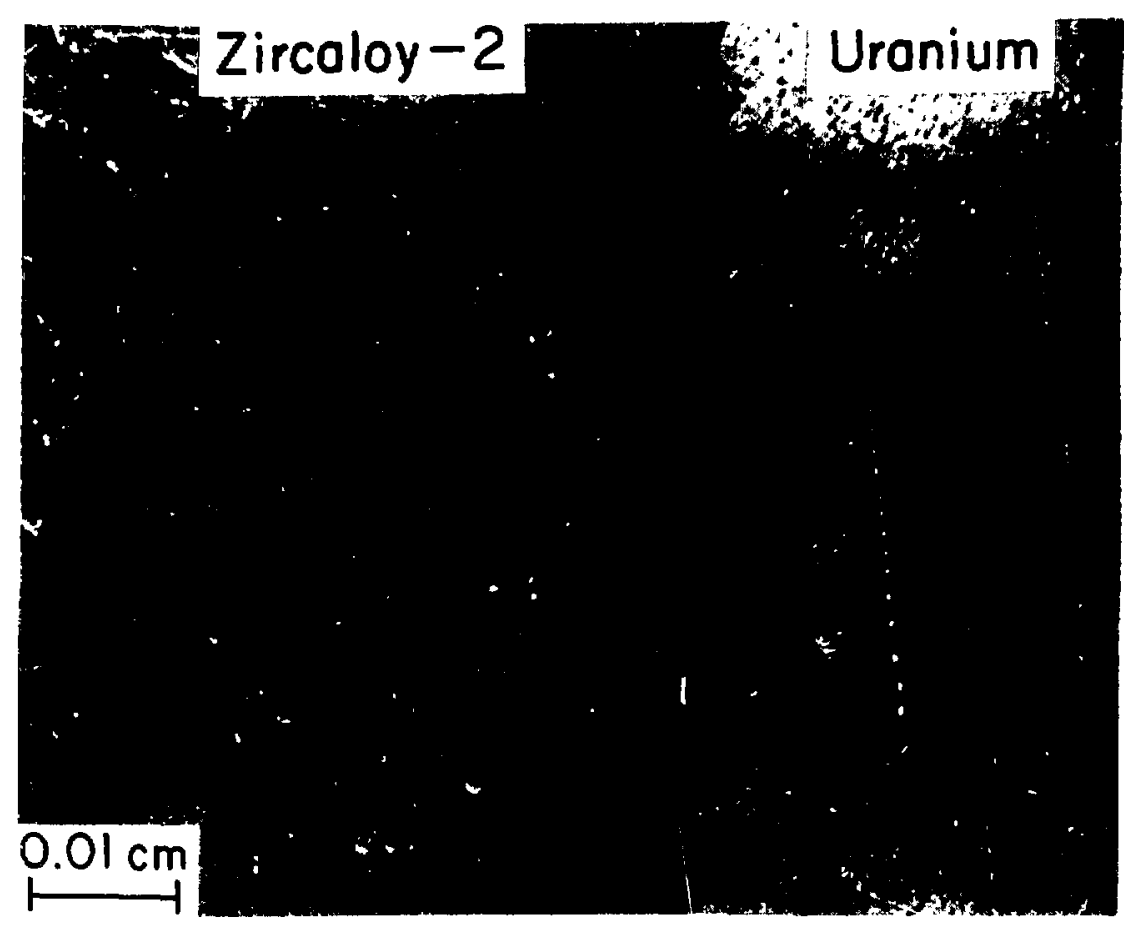

Fig. 3.4. Zircaloy-Uranium Interface after HIP Bonding. 


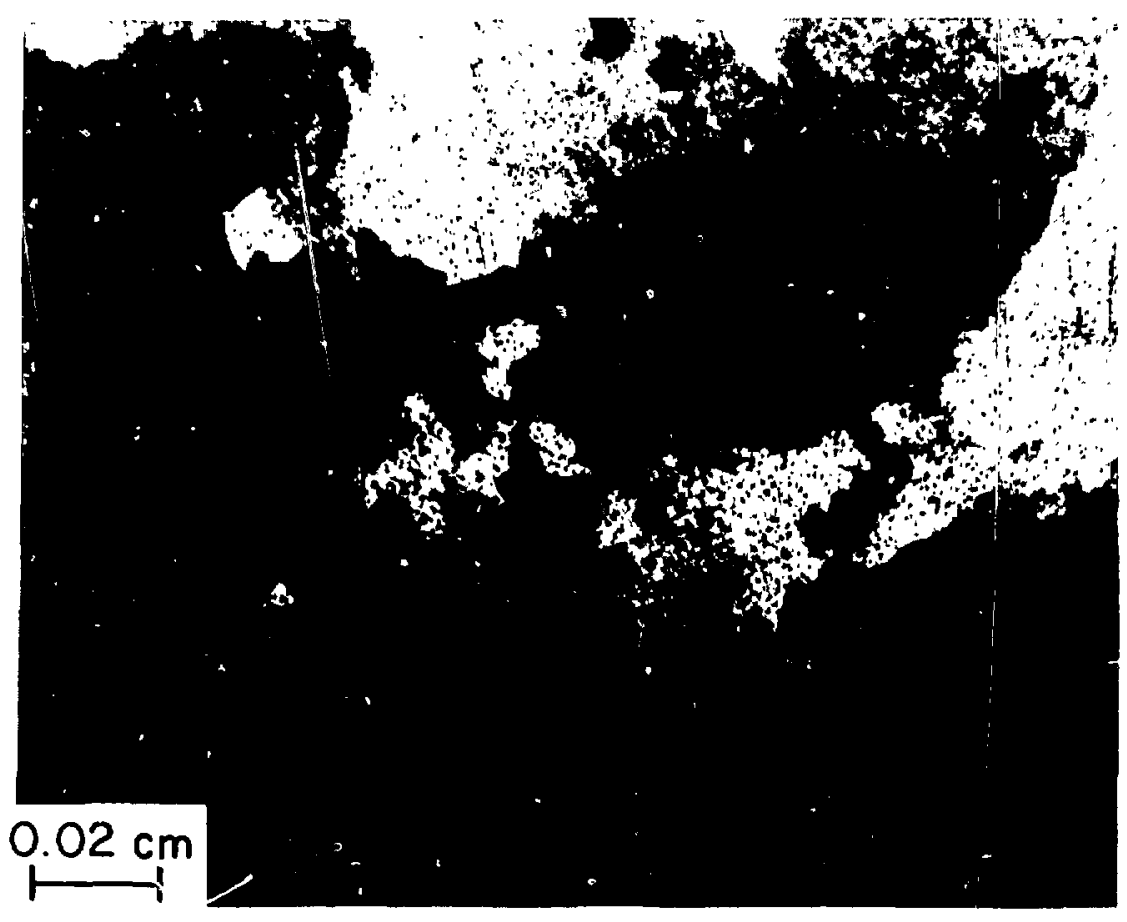

Fig. 3.5. Microstructure of Uranium aiter HIP Bonding. 


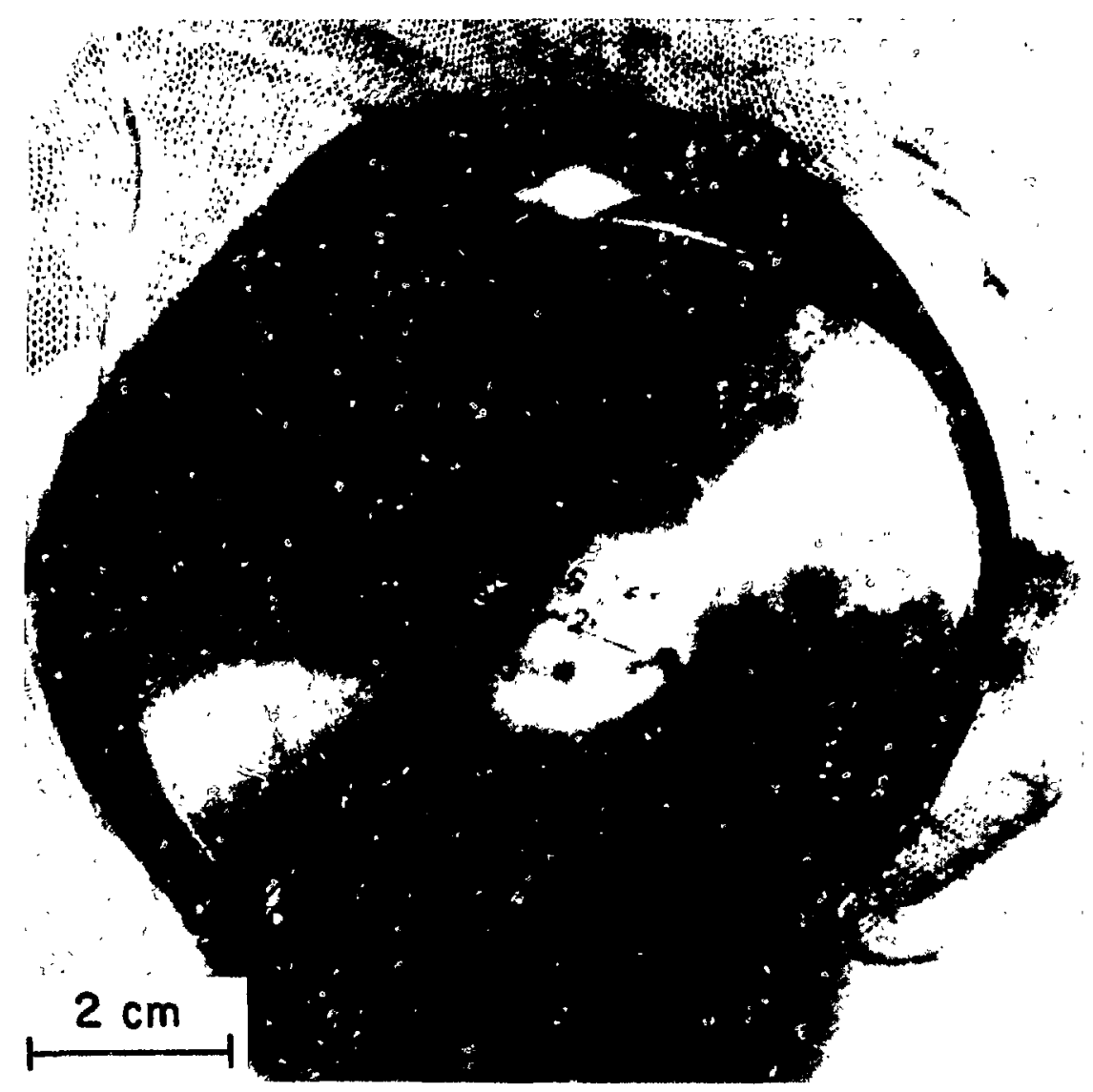

Fig. 3.6. Zircaloy-2 Clad Uranium Disc with Thermocouple Well. 
Table 3.1 from Ref. [3.4] gives the tensile properties of ZirconiumUranium alloys annealed 24 hours at $575^{\circ} \mathrm{C}\left(1065^{\circ} \mathrm{F}\right)$. 
Table 3.1. TENSRL PROPERTIES OF 2IRCONUM-JRANIUM ALLOYS ANNEALED Z2 HR AT STSC (1055 F)

\begin{tabular}{|c|c|c|c|c|c|c|c|c|c|c|}
\hline & & \multicolumn{5}{|c|}{ Room Tc:nperature } & \multicolumn{4}{|c|}{$370 \mathrm{C}(700 \mathrm{~F})$} \\
\hline \multicolumn{2}{|c|}{ Aralysls, W/o } & $\begin{array}{l}0.28 c t \text { Cent } \\
\text { Offset Yield } \\
\text { Stuens:h, osi }\end{array}$ & $\begin{array}{c}\text { Telusile } \\
\text { Suengih, } \\
\text { psi }\end{array}$ & $\begin{array}{l}\text { Elongation } \\
\text { in } 2 \text { In.. } \\
\text { per cent }\end{array}$ & $\begin{array}{l}\text { Reduction } \\
\text { in Area, } \\
\text { per cen: }\end{array}$ & $\begin{array}{l}\text { Hardress } \\
\text { (DPHii) }\end{array}$ & $\begin{array}{l}\text { O.2 Per Cen: } \\
\text { Offser Yield } \\
\text { Sisenoth, ps! }\end{array}$ & $\begin{array}{c}\text { Tersile } \\
\text { Suenzth, } \\
\text { psi }\end{array}$ & $\begin{array}{l}\text { Elongation } \\
\text { In } 2 \text { In.. } \\
\text { per cene }\end{array}$ & $\begin{array}{l}\text { Reduction } \\
\text { In Area. } \\
\text { Per cent }\end{array}$ \\
\hline \multicolumn{11}{|c|}{ Induction-Mcled Fersa!d Uranium } \\
\hline 100.0 & 0 & 26,700 & 53,800 & 34.0 & 27.0 & 138 & 10,500 & 22,400 & 30.0 & 55.0 \\
\hline 90.0 & 10.0 & 58,800 & 84,300 & 16.0 & $2 ? .0$ & 197 & 43,800 & 61,000 & 5.6 & 29,0 \\
\hline 80.8 & 19.2 & 85,500 & 103,900 & 10.0 & 8.0 & 252 & 69,300 & 80,100 & 5.7 & 9.0 \\
\hline 71.7 & 28.3 & 87,700 & 110. 000 & 4.0 & 4.0 & 293 & 73,900 & 93,600 & 8,0 & 8.0 \\
\hline 59.5 & 40.5 & 60,700 & 116,500 & 3.6 & 6.2 & 302 & 60,100 & 04,100 & 3.5 & 1.1 \\
\hline 50.1 & 49.9 & 79,700 & 100,000 & 2,6 & 3.6 & 264 & 67. 600 & 85,800 & 6.0 & 9.7 \\
\hline 39.7 & - & 118,700 & 157,300 & 1.5 & 1.6 & 384 & 113,300 & 225,700 & 0.5 & 1.8 \\
\hline 29.9 & - & (2) & $\therefore$ & $\cdots$ & $\cdots$ & 370 & $114_{0} 000$ & 145,000 & 2.0 & $=$ \\
\hline 21.8 & $-\infty$ & 140,000 & 179,000 & 4.0 & 6.8 & 291 & 116,700 & 137,200 & 4.3 & 8.3 \\
\hline 10.0 & - & 110,600 & 163,200 & 5.0 & 6.0 & 363 & 75,800 & 100,800 & 6.0 & 17.0 \\
\hline 5.8 & - & 97,200 & 166,200 & 5.0 & 6.0 & 347 & 63,700 & 84,600 & 8.0 & 35.0 \\
\hline 0 & - & 65,900 & 117,300 & 3.5 & 4.9 & 265 & 27.100 & 34,550 & 16.0 & 37.0 \\
\hline \multicolumn{11}{|c|}{ Arc-Melted Derby Uranium } \\
\hline 100.0 & 0 & 18,000 & 36,700 & 43.0 & 50.0 & 113 & 8,500 & 17,300 & 42.0 & $\infty$ \\
\hline 89.4 & 10.6 & 60,500 & 70,200 & $6,0(b)$ & $19.0(b)$ & 246 & 53,200 & 64,200 & $7 .(x)$ & $11.0(b)$ \\
\hline 80.0 & 20.0 & 86,800 & 101,800 & 24.0 & 41.0 & 235 & 72,000 & 77.900 & 5.0 & 22.0 \\
\hline 70,4 & 29.6 & 71,300 & 115,000 & 14.0 & 16.0 & 243 & 64,800 & 86,400 & 20.0 & 27.0 \\
\hline 60.6 & 39.4 & 80,800 & 131,800 & 9.0 & 14.0 & 295 & 63,800 & 97.800 & 22.0 & 20.0 \\
\hline 50.5 & 49.5 & 81,300 & 118,000 & 4.5 & 8.0 & 272 & 68,100 & 96.100 & 22.0 & 28.0 \\
\hline 41.7 & 58.3 & 95,000 & 103,300 & 1.0 & - & 279 & 97,000 & 115,300 & 8.0 & 13.0 \\
\hline 31.4 & $\cdots$ & 132,700 & 161,600 & 2.0 & 4.0 & 350 & 112,000 & 145,200 & 7.0 & 7.0 \\
\hline 20.5 & - & (a) & - & - & -. & 411 & 124,000 & 135,200 & 8.0 & 18.0 \\
\hline 11.5 & $-\infty$ & 145,000 & 199,000 & 9.0 & $-\infty$ & 359 & 100,800 & 122,800 & 8.0 & 29.0 \\
\hline 5.5 & $\infty$ & 89,000 & 162,000 & 6.0 & 7.3 & 307 & 30,500 & 77,000 & 10.0 & 25.0 \\
\hline 2.4 & $-\infty$ & 47,300 & $133,0 \mathrm{CO}$ & 18.0 & 21.0 & 283 & 35,100 & 48,400 & 17.0 & 49.0 \\
\hline 0 & - & 48,400 & 123,000 & 21.0 & $-\infty$ & 263 & 21,300 & 31,400 & 27.0 & 57.0 \\
\hline
\end{tabular}

(b) Specimens broke in what appeared to be rolling defect. 


\section{References}

[3.1]. B. A. Loomis, H. R. Thresh, G. L. Fogle, and S. B. Gerber, Design, Production, and Evaluation of a Zircaloy-Clad Uranium Target for an Intense Pulsed Neutron Source Application, Nuc 1. Technol. 55, 617 (Dec. 1981).

[3.2]. F. A. Rough and A. A. Bauer, Constitutional Diagrams of Uranium and Thor ium Alloys, Addison-Wesley Publishing Co., Inc., Reading, Mass. (1958).

[3.3]. C. L. Angerman and R. T. Huntoon, J. Less-Common Metals, Met. 9, 338 (1965).

[3.4]. Nuclear Reactor Fuel Elements, Metallurgy, and Fabrication, edited by A. R. Kaufmann, Interscience Publishers (1962), p. 77. 


\section{MATERIAL CONSIDERATIONS}

\subsection{Heat-Treatment Effects}

This chapter deals with the evaluation of heat-treatment effects in IPNS-I and Zing-P' targets. Temperature polyriomials of the mean coefficients of thermal expansion for zirconium, Zircaloy, and uranium that are generally used for the evaluation of the thermal-expansion effects for these materials are:

$$
\begin{aligned}
\text { zirconiuun } \bar{\alpha} & =3.19 \times 10^{-6}+0.0017 \times 10^{-6} \mathrm{~T} \text { in. } / \mathrm{in} .-^{\circ} \mathrm{F},\left(T_{\text {ref }}=68^{\circ} \mathrm{F}\right) ; \\
& \text { for } \mathrm{T}=932^{\circ} \mathrm{F}, \bar{\alpha}=4.77 \times 10^{-6} \text { in. } / \mathrm{in} .-^{\circ} \mathrm{F} . \\
\text { Zircaloy } \bar{\alpha} & =3.11 \times 10^{-6}+0.00095 \times 10^{-6} \mathrm{~T} \text { in. } / \mathrm{in} .-^{\circ} \mathrm{F},\left(T_{r e f}=68^{\circ} \mathrm{F}\right), \\
& \text { for } \mathrm{T}=932^{\circ} \mathrm{F}, \bar{\alpha}=4.00 \times 10^{-6} \text { in. } / \mathrm{in} .-^{\circ} \mathrm{F} . \\
\text { uranium } \bar{\alpha} & =8.17 \times 10^{-6}+0.0017 \times 10^{-6} \mathrm{~T} \text { in. } / \mathrm{in} .-^{\circ} \mathrm{F},\left(T_{r e f}=68^{\circ} \mathrm{F}\right) ; \\
& \text { for } \mathrm{T}=932^{\circ} \mathrm{F}, \bar{\alpha}=9.75 \times 10^{-6} \text { in. } / \mathrm{in} .-^{\circ} \mathrm{F} .
\end{aligned}
$$

These mean coefficients of thermal expansion are measured values with respect to a reference temperature that is the room temperature. In IPNS-I and Zing-P' target discs, the zero stress state, as discussed in Chapter 3 , was about $932^{\circ} \mathrm{F}$. The target discs are placed in a residual stress state when they are cooled from $932^{\circ} \mathrm{F}$ to room temperature during the bonding process. In this case the reference (zero stress) temperature is $932^{\circ} \mathrm{F}$, and Eqs. 4.1-4.3 need to be modified to include the effect of a reference temperature other than the room temperature. These modifications are shown in the following:

and

$$
R_{0}=\text { Initial radius of target }
$$

$$
R_{1}=R_{0}\left(1+a\left(T_{1}\right)\left(T_{1}-T_{0}\right)\right)
$$

where $a\left(T_{1}\right)=$ an average value between $T_{0}^{\overrightarrow{0}}$ and $T_{1}$ (known).

$$
R_{\text {ref }}=R_{0}\left(1+a\left(T_{\text {ref }}\right)\left(T_{\text {ref }}-T_{0}\right)\right) \text {, }
$$

where $a\left(T_{\text {ref }}\right)$ is an average value of the thermal expansion coefficient between $T_{0}$ and $T_{\text {ref }}$ (known). 


$$
R_{1}=R_{\text {ref }}\left[1+a_{\text {eff }}\left(T_{1}\right)\left(T_{1}-T_{\text {ref }}\right)\right],
$$

where $a_{\text {eff }}\left(T_{1}\right)$ is an average value of a between $T_{R E F}$ and $T_{1}$

(unknown).

Note that

$$
\frac{R_{1}}{R_{\text {ref }}} \times \frac{R_{\text {ref }}}{R_{0}}=\frac{R_{1}}{R_{0}} \text {. }
$$

Equation 4.7 can be used with Eqs. 4.4 and 4.6 to give

$$
\begin{aligned}
& {\left[1+a_{\text {eff }}\left(T_{1}\right)\left(T_{1}-T_{\text {REF }}\right)\right]\left[1+\alpha\left(T_{\text {ref }}\right)\left(T_{\text {ref }}-T_{0}\right)\right]} \\
& =\left[1+\alpha\left(T_{1}\right)\left(T_{1}-T_{0}\right)\right] \text {, }
\end{aligned}
$$

which simplifies to

$$
\begin{aligned}
& \alpha_{e f f}\left(T_{1}\right)\left(T_{1}-T_{\text {ref }}\right)+\alpha\left(T_{\text {ref }}\right)\left(T_{\text {ref }}-T_{0}\right) \\
& =\alpha\left(T_{1}\right)\left(T_{1}-T_{0}\right)
\end{aligned}
$$

or

$$
\begin{aligned}
& \alpha_{\text {eff }}\left(T_{1}\right)\left(T_{1}-T_{\text {ref }}\right)+\alpha\left(T_{\text {ref }}\right)\left(T_{\text {ref }}-T_{0}\right) \\
& =\alpha\left(T_{1}\right)\left(T_{1}-T_{\text {ref }}\right)+\alpha\left(T_{1}\right)\left(T_{\text {ref }}-T_{0}\right)
\end{aligned}
$$

and finally,

$\alpha_{\text {eff }}\left(T_{1}\right)=a\left(T_{1}\right)+\frac{a\left(T_{1}\right)-\alpha\left(T_{\text {ref }}\right)}{T_{1}-R_{\text {ref }}}\left(T_{\text {ref }}-T_{0}\right)$,

an expression for the coefficient of thermal expansion from Tref.

With the modified equations for thermal expansion developed above, the computer programs in Tables 4.1 and 4.2 for uranium, zirconium, and Zircaloy were written to calculate the thermal-expansion values. The displacement and stress calculations for Zing-P' calculated from the modified thermal-expansion expressions are given in Figs. 4.1-4.5. A maximum stress of 93,000 psi is noted near the lower corner. Figures 4.64.10 are similar results for an IPNS-I Zircaloy-clad disc design of 3/4in. radius and 0.050-in. cladding, where a maximum stress of 90,500 psi is noted at the radial edge midway between the front and back faces. Figures 4.11-4.18 give the IPNS-I heat-treatment displacement and stress 
Table 4.1. Computer Program for Adjustment of Mean Coefficient of Expansion

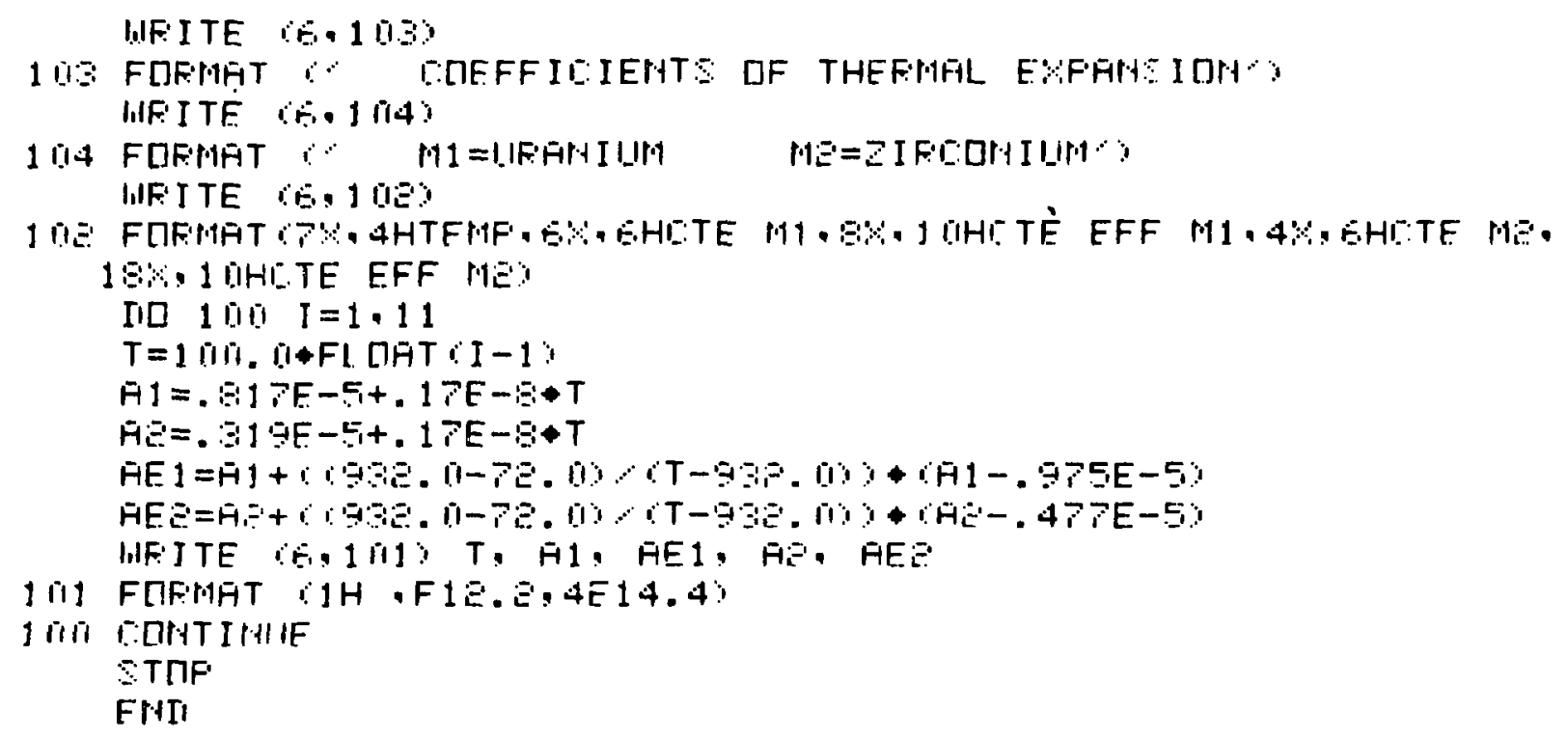

\begin{tabular}{|c|c|c|c|c|}
\hline \multirow{3}{*}{ 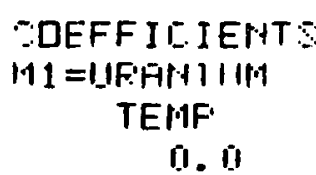 } & \multicolumn{4}{|c|}{ 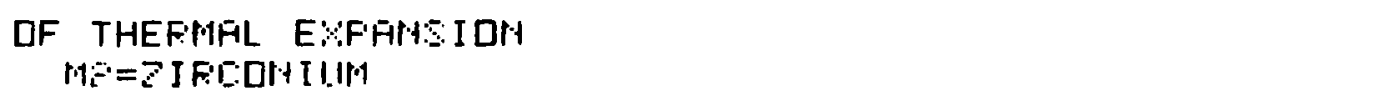 } \\
\hline & ETE MI & ETE EFF M1 & ETE ME & ETE EFF ME \\
\hline & i. $817 \mathrm{ME}-1 \mathrm{~S}$ & 1. $9 E . E E-115$ & $0.3190 \mathrm{E}-0.5$ & $0.4 E .4 \mathrm{E}-1.5$ \\
\hline 1001.011 & $0.8: 34 \cap E-115$ & 1. $9797 \mathrm{~F}-1.5$ & $0.35 E 0 E-0.5$ & $0.4817 E-0.5$ \\
\hline Enn. กั1 & ก. : : & 11. 9G. & 1. $350 \bar{F}-15$ & $0.49 B P E-105$ \\
\hline 300.010 & 0. GB:GE-015 & D. $1014 E-114$ & $0.37010-0.5$ & $0.5158 .0-05$ \\
\hline 4010.110 & 0. $8195.11 E-0.5$ & $0.1030-n 4$ & $0.39 P \square E-0.5$ & $0.5 G=5-0.5$ \\
\hline 5111.011 & $0.911=n E-1.5$ & $0.111475-114$ & $0.4040 E-115$ & $0.545 E-115$ \\
\hline 6nO. & 0.919 IIE- 015 & $0.105 .4 E-0.4$ & 11. $4 \geq 10 E-1.5$ & $0.55 .1 E-0.5$ \\
\hline 7011.011 & $0.9 B E-0.0$ & ㅁ. 1 10 $1 \mathrm{E}-114$ & 11. $43: 0 E-05$ & $0.5 B E \bar{E}-0.5$ \\
\hline 8010.010 & 11. $95.90 E-1.5$ & $0.10 \% E-114$ & $0.45 .50-0.5$ & $93 E-0.5$ \\
\hline 9110.00 & 0.97 OIIE- 1.5 & 11. $1104 E-1.4$ & $0.47=0 E-0.5$ & $0.50 .4 E-05$ \\
\hline 1 non. no & ก. 907 ПE- & $0.1139 \mathrm{~F}-0.14$ & $0.4590 \mathrm{E}-0.5$ & 11. $64119 E-115$ \\
\hline
\end{tabular}


Table 4.2. Computer Program for Adjustment of Mean Coefficient of Thermal Expansion. $M_{1}=$ uranium, $M_{2}=$ Zircaloy

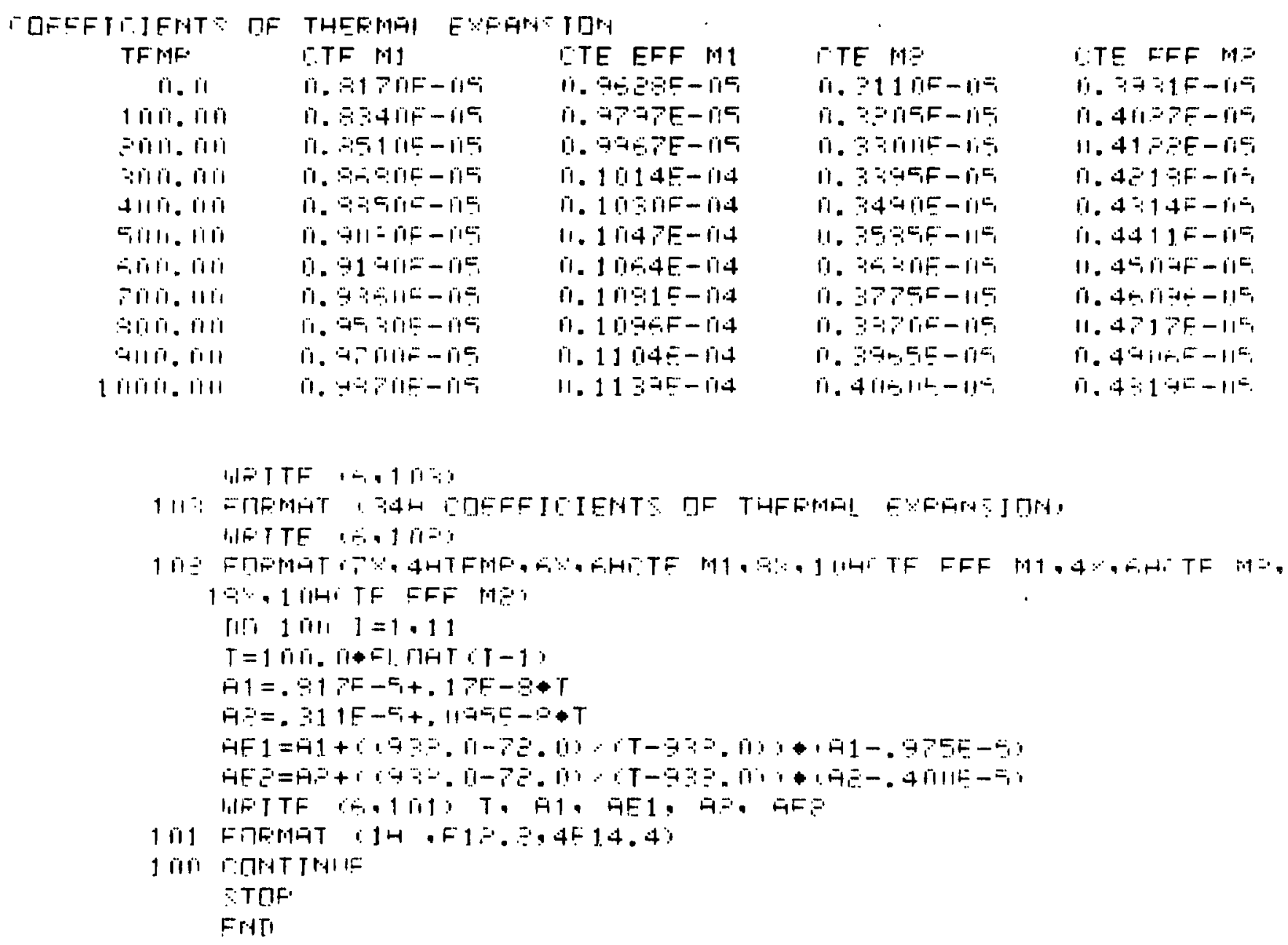




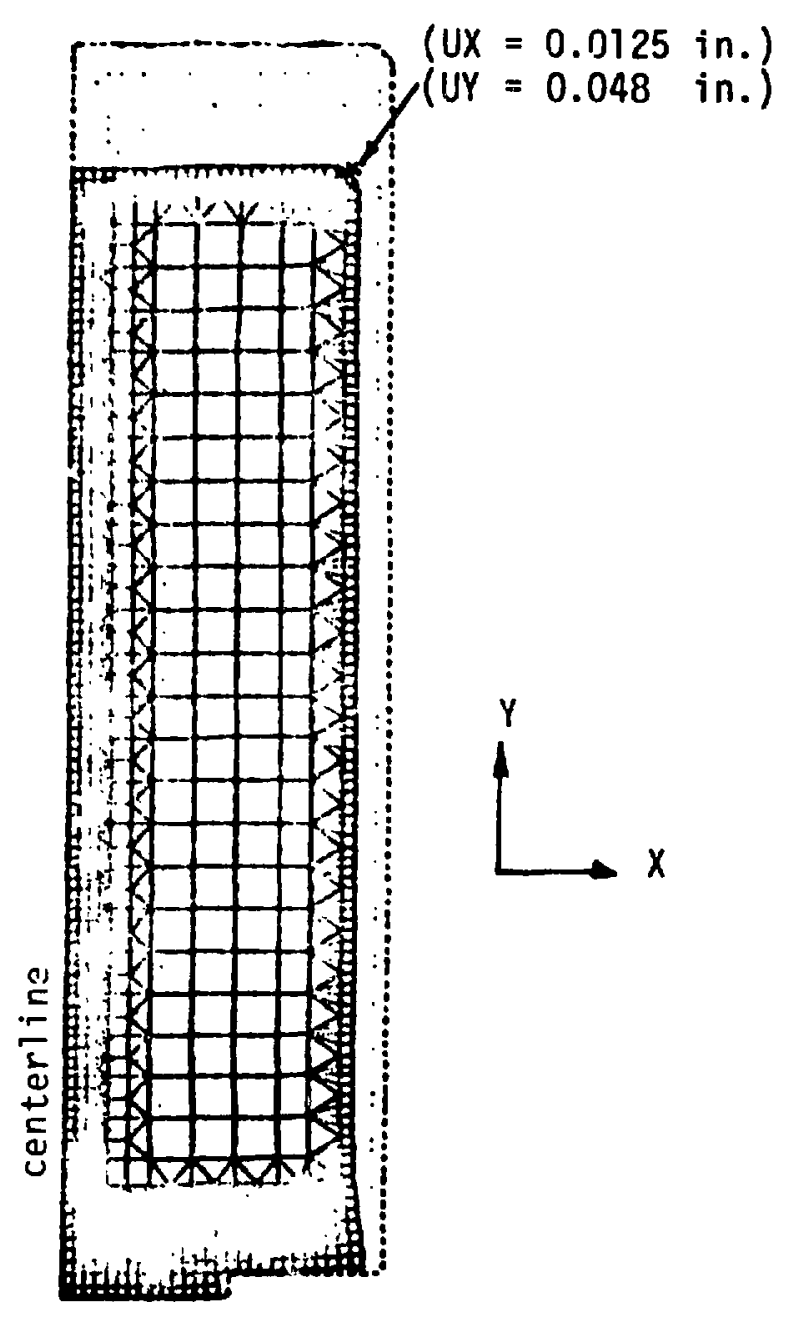

Fig. 4.1.

Zing $P$ ' Target Displacement due to Heat-treatment Effect. 


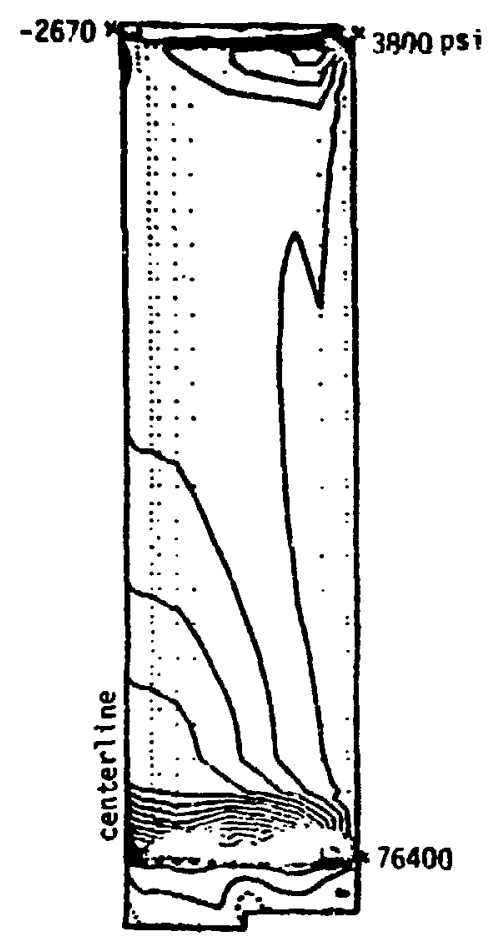

Fig. 4.2

Zing $P^{\prime}$ Target Maximum Principal Stress Distribution - Heat Treatment Effect Only.

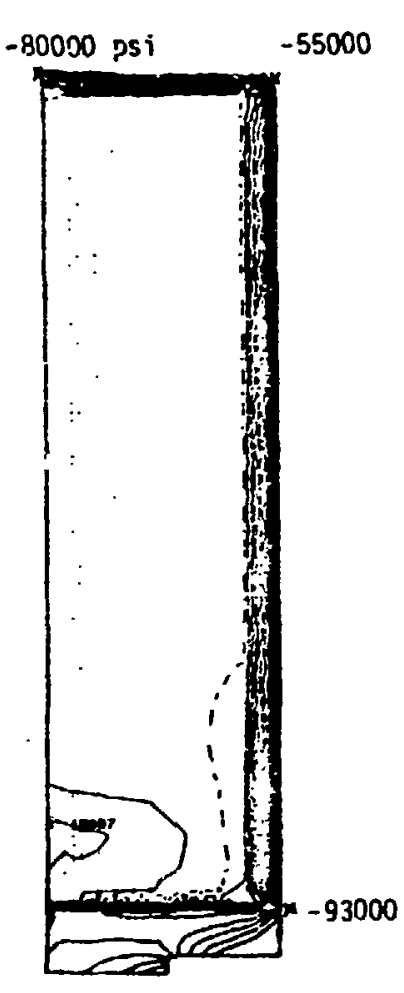

Fig. 4.3

Minimum Principal Stress Distribution with Stress Difference of 800 psi between Countour Lines.

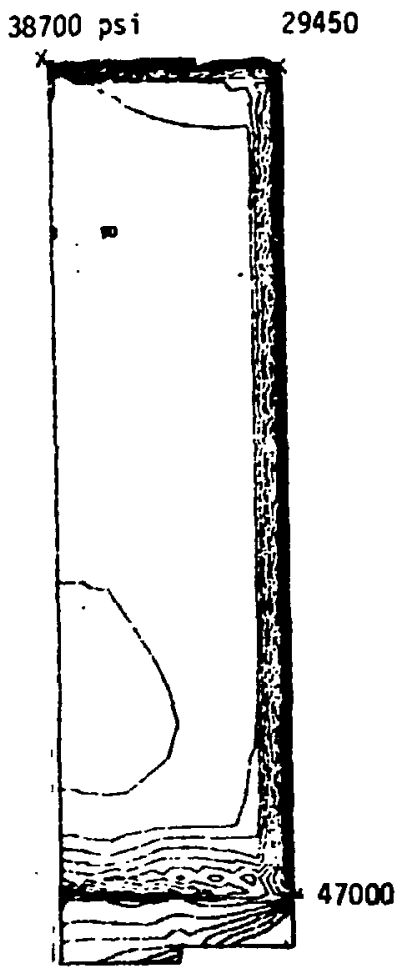

Fig. 4.4

Principal Shear Stress Distribution with Stress Difference of 4000 psi between Contour Lines.

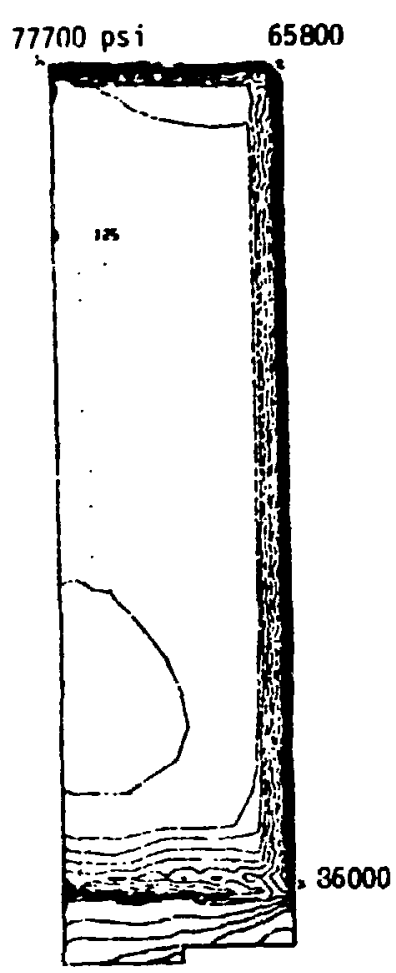

Fig. 4.5

Effective Stress Distribution with Stress Difference of 8000 psi Contour Lines. 


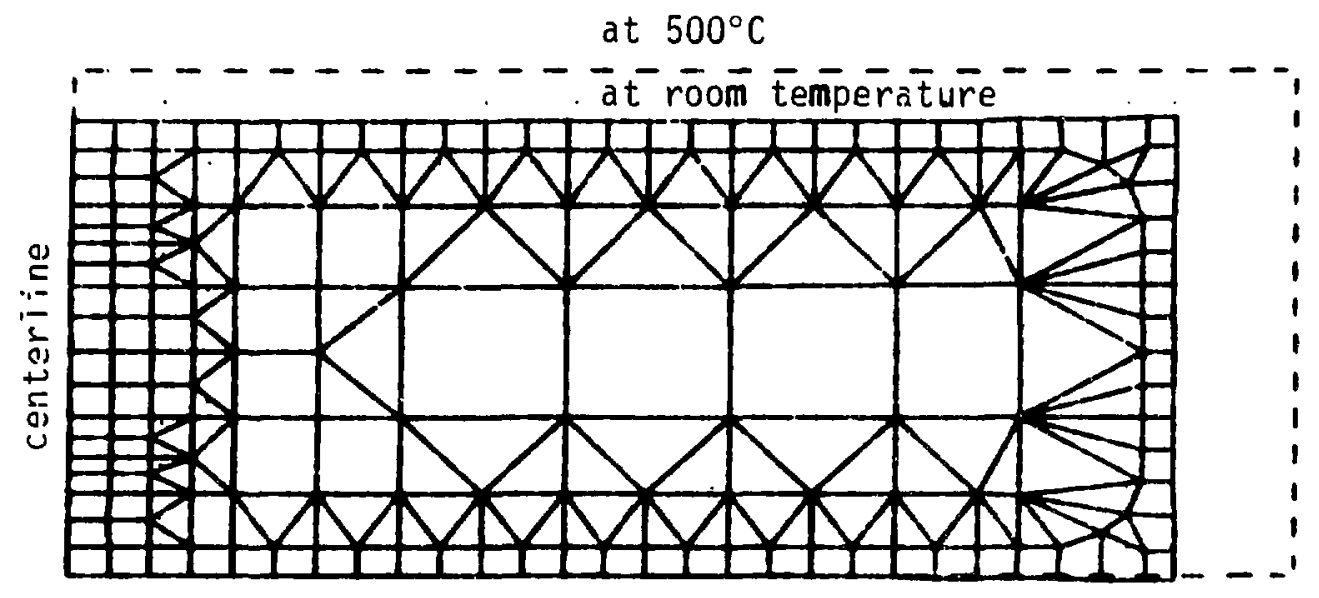

Fig. 4.6. IPNS-1 Target Displacement during Heat Treatment and Bonding. 


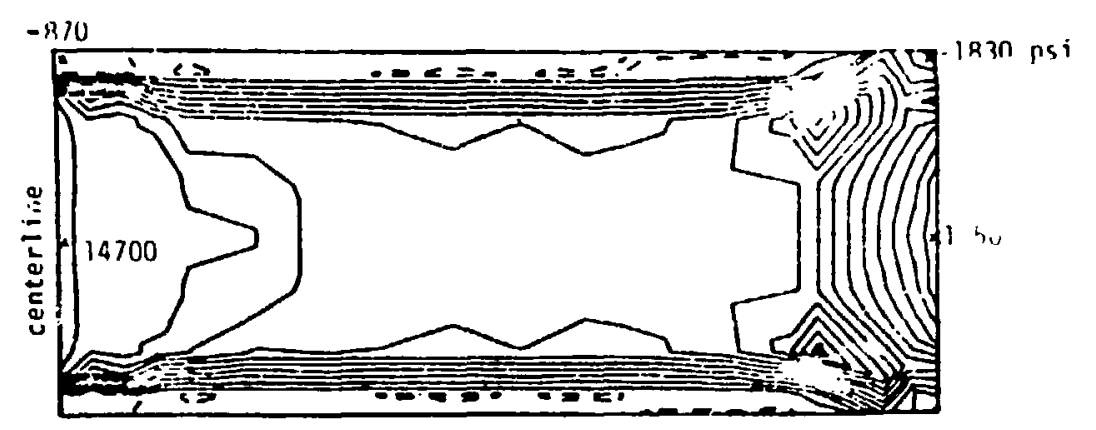

Fig. 4.7

IPNS Target Maximum Principal Stress Distribution due to Heat-treatment Effect Only with

Stress Difference of 1500 psi between Contour

Lines. (Disc design of $3 / 4-i n$. thick and $0.05-$

in. Zircaloy thickness all around.)

Fig. 4.8

IPNS-1 Target Minimum Principal Stresses due to Heat-treatment Effect Only with Stress Difference of 8000 psi between Contour Lines. (Disc design of 3/4-in. thick and 0.05-in. Zircaloy thickness all around.)
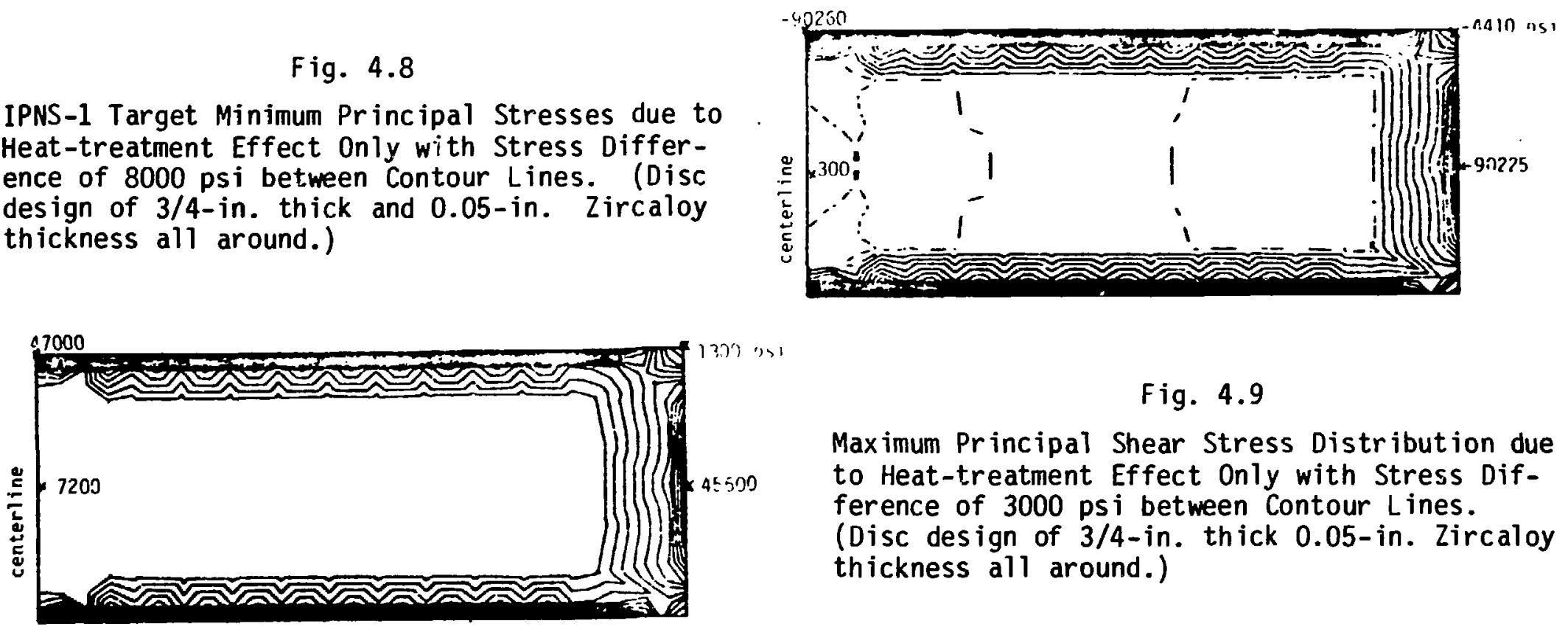

Fig. 4.9

Maximum Principal Shear Stress Distribution due to Heat-treatment Effect Only with Stress Difference of 3000 psi between Contour Lines.

(Disc design of 3/4-in. thick 0.05-in. Zircaloy thickness all around.)

Fig. 4.10

IPNS-1 Target Effective Stress Distribution due to Heat-treatment Effect Only with Stress Difference of 7000 psi between Contour Lines. (Disc design of 3/4-in. thick and 0.05-in. Zircaloy thickness all around.)

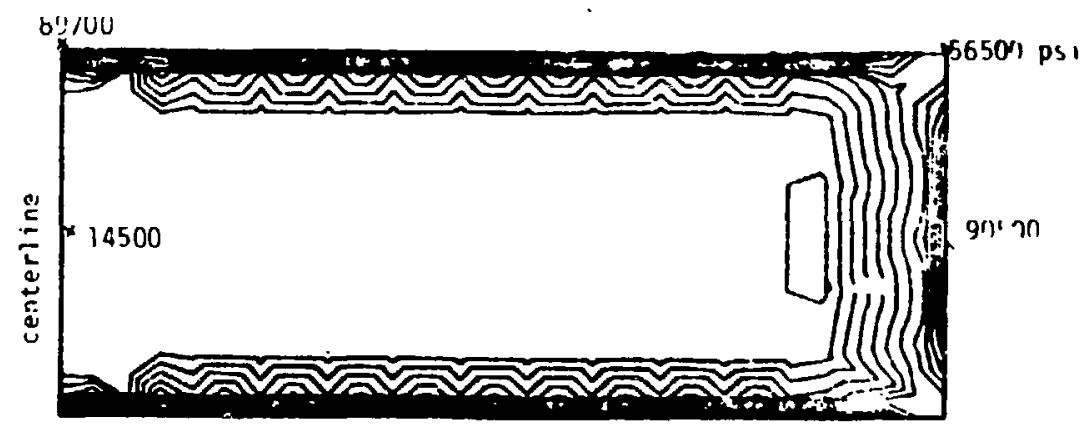


IPNS-I Uranium $t=1$ in., Clad $t=0.02$ in. (Top and Bottom), Clad $t=0.06$ in. (Side).

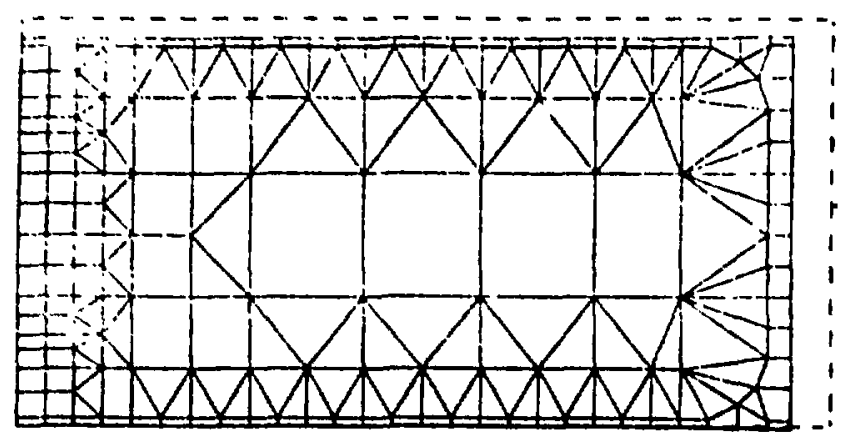

Fig. 4.11

IPNS-1 Target Dispiacement during Heat Treatment (dotted lines indicate undeflected boundary line).

Fig. 4.12

IPNS-1 Target Radial Stress (psi) due to Heat-treatment Effect Only with Stress Difference of 8000 psi between Contour Lines.
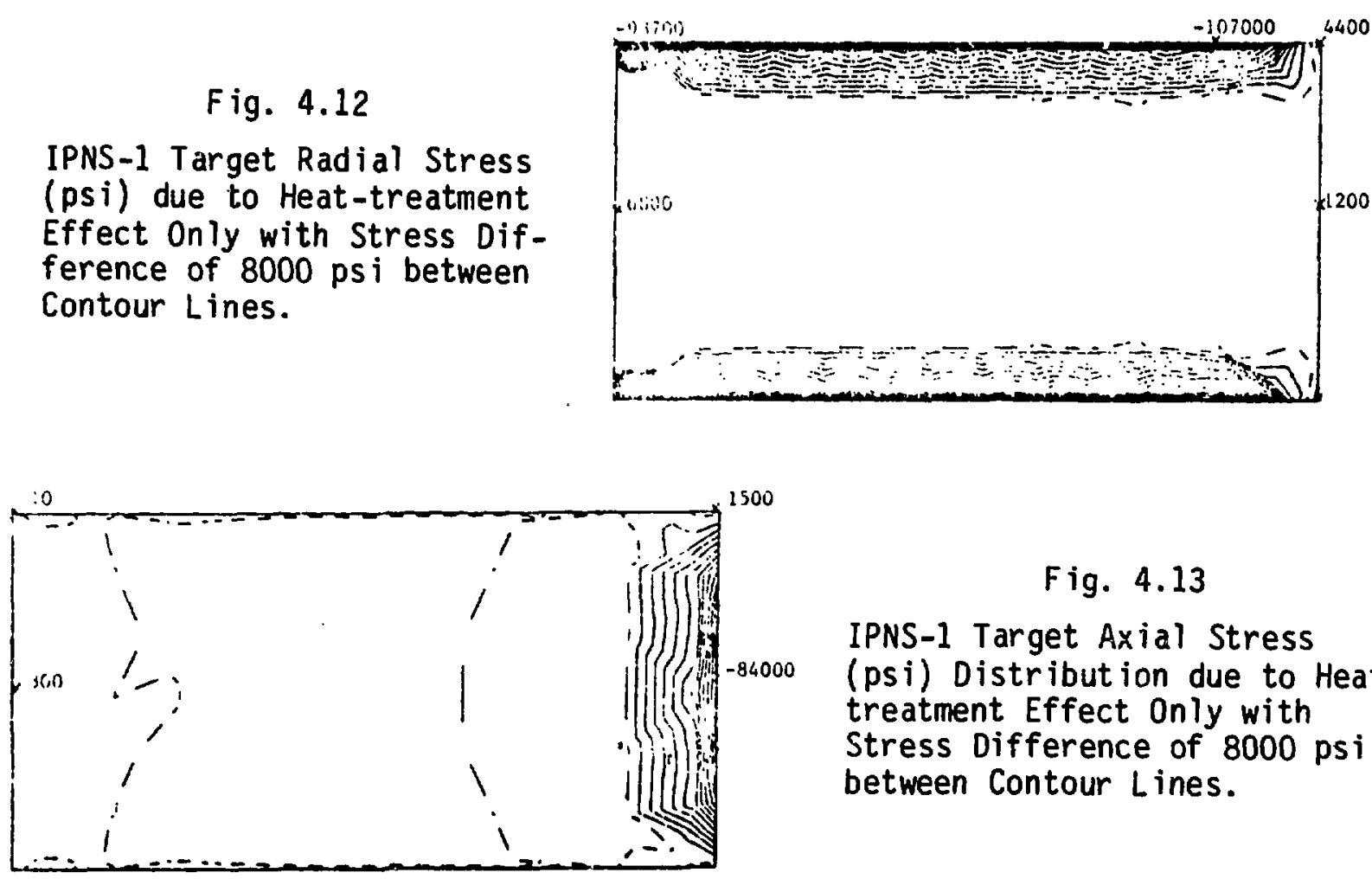

Fig. 4.13

IPNS-1 Target Axial Stress (psi) Distribution due to Heattreatment Effect Only with Stress Difference of 8000 psi between Contour Lines.

Fig. 4.14

IPNS-1 Target Hocp Stress (psi) ijistribution due to Heattreatment Effect Only with Stress Difference of 8000 psi between Contour Lines.

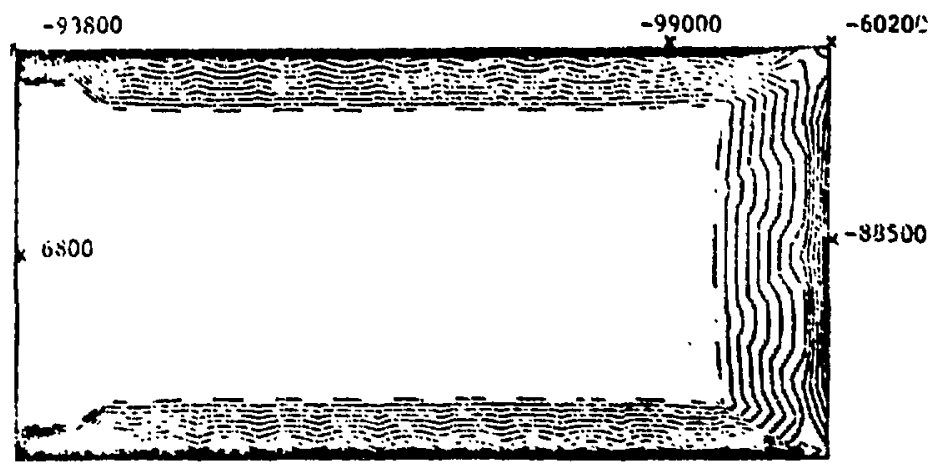


IPNS-I Target Uranium $t=1$ in., $C l$ ad $T=0.02$ in. (Top and Bottom), Clad $t=0.06$ in. (Side).

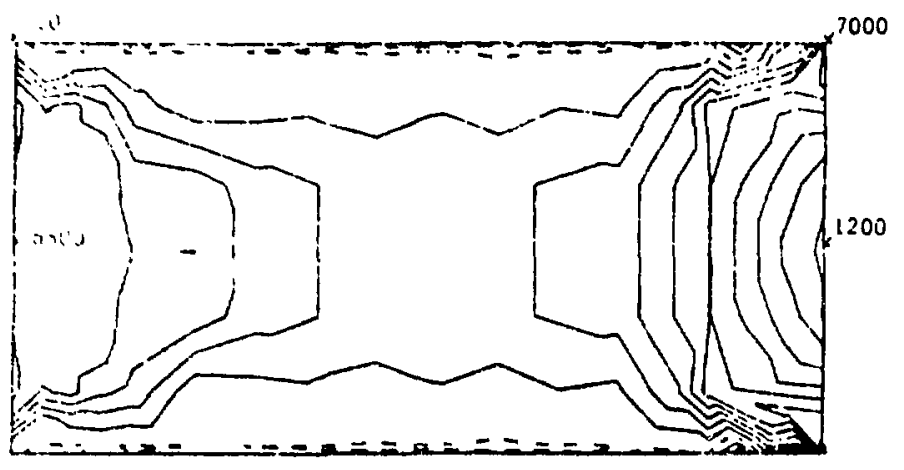

Fig. 4.15

IPNS Target-Maximum Principal Stress Distribution ( $p s i$ ) due to Heat Treatment Effect only with stress Difference of 1500 psi between Contour Lines.

Fig. 4.16

IPNS-1 Target Minimum. Principal Stress (psi) Distribution due to Heat-treatment Effect Oniy with Stress Difference of 800 ps i between Contour Lines
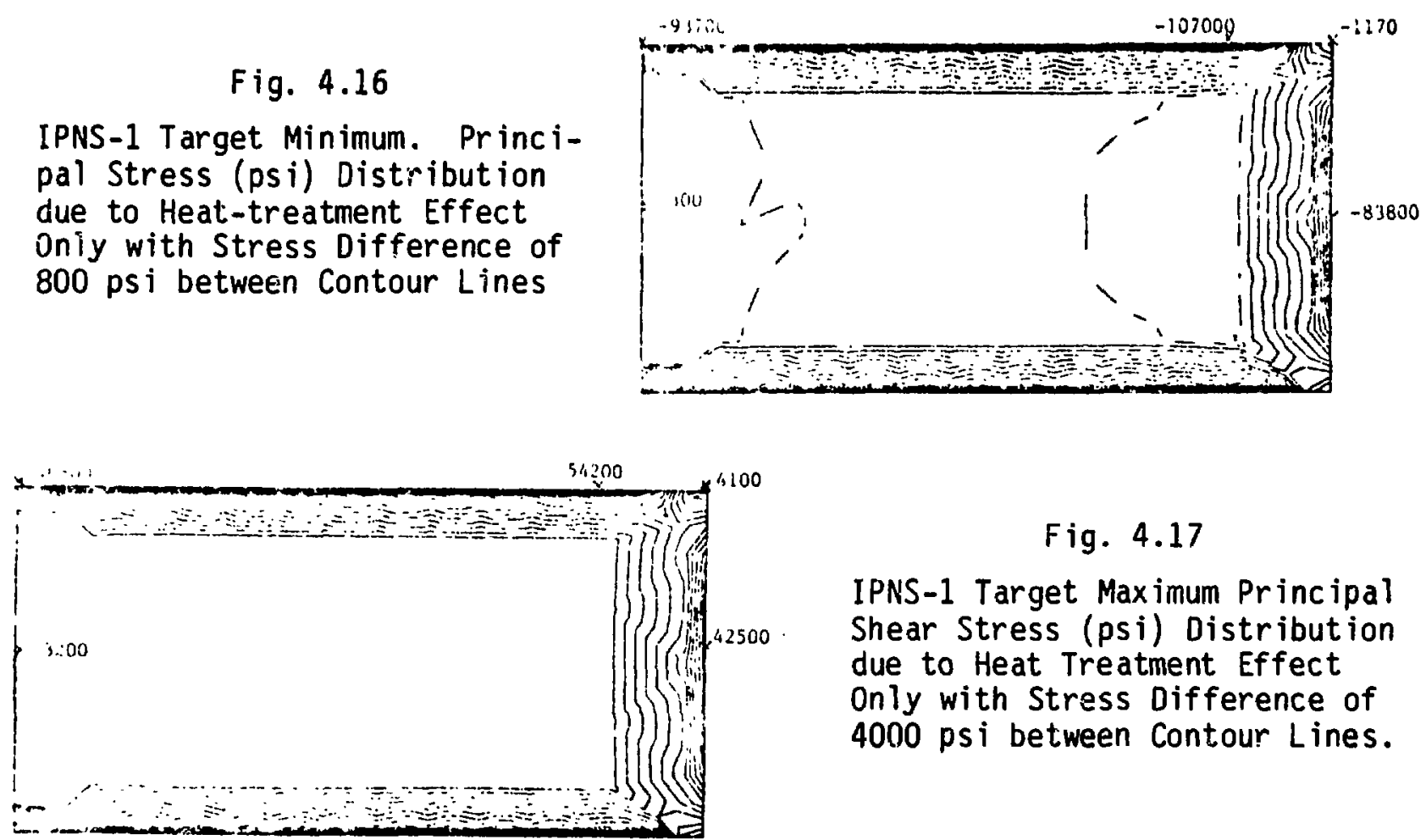

Fig. 4.17

IPNS-1 Target Maximum Principal Shear Stress (psi) Distribution due to Heat Treatment Effect Only with Stress Difference of 4000 psi between Contour Lines.

Fig. 4.18

IPNS-1 Target-effective Stress (psi) Distribution due to Heattreatment Effect Only with Stress Difference of 8000 psi between Contour Lines.

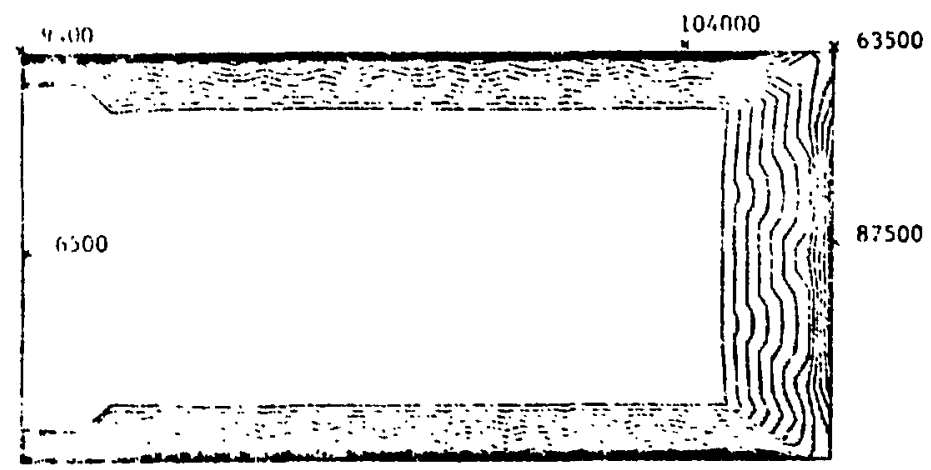


results for a $1-i n$. thick disc design with a 2-in. radius, $0.02-i n$. thick Zircaloy cladding bonded to Uranium on the radial cylindrical edge. A maximum stress of $107,000 \mathrm{psi}$ is noted on the corner near the top face.

The principal stress formula used is

$$
\operatorname{Det} .\left[\begin{array}{llc}
\sigma_{r r}-\sigma_{n} & \tau_{r z} & { }^{\theta_{r \theta}} \\
\tau_{r z} & \sigma_{z z}-\sigma_{n} & \tau_{\theta z} \\
\tau_{r \theta} & \tau_{\theta z} & \sigma_{\theta \theta}-\sigma_{n}
\end{array}\right]=0 .
$$

For axisymmetric applications, the equation is

$$
\begin{aligned}
& \sigma_{1,2}=\frac{\sigma_{r}+\sigma_{z}}{2} \pm \sqrt{\left(\frac{\sigma_{z}-\sigma_{r}}{2}\right)^{2}+\tau_{r z}^{2} ;} \\
& \sigma_{3}=\sigma_{\theta} .
\end{aligned}
$$

Effective Stress Formula Used

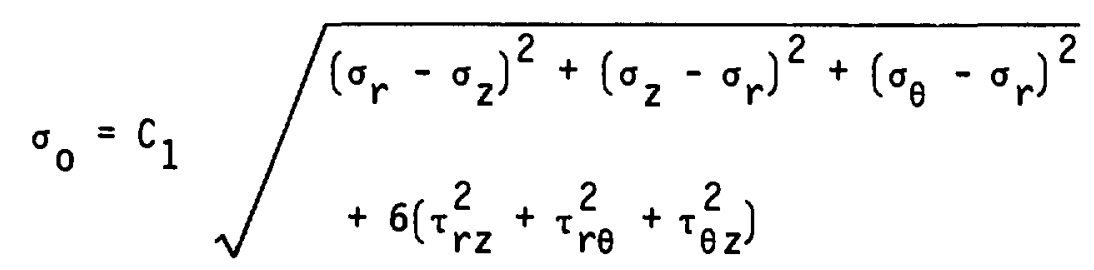

and $c_{1}=1 / 3$, if the effective stress is the octahedral shear stress, while $c_{1}=1 / 2$, if the efffective stress is for a uniaxial test.

\subsection{Swelling Effects.}

\subsubsection{Swelling of Uranium Disc (MAT = 1)}

The dimensional change of the target disc $(\mathrm{U}+\mathrm{C}, \mathrm{Fe}, \mathrm{St}$ alloy) is illustrated in Fig. 10 of Ref. 4.1. The change is a function of temperature above $752^{\circ} \mathrm{F}$, and below $752^{\circ} \mathrm{F}$, it is a constant. In IPNS-I, the maximum temperature does not exceed $600^{\circ} \mathrm{F}$. Hence, it may be safely assumed that swelling of the uranium disc is independent of temperature. Within the accuracy of Fig. 10 of Ref. [4.1], an approximate value is: 
$\frac{\Delta V}{V}=5 \%=0.05$ per 500 DPA.

The conversion factors are:

500 DPA $=1$ at.\% burnup,

0.13 at.\% burnup $=1000 \mathrm{MWD} /$ ton,

and

$1 \mathrm{MWD} /$ ton $=10^{17}$ neutrons $/ \mathrm{cm}^{2}$.

Hence, $\frac{\Delta V}{V}=0.05$ per $\frac{10^{20}}{0.13}$ neutrons $/ \mathrm{cm}^{2}$

$=0.05$ per $7.6923077 \times 10^{20}$ neutrons $/ \mathrm{cm}^{2}$

$=6.5 \times 10^{-23_{\phi} t}$,

where $\phi t$ is the neutron fluence in neutrons $/ \mathrm{cm}^{2}$. Hence, we get

$$
\frac{\Delta V}{V}=1.007502 \times 10^{-23} \phi \mathrm{t} \text {. }
$$

The mean strain is defined as $\rho_{m}=\frac{\rho_{11}+\rho_{22}+\rho_{33}}{3}$

and the volumetric strain as $\rho_{v}=3 \rho_{m}=\rho_{11}+\rho_{22}+\rho_{33}$.

If we set $\sigma_{11}=\sigma_{22}=\sigma_{33}=\sigma_{m}$, then we obtain

$$
\rho_{11}=\rho_{22}=\rho_{m}=\frac{\rho v}{3} \text {. }
$$

The ANSYS program assumes that $\varepsilon_{i j}=\frac{\ell V}{3}=\frac{1}{3} \frac{\Delta V}{V}$.

Then the strain due to swelling is given by

$$
\rho_{\text {sw }}=0.335834 \times 10^{-23} \phi t \text {. }
$$

If we use the ANSYS option then $C_{72}=0.0$ for MAT $=1$. This option is given by

$$
\rho_{s w}=C_{67}(\phi t) C_{68}\left(C_{69}+C_{70} T+C_{71} T^{2}+C_{73} T^{3}\right)
$$


The set $C_{67}=0.335834 \times 10^{-23}$,

$$
\begin{aligned}
& c_{68}=1.0, \\
& c_{69}=1.0,
\end{aligned}
$$

and

$$
c_{70}=c_{71}=c_{73}=0 \text {. }
$$

\subsubsection{Swelling of Zircaloy (MAT $=2$ )}

The correlation developed by EG\&G Ref. [4.1] is given by

$$
\rho_{s w, i}=A\left(\exp \frac{240.8}{T_{a b}}\right)\left(\phi_{f} t\right) 1 / 2\left(1-3 f_{j}\right)(1+2.0 \mathrm{CW}) \text {, }
$$

where

$$
\begin{aligned}
A & =1.407 \times 10^{-16}\left(\frac{\text { neutrons }}{\mathrm{m}^{2}}\right)^{-1 / 2,} \\
T_{a b} & =\text { cladding temperature, } k \text { (absolute), } \\
\phi_{f} & =\text { fast neutron flux, neutrons } / \mathrm{m}^{2} \cdot \mathrm{s} \\
t & =\mathrm{E}(\mathrm{E}>1.0 \mathrm{MeV}), \mathrm{s},
\end{aligned}
$$

$f_{i}=$ texture factor, $i=1,2,3$ in the radial, circumferential, and axial directions,

and

$$
\mathrm{CW}=\text { cold work percent. }
$$

This correlation is valid for Zircaloy temperatures between 40 and $360^{\circ} \mathrm{C}$. For temperatures below $40^{\circ} \mathrm{C}$, the temperature is set at $40^{\circ} \mathrm{C}$, and above $360^{\circ} \mathrm{C}$, it is set at $360^{\circ} \mathrm{C}$.

Notes about texture factor, $f_{i}$. The irradiation growth of Zircaloy is quite sensitive to texture. It involves the reduction of the c-axis dimension of individual grains and an increase in the basal plane dimensions of the grains. The effective fraction of grains aligned with their c axle parallel to a reference direction (axial, circumferential, or radial direction) is to be determined from $X$-ray diffraction studies. EG\&G [4.1] has developed a subroutine CTXTR to determine $f_{j}$. However, it requires an input of basal poles found at specified orientations from experimental $x$-ray diffraction. A value of $f_{z}=0.05$ is typical; i.e., only $5 \%$ of 
the cells are aligned with their c-axis parallel to the tube axis. However, Harbottle [4.1] found that $f_{z}=0.13$ and $f_{0}=0.36$; hence, we would get $f_{r}=0.51$. These values could be used in a preliminary study.

We may also assume that Zircaloy is completely annealed, and set

$\mathrm{CW}=0$. Hence, Eq. 4.19 becomes

$$
\rho_{S W, i}=1.407 \times 10^{-16}\left[\exp \frac{240.8}{T_{a b}}\right] \phi_{f} t^{1 / 2}\left(1-3 f_{j}\right) \text {, }
$$

where

$i=r, 0$, and $z$ for the three axes, respectively. Here, $T_{a b}$ is in $k$, and $\phi_{f} t$ is in neutrons $/ m^{2}$. Note, however, that in the radial and axial directions, $\rho_{s w}$ will become negative because $1-3 f_{i}<0$. Hence, Eq. 4.20 may be used only for the axial direction with $f_{j}=0.05$. Also note that, in our case, $\phi_{f}=\phi ;$ i.e., all neutrons are fast neutrons.

Then Eq. 4.20 becomes

$$
\rho_{s W}=1.19595 \times 10^{-16}\left(\exp \frac{240.8}{T_{a b}}(\phi t)^{1 / 2} .\right.
$$

Converting the units, we obtain

$$
\rho_{S H}=5.5394 \times 10^{-8}\left(\exp \frac{433.44}{T_{a b}}\left(\frac{\phi t}{10-22}\right)^{1 / 2}\right. \text {, }
$$

where $T_{a b}$ is in ${ }^{\circ} R$ and $\phi t$ is in neutrons $/ \mathrm{m}^{2}$.

If we use the ANSYS option then $C_{72}=2.0$ for MAT $=2$.

Choose $c_{69}=0.5, c_{70}=0, c_{71}=0$,

$$
\begin{aligned}
& c_{73}=0, c_{74}=433.44, c_{75}=0, \\
& c_{79}=100, c_{80}=1000,
\end{aligned}
$$$$
c_{67}=c_{77}=c_{82}=5.5394 \times 10^{-8} \text {, }
$$

and

$$
c_{68}=c_{78}=c_{83}=0 \text {. }
$$

(Note that $T_{a v b}$ is in ${ }^{\circ} R$.) 
Chapter 4 Reference

[4.1]. A Handbook of Material Properties for Use in the Analysis of Light Water Reactor Fuel Rod Behavior, NUREG/CR-0497, TREE-1280, Rev. 1 TFeb. 1980). 


\section{THERMAL ANALYSIS}

The analysis of the thermal behavior of the Zing-P' and IPNS-1 targets under proton irradiation is a twofold problem. As a first step, the heatgeneration rates in the target material due to the proton bombardment must be evaluated. Second, given a knowledge of the internal heat-generation rates and the associated boundary conditions, the target temperature distributions can then be computed.

Temperatures were computed in the zirconium-clad Zing-P' target and the Zircaloy-clad IPNS-1 target by the ANSYS computer code using heat rates furnished by neutron charged particle transport calculations (adjusted in view of measurements). It is assumed that no heat is generated in the cladding, and that cooling at the boundary occurs by convection to circulating water.

For a cylindrical geometry with axial symmetry, the time-dependent thermal behavior in the presence of internal heat generation is described by

$$
\frac{1}{B} \frac{\partial T}{\partial r}=\frac{\partial^{2} T}{\partial r^{2}}+\frac{1}{r}+\frac{\partial^{T}}{\partial r}+\frac{\partial^{2} T}{\partial Z^{2}}+\frac{1}{K} q(r, Z),
$$

where ${ }_{B}=K /{ }_{p} C_{p}, K$ is the thermal conductivity, $\rho$ is the density, $C_{p}$ is the specific heat at constant pressure, and $q$ is the heat-generation rate. Temperature-dependent properties are used for $B, K$, and $C_{p}$. For this problem, the steady-state solution is conservative with respect to the transient solution, since the maximum temperatures are reached in the steadystate (see Ref. 5.1).

Appendix $C$ provides a discussion of the heat-transfer coefficients used in the analysis. Material properties for the thermal model are reported in Appendix D.

\subsection{Zing $P^{\prime}$ Experimental Verification}

This section describes the method used to compare the steady-state thermal analysis performed using the ANSYS finite-element computer code with the Zing- $P^{\prime}$ experimental ly determined temperatures.

The accurate solution of the heat-conduction equations for this problem is encumbered by an incomplete knowledge of the heat-generation 
rate distribution in the target. The heat generation arises from the interaction between $500-\mathrm{MeV}$ beam protons and the target nuclei. For a target composed of fissionable uranium, the total thermal-energy release in the target can significantly exceed the energy deposited in the target by the proton beam.

\subsubsection{Heat-Generation Rate Distribution}

Hubeny $[5.2,5.3]$ has computed the heat-generation rate distribution in the Zing-P' target geometry due to axial irradiation by $500-\mathrm{MeV}$ protons using the HETC/VIM [5.4] neutron-transport code. Ref. [5.3] cites the beam profile determined by densitometer measurements of teflon plates irradiated in the proton beam. Both Gaussian and Moffett $\left[\left(1-(r / a)^{2}\right)^{2}\right]$ representations of the beam profile were used in the Zing-P' neutron-transport calculations, and the heat-generation rate was determined for four radial regions at each of eight axial locations (for a total of 32 points). These values are shown in Table 5.1 .

The finite-element model of the Zing-P' target is composed of more than 1000 elements. Because the heat-generation rate is assumed to be known at only 32 locations, we tried several means of interpolation to determine the heat rate at the intermediate locations.

Table 5.1. HETC/VIM Thermal Energy Deposition for Zing-P' Target with Beryllium Reflector ( $500 \mathrm{MeV}, 1-\mu \mathrm{A}$ beam, FWHM $=2.54 \mathrm{~cm}$, Moffet Beam Profile)

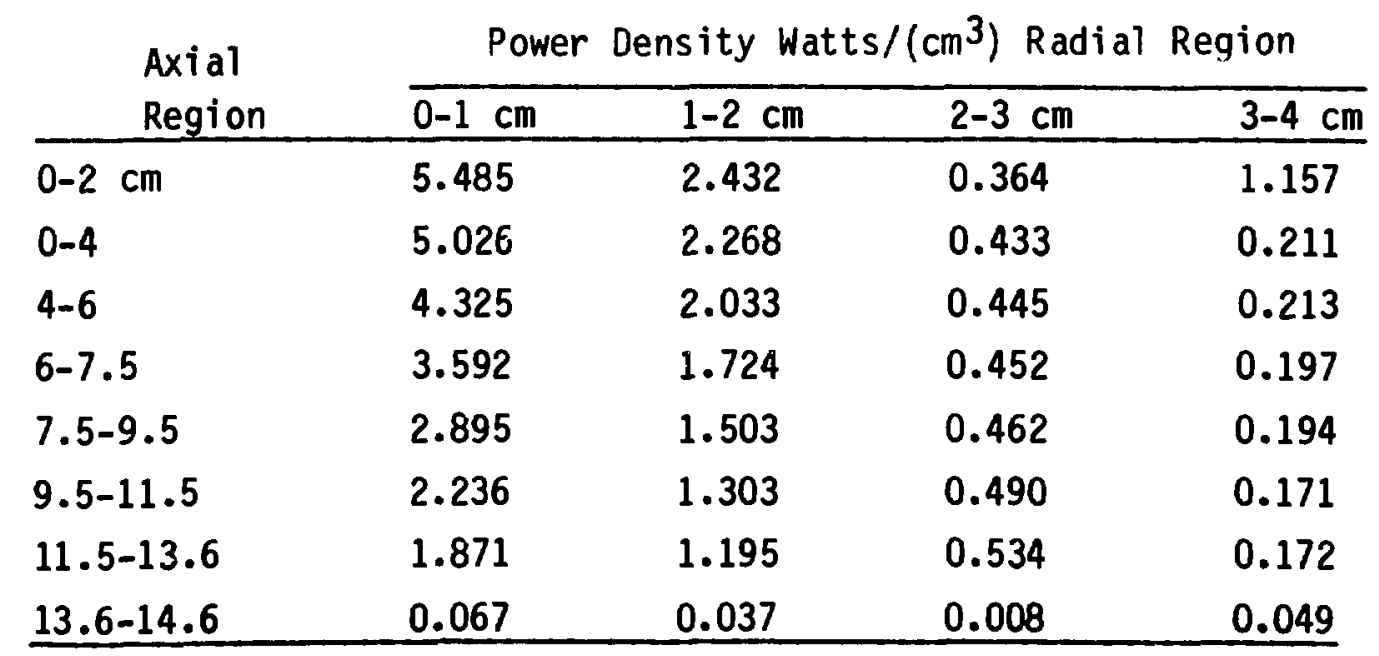


Interpolation schemes used in the thermal analysis are illustrated in Fig. 5.1. The Fuji fit depicted in the figure is a polynomial fit of the form $A(r-3.9)^{2}+B(r-3.9)^{4}$. The $A$ and $B$ coefficients are computed at each of the eight axial locations to give the best radial fit in a least-squares sense (weighted toward small $r$ values, which are regarded as most accurate). Linear interpolation of the $A$ and $B$ coefficients is used to construct the radial fit at intermediate axial locations. The Fuji fit is a non-physical representation of the heat-source distribution for intermediate $r$ values, in that it provides a poor extrapolation of the heat source near the target axis, $r=0$, where it overestimates the expected behavior of the heat source.

A more viable option for fitting the HETC/VIM data while preserving the expected physical behavior of the heat source is the spline fit. The spline curve illustrated in Fig. 5.1 was constructed by requiring the total energy deposition to match the HETC/VIM total energy in each of the four radial regions, i.e., $0-1,1-2,2-3$, and $3-4 \mathrm{~cm}$. Additionally, the slope of the spline curve was constrained to zero at $r=0$. However, implementation of a spline fitting procedure for a three-dimension geometry is cumbersome. Hence, a simpler but adequate scheme, the "Aztec" fit, was adopted. In this scheme, all points lying in one of the 32 spatial regions of the HETC/VIM Zing-P. model are assigned the same value, according to Table 5.1. The resulting step-like functional form inherently preserves the total thermal-energy deposition in each of the 32 regions of the Monte-Carlo simulation.

Table 5.2 indicates that scaling the Moffet beam/Fuji fit heat rates by a factor $1.5 / 1.1$ brings the calculated temperatures into good agreement with the Zing-P' experimental values. Similarly, good agreement is obtained by scaling the Moffet/Aztec heat rates by 1.7/1.1. Additional justification for using uranium-target thermal energy ratios of 1.5-1.7 is found in other theoretical studies. Alsmiller [5.5] for example, has determined a ratio of 1.65 for axial irradiation of a $10-\mathrm{cm}$ diam. by $18-\mathrm{cm}-10 n$ uranium target by $500-\mathrm{MeV}$ protons using the MORSE and HETC computer codes.

These variations in temperature and total power appear to be more a consequence of shortcomings of the charged-particle and neutron transport codes than of the schemes used to interpolate the data. 


\subsubsection{Zing-P' Temperatures}

Thermal calculations were performed on the zing $P^{\prime}$ target using the Fuji and Aztec representations of the HETC/VIM heat-generation rates. (See the Appendixes $C$ and $D$ for discussion of the heat-transfer constants and material properties used.) Preliminary temperature calculations underestimated experimental predictions by about $50 \%$. The probable cause of the discrepancy was traced to the HETC/VIM heat-source values. Knox [5.6] has experimentally measured the total energy deposition in the Zing $P^{\prime}$ target to be $1.5(+0.2)$ times the proton-beam energy. By contrast, the HETC/ $\checkmark I M$ results for a Moffet beam with FWHM $=2.54 \mathrm{~cm}$ give a total energy deposition of $55 \mathrm{MeV}$, or a ratio of thermal energy to beam energy of only 1.1 .

Scaling the HLTC/VIM results by a factor $(\sim 1.5 / 1.1)$ to bring the computed total thermal energy in accordance with experiment permitted the computed temperatures to closely match experimentally determined values. The computed temperature distributions for Zing $P^{\prime}$ are displayed in Figs. 5.2 and 5.3, respectively, for the Fuji and Aztec cases. The bulk fluid temperature of the water coolant is taken to be $30^{\circ} \mathrm{C}$. Table 5.2 compares calculated and experimental values of $\Delta T=\left(T-30^{\circ} \mathrm{C}\right)$ at the four thermocouple locations in the zing- $\mathrm{P}^{\prime}$ target. The $\Delta T_{3}$ and $\Delta T_{4}$ locations have the same radial and axial coordinates, but differ in the angular coordinate $\theta$. The discrepancy in the measured values of $\triangle T 3$ and $\Delta T 4$ is thus a measure of the beam symmetry and the centering of the beam on the target. The computed values of $\Delta T_{3}$ and $\Delta T_{4}$, on the other hand, are equivalent, since axial symmetry is strictly enforced in the computational model.

Table 5.2. Comparison of Zing-P' Theoretical and Experimental Resultsa

\begin{tabular}{lccccc}
\hline & \multicolumn{5}{c}{ Temperature Differerice $\mathrm{T}-30^{\circ} \mathrm{C}\left({ }^{\circ} \mathrm{C}\right)$} \\
\cline { 2 - 6 } & $\Delta \mathrm{T} 1$ & $\Delta \mathrm{T} 2$ & $\Delta \mathrm{T3}$ & $\Delta \mathrm{T} 4$ \\
\hline Calculated Moffet/Fuji $\times 1.5 / 1.1$ & 41 & 33 & 18 & 18 \\
Calculated Moffet/Aztec $\times 1.7 / 1.1$ & 42 & 33 & 17 & 17 \\
Calculated Gaussian/Fuji $\times 1.5 / 1.1$ & 34 & 27 & 16 & 16 \\
Experiment Case II Run 5 & 42 & 34 & 20 & 17 \\
\hline
\end{tabular}

a500-MeV. 0.981- $\mu \mathrm{A}$ beam. FWHM $=2.54 \mathrm{~cm}$.

See Figs. 5.1 and 5.2 for $\Delta T 1, \Delta T 2, \Delta T 3$, and $\Delta T 4$ locations. 


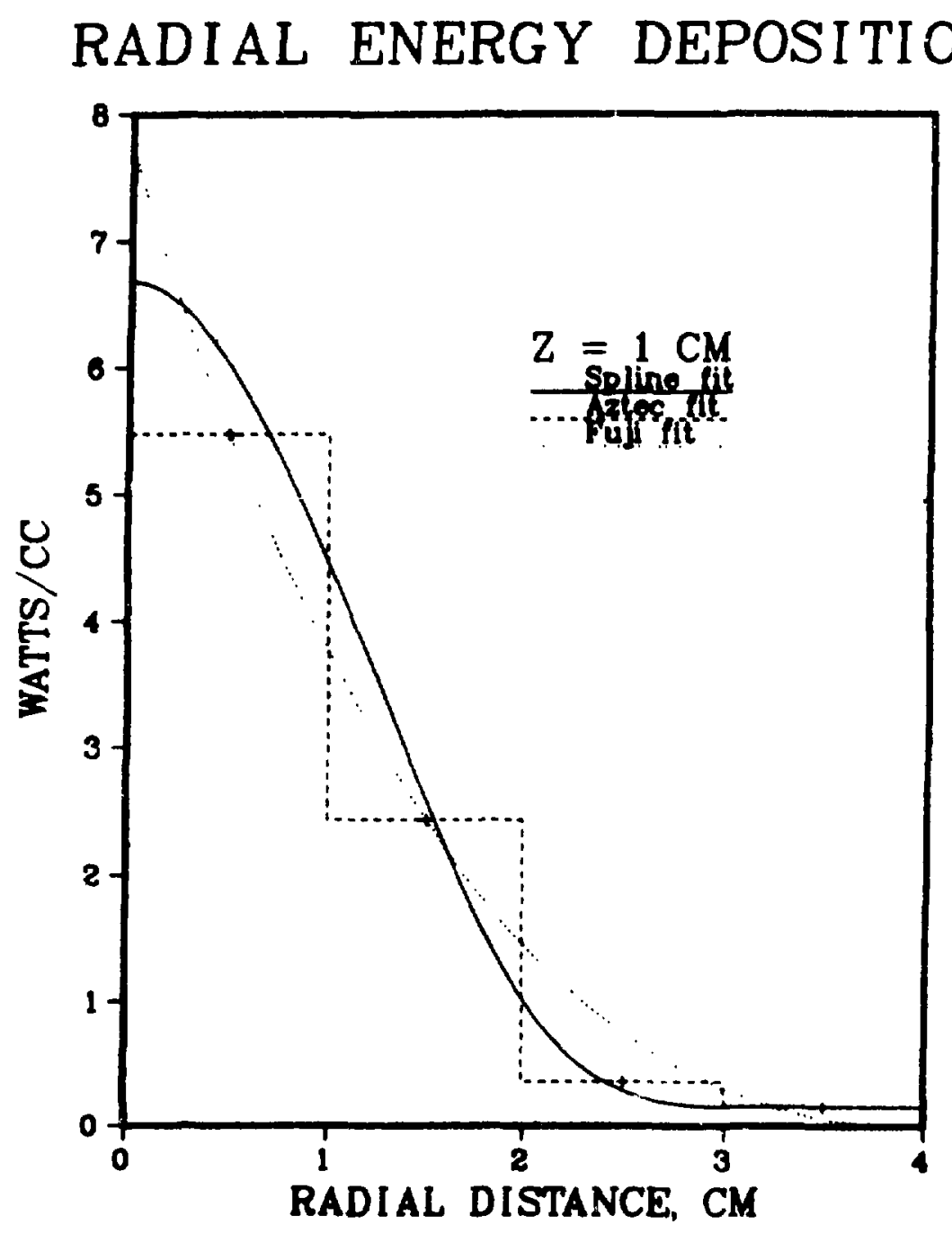

Fig. 5.1. Interpolation Schemes. 


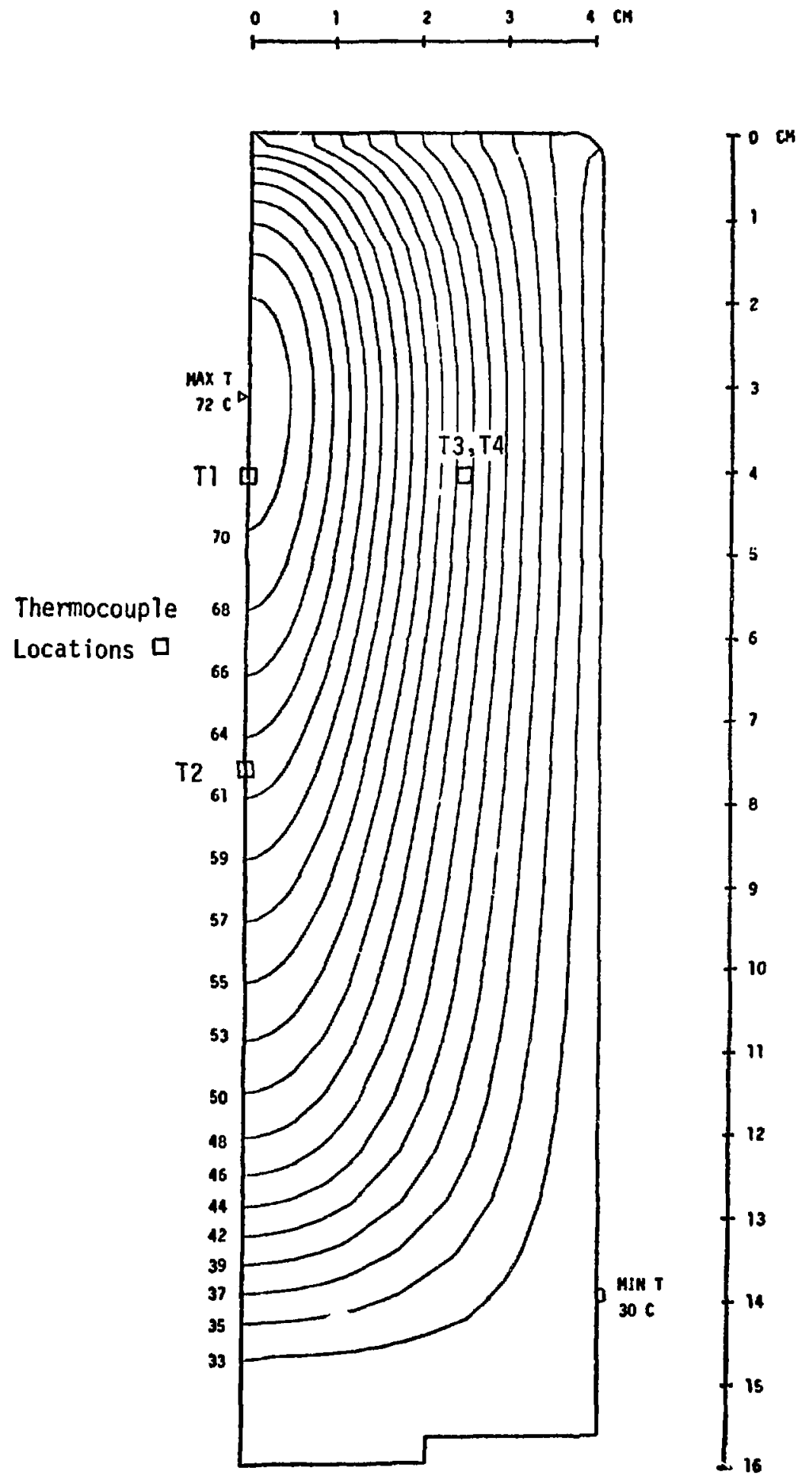

Fig. 5.2. Zing $P^{\prime}$ Temperature Distribution; Fuji Fit. (HETC/VIM heat rates scaled by 1.5/1.1.) 


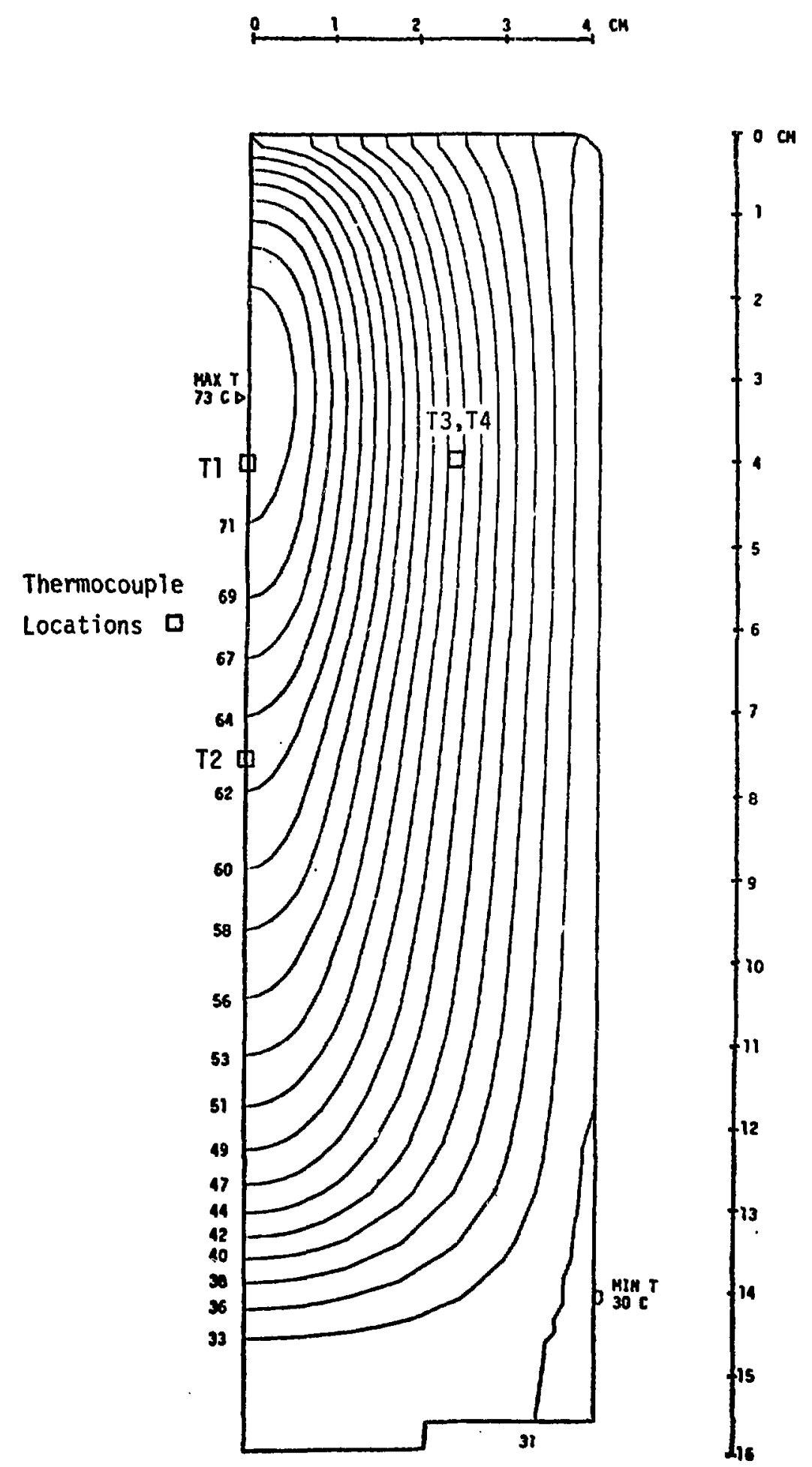

Fig. 5.3. Zing-P' Temperature Distribution; Aztec Fit. (HETC/VIM heat rates scaled by 1.1.) 
We have additionally performed a calculation using a Gaussian beam shape instead of a Moffet profile (see Table 5.2); however, less satisfactory agreement was obtained. Using both Fuji and Aztec fits and a 1.5/1.1 scale factor, we were able to reasonably match the measured temperatures. Since $\Delta T$ is a linear function of the heat source, orie may estimate that using a scale factor of approximately $1.85 / 1.1$ is required to achieve good agreement between Gausian power density calculations and experiment for values $\Delta T_{1}$ and $\Delta T_{2}$. However, a ratio of target thermal energy to beam energy 1.85 is unjustifiably high. We conclude that the Gausian is poor representation of the beam profile.

\subsection{IPNS-1 Thermal Analysis}

Based on a Moffet beam profile, heat-generation rates have been computed using the HETC/VIM computer code at five radial and 11 axial locations for the IPNS-1 target. These values, normalized for a 1- $\mu \mathrm{A}$ beari, are tabulated in Table 5.3. The Aztec fitting procedure with a 1.7/1.1 (rather than 1.5/1.1 for conservatism) scale factor is used in the thermal analysis of the 2.54-cmthick by $10-\mathrm{cm}-d i a m$. uranium target clad with Zircaloy-2. The analys is was performed using a 1173-element, axisymmetric model of the target gecmetry on the ANSYS computer code.

Table 5.3. HETC/VIM Thermal Energy Deposition for IPNS-1 Target with Beryllium Reflectora

Power Density Watts $/\left(\mathrm{cm}^{3}\right)$ Radial Region

\begin{tabular}{llllll} 
Axial Region & $0-1 \mathrm{~cm}$ & $1-2 \mathrm{~cm}$ & $2-3 \mathrm{~cm}$ & $3-4 \mathrm{~cm}$ & $4-5.3 \mathrm{~cm}$ \\
\hline $0-2 \mathrm{~cm}$ & 2.653 & 1.913 & 0.895 & 0.206 & 0.072 \\
$2-4$ & 2.468 & 1.836 & 0.881 & 0.228 & 0.100 \\
$4-6$ & 2.121 & 1.634 & 0.783 & 0.250 & 0.105 \\
$6-8$ & 1.766 & 1.348 & 0.698 & 0.232 & 0.103 \\
$8-10$ & 1.444 & 1.113 & 0.613 & 0.244 & 0.093 \\
$10-12$ & 1.202 & 0.983 & 0.556 & 0.236 & 0.084 \\
$12-14$ & 1.063 & 0.874 & 0.547 & 0.250 & 0.084 \\
$14-16$ & 0.050 & 0.047 & 0.039 & 0.035 & 0.031 \\
$16-18$ & 0.023 & 0.025 & 0.025 & 0.027 & 0.026 \\
$18-20$ & 0.021 & 0.019 & 0.020 & 0.014 & 0.013 \\
$20-22$ & 0.012 & 0.014 & 0.012 & 0.012 & 0.010
\end{tabular}

500-MeV, 1- $\mu \mathrm{A}$ beam, FWHM $=4 \mathrm{~cm}$, Moffet Beam Profile 
Use of the scale factor 1.7/1.1 conservatively derived from the Zing-P' measurements to describe the IPNS-1 target implicitly assumes that the ratio of thermal energy deposition to beam energy is relatively insensitive to the difference in geometry. Evidence that this is the case is provided by the HETC/VIM calculations, wich predict the same ratio of energy deposition to beam energy of 1.1 for either target geometry. The heat-generation rates are additionally scaled to simulate nominal full-power $(22-\mu \mathrm{A})$ operation of the proton beams.

The first disc of the eight-disc stack, i.e., the disc that receives the greatest energy deposition, is modeled. This is aiso the target disc that receives the least amount of coolant flow. The first disc thus provides the worst thermal case.

\subsubsection{IPNS-1 Target Cooling}

The target disc is cooled by $120^{\circ} \mathrm{F}$ water flowing in parallel channels on the disc face. Two coolant-channel geometries are investigated: a seven-channel geometry designed to provide fairly uniform cooling over the disc face, and a five-channel geometry which concentrates cooling at the center of the disc face (see Fig. 5.4). The highest temperatures occur at the center of the target disc; hence, the five-channel geometry is expected to provide more effective cooling.

Coolant flow rates within the target assembly have been computed for the five-channel geometry using the HYNAL hydraulic-analysis computer code (see Appendix C). The results indicate, for an assumed inlet flow of $45 \mathrm{gpm}$ at $35 \mathrm{psia}$, that the first target receives $4.5 \mathrm{gpm}$ of cooling water with channel flow velocities of 9.5-11.5 fps in the five-channel geometry. A hydraulic analysis has not been performed for the seven-channel design, but assuming a 4.5-gpm flow to the disc an average channel flow velocity of 13.2 fps is comiputed. This value is assumed in the thermal analysis of the seven-channel case.

Because of the dependence on an axisymmetric finite-element model, the exact slotted geometry is impossible to treat. Instead, the 


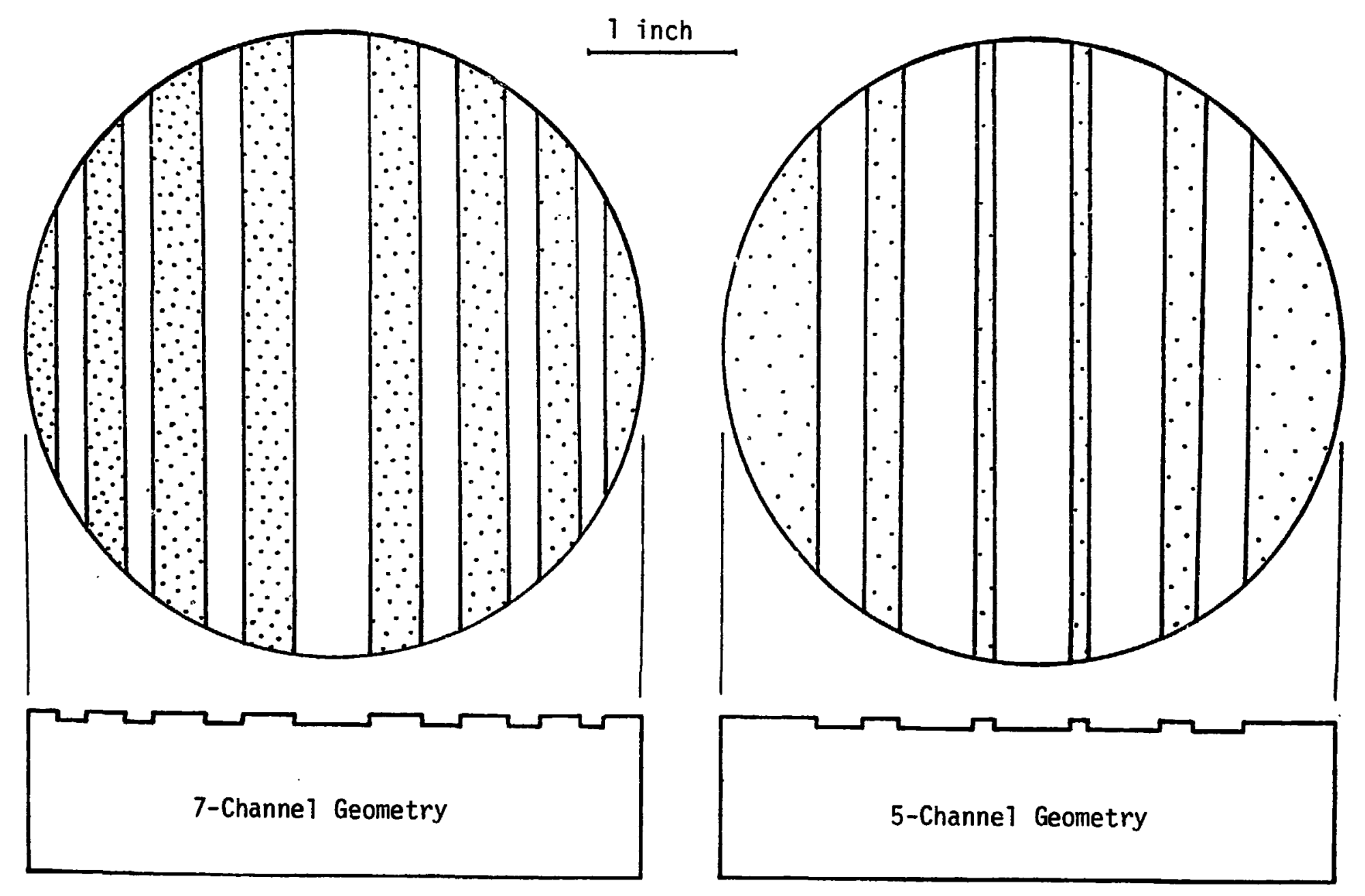

Fig. 5.4. IPNS-1 Target-cooling Channel Geometries. 
heat-transfer characteristics of the target disc are cylindrically averaged to derive effective convective coefficients within concentric zones.

The simplest such approach used in the thermal analysis is denoted by the one-convective-zone approach. In the one-zone method, an effective value of the convective coefficient, $h$, is computed for the entire disc face (assumed to be one convective zone), based on an averaging of the individual channel heat-transfer coefficients over the face of the disc. Since the convective coefficient, $h$, is a function of the coolant-film temperature, which is not precisely known in advance, an iterative procedure is required to arrive at a consistent solution for $h$.

The one-zone approach is inherently ccirservative. Since the heat flux is greatest toward the center of the disc where the temperature is highest, the actual convective coefficient at the center is larger than the assumed average value. Accordingly, the actual center temperatures are lower than those calculated using the one-zone approach. Conversely, near the edge of the disc, the actual convective coefficient is lower than the assumed average value; however, since the heat-generation rate near the disc edge is very $1 \mathrm{cw}$, the actual temperatures near the edge remain low compared to the center temperatures.

The one-convective-zone scheme suffers from the added drawback that distinctions in thermal performance between target geometries differing, for example, in channel arrangement are obscured by the averaging procedure. In the present study, where it is desired to gauge the effectiveness of a five-channel geometry (with channels concentrating cooling at the center) against a seven-channel geometry (with relatively uniformly spaced channels), such distinctions are important.

In an attempt to alleviate some of the shortcomings of the one-zone approach while maintaining the simplicity of an axisymmetric moder, an additional scheme--the two-convective-zone aproach--has been used. in the two-zone approach, the disc is divided into two concentric zones: an inner circle of $1-i n$. radius, and the remaining outer ring. An effec- 
tive convective coefficient is separately computed for each zone by averaging the individual channel heat-transfer coefficients within the zone. A trial-and-error approach is required to arrive at convective coefficients consistent with the average coolant-film temperature in each zone. The computation of the zone convective coefficients is further described in Appendix C.

Although the two-zone calculations are expected to provide more realistic temperatures, one-zone calculations are also made to provide more conservative thermal inputs for the target stress analysis and fatigue life evaluation.

\subsubsection{IPNS-1 Temperatures}

The maximum computed interior target temperature and channel-wall temperatures are tabulated in Table 5.4. Results of the one- and two-zone calculations are given for both five- and seven-channel geometries. Also included are the results of hypothetical accident studies involving impaired coolant flow to the five-channel geometry. The first two impairedflow cases represent uniform reductions in flow of $50 \%$ and $60 \%$, respectively. The third case represents a blocked center-channel accident, in which no flow is assumed in the center channel.

The one-zone approach is overly pessimistic where a large temperature variation occurs between the disc center and edge. Accordingly, only two-zone results are furnished for the reduced-flow cases. The blockedchannel case is effectively a three-zone calculation, since the convective coefficient is set to zero in a $3 / 4-i n .-d i a m$ circle centered on the disc face.

Contour plots of the temperature distributions for the tabulated cases are displayed in Figs. 5.5 and 5.6 for the full-flow cases, and in Figs. 5.7 and 5.8 for the impaired-flow cases. In all full-flow cases, the results indicate that the flow is coinfortably below the nucleate boiling regime $\left(T_{\text {Sat }}=260^{\circ} \mathrm{F}\right)$. 

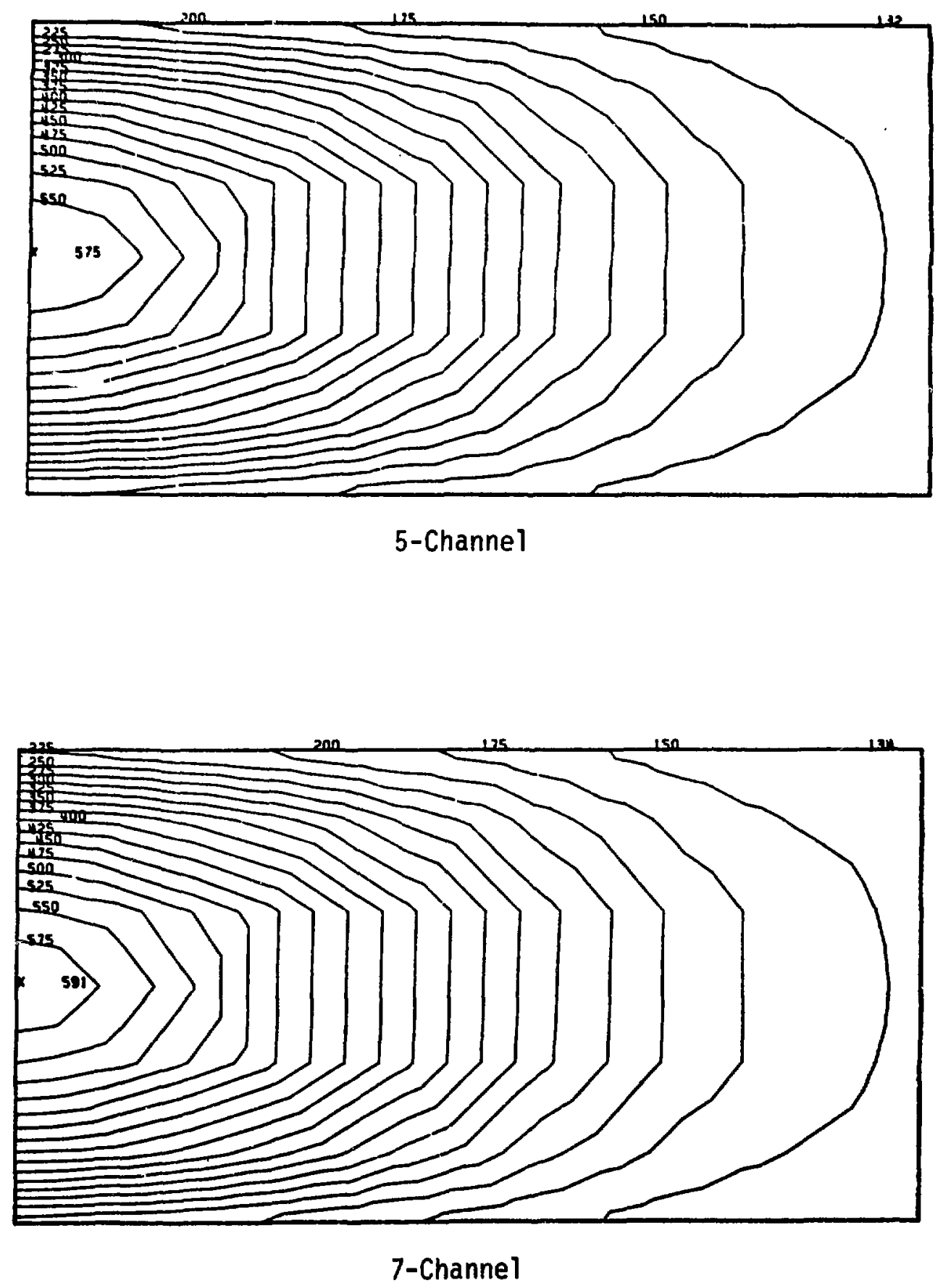

Fig. 5.5. Two-convective-zone Temperature Distributions ( $F$ ) for Five- and Seven-channel Geometries with Full Flow. 

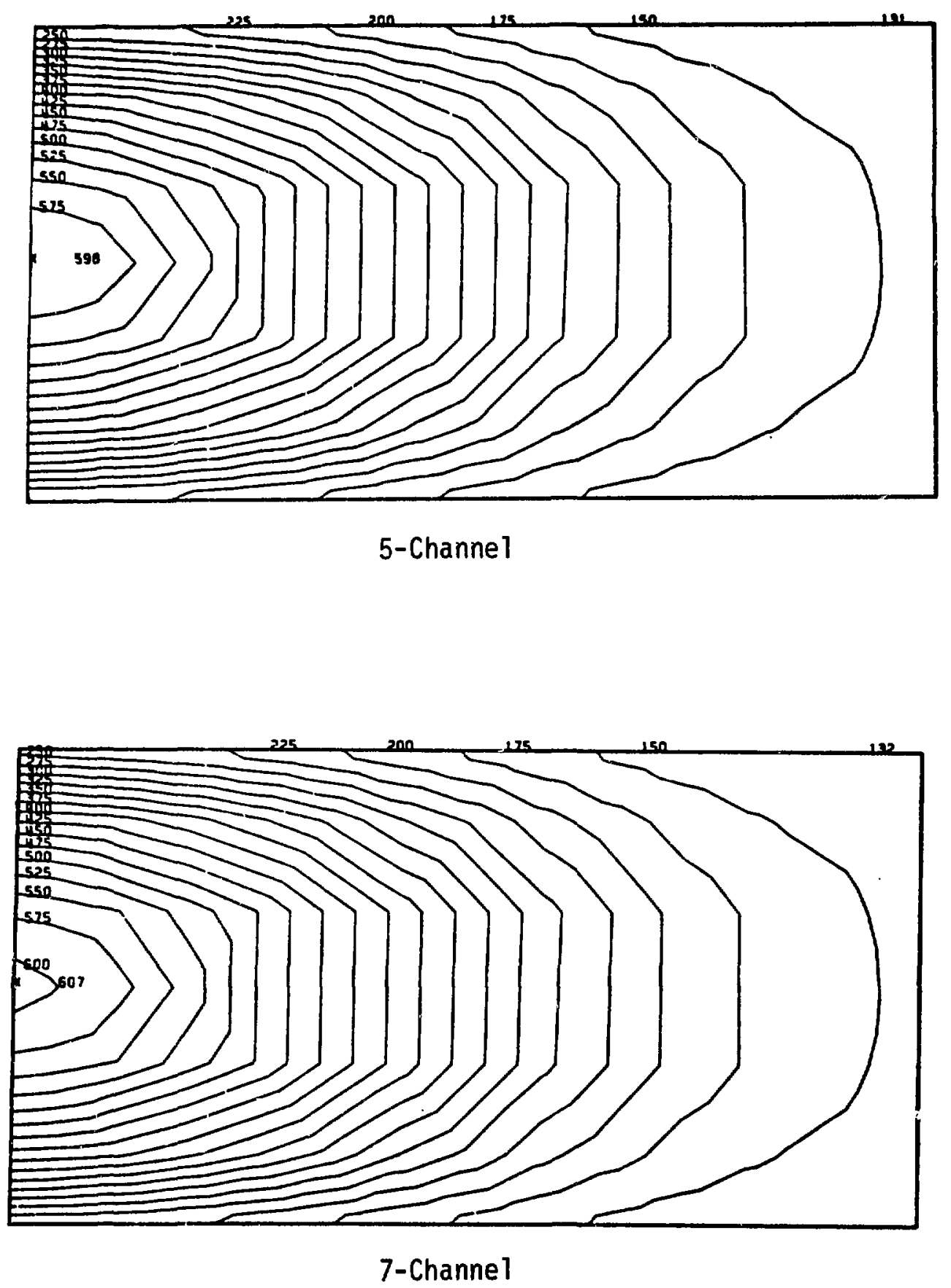

Fig. 5.6. One-convective-zone Temperature Distributions $\left({ }^{\circ} F\right)$ for Five- and Seven-channel Geometries with Full Flow. 


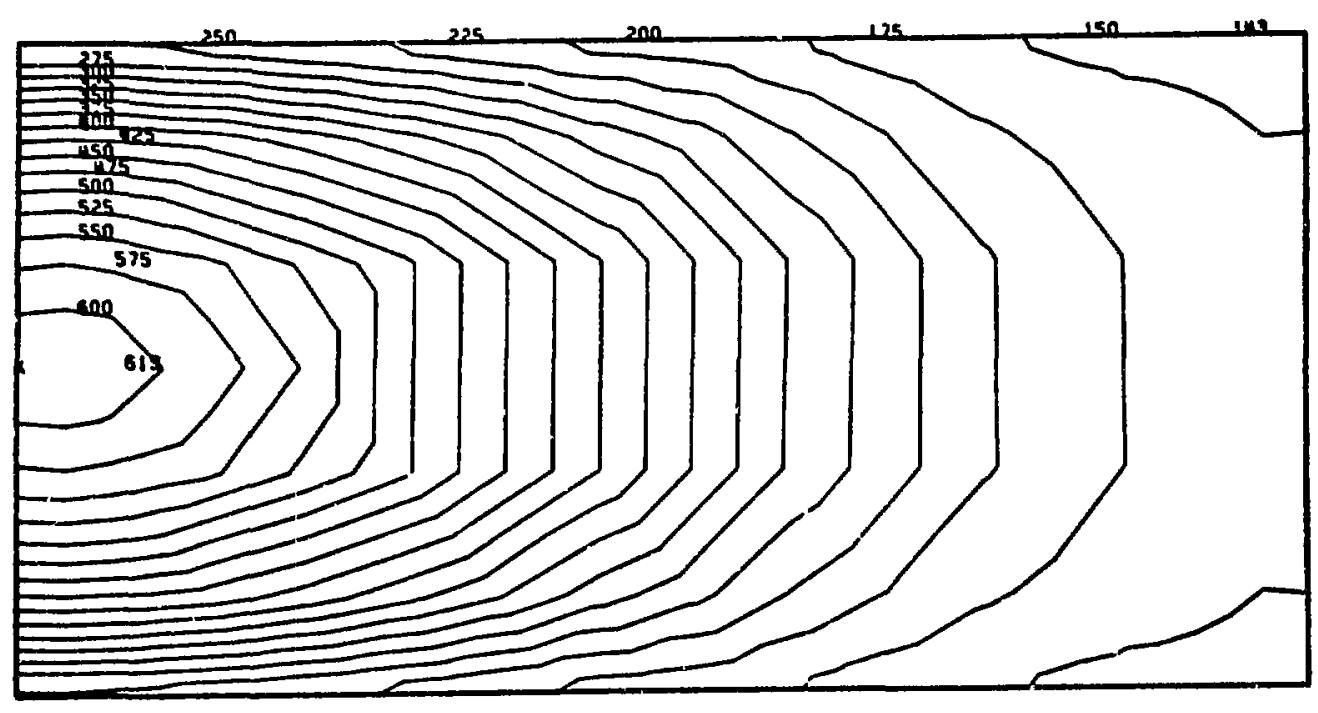

$50 \%$ Flow

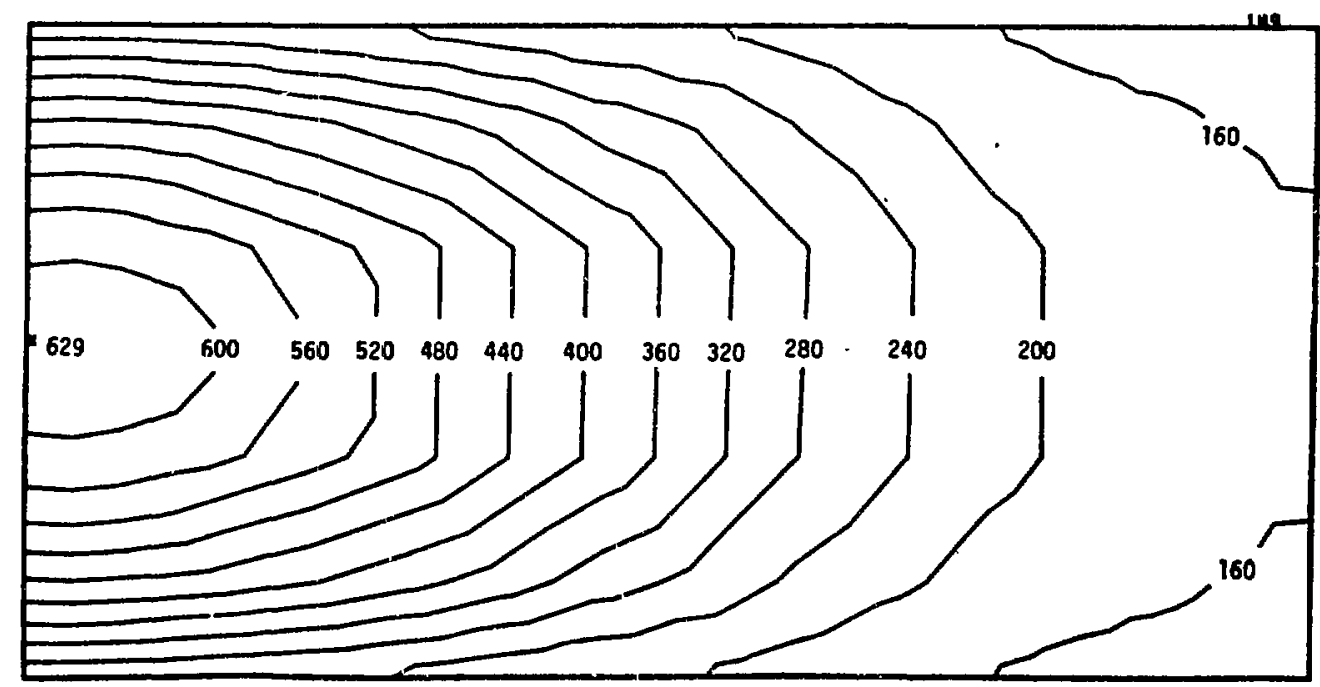

$40 \%$ Flow

Fig. 5.7. Reduced-flow Temperature Distributions ( $\left.{ }^{\circ} \mathrm{F}\right)$ for Five-channel Geometry (Two-zones). 


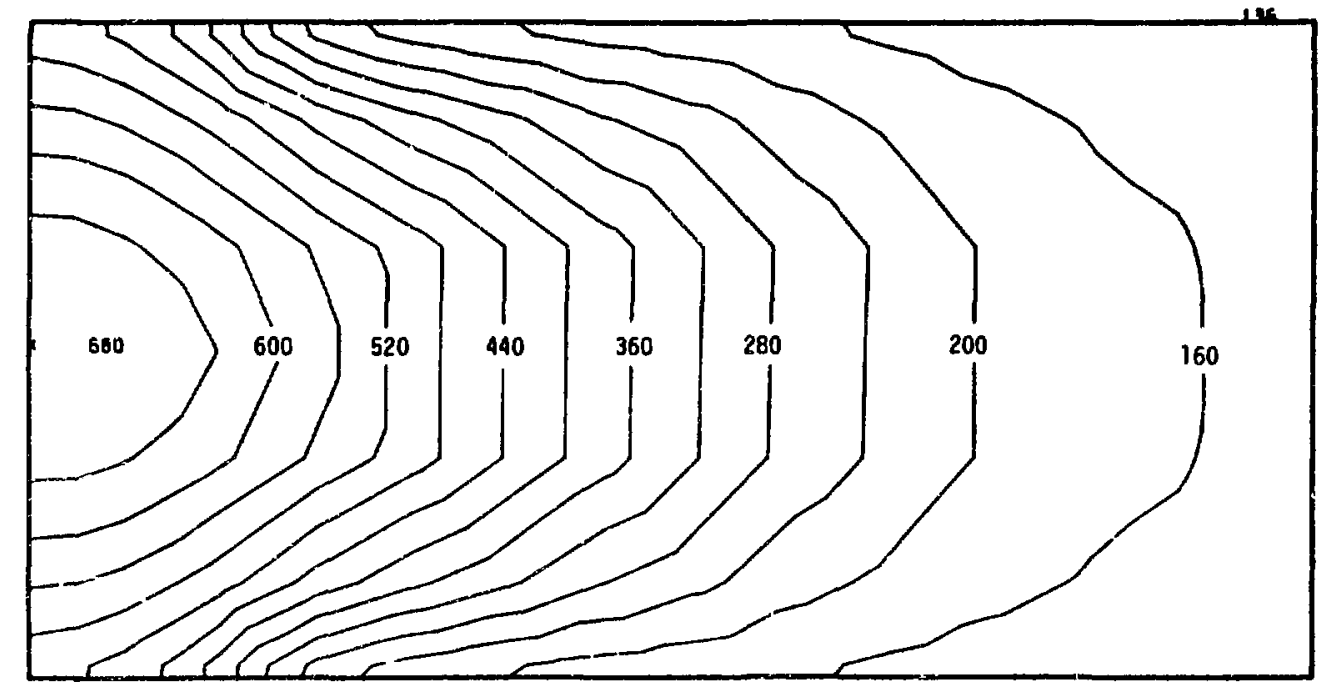

Fig. 5.8. Temperature Distribution $\left({ }^{\circ} \mathrm{F}\right)$ in Five-channel Geometry with Blocked-center Channel (Three-zone Calculation). 
Table 5.4. Maximum Interior Target Temperature and Channel-Wall Temperatures ${ }^{\mathrm{a}}$ Geometry

\begin{tabular}{lcc}
\cline { 2 - 3 } & Five-channel & Seven-channel \\
\cline { 2 - 3 } Full flow, one-zone & $598(236)$ & $607(247)$ \\
Full flow, two-zone & $575(203)$ & $591(224)$ \\
$50 \%$ flow, two-zone & $613(252)$ & $-\ldots$ \\
$40 \%$ flow, two-zone & $629(271)$ & $-\ldots$ \\
$\begin{array}{l}\text { Blocked center } \\
\text { channel, three-zone }\end{array}$ & $680(503)$ & - \\
\hline
\end{tabular}

a The first number gives the maximum interior temperature $\left({ }^{\circ} \mathrm{F}\right)$; the second number in parentheses gives the maximum wall temperature $\left({ }^{\circ} \mathrm{F}\right)$.

Accuruing to the two-zone estimates, the maximum cladding wall temperature is $203^{\circ} \mathrm{F}$ for the five-channel design, or about $20^{\circ} \mathrm{F}$ cooler than for the seven-channel geometry. The more-conservative one-zone estimates for the peak wall temperatures are $236^{\circ} \mathrm{F}$ and $247^{\circ} \mathrm{F}$, respectively, for the fiveand seven-channel geometries. Because the actual slotted geometry is modeled by an axisymmetric geometry with flow averaged over the channels, the actual cladding wall temperature is expected to be slightiy higher than predicted between coolant channels, and slightly lower than predicted within the channels.

Although the actual temperature variation may increase the thermal stress in the cladding over that predicted assuming averaged convective coefficients, the use of the more conservative one-zone temperature distributions for the stress and fatigue analysis offsets this effect somewhat.

The reduced-flow cases suggest that the wall reaches the saturation temperature $\left(260^{\circ} \mathrm{F}\right)$ at between $50 \%$ and $40 \%$ flow. This provides a generously large safety margin against accidental boiling. However, some flow boiling can probably be tolerated, since the flow is expected to be stable.

In the blocked center-channel case, the peak wall temperature reaches about $500^{\circ} \mathrm{F}$ at the center. However, the wall temperature drops away from the center, and all channels that contain coolant are predicted to remain below saturation temperature. 


\section{Ref erences Chapter 5}

[5.1]. Bailey, J. L., "Thermal Analys is of a Uranium Target Disc for Intense Pulsed Neutron Sources," ANL/ENG-81-06, July (1981).

[5.2]. Hubeny, H. to Wor Iton, T. G., memos, "Zing-P' Uranium Target," June 4, 1979, and June 12, 1979.

[5.3]. Hubeny, H. to Worlton, T. G., memo, "Effect of Proton Beam Profile on Uranium Target," December 13, 1979.

[5.4]. K. C. Chandler and T. W. Armstrong, Operat ing Instructions for the High-Energy Nuc leon-Meson Transport Code HETC, ORNL-4744 (1972).

[5.5]. R. G. Alsmiller, referenced in IPNS--A National Facility for Condensed Matter Research, ANL-78-88, pp. 86-87, (Nov. 1978).

[5.6]. Knox, A. E. to T. Wor Itor, J. Carpenter, and J. Bailey, "Ratio of Total Target Thermal Power to Proton Beam Power in Zing-P1," memo, December 7, 1979. 


\section{TARGET MATERIAL STRESS}

The distribution of stress intensity that would be developed in the Zing-P' and IPNS-1 targets during steady axial irradiation by protons was evaluated by use of the ANSYS (STIFF 42) computer code Ref. [6.4] toqether with the energy deposition data presented in Tables 5,1 and 5.3. An evaluation of the intensity and distribution of stress in the tarqets was considered essential in order to determine the potential for rupture of the zirconium or Zircaloy-2 cladding on the uranium during operation. Unacceptable lev ls of stress intensity might be developed in the cladding by irradiation- and thermal-cycling-induced dimensional change of the uranium, nonuniform temperature distribution within the uranium in the Zing $\mathrm{Pl}^{\prime}$ target cylinder (see Fig. 5.2) or in the IPNS-1 target discs (see Fig. 5.5), and by the greater thermal expansion of the uranium in comparison with the zirconium or Zircaloy-2 cladding (Chapter 4). Also, even though the stress in the zirconium or Zircaloy-2 cladding remains near the yield stress, the cladding could develop cracks owing to metal fatique failure which results from temperature cycles in the target during interruptions in the operation of the proton source. The number of temperature cycles that would result in fatique failure of the cladding for the expected level of stress intensity in the cladding was evaluated to determine the anticipated lifetime of the target.

The stress analyses included the residual stress state that was present in the targets following fabrication and heat treatment (Chapters 3 and 4). In the Zing- $P$ ' target, an axial restraint at the circumference of the zirconium plate on the back of the target was imposed on the analysis as a boundary condition. In addition, for the ZING-P' target, "dead-weight" effects of the target were included in the analysis.

\subsection{Zing P' Target Stresses}

The steady-state distortion and the resultant distribution of stress intensity in the Zing-P' target (see Fig. 6.1) were evaluated for the continuous axial irradiation by 1 and $10 \mu \mathrm{A}$ proton current. 


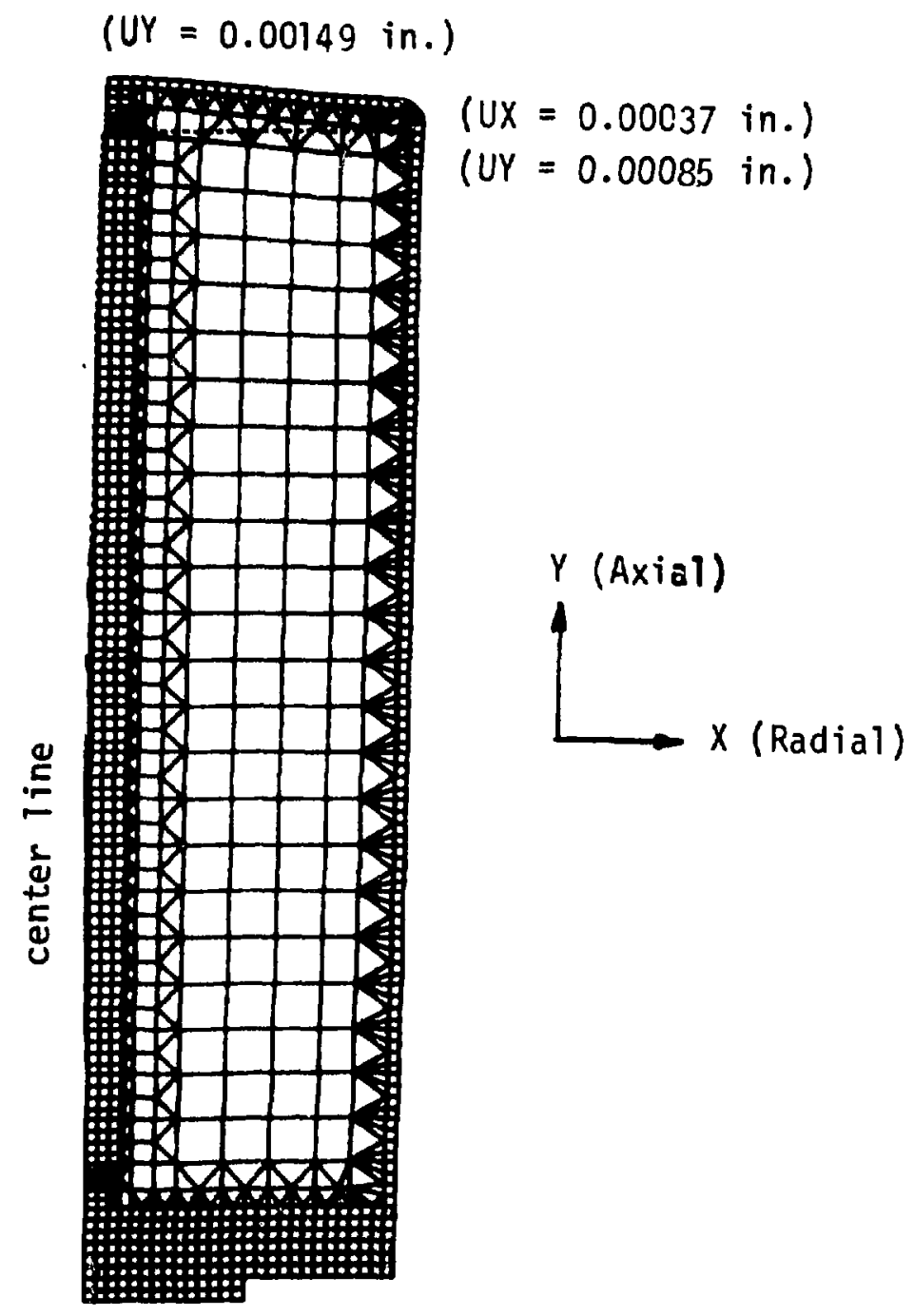

Fig. 6.1. Zing P' Target-Deflected Shape (Solid Lines) due to Power Cycle; $0.981 \mu \mathrm{A}$ Case (Dotted Lines Indicate Undeflected Boundary Outline). 


\subsubsection{One-Microampere ?roton Current}

Figure 6.1 shows the distortion of the Zing $P^{\prime}$ target cylinder that results from axial irradiation by $1 \mu A$ proton current. This distortion results from the nonuniform temperature distribution within the cylinder and and the thermal expansion of the uranium. The irradiation- and thermal-cyclinginduced dimensional change of the uranium is negligible for the intended lifetime of the target. As shown in Fig. 6.1, the distortion of the target cylinder for $1 \mu \mathrm{A}$ of proton current is a maximum $(0.00149$ in.) along the cylinder axis and decreases toward the cylinder circumference $(0.00085 \mathrm{in}$.). The radial distortion of the cylinder is 0.00037 in.

Figures $6.2,6.3$, and 6.4 , respectively, show the radial $\left(\sigma_{r}\right)$, axial $\left(\sigma_{z}\right)$, and hoop $\left(\sigma_{\theta}\right)$ components of the stress that is developed in the zirconium-clad-uranium composite by the uranium distortion in the Zing-P' target for $1_{\mu} \mathrm{A}$ of proton current. The maximum principal stress, minimum principal stress, and principal shear stress are shown in Figs. 6.5, 6.6 , and 6.7 , respectively.

Examination of Figs. 6.2-6.7 shows that the stress intensity in the Zing- $P$ ' target cylinder is separated (dashed line in the figures) into zones that are in a state of compression or tension. The maximum compressive stress $(-11220 \mathrm{psi}$, Fig. 6.3) in the uranium is located at $\mathrm{s} 5 \mathrm{-cm}$ distance on the cylinder axis from the front (proton impingement) face, whereas the maximum tensile stress ( 8670 psi, Fig. 6.4) in the zirconium cladding is located at the center of the front face. A comparison of Fig. 5.2 with Figs. 6.2 and 6.3, for example, shows that the zone in the uranium with high compressive stress is associated with the maximum temperature region in the target.

The effective stress ( $\sigma_{0}$, Eq. 4.15) in the Zing-P' target materials for $1 \mu \mathrm{A}$ of proton current is shown in Fig. 6.8. The maximum effective stress in the zirconium cladding ( $8400 \mathrm{ps} i$ ) occurs at the center of the front face, and the maximum effective stress in the uranium ( $5800 \mathrm{psi}$ ) is located at $-5-\mathrm{cm}$ distance from the front face and $\sim 3.5-\mathrm{cm}$ distance from the target centerline. In the present study, the computed value of the effective stress $\left(\sigma_{0}\right)$ was 


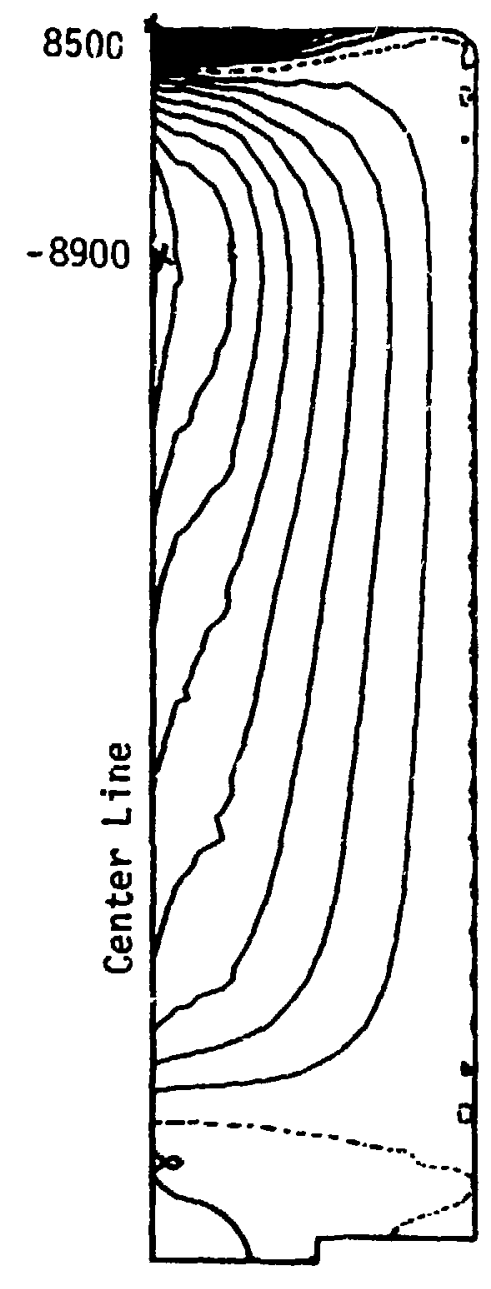

Fig. 6.2

Zing P' Target-radial Stress (psi) Distribution due to Power Cycle; $0.981 \mu \mathrm{A}$ Case (Stress Difference of 1000 psi between Contour Lines).

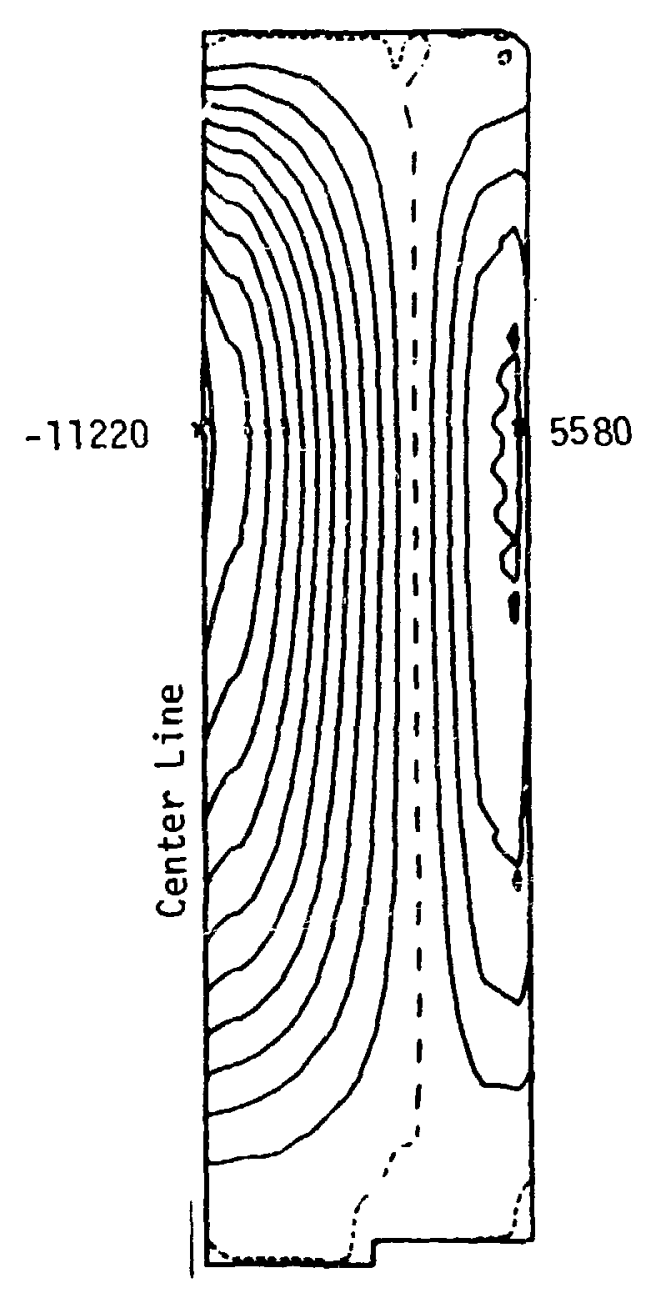

Fig. 6.3

Axial Stress (psi) Distribution Stress Difference of 1000 psi between Contour Lines.

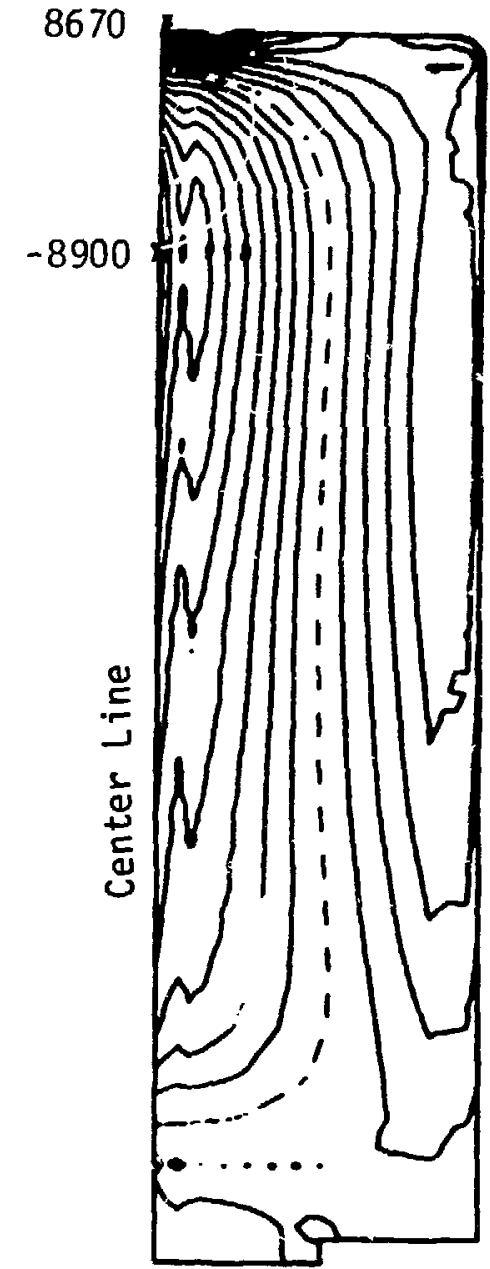

Fig. 6.4

Hoop Stress (psi) Distribution with Stress Differences of 1000 psi between Contour Lines. 


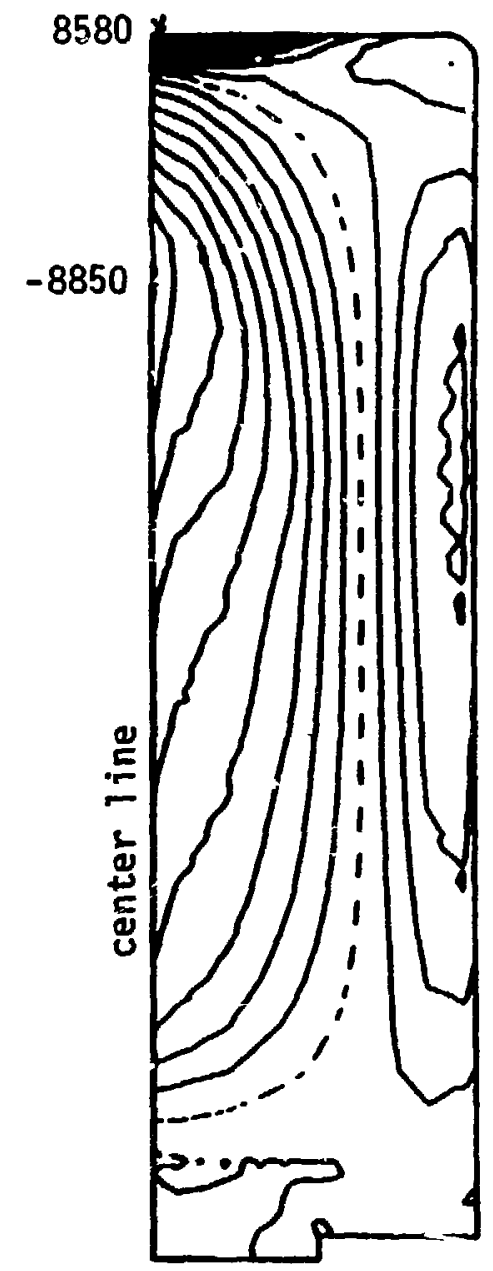

Fig. 6.5

Zing $P^{\prime}$ Target-maximum Principal Stress (psi) Distribution due to Power Cycle (0.981- $\mathrm{A}$ Case) with Stress Difference of 1000 psi between Contour Lines.

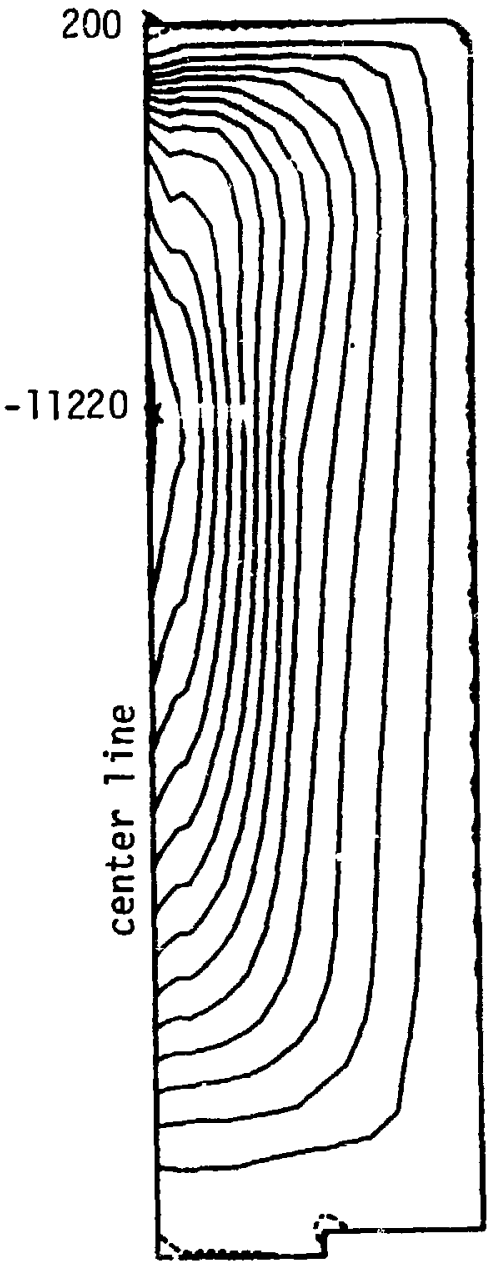

Fig. 6.6

Minimum Principal Stress Distribution with Stress Difference of 800 psi between Contour Lines.
4200

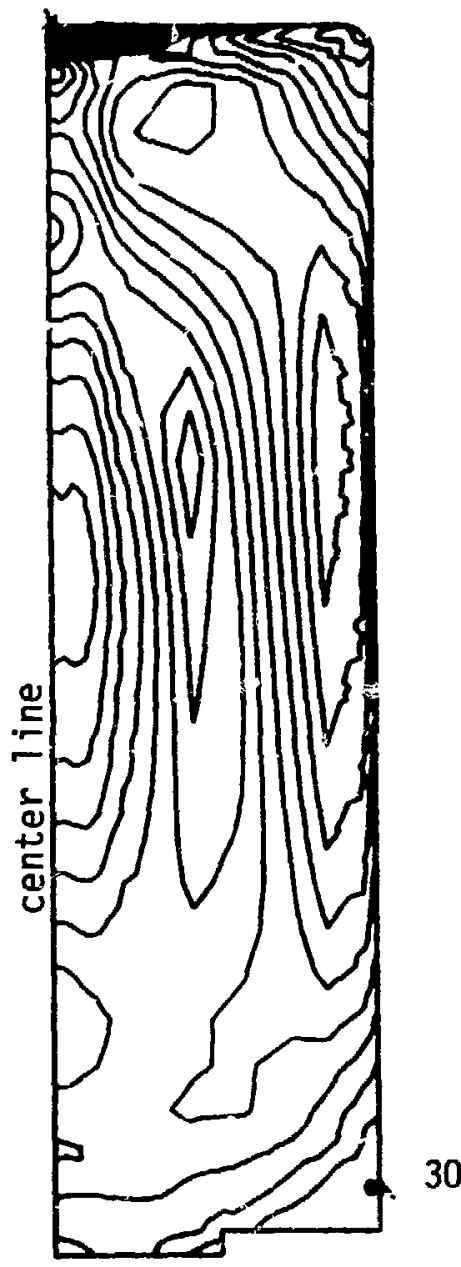

Fig. 6.7

Principal Shear (psi) Distribution with Stress Difference of 250 psi between Contour Lines. 
considered to be directly related to the yield stress $10.2 \%$ offset) value that is commonly reported from a conventional uniaxial tensile test. On this basis, the yield stress of the uranium ( $\sim 40,000 \mathrm{psi}$, Appendix $D)$ and the zirconium ( $\sim 27,000$ psi, Appendix $U$ ) materials in the Zing-p' target would not be exceeded for $1 \mu \mathrm{A}$ of proton current.

\subsubsection{Ten-Microampere Proton Current}

The distortion of the Zing-P' target cylinder that results from the axial irradiation by $10 \mu \mathrm{A}$ proton current is shown in Fig. 6.9. The distortion is a maximum (0.0156 in.) along the cylinder axis and decreases toward the cylinder circumference $(0.0088 \mathrm{in.})$. The radial distortion of the cylinder is $0.0040 \mathrm{in}$.

Figures $6.10,6.11$, and 6.12 respectively show the radial $\left(\sigma_{r}\right)$, axial $\left(\sigma_{z}\right)$, and hoop $\left(\sigma_{\theta}\right)$ components of the stress that is developed in the zirconium-clad-uranium composite by the uranium distortion in the Zing- $P^{\prime}$ target for $10 \mu A$ of proton current. Figures $6.13,6.14$, and 6.15 , respectively, show stress, minimum principal stress, and the principal shear stress. A comparison of the data in Figs. 6.9-6.15 $(10 \mu \mathrm{A})$ with the corresponding data in Figs. 6.1-6.7 $(1 \mu \mathrm{A})$ shows that the dimensional change and the resultant induced stress are directly proporational to proton current in the range of $1-10 \mu \mathrm{A}$.

Figure 6.16 shows the effective stress $\left(\sigma_{0}\right.$, Eq. 4.15$)$ in the Zing $P^{\prime}$ target materials for $10 \mu \mathrm{A}$ of proton current. The maximum effective stress in the zirconium cladding $(89,500$ psi) occurs at the center of the front face, and the maximum effective stress in the uranium $(58,000 \mathrm{psi})$ is located at $\mathrm{r} 5 \mathrm{-cm}$ distance from the front face and $\mathrm{r} 3.5 \mathrm{-cm}$ distance from the target centerline. These computed results for the effective stress show that the yield stress of the uranium ( 21,000 psi, part 1 of Appendix $D)$ and the zirconium $(\sim 27,000$ psi, part 2 of Appendix D) would be substantially exceeded for $10 \mu \mathrm{A}$ of proton current 


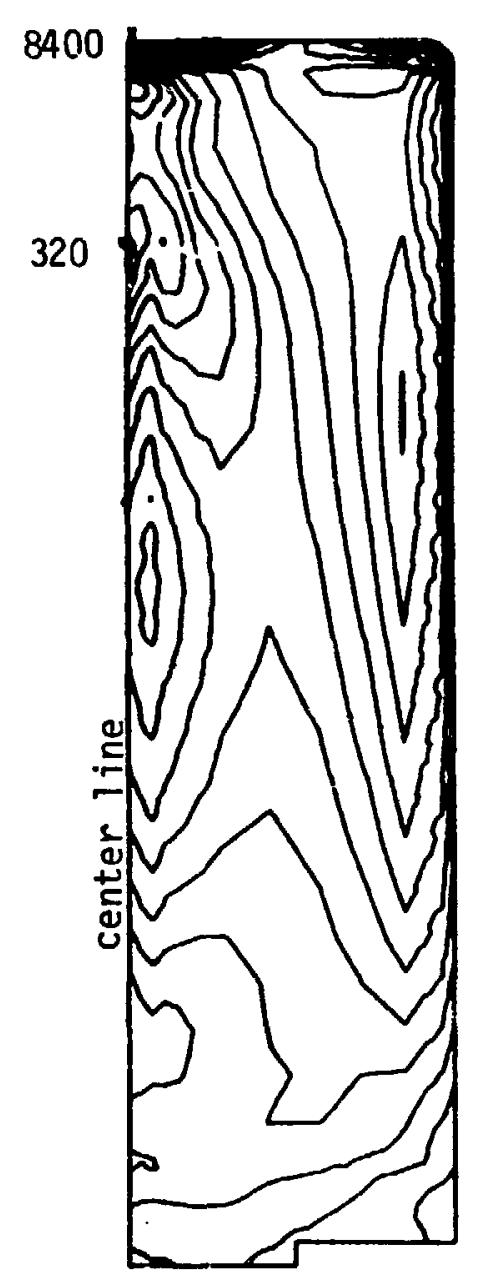

Fig. 6.8

Zing P' "Target Effective Stress (psi) Distribution due to Power Cycle $10.981-\mu \mathrm{A}$ Case with Stress Difference of 500 psi between Contour Lines).
$(U Y=0.0156$ in. $)$

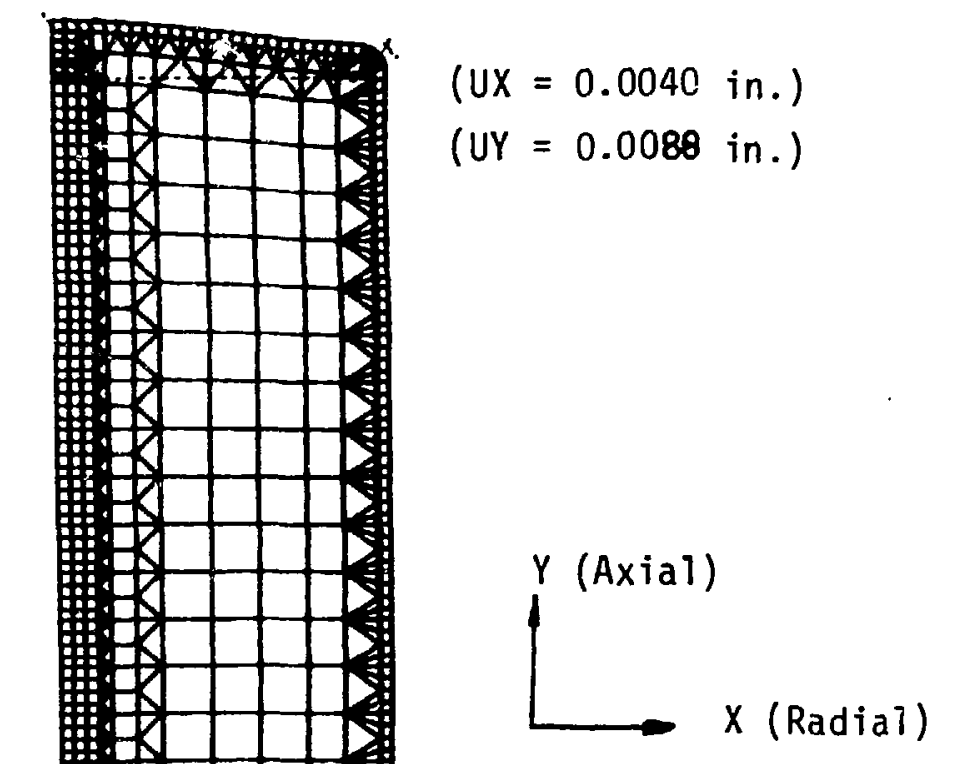

Fig. 6.9

Zing $P^{\prime}$ Target-deflected Shape (Solid Lines) due to Power Cycle; 10- $\mathrm{A}$ Case (Dotted Lines Indicate Undeflected Boundary Outline). 


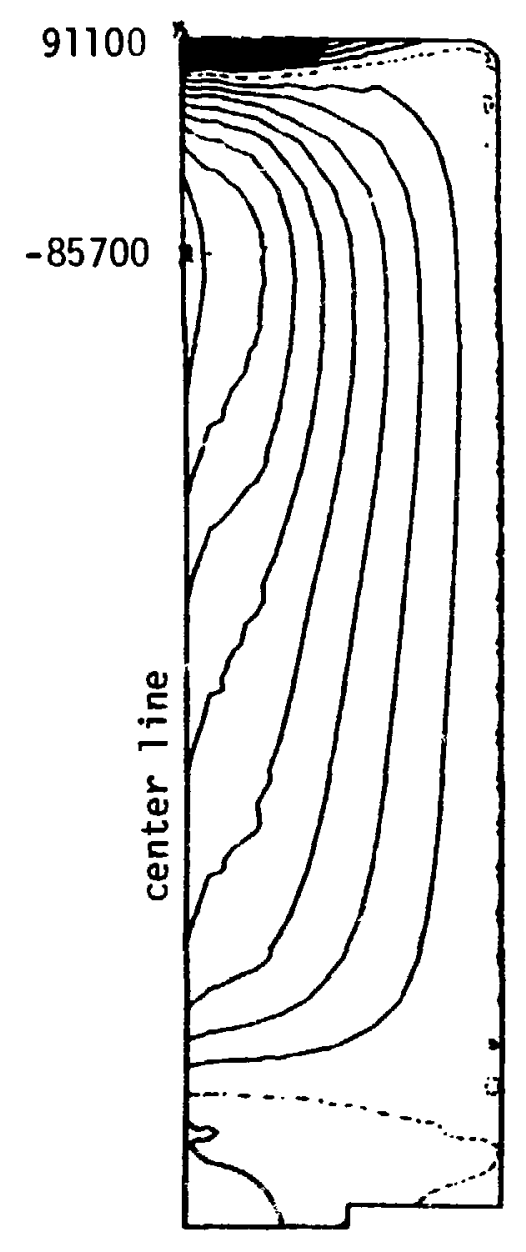

Fig. 6.10

Zing $P^{\prime}$ Target-radial Stress (psi) Distribution due to Power Cycle; 10-uA Case (with Stress Difference of 10,000 psi between Contour Lines).

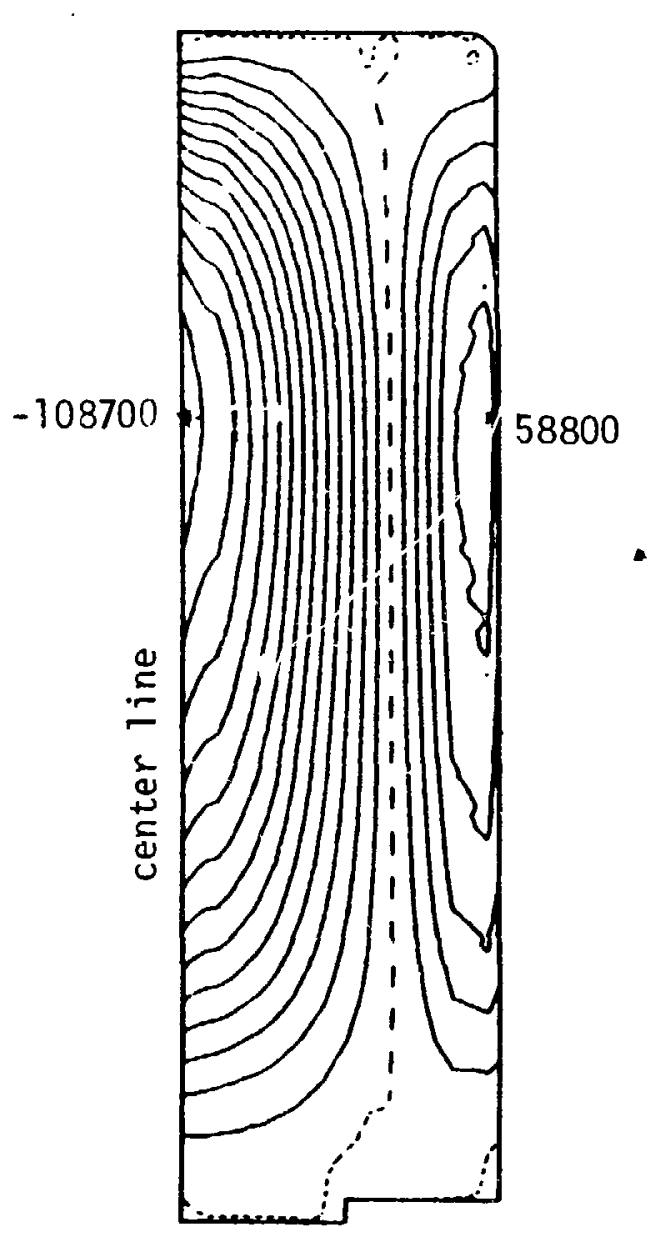

Fig. 6.11

Axial Stress (psi) Distribution with Stress Difference of

8000 psi between Contour Lines.

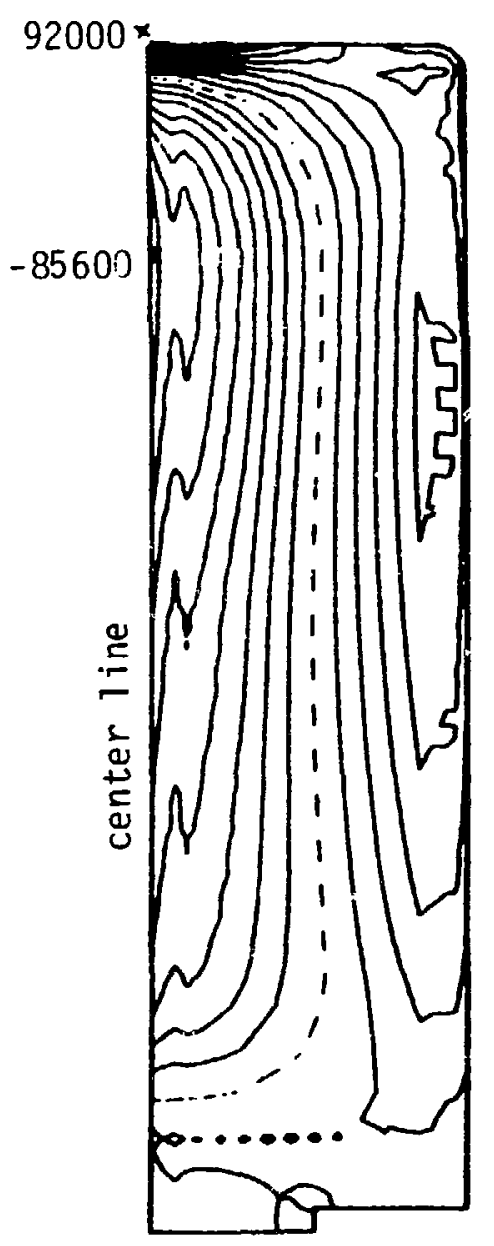

Fig. 6.12

Hoop Stress (psi) Distribution with Stress Difference of 10,000 psi between Contour Lines. 


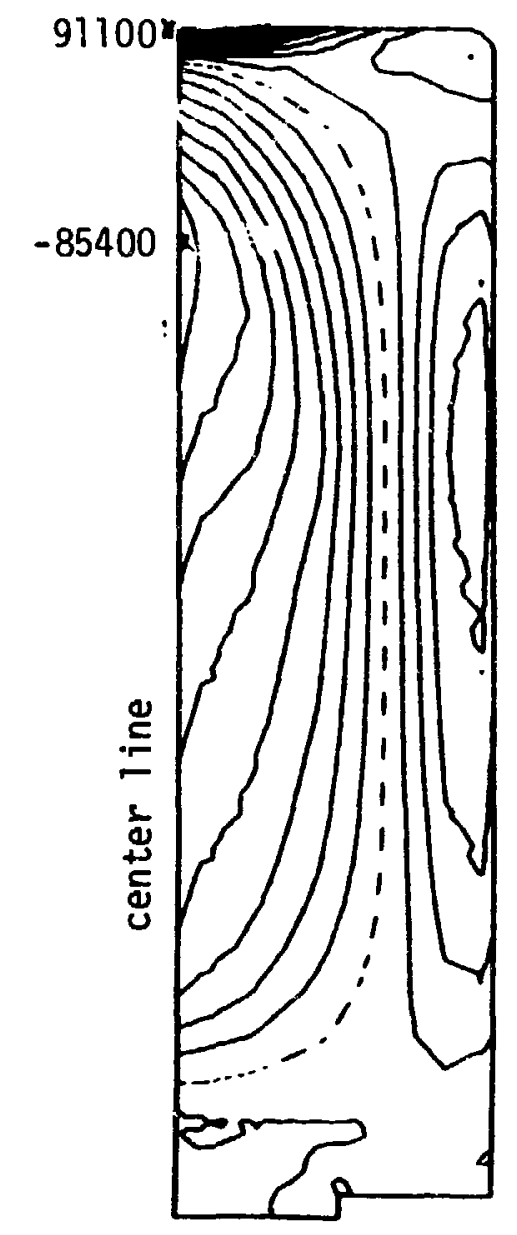

Fig. 6.13

Zing $P^{\prime}$ Target-maximum Principal Stress (psi) Distribution due to Power Cycle $10 \mu \mathrm{A}$ Case with Stress Difference of 10,000 psi between Contour Lines.

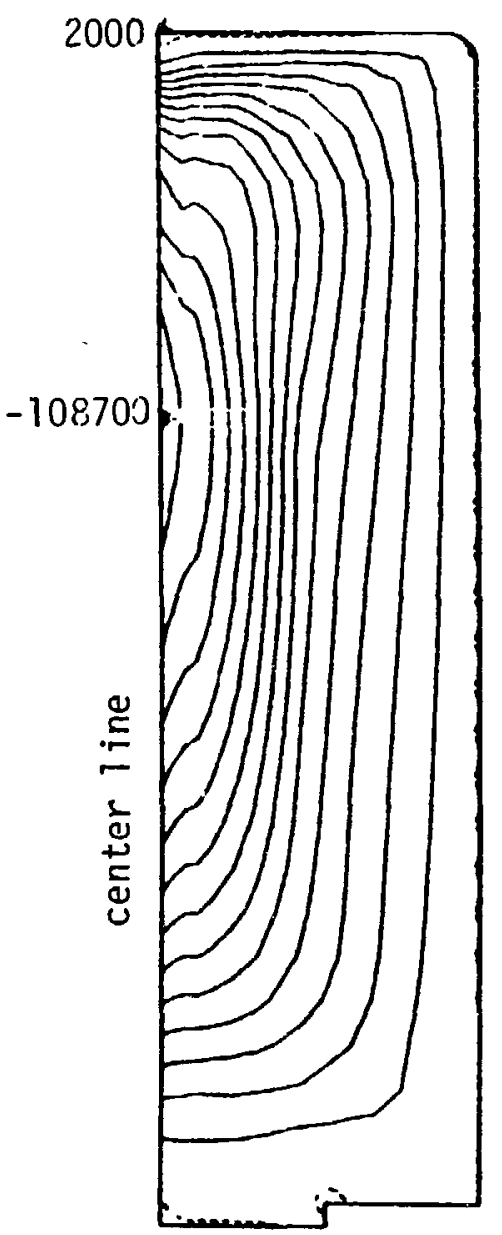

Fig. 6.14

Minimum Principal Stress (psi) Distribution with stress Difference of 8000 psi between Contour Lines.

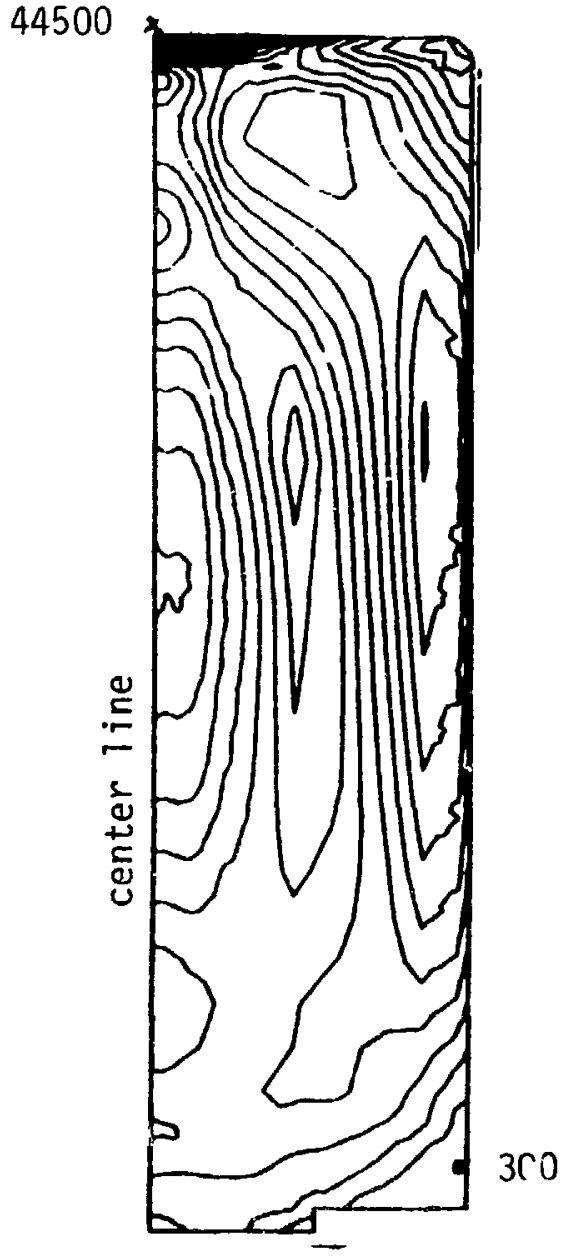

Fig. 6.15

Principal Shear Stress (psi) Distribution with Stress Difference of 2500 psi between Contour Lines. 


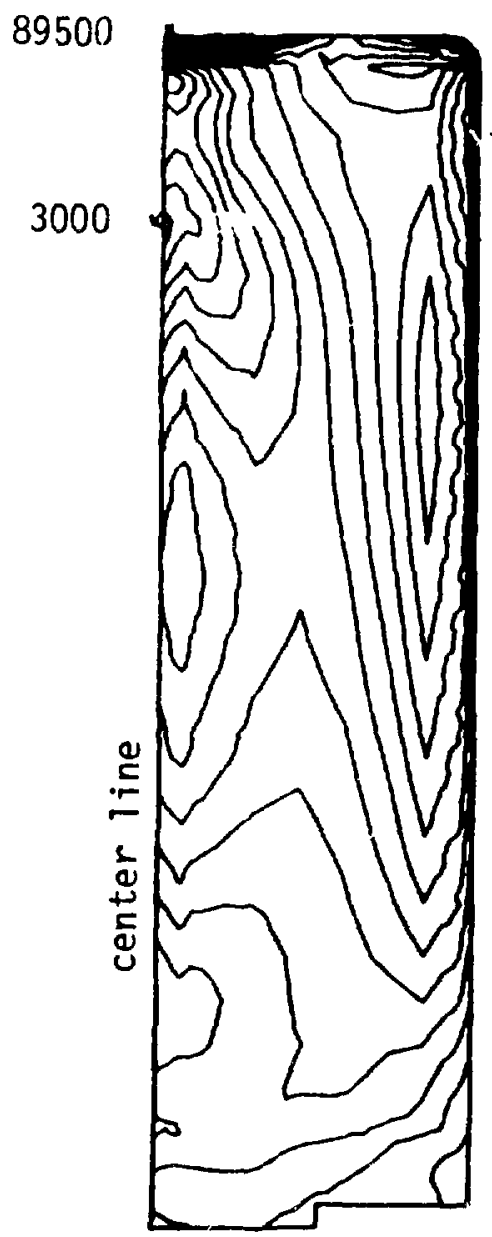

Fig. 6.16

Zing $P^{\prime}$ Target-effective Stress (psi) Distribution due to Power Cycle (10- $\mu$ A Case) with Stress nifference of 5000 psi between Contour Lines. 


\subsection{IPNS-1 Target Stresses}

The steady-state distortion and the resultant distribution of stress intensity in an IPNS-1 target (see Fig. 3.2) were evaluated for $22 \mu \mathrm{A}$ of proton current impinging on the face of the first disc in the stack of eight discs that comprise the IPNS-1 tarqet. The distortion and the resultant induced-stress intensity will have maximum values in the first disc since the energy deposition is highest in this disc (see Table 5.3). The computed temperature distribution in the first disc for $22 \mu \mathrm{A}$ of proton current is shown in Fig. 5.5.

Figure 6.17 shows the distortion of the IPNS-1 target disc that results from the $22 \mu \mathrm{A}$ of proton current. The distortion of the first disc results in a $0.15-\mathrm{cm}$ decrease in thickness of the disc at the edge with the as-fabricated thickness $(2.5 \mathrm{~cm})$ being approximately retained at the centerline of the disc. The distortion of the disc in the radial direction gives rise to a $0.14-\mathrm{cm}$ increase of the as-fabricated disc radius $(4.65-\mathrm{cm})$.

Figures $6.18,6.19$, and 6.20 , respectively, show the radial $\left(\sigma_{r}\right)$, axial $\left(\sigma_{z}\right)$, and hoop $\left(\sigma_{\theta}\right)$ coliponents of the stress that is developed in the Zircaloy-clad-uranium composite by the uranium distortion in the IPNS-1 target disc for $22 \mu \mathrm{A}$ of proton current. The maximum principal stress, minimum principal stress, and principal shear stress are shown in Figs. 6.21, 6.22, and 6.23, respectively. Examination of Figs. 6.18-6.23 shows that the stress intensity in the IPNS-1 target disc is separated (dashed line in the figures) into zones that are in a state of compression or tension. In general, the central uranium region of the disc is in a state of high tension ( 445,000 psi, Figs. 6.18 and 6.20). A zone of moderately high tension stress $(-16,000$ psi, Fig. 6.20) in the Zircaloy-2 cladding also exists at the midheight on the circumferential surface. A zone of high stress concentration does not exist in the Zircaloy-2 cladding on the disc edges, i.e., the intersection of the disc faces with the cylindrical surface, if the bond interface is not ruptured. In the event of a ruptured bond interface, the zone of maximetit tensile stress ( 45,000 psi) in the Zircaloy-2 cladding is shifted to the disc edges. 


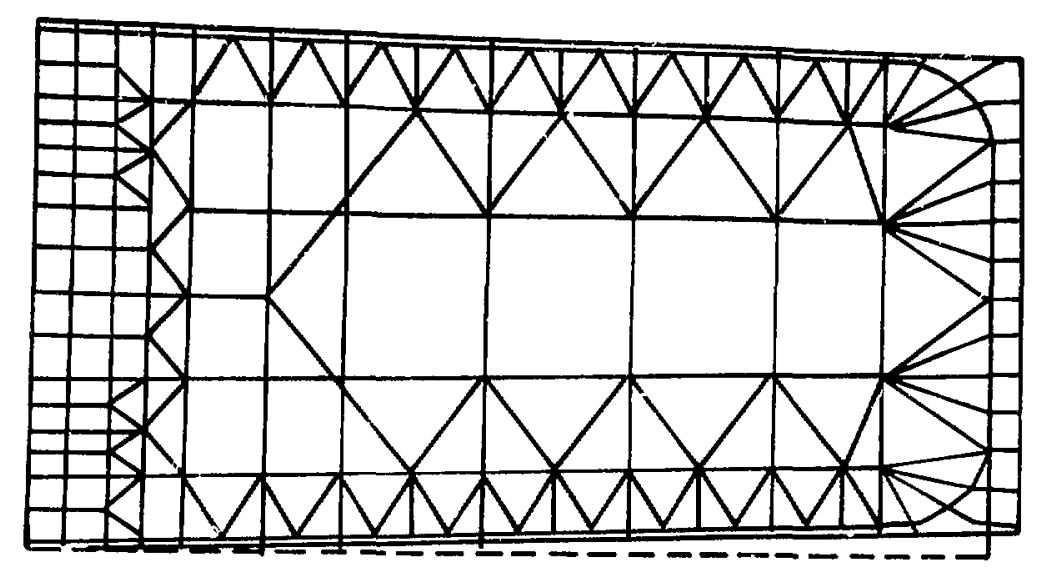

Fig. 6.17

IPNS-1 Target-deflected Shape (Solid Line) due to Power Cycle (Dotted Line Indicates Undeflected Shapes) (Uran. $\mathrm{t}=2.5 \mathrm{~cm}$ case).

Fig. 6.18

Radial Stress (psi) Distribution (Stress Difference of 8000 psi between Contours).
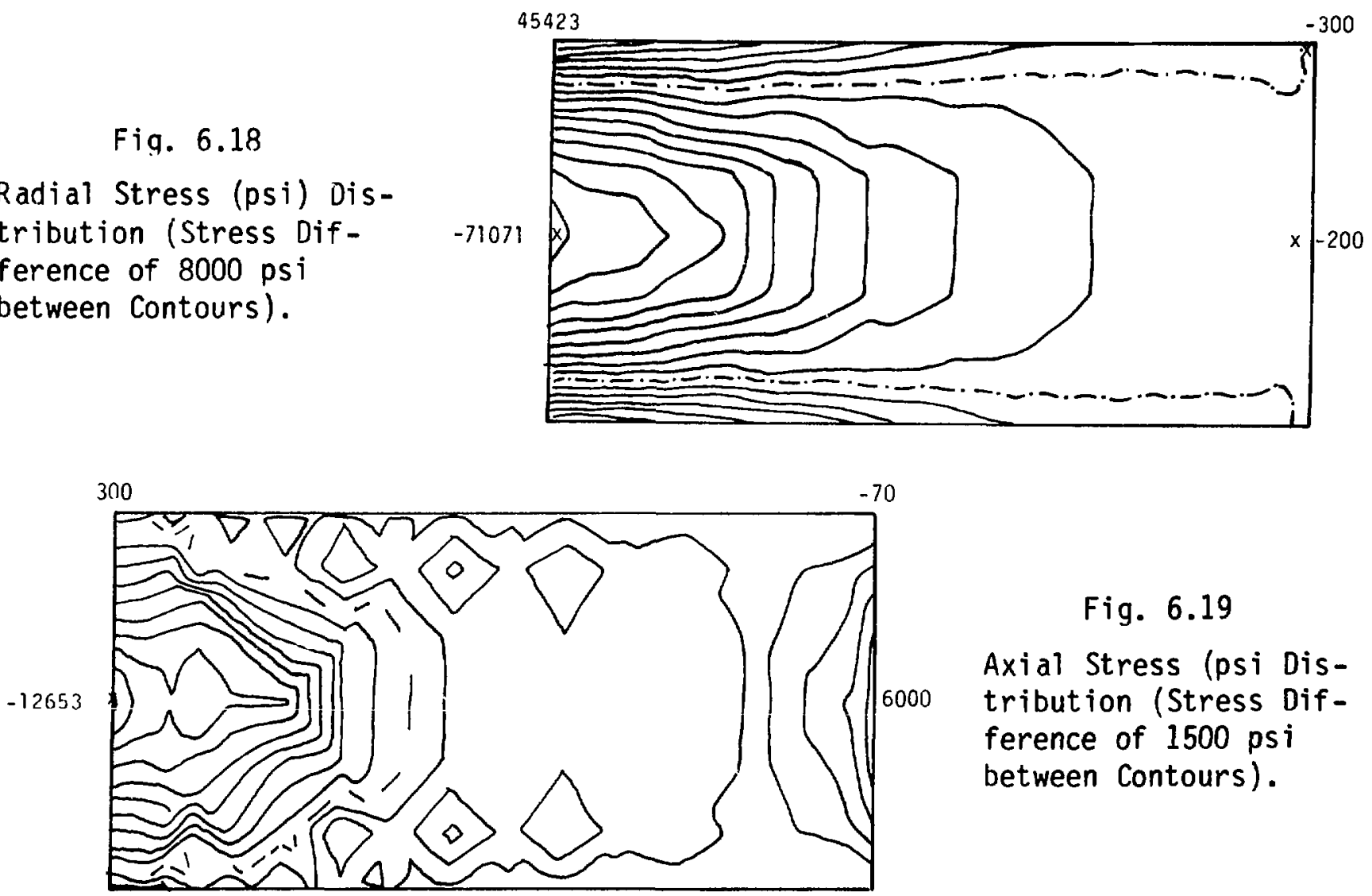

Fig. 6.19

Axial Stress (psi Distribution (Stress Difference of 1500 psi between Contours).

Fig. 6.20

Hoop Stress (psi) Distribution (Stress Difference of 8000 psi between Contours).

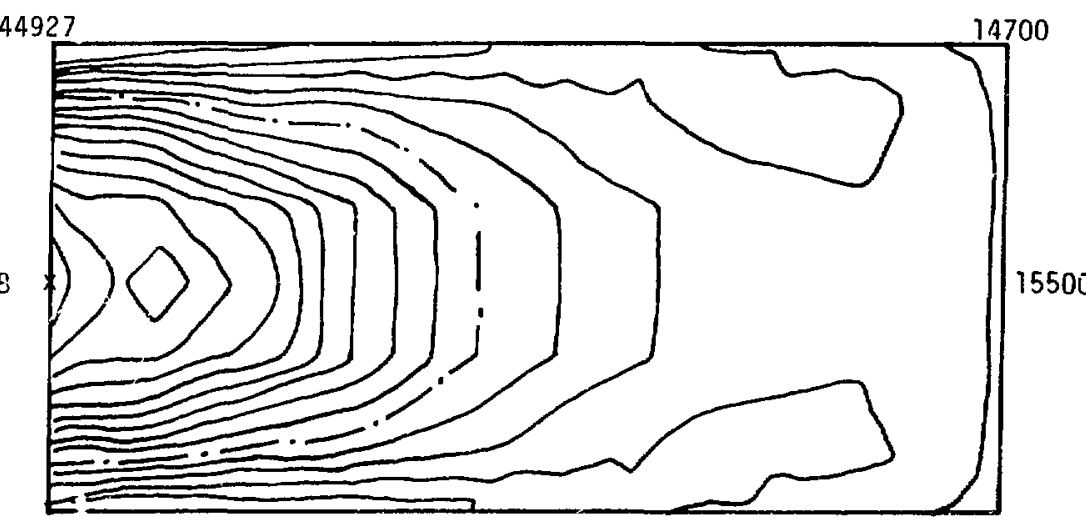




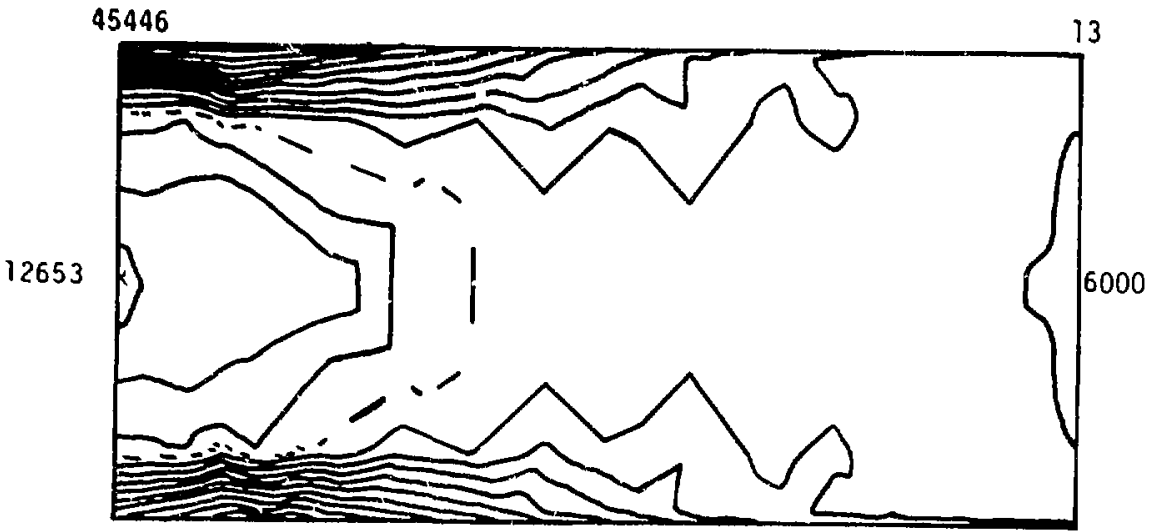

Fig. 6.21

Maximum Principal Stress (psi) (Stress Difference of 4000 psi between Countours).

Fig. 6.22

Minimum Principal Stress Distribution (Stress Difference of $4000 \mathrm{psi}$ between Contour Lines).
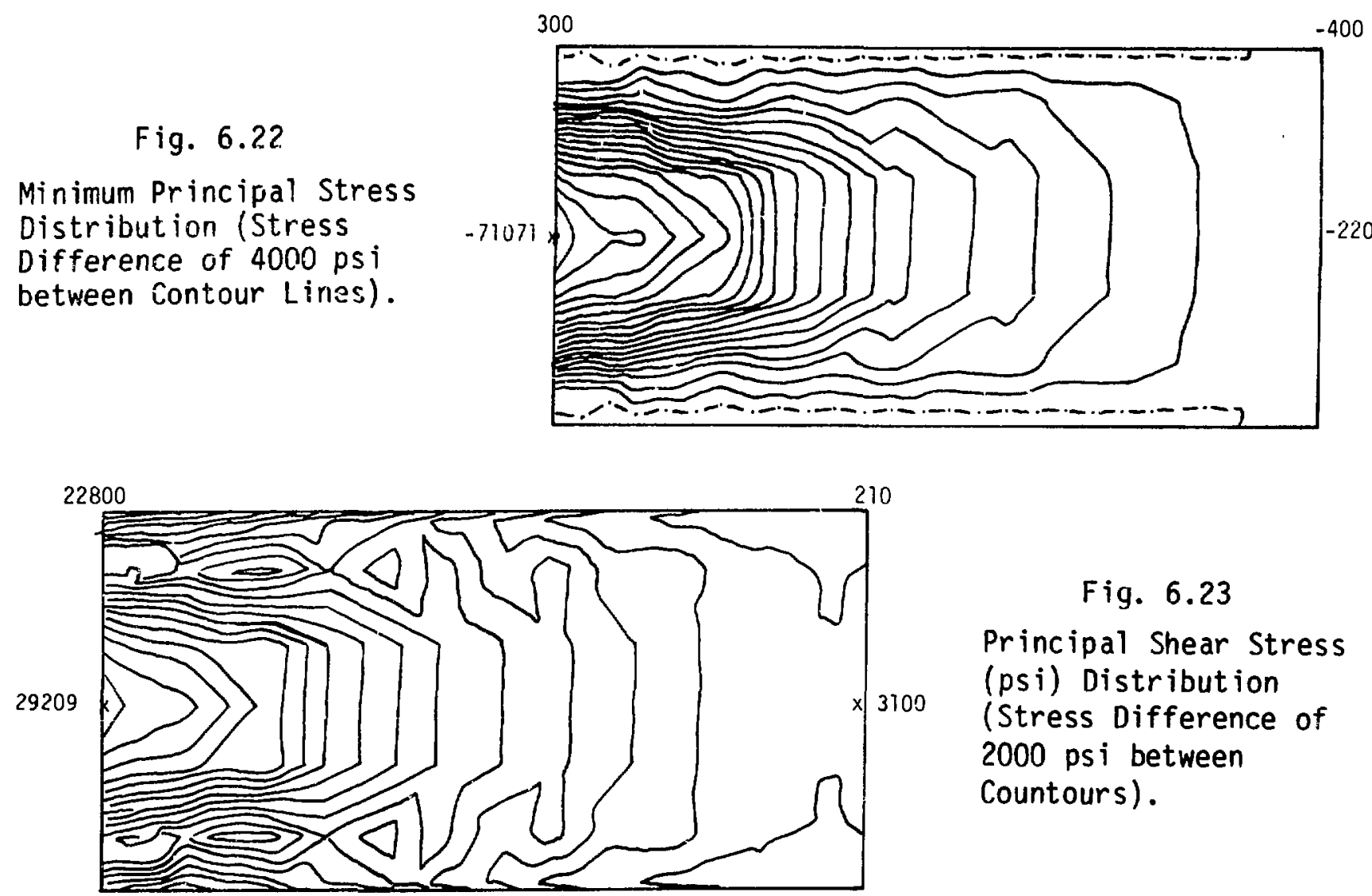

Fig. 6.23

Principal Shear Stress (psi) Distribution (Stress Difference of 2000 psi between Countours).

Fig. 6.24

IPNS-1 Target-effective Stress (psi) Distribution due to Power Cyr.le (Stress Difference of 4000 psi between Contour Lines).

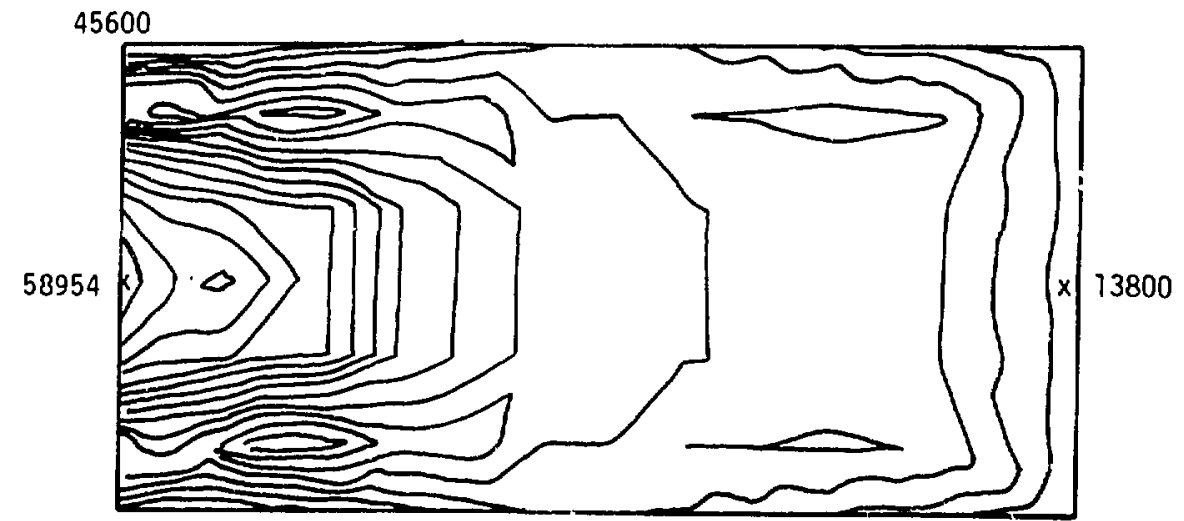


Figure 6.24 shows the effective stress $\left(0_{0}\right)$ in the IPNS-1 target materials for $22 \mu \mathrm{A}$ of proton current. The maximum effective stress in the Zircaloy-2 cladding (45,600 psi) occurs at the center of the disc faces, and the maximum effective stress in the uranium $(58,954 \mathrm{psi})$ is located at the center of the disc. These computed results for the effective stress show that the yield stress of the uranium ( $\sim 40,000 \mathrm{psi}$, part 1 of Appendix D) and the Zircaloy-2 cladding ( $\sim 50,000$ psi, part 3 of Appendix D) would be exceeded or closely approached for $22 \mu \mathrm{A}$ of proton current impinging on the first disc in the stack of eight discs that comprise the IPNS-1 target.

\subsection{Fatigue Failure}

In Chapter 3 we presented the design of the targeis and the required operational parameters that will limit the irradiation-and thermal-induced dimensional changes of the zirconium or Zircaloy-2-clad uranium to acceptable amounts during the desired lifetime of the target, i.e., 6 months for Zing-P and 12 months for IPNS-1. However, these design and operational parameters do not ensure against the premature failure of the target owing to thermal-cycling fatigue. The continuous pulsing of the proton beam at $30 \mathrm{~Hz}$ induces temperature cycles of $<1^{\circ} \mathrm{C}$ in the uranium and taraet temperatures less than $350^{\circ} \mathrm{C}$. However, if the proton source does not operate in a continuous manner, the interruptions will result in cooling of the target to approximately ambient temperature $\left(50^{\circ} \mathrm{C}\right)$. These latter temperature cycles $\left(350^{\circ} \mathrm{C}\right.$ to $\left.60^{\circ} \mathrm{C}\right)$ impact especially on the integrity of the target and can give rise to crack formation in the uranium and the cladding (fatigue failure). We consider the number of thermal cycles to failure of the cladding by fatigue-induced cracking as the parameter determining the lifetime of the target.

The number of fatigue cycles to failure of the Zircaloy-2 cladding on the IPNS-1 discs may be determined from Figs. 6.25 and 6.26 for unirradiated ( $\left.<10^{19} \mathrm{nvt}\right)$ and irradiated $\left(1.5 \times 10^{21}\right.$ to $\left.\left.5.5 \times 10^{21} \mathrm{nvt}, \mathrm{E},\right\rangle 0.625 \mathrm{eV}\right)$ Zircaloy-2, respectively [6.3]. These figures show the completely reversed (zero mean stress) stress amplitude, $S_{a}$, that produces failure in $N$ cycles. Cyclic stress-strain tests [6.3] on the Zircaioy-2 were used to obtain the total strain amplitude ( $\varepsilon_{t} / 2$ ) multiplies by the elastic modulus (E) that results in failure at $N$ cycles. 
For design purposes, a factor of safety of either 2 on the stress amplitude $\left(1 / 2 E_{t}\right)$ or a factor of 20 on cycles was incorporated in the construction of Figs. 6.25 and 6.26. To estimate the number of temperature cycles to failure of the Zircaloy-2 cladding on the IPNS-1 disc, we have used the maximum shear stress as a fatigue-failure criterion. On this basis, $S_{a}$ is one-half the maximum of $\left(\sigma_{1}-\sigma_{2}\right)$ or $\left(\sigma_{1}-\sigma_{3}\right)$, where $\sigma_{1}, \sigma_{2}$, and $\sigma_{3}$ are the three principal stresses such that $\sigma_{1}<\sigma_{2}<\sigma_{3}$ [6.3]. From Figs. 6.21, 6.20, and 6.22, the values of the principal stresses are 45446, 44927, and 300 psi, respectively. Therefore, the value of $S_{a}$ is 22573 psi. From Fig. 6.25, the expected number of stress cycles (which result from temperature cycles in the uranium) that the Zircaloy-2 can endure before cracking is $\sim 6000$ cycles for a total irradiation exposure of $<10^{19}$ nvt. For irradiation exposures in the range of $1.5 \times 10^{21}$ to $5.5 \times 10^{21} \mathrm{nvt}$, the expected number of cycles before failure is $\sim 3000$ (see Fig. 6.25). Previous experience with synchrotron (proton source) operations suggests that $\sim 10$ interruptions per day can be expected. On this basis, the lifetime of the IPNS-1 target would be $>300$ days.

Loomis, et al. [6.2] have tested the response of an as-produced Zircaloyclad uranium disc to thermal cycling. An 800-W, flat plate heat source was placed in contact with one face of a disc, resulting in a temperature $T_{1}$, and a water-cooled flat plate heat sink was placed in contact with the other face of the disc resulting in a temperature $T_{3}$. Thermocouples were attached to each face and an additional thermocouple was inserted to the center of the disc, which was at temperature $T_{2}$. The disc temperature and time at temperature were controlled by two variable time-delay relays that automatically energized and de-energized the power supply to the heat source. With this arrangement, the temperature $T_{1}$ could be cycled between 140 and $350^{\circ} \mathrm{C}$, with the simultaneous cycling of $\mathrm{T}_{2}$ between 130 and $325^{\circ} \mathrm{C}$, and $T_{3}$ between 65 and $155^{\circ} \mathrm{C}$, with a frequency of 24 cycles/day. This temperature distribution in the disc gives $\Delta T$ values of $195^{\circ} \mathrm{C}\left(T_{1}-T_{3}\right)$ and $175^{\circ} \mathrm{C}\left(T_{2}-T_{3}\right)$ at the peak temperature, which can be compared with the expected $\Delta T$ of $250^{\circ} \mathrm{C}$ in the target disc during irradiation by $22 \mu \mathrm{A} 500-\mathrm{MeV}$ protons (see Fig. 5.5).

The dimensional change of the disc and the integrity of the Zircaloyuranium bond were determined at 1000-cycle intervals by ultrasonic tests 


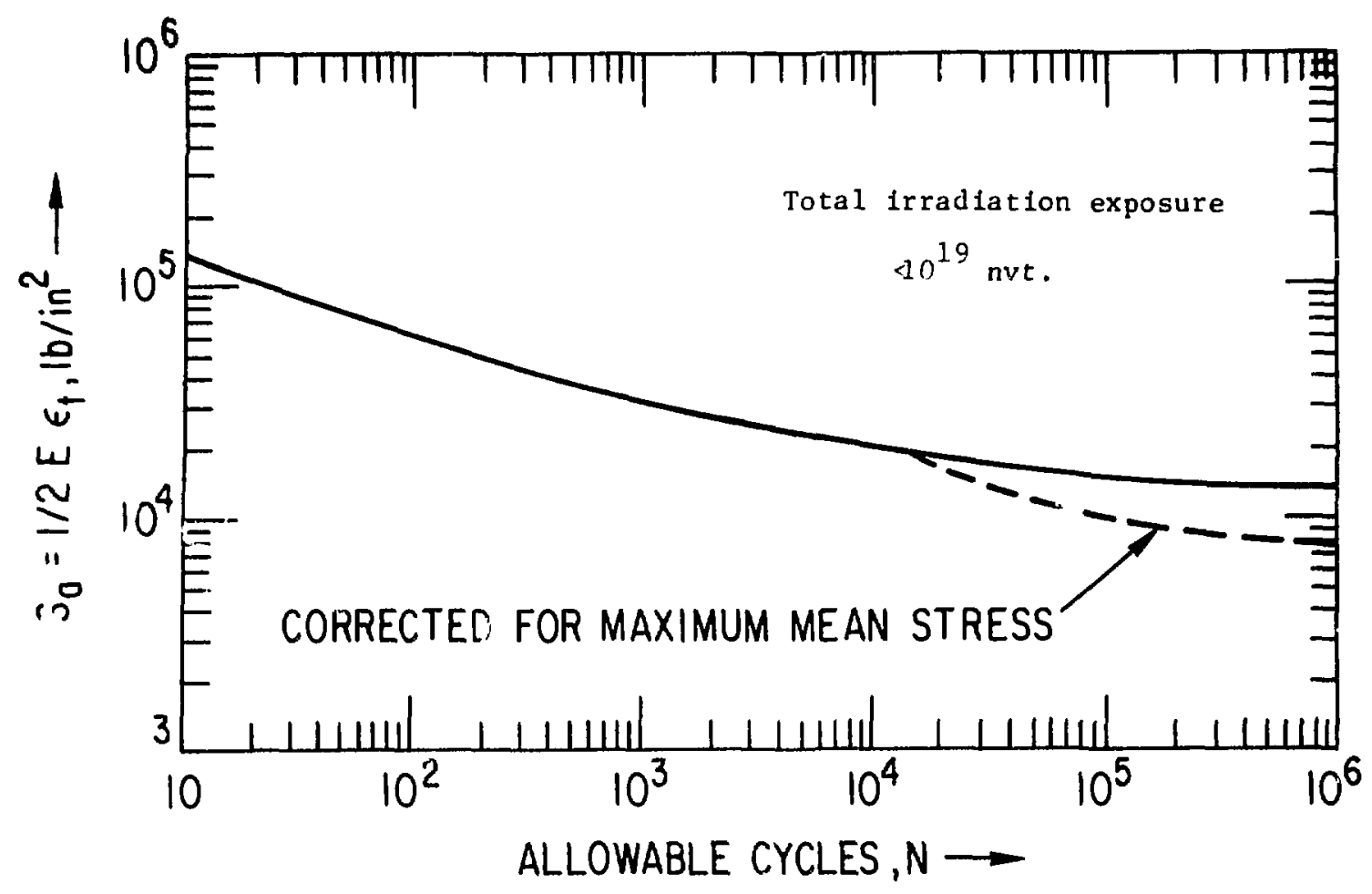

Fig. 6.25. Design Curve for Unirradiated Zircaloy-2, 3 , or 4 . Room temperature to $600 \mathrm{~F}$.

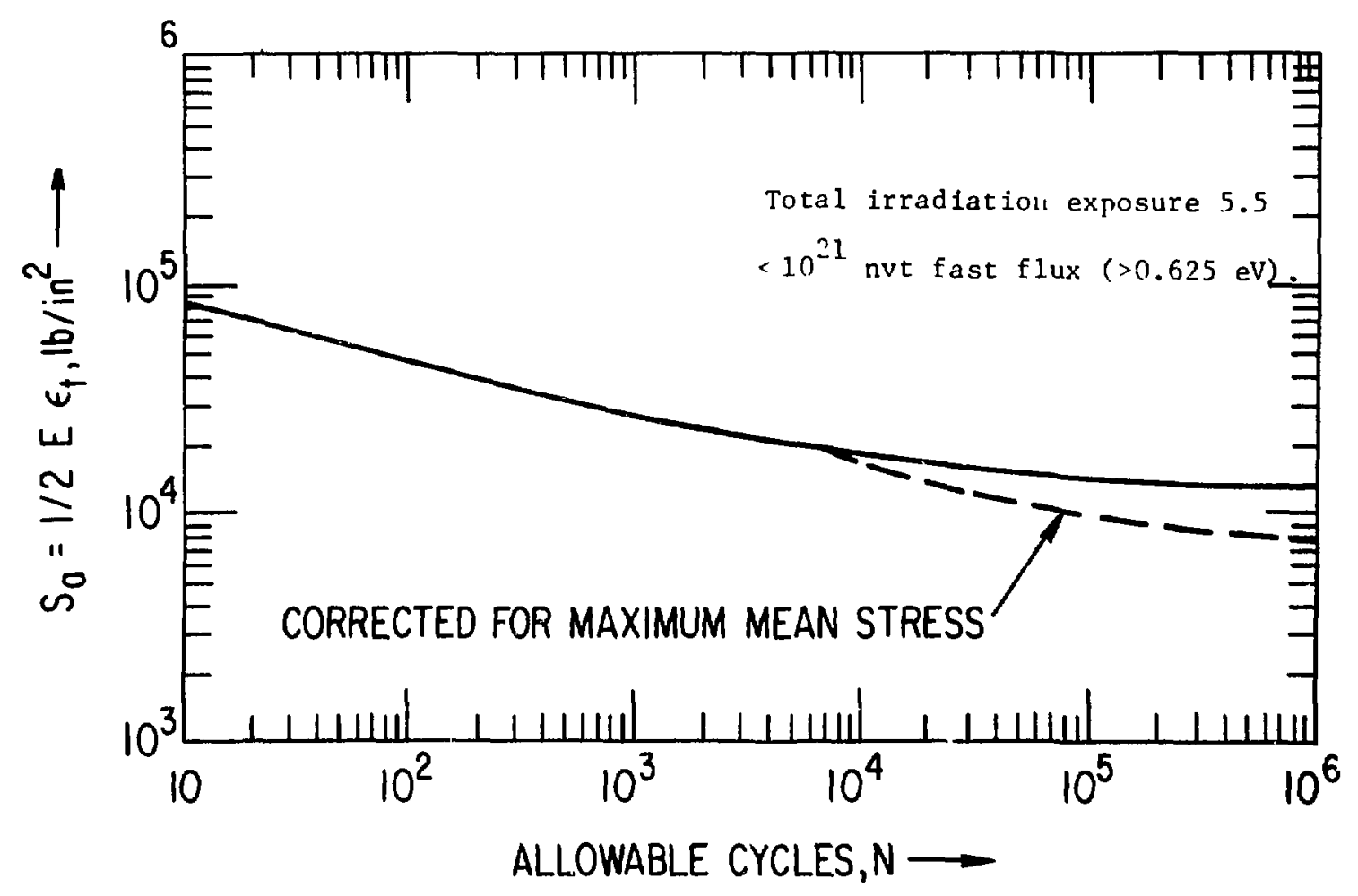

Fig. 6.26. Design Curve for Irradiated Zircaloy-2, 3 , or 4 . Room temperature to $600 \mathrm{~F}$. 
and dimensional measurements. These result; showed no measurable change in either the dimensions of the disc or the integrity of the Zircaloy-uranium bond after 6000 cycles. However, on removal of the disc for the examination after 7000 cycles, a crack $(0.4-\mathrm{cm}$ length) appeared which had propagated in a ductile manner and was located at $\sim 1.1-\mathrm{cm}$ radial distance from the axis of the disc. Even though the Zircaloy was machined to a $0.003-\mathrm{cm}$ surface finish, there was some evidence to indicate that the crack was initiated and propagated along a machining-tool groove.

Although the conditions of this tests only roughly simulated operating conditions (we expect that they were more severe, because the warping of the disc caused a "hot spot" at the center of the disc where it touched the heated plate), we conclude that the target discs will perform according to design expectations. 


\section{References Chapter 6}

[6.1]. G. J. Desalvo and J. A. Swanson, ANSYS Engineering Analys is User's Manual, Vol. 1, Swanson Analysis Systems, Inc., Houston (1979).

[6.2]. B. A. Loomis, H. R. Thresh, G. L. Fogle, and S. B. Gerber, Design Production, and Evaluation of a Zircaloy-Clad Uranium Target for an Intense Pulsed Neutron Source Application, Nucl. Techno 1. 55, No. 617 (Dec 1981).

[6.3]. W. J. O'Donnell and B. F. Langer, Fatigue Design Basis for Zircaloy Components, Nuc. Eng. Sci., 20, 2 (1964).

[6.4]. ANSYS, Engineering Analysis System User's Manual by Swanson Analys is Systems, Inc., P. 0. Box 65, Houston, Pennsylvania 15342, August 1, 1978. 
Appendix A

Hydraulic Study of Flow Center and Pressure Profiles in IPNS Target

The IPNS-1 target assembly consists of eight discs, which are mechanically supported within a flow-distribution housing. The target is cooled by water circulating at the design conditions of $45 \mathrm{gpm}$ at 35-psia inilet pressure. The inlet maximum temperature is $120^{\circ} \mathrm{F}$, and at the design conditions the outlet temperature is $124^{\circ} \mathrm{F}$. The geometry is shown in Fig. A.1; each disc contains five flow charnels for the circulation of cooling water. The physical data for each of the five channels are given in Table A.1.

A study was conducted to detemine the pressure drops and velocity and pressure profiles in the target assembly. The computer program used for this purpose is callea Mydrautic Network Arialysis (HYNAL) and was developed by Logicomp Corporation. This program uses the Hardy-Cross method, which is based on relaxation or controlled trial and error. The network to be analyzed is limited to a maximum of 500 pipes, 200 loops, and 300 junctions. The number of inflows and outflows is limited to 300 . Either U. S. customary unics or SI units may be used [A.1].

\section{Methodology}

The HYNAL program uses the Hazen-Wiliiams formula to calculate the pressure drop due to friction. This formula is

$$
\Delta H=\frac{10.43 L}{C^{1.85 D^{4.87}}} Q^{1.85}
$$

where

and

$$
\begin{aligned}
\Delta H & =\text { head loss, ft of water, } \\
L & =\text { length of pipe, ft, } \\
D & =\text { inside diameter of pipe, in., } \\
Q & =\text { flow, gpm, }
\end{aligned}
$$

$C=$ constant, which depends on surface roughness.

The values of the constant $C$ in water-supply networks for water at $60^{\circ} \mathrm{F}$ range from $C=150$ for a cement or fiber $\mathrm{glass} p$ ipe to $C=100$ for $a$ spirally-riveted steel pipe. However, the viscosity of water varies in the 


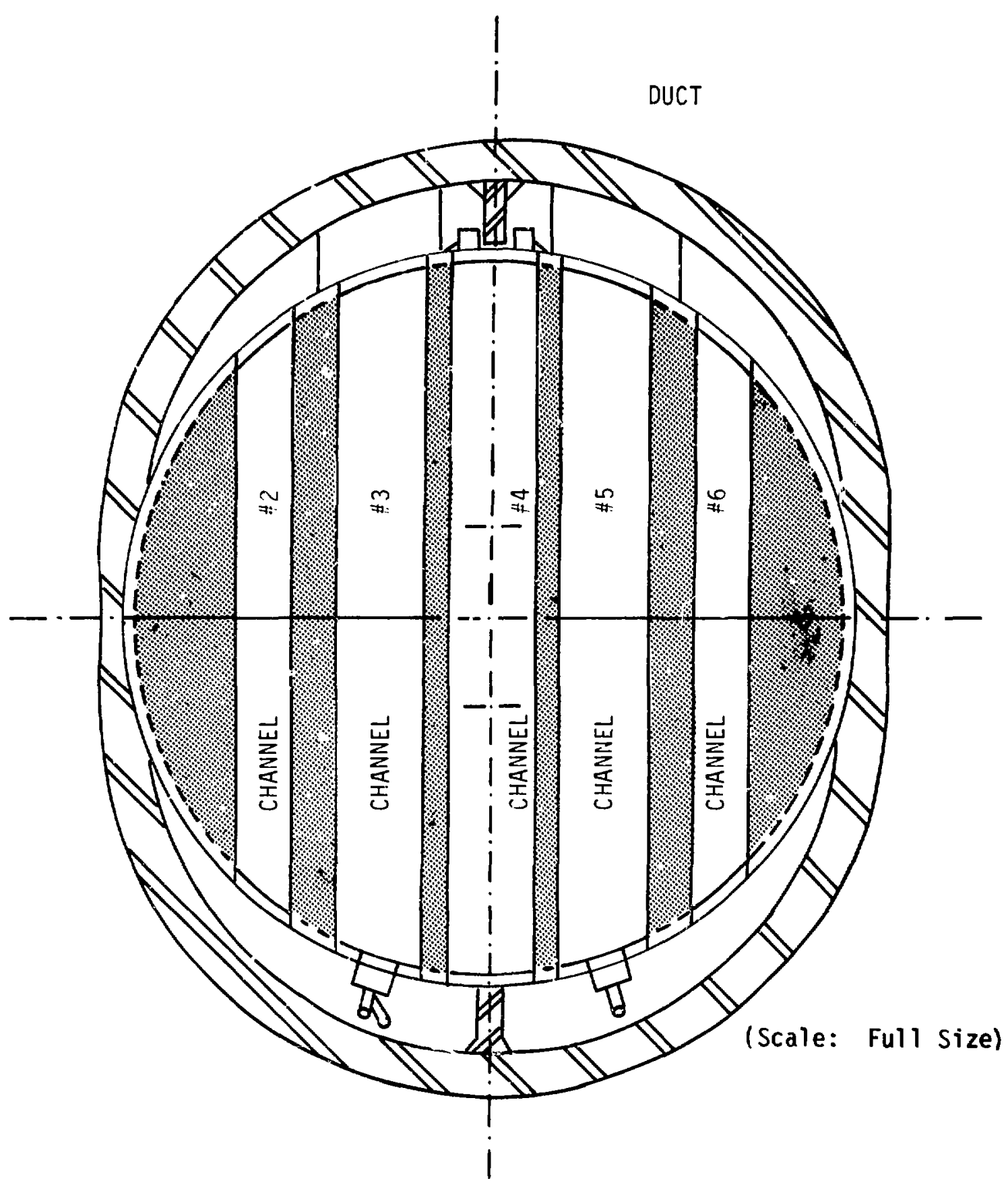

Fig. A.1. Disc Geometry. 
Table Al. Channel Parameter Values

\begin{tabular}{|c|c|c|c|c|c|}
\hline & $\begin{array}{c}\text { Channel } \\
2\end{array}$ & $\begin{array}{c}\text { Channel } \\
3\end{array}$ & $\underset{4}{\text { Channe } 1}$ & $\begin{array}{c}\text { Channel } \\
5\end{array}$ & $\begin{array}{c}\text { Channel } \\
6\end{array}$ \\
\hline Flow area, in. ${ }^{2}$ & 0.01953 & 0.03125 & 0.03125 & 0.01325 & 0.01953 \\
\hline Flow area, ft. 2 & $0.1356 \times 10^{-3}$ & $0.217 \times 10^{-3}$ & $0.217 \times 10^{-3}$ & $0.217 \times 10^{-3}$ & $0.1356 \times 10^{-3}$ \\
\hline $\begin{array}{l}\text { Hydraul ic di- } \\
\text { ameter, in. }\end{array}$ & 0.10416 & 0.1111 & 0.1111 & 0.1111 & 0.10416 \\
\hline $\begin{array}{l}\text { Hydraul ic di- } \\
\text { ameter, ft }\end{array}$ & 0.00868 & 0.00926 & 0.00926 & 0.00926 & 0.00868 \\
\hline $\begin{array}{l}\text { Apportioned } \\
\text { duct area, in.2 }\end{array}$ & 0.273 & 0.243 & 0.243 & 0.243 & 0.243 \\
\hline $\begin{array}{l}\text { Ratio of chan- } \\
\text { nel area to ap- } \\
\text { pertioned duct } \\
\text { area, Ac/Ad }\end{array}$ & 0.0804 & 0.1286 & 0.1286 & 0.1286 & 0.0804 \\
\hline$k_{\text {in }}$ & 0.42 & 0.38 & 0.38 & 0.38 & 0.42 \\
\hline$k_{0}$ & 0.84 & 0.75 & 0.75 & 0.75 & 0.84 \\
\hline $\begin{array}{l}\text { Channel } \\
\text { length, ft }\end{array}$ & 0.260 & 0.323 & 0.333 & 0.323 & $0.26 \hat{U}$ \\
\hline
\end{tabular}


ratio of almost 6 to 1 as the temperature is changed from 32 to $212^{\circ} \mathrm{F}$. For our case, the values of $C$ have to be estimated for a trial run and then refined for more accurate results. This procedure is discussed in the following section.

According to the HYNAL program, only the first decimal place can be used for the channel length in feet. Hence, the length of each channel was assumed to be $0.3 \mathrm{ft}$ in the HYNAL program. To determine value for the coefficient $C$ in Eqn. A1, we assume a value of $C$, along with a flow $Q$, and a corresponding velocity $V$. With the assumed a value of $C$ and the values for $Q$ and $V$, an iteration is performed on Eqns. $A 1$ and $A 2$ to obtain a more accurate value of $C$. The results of these iterations are not included here, and only the final values used are shown in Table A2. The pipe numbers correspond to those shown in Fig. A2.

A similar procedure was also used for each length of the duct. However, the pressure drop in the duct was calculated from

$$
\Delta H=\frac{f L_{e}}{D_{H}} \quad \frac{V^{2}}{2 g},
$$

where $L_{e}$ is the equivalent length of the duct that accounts for the pressure losses in bending of the flow through a right angle from the duct to the channel. Hence, we use $L_{e}=L+580_{H}$, where $L$ is the actual duct length and $L / D_{H}=58$ is assumed for a right-angle bend. The trial-and-error method was also required to obtain the values of the coefficient $C$ for the duct by using Eqns. Al and A2. The final values used are shown in Table A2. The duct numbers correspond $w$ those shown in Fig. A2. The duct parameters are:

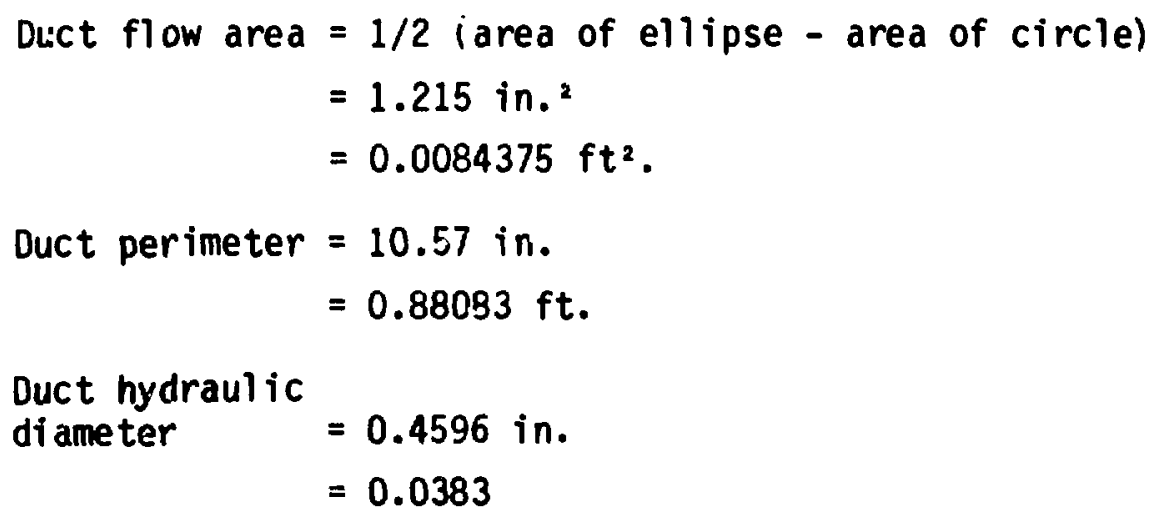




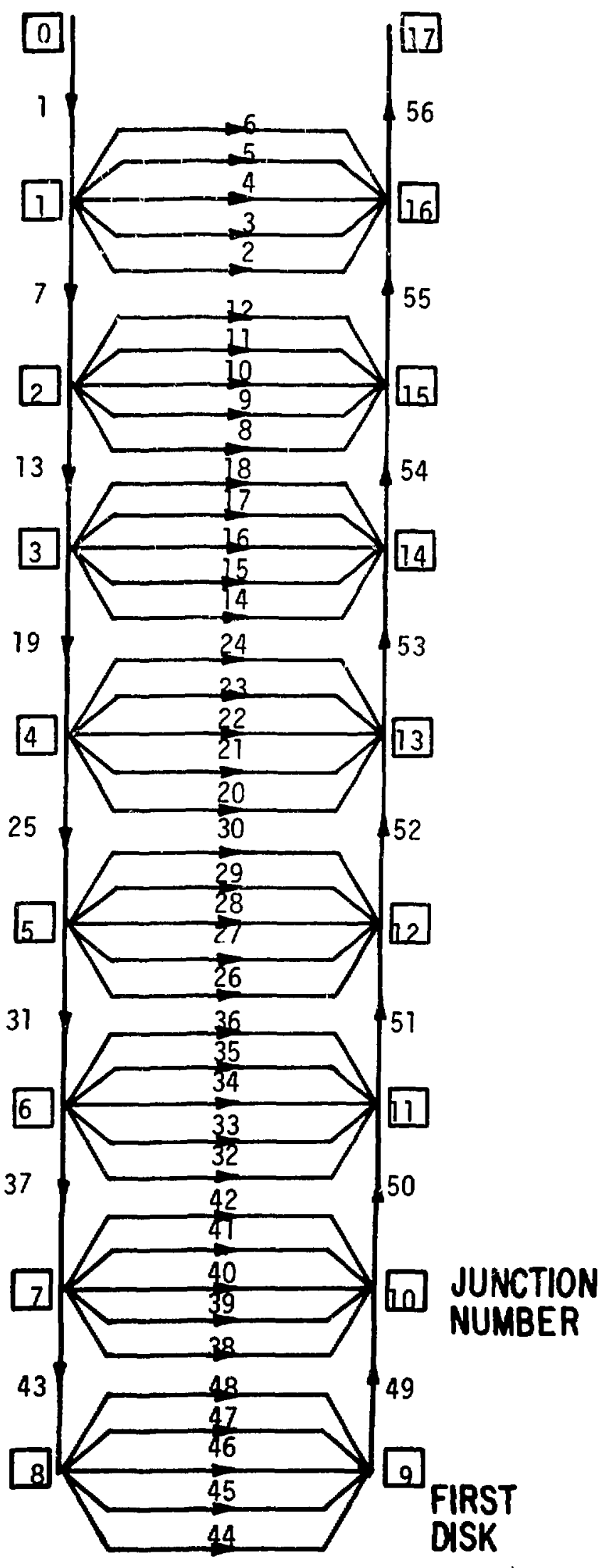

Fig. A.2. Layout of Pipe Lines. 
Table A2. Pipeline Parameters

\begin{tabular}{|c|c|c|c|c|}
\hline $\begin{array}{l}\text { Pipe } \\
\text { Number }\end{array}$ & $\begin{array}{l}\text { Reynolds } \\
\text { Number }\end{array}$ & $\begin{array}{l}\text { Friction Factor } \\
f\end{array}$ & $\begin{array}{l}\text { Head Loss } \\
\Delta \mathrm{H}, \mathrm{ft}\end{array}$ & $\begin{array}{c}\text { Hazen-Witliams } \\
\text { C }\end{array}$ \\
\hline 1 & 61,460 & 0.0235 & 3.36 & 1054 \\
\hline 2 & 21,198 & 0.027 & 13.8 & 177 \\
\hline 3 & 26,692 & 0.0265 & 16.04 & 299 \\
\hline 4 & 26,942 & 0.0265 & 16.58 & 302 \\
\hline 5 & $26,69 \hat{c}$ & 0.0265 & 16.04 & 299 \\
\hline 6 & 21,198 & 0.027 & 13.8 & 177 \\
\hline 7 & 49,924 & 0.024 & 2.08 & 1060 \\
\hline 8 & 16,416 & 0.029 & 7.39 & 204 \\
\hline 9 & 22,339 & 0.027 & 10.81 & 304 \\
\hline 10 & 22,477 & 0.027 & 11.16 & 306 \\
\hline 11 & 22,339 & 0.027 & 10.81 & 304 \\
\hline 12 & 16,416 & 0.029 & 7.39 & 204 \\
\hline 13 & 40,301 & 0.025 & 1.41 & 1055 \\
\hline 14 & 14,914 & 0.029 & 5.25 & 206 \\
\hline 15 & 18,962 & 0.028 & 7.58 & 308 \\
\hline 16 & 19,150 & 0.028 & 7.84 & 311 \\
\hline 17 & 18,962 & 0.028 & 7.58 & 308 \\
\hline 18 & 14,914 & 0.029 & 5.25 & 206 \\
\hline 19 & 32,127 & 0.026 & 0.94 & 1050 \\
\hline 20 & 13,061 & 0.03 & 3.93 & 208 \\
\hline 21 & 16,623 & 0.029 & 5.66 & 312 \\
\hline 22 & 16,773 & 0.029 & 5.86 & 315 \\
\hline 23 & 16,623 & 0.029 & 5.66 & 312 \\
\hline 24 & 13,061 & 0.03 & 3.93 & 208 \\
\hline
\end{tabular}


Table A2. Pipeline Parameters (contd)

\begin{tabular}{|c|c|c|c|c|}
\hline $\begin{array}{l}\text { Pipe } \\
\text { Number } \\
25\end{array}$ & $\begin{array}{l}\begin{array}{l}\text { Reynotds } \\
\text { Number }\end{array} \\
24,396\end{array}$ & $\begin{array}{l}\text { Friction Factor } \\
f \\
0.027\end{array}$ & $\begin{array}{l}\text { Head Loss } \\
\Delta \mathrm{H}, \mathrm{ft} \\
0.58\end{array}$ & $\begin{array}{c}\frac{{ }_{\text {Hazen-WitTiams }}}{C} \\
1053\end{array}$ \\
\hline 26 & 12,018 & 0.03 & 3.18 & 212 \\
\hline 27 & 15,047 & 0.029 & 4.67 & 313 \\
\hline 28 & 15,135 & 0.029 & 4.87 & 315 \\
\hline 29 & 15,047 & 0.029 & 4.67 & 313 \\
\hline 30 & 12,018 & 0.03 & 3.18 & 212 \\
\hline 31 & 18,417 & 0.028 & 0.33 & 1058 \\
\hline 32 & 11,467 & 0.031 & 2.86 & 214 \\
\hline 33 & 14,322 & 0.03 & 4.17 & 315 \\
\hline 34 & 14,547 & 0.03 & 4.30 & 320 \\
\hline 35 & 14,322 & 0.03 & 4.17 & 315 \\
\hline 36 & 11,467 & 0.031 & 2.86 & 214 \\
\hline 37 & 12,209 & 0.031 & 0.16 & 1035 \\
\hline 38 & 11,174 & 0.031 & 2.78 & 213 \\
\hline 39 & 14,222 & 0.03 & 4.05 & 318 \\
\hline 40 & 14,259 & 0.03 & 4.20 & 319 \\
\hline 41 & 14,222 & 0.03 & 4.05 & 318 \\
\hline 42 & 11,174 & 0.031 & 2.78 & 213 \\
\hline 43 & 6,105 & 0.035 & 0.05 & 1016 \\
\hline 44 & 11,103 & 0.031 & 2.77 & 212 \\
\hline 45 & 14,084 & 0.03 & 4.15 & 314 \\
\hline 46 & $14,32 ?$ & 0.03 & 4.23 & 319 \\
\hline 47 & 14,084 & 0.03 & 4.15 & 314 \\
\hline 48 & 11,103 & 0.031 & 2.77 & 212 \\
\hline
\end{tabular}


Table A2. Pipeline Parameters (contd)

\begin{tabular}{lllll}
$\begin{array}{l}\text { Pipe } \\
\text { Number }\end{array}$ & $\begin{array}{l}\text { Reynoids } \\
\text { Number }\end{array}$ & $\begin{array}{c}\text { Friction Factor } \\
f\end{array}$ & $\begin{array}{c}\text { Heat Loss } \\
\Delta, \mathrm{ft}\end{array}$ & $\begin{array}{c}\text { Hazen-WiTTiams } \\
\mathrm{C}\end{array}$ \\
\hline 49 & 6,105 & 0.035 & 0.05 & 1016 \\
50 & 12,209 & 0.031 & 0.16 & 1035 \\
51 & 18,417 & 0.028 & 0.33 & 1058 \\
52 & 24,936 & 0.027 & 0.58 & 1053 \\
53 & 32,127 & 0.026 & 0.94 & 1050 \\
54 & 40,301 & 0.025 & 1.41 & 1055 \\
55 & 49,924 & 0.024 & 2.08 & 1060 \\
56 & 61,460 & 0.0235 & 3.36 & 1054 \\
\hline
\end{tabular}

The pipeline network is shown in Fig. A.2. The pipelines are numbered as shown, and the junction numbers are enclosed in square boxes. It is seen that there are 56 pipes, 17 junctions, and several loops. Pipes numbered 44-48 correspond to the five channels in the first disc. Junctions $0-8$ are located $0.3 \mathrm{ft}$ above junctions 9-17.

The cases of a channel and a duct are treated separately. For a channel, the total pressure drop is calculated from

$$
\Delta H=K_{i n}+K_{0}+\frac{f L}{D_{H}} \frac{V^{2}}{2 g},
$$

where $K_{i n}$ is a coefficient to account for the entrance loss due to a sudden contraction from a part of the duct area to the channel area. Simi$l a r l y, K_{0}$ is a coefficient to account for the exit loss due to a sudden expansion from the channel area to a part of the duct area. In the third term, which accounts for the frictional pressure drop in the channel, $f$ is the coefficient of friction, $L$ is the channel length, and $D_{H}$ is its hydraulic diameter.

For the calculation of $K_{i n}$ and $K_{0}$, the parts of the duct area to be apportioned to the different channels were obtained from Fig. A.I and were found to be approximately equal to one another with a value of 0.234 in.2 
The values of coefficients $K_{i n}$ and $K_{0}$ were obtained from Crane Company catalog [A.2] (reproduced as Fig. A3). These values are also given in Table Al. The channel numbers correspond to those shown in Fig. Al.

Three different modes of operation were studied.

Mode 1: Normal operation at the design conditions.

Mode 2: Abnormal operation under conditions of blockage at certain channels in the first disc.

Mode 3: Abnormal operation under conditions of spring breakage.

The results for these three modes of operation are given below.

\section{Mode 1. Normal Operation at the Design Conditions}

The network is assumed to be supplied with $45 \mathrm{gpm}$ at a pressure of 34.7 psia at junction 0 . With the HYNAL program and the methodology discussed in the preceding section, Fig. A.4 shows the flow through the different lines and the pressures at the different junctions. The velocities through the different lines are given in Fig. A.5. It is seen that $4.5 \mathrm{gpm}$ flows through the last disc. The pressure at the exit of the plenum is 24.5 psia. The highest velocity is $21.54 \mathrm{ft} / \mathrm{sec}$ in the central channel of the last disc, and the lowest velocity is $9.47 \mathrm{ft} / \mathrm{sec}$ in the two side channels of the first disc.

\section{Mode 2. Operation with Blocked Channel}

Consider the flow and pressure distribution that results when certain channels are blocked. Since the first disc is the critical one, blockage of a channel was studied for only that disc. Blockage of a particular channel was simulated by increasing its head loss, i.e., the Hazen-Williams coefficient for that channel was chosen such that $C \approx 0$ (a very small number). Results are given for the following four cases.

a. Case 1. The 5/16-in. wide $\times 3-1 / 8-i n$. long channel in the first disc, i.e., channel 44 in Fig. A.1 is blocked. The flow and pressure distributions are shown in Fig. A.6, and the velocity distribution is given in Fig. A.7. The flow to the first disc is decreased from $4.46 \mathrm{gpm}$ of the design 

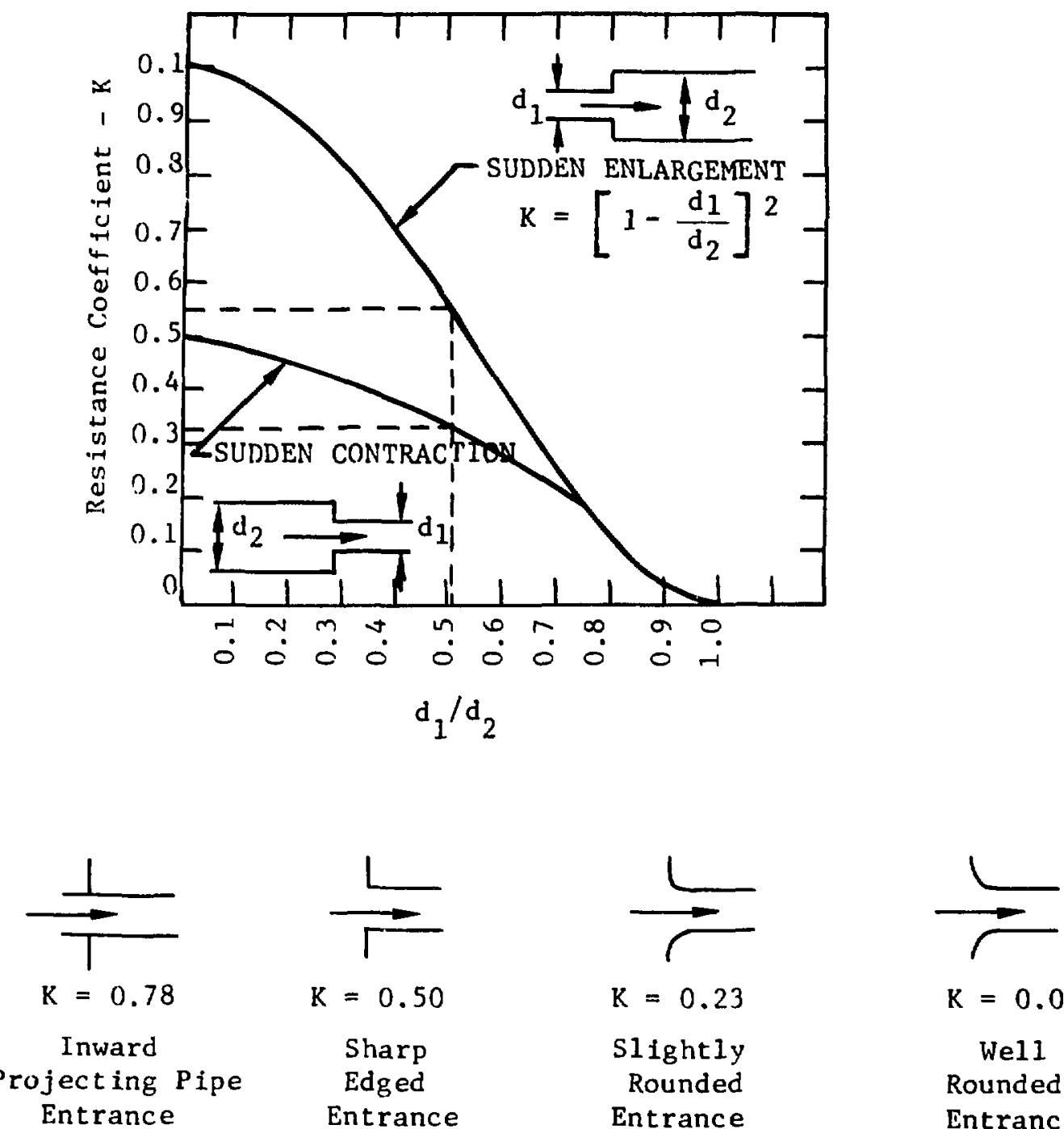

$K=0.50$

$K=0.23$

$\mathrm{K}=0.04$

Sharp

$$
\text { Edged }
$$

Slightly

Rounded

We11

Rounded

Entrance
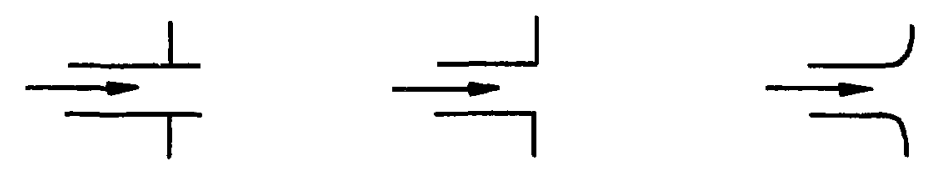

$K=1.0$

$\mathrm{K}=1.0$

$\mathrm{K}=1.0$

Projecting

Sharp

Pipe Exit

Edged Exit

Rounded

Exit

Fig. A.3. Resistance in Pipe due to Sudden Enlargements and Contractions. From Ref. [A.2]. 


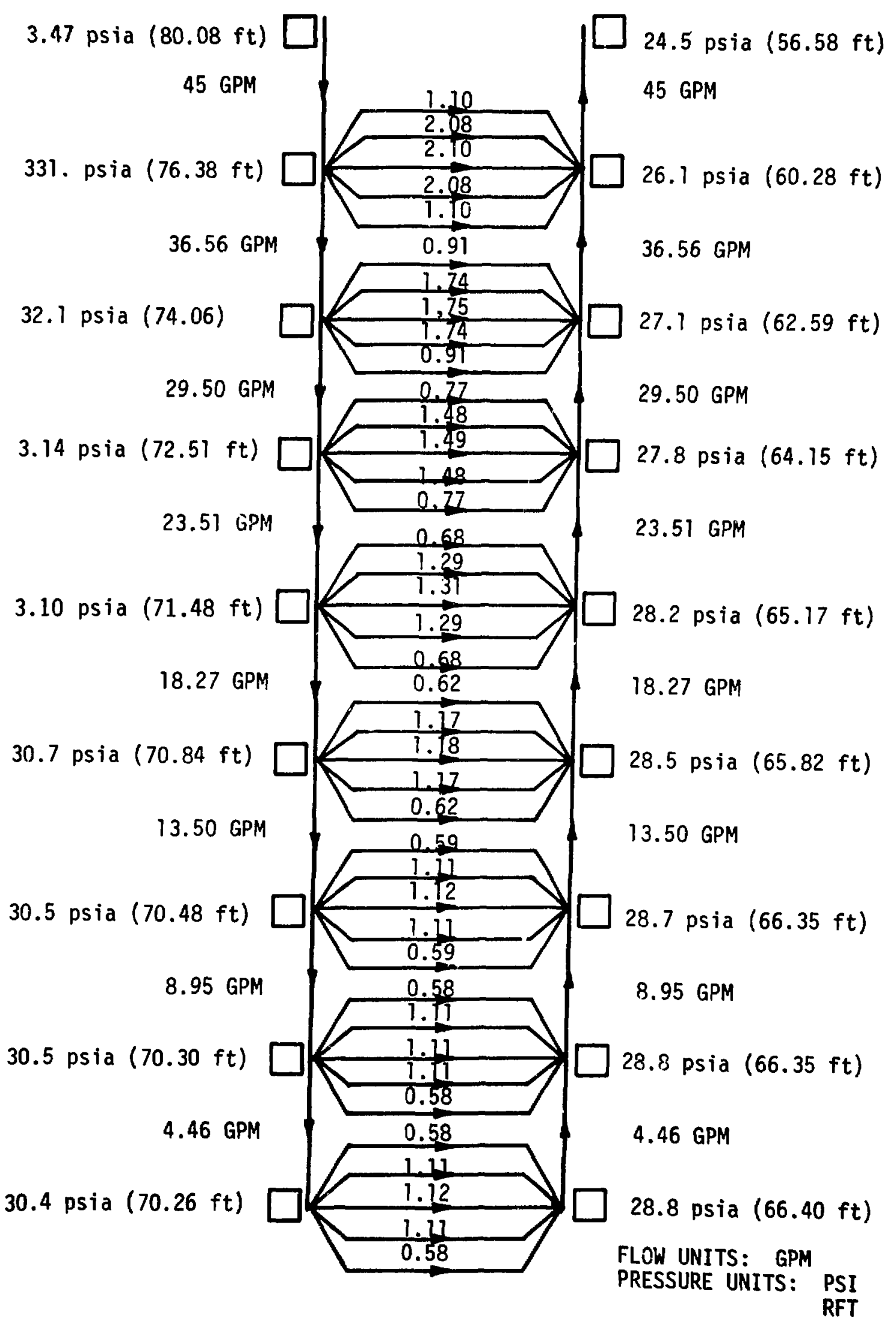

Fig. A.4. Flow and Pressure Profile. 


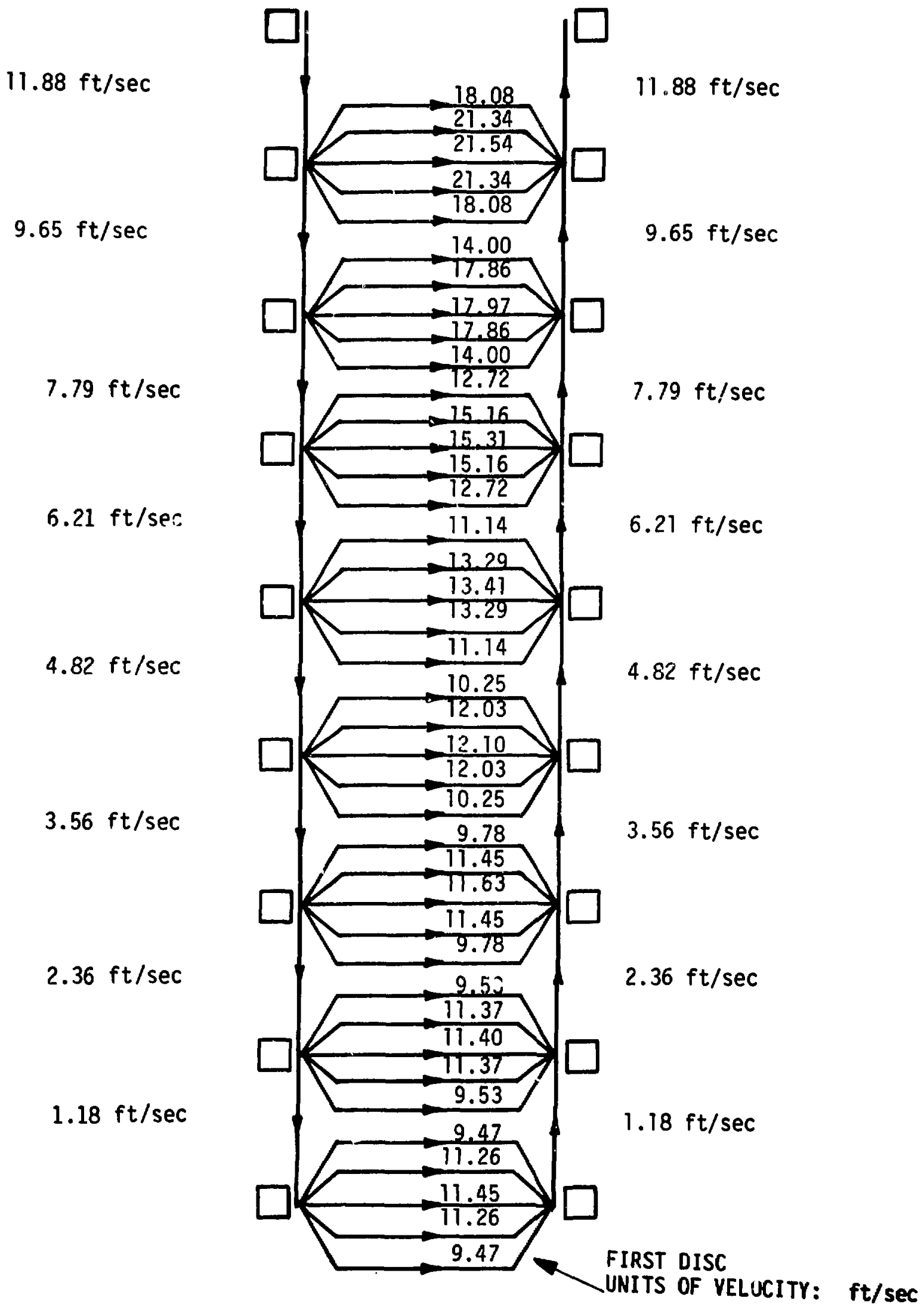

Fig. A.5. Velocity Distribution. 
conditions to $4.00 \mathrm{gpm}$. The velocities in the unblocked channel are increased slightly.

b. Case 2. The 1/2-in.-wide $\times 3-7 / 8-i n .-1$ ong channel in the first disc, i.e., channel 45 in Fig. A.1 is blocked. The flow and pressure distributions for this case are shown in Fig. A.8 and the velocity distribution in Fig. A.9. The flow to the first disc is now decreased to $3.54 \mathrm{gpm}$, and the velocities in the unblocked channels are increased slightly.

c. Case 3. The 1/2-in-wide $\times$ 4-in.-iong channel in the first disc, i.e., channel 46 in Fig. A.1 is blocked. The flow and pressure distributions for this case are shown in Fig. A.10, and the velocity distribution in Fig. A.11. The flow to the first disc is now decreased still further to $3.52 \mathrm{gpm}$.

d. Case 4. All five channels in the last disc, i.e., channels 2-6, in Fig. A.1 are blocked. The flow and pressure distributions are shown in Fig. A.12 and the velocity distribution in Fig. A.13. The flow to the first disc is now increased from $4.46 \mathrm{gpm}$ of the design conditions to $5.42 \mathrm{gpm}$. The velocities in the channels of the first disc are increased by about $2 \mathrm{ft} / \mathrm{sec}$ from the design conditions.

\section{Mode 3. Operation with Broken Spring}

A further study was conducted to deterimine the flow and pressure profile under certain coriditions brought about by the breaking of the spring that supplies the mechanical force to keep all the discs together in the target. The following cases were of interest: 1) a hole of 1/4-in. diameter connecting the entrance and exit plenums; 2) a gap of 1/4-in. between any two discs.

Case 1. A hole of 1/4-in. diameter connecting the entrance and exit plenums. This is simulated by a 1/4-in. diameter pipe of $0.3 \mathrm{ft}$ length connecting the two plenums as shown in Fig. A.1. The Hazen-Williams coefficient $C$ must be chosen appropriateiy. For an orifice, the velocity and 


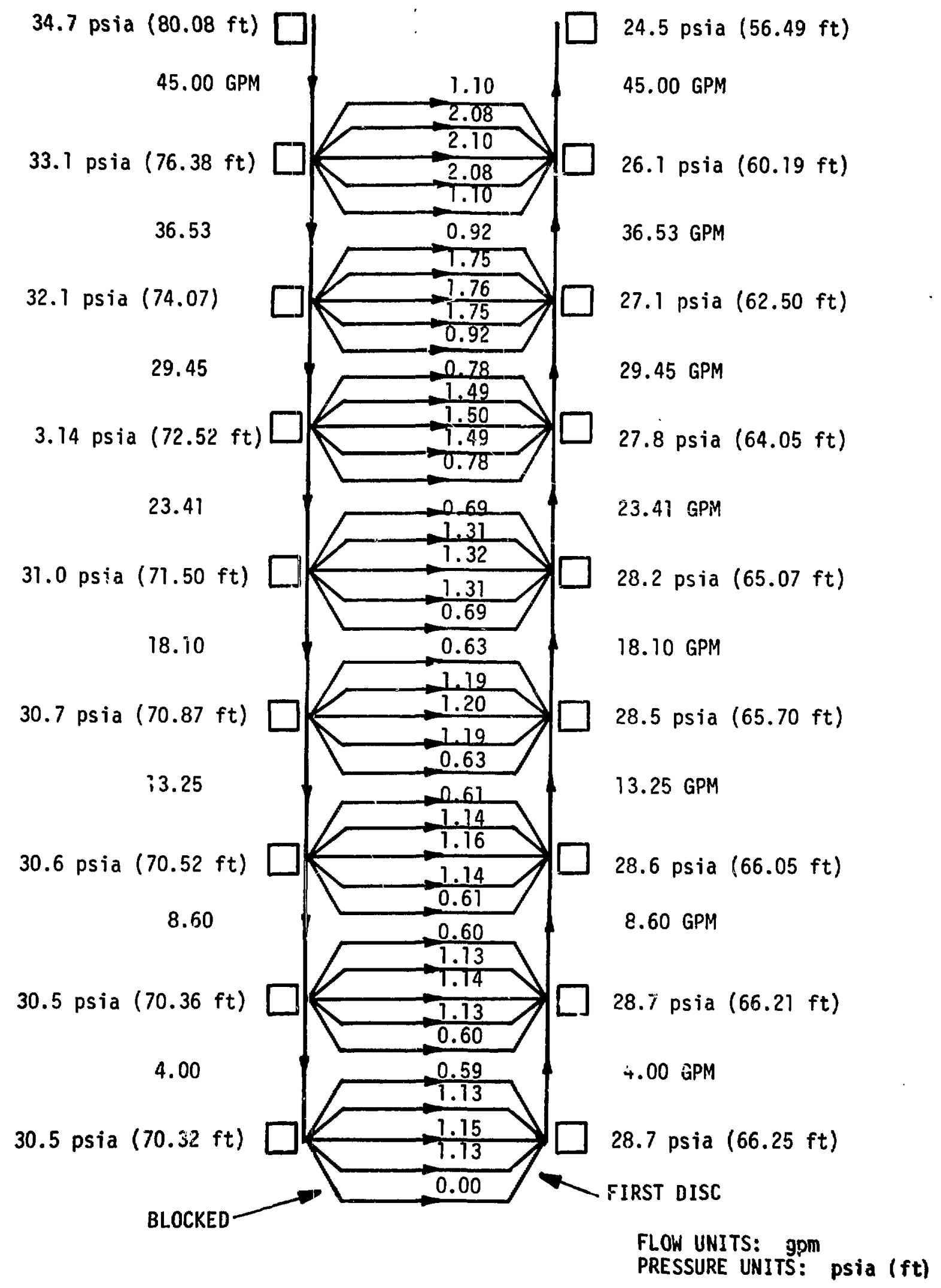

Fig. A.6. Flow and Pressure Distribution when Channel in First Disc is Blocked. 
$11.88 \mathrm{ft} / \mathrm{sec}$

$9.65 \mathrm{ft} / \mathrm{sec}$

$7.78 \mathrm{ft} / \mathrm{sec}$

$6.18 \mathrm{fi} / \mathrm{sec}$

$4.78 \mathrm{ft} / \mathrm{sec}$

$3.50 \mathrm{ft} / \mathrm{sec}$

$2.27 \mathrm{ft} / \mathrm{sec}$

$1.06 \mathrm{ft} / \mathrm{sec}$
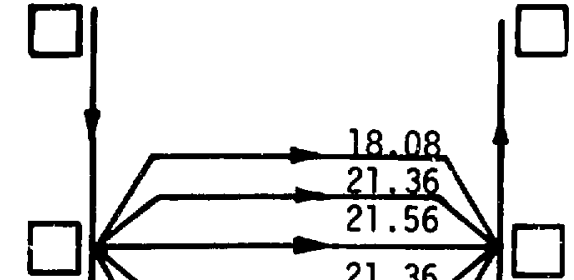

$11.88 \mathrm{ft} / \mathrm{sec}$

$9.65 \mathrm{ft} / \mathrm{sec}$

$7.78 \mathrm{ft} / \mathrm{sec}$

$6.18 \mathrm{ft} / \mathrm{sec}$

$4.78 \mathrm{ft} / \mathrm{sec}$

$3.50 \mathrm{ft} / \mathrm{sec}$

$2.27 \mathrm{ft} / \mathrm{sec}$

.32

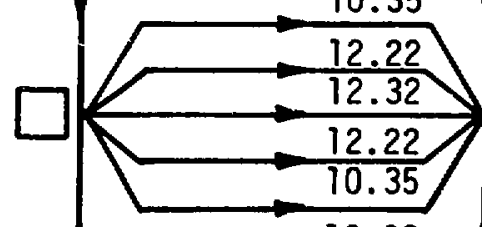

0.02

$3.50 \mathrm{ft} / \mathrm{sec}$

1.71
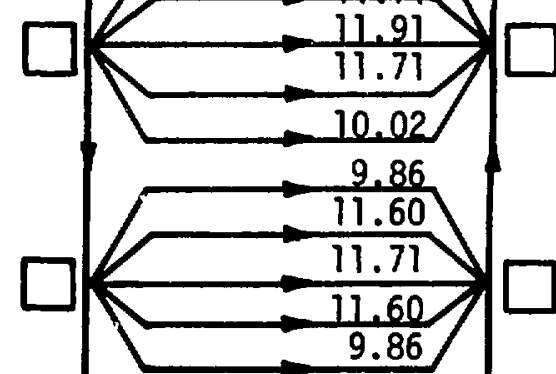

$1.06 \mathrm{ft} / \mathrm{sec}$

VELOCITY UNITS: $\mathrm{ft} / \mathrm{sec}$

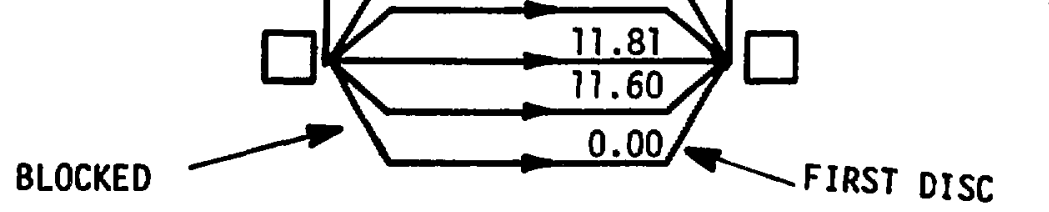

Fig. A.7. Velocity Distribution when 5/16-in. $\times 3-1 / 8-$ in. Channel in First Disc is Blocked. 


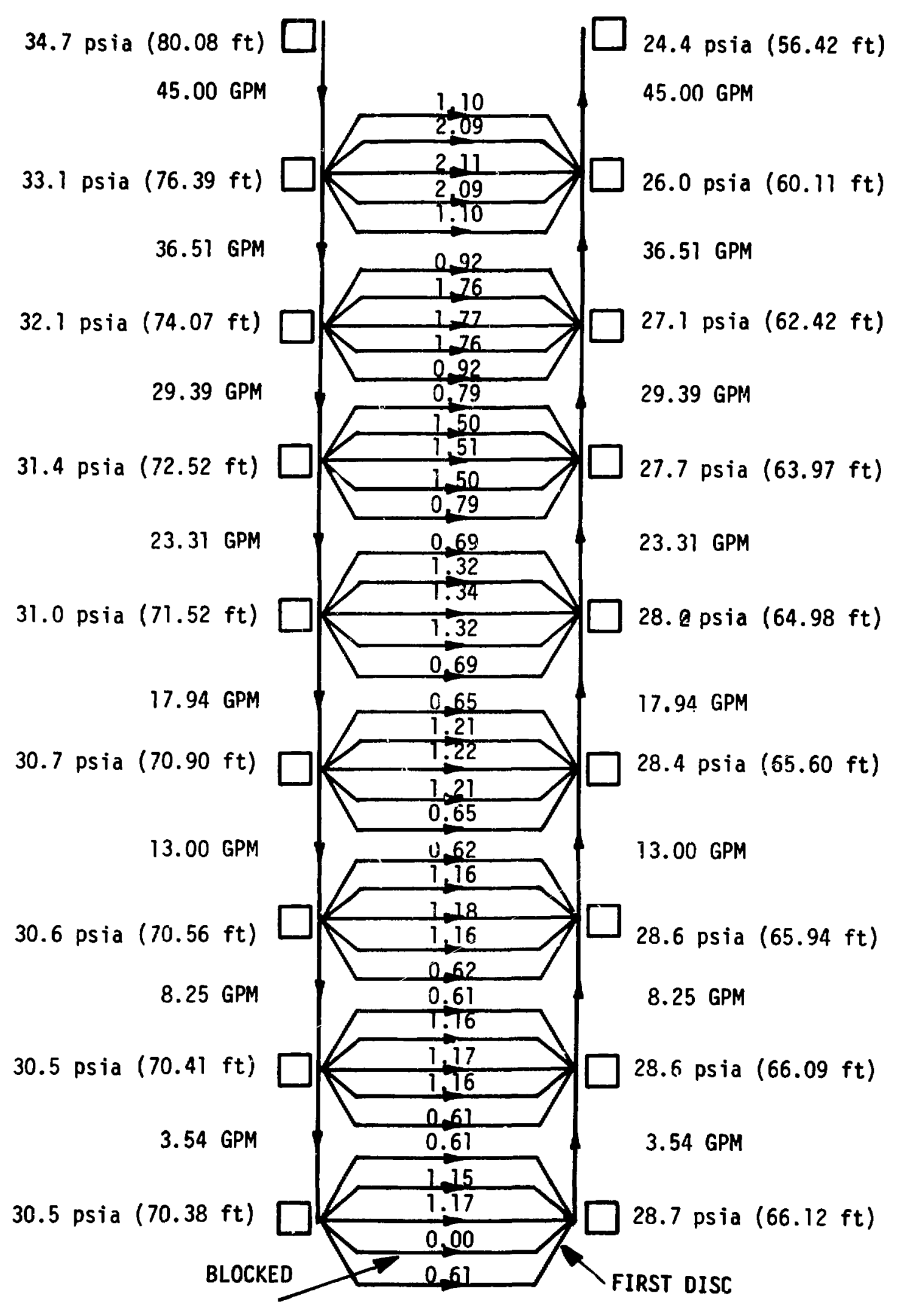

Fig. A.8. Flow and Pressure Distribution when 1/2-in. $\times 3-7 / 8-i n$. Channel in First Disc is Blocked. 
$11.88 \mathrm{ft} / \mathrm{sec}$

$9.74 \mathrm{ft} / \mathrm{sec}$

$7.76 \mathrm{ft} / \mathrm{sec}$

$6.16 \mathrm{ft} / \mathrm{sec}$

$4.74 \mathrm{ft} / \mathrm{sec}$

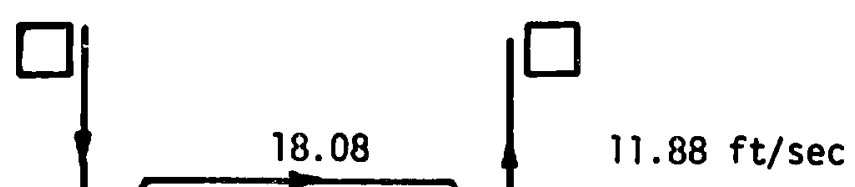

$3.4 ? \mathrm{ft} / \mathrm{sec}$

$2.18 \mathrm{ft} / \mathrm{sec}$

$0.93 \mathrm{ft} / \mathrm{sec}$

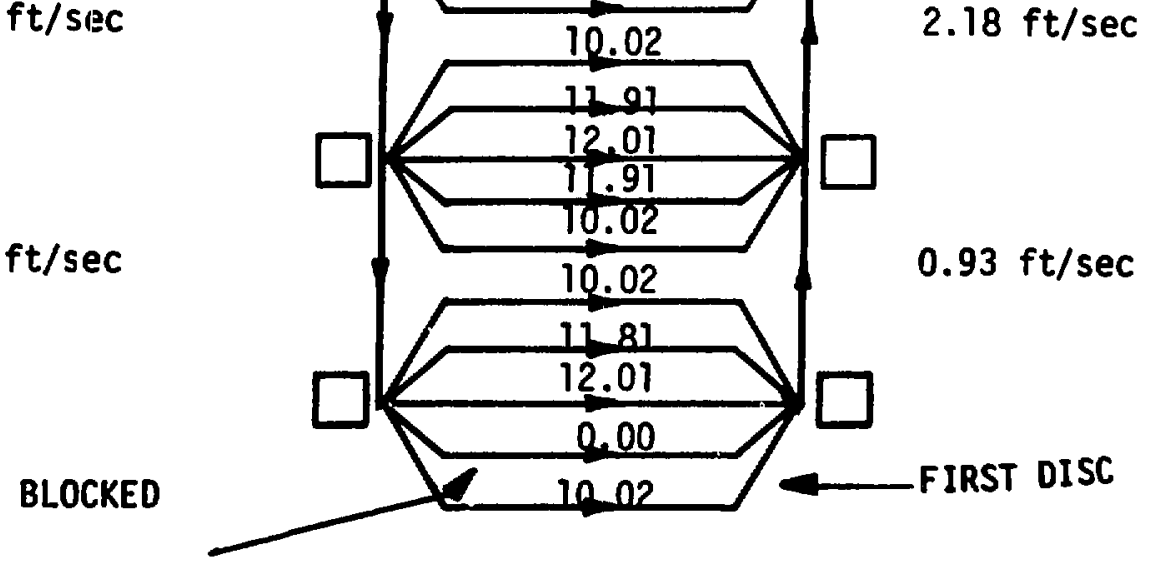

Fig. A.9. Velocity Distribution when $1 / 2-$ in. $\times 3-7 / 8-i n$. Channel in First Disc is Blocked. 


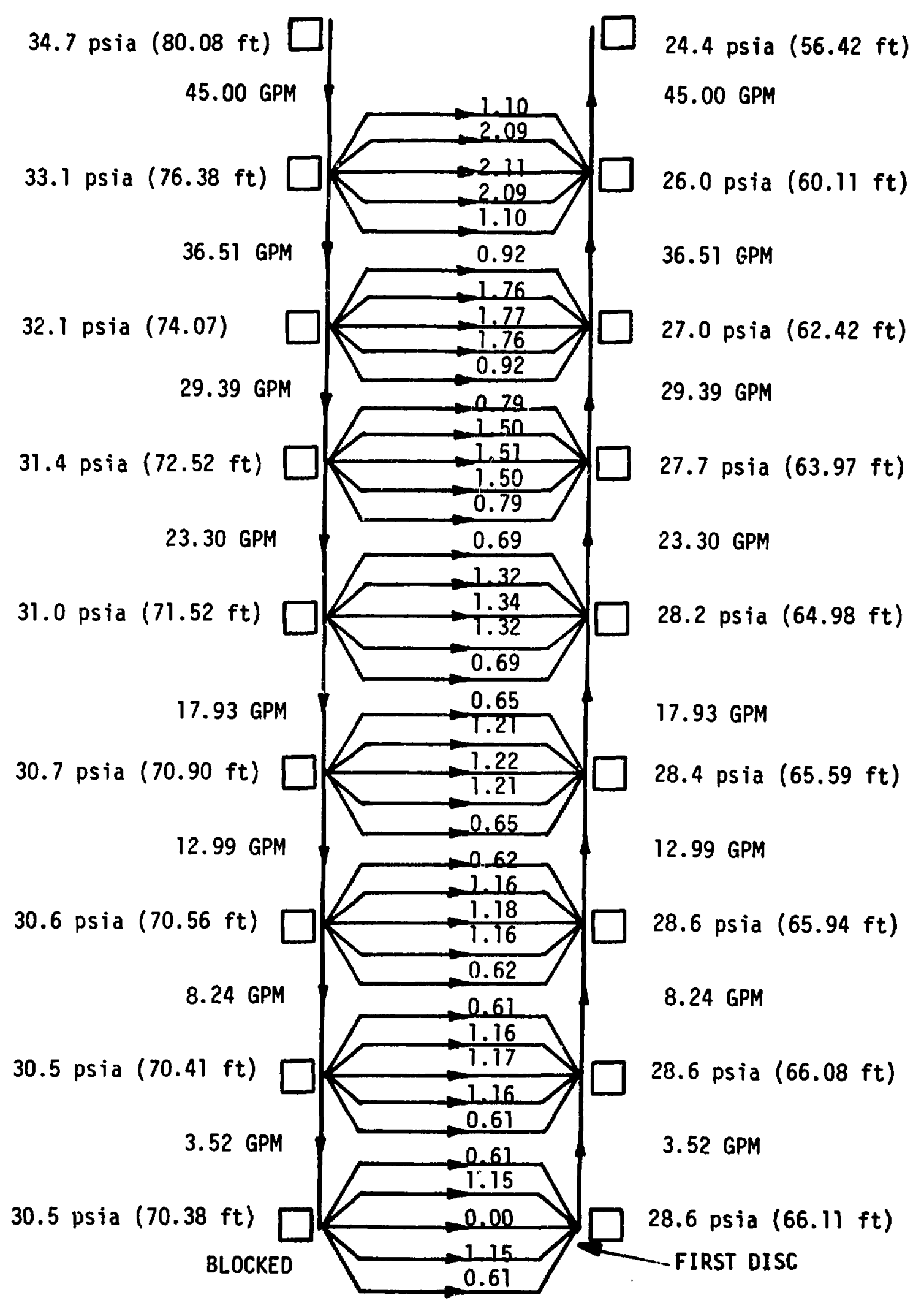

Fig. A.10. Flow and Pressure Distribution when 1/2-in. $\times$ 4-in. Channel in First Disc is Blocked. 
$11.88 \mathrm{ft} / \mathrm{sec}$

$9.64 \mathrm{ft} / \mathrm{sec}$

$7.76 \mathrm{ft} / \mathrm{sec}$

$6.15 \mathrm{ft} / \mathrm{sec}$

$4.74 \mathrm{ft} / \mathrm{sec}$

$3.43 \mathrm{ft} / \mathrm{sec}$

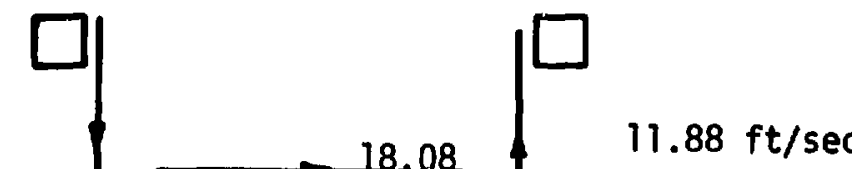

$2.18 \mathrm{ft} / \mathrm{sec}$

$0.93 \mathrm{ft} / \mathrm{sec}$

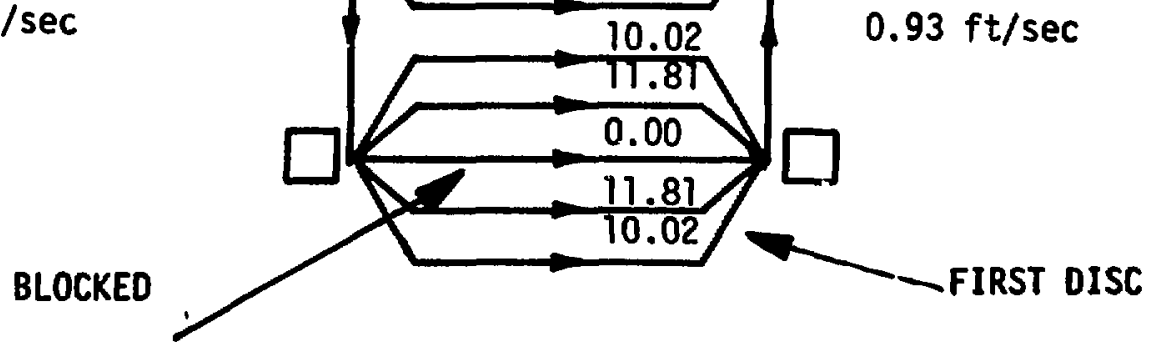

Fig. A.11. Velocity Distribution when $1 / 2-$ in. $\times 4-i n$. Channel in First Disc is Blocked. 


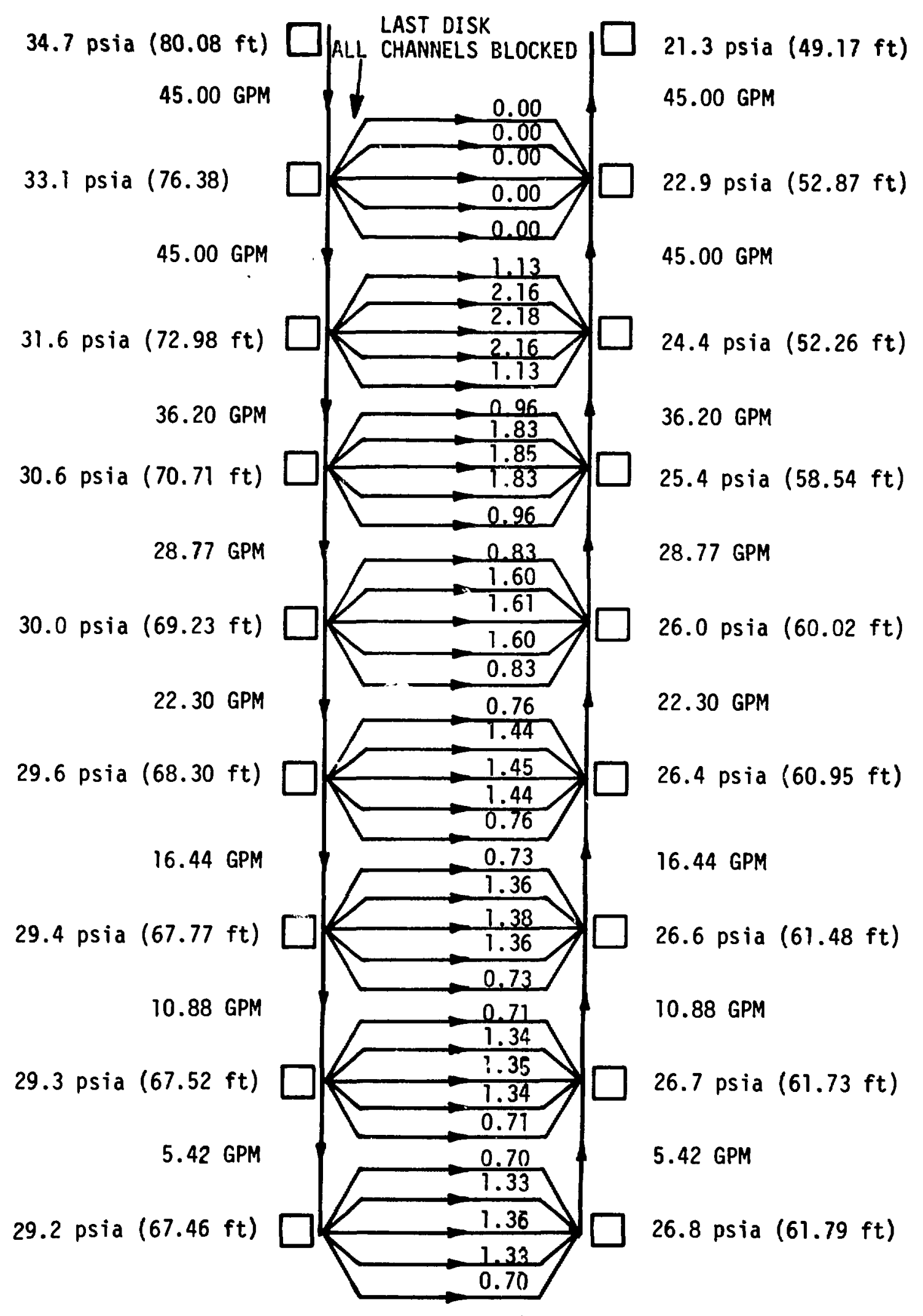

Fig. A.12. Flow and Pressure Distribution when All Channels in Last Disc are Blocked. 
$11.88 \mathrm{ft} / \mathrm{sec}$

$11.88 \mathrm{ft} / \mathrm{sec}$

$9.56 \mathrm{ft} / \mathrm{sec}$

$7.60 \mathrm{ft} / \mathrm{sec}$

$5.89 \mathrm{ft} / \mathrm{sec}$

$4.34 \mathrm{ft} / \mathrm{sec}$

$2.87 \mathrm{ft} / \mathrm{sec}$

$1.43 \mathrm{ft} / \mathrm{sec}$

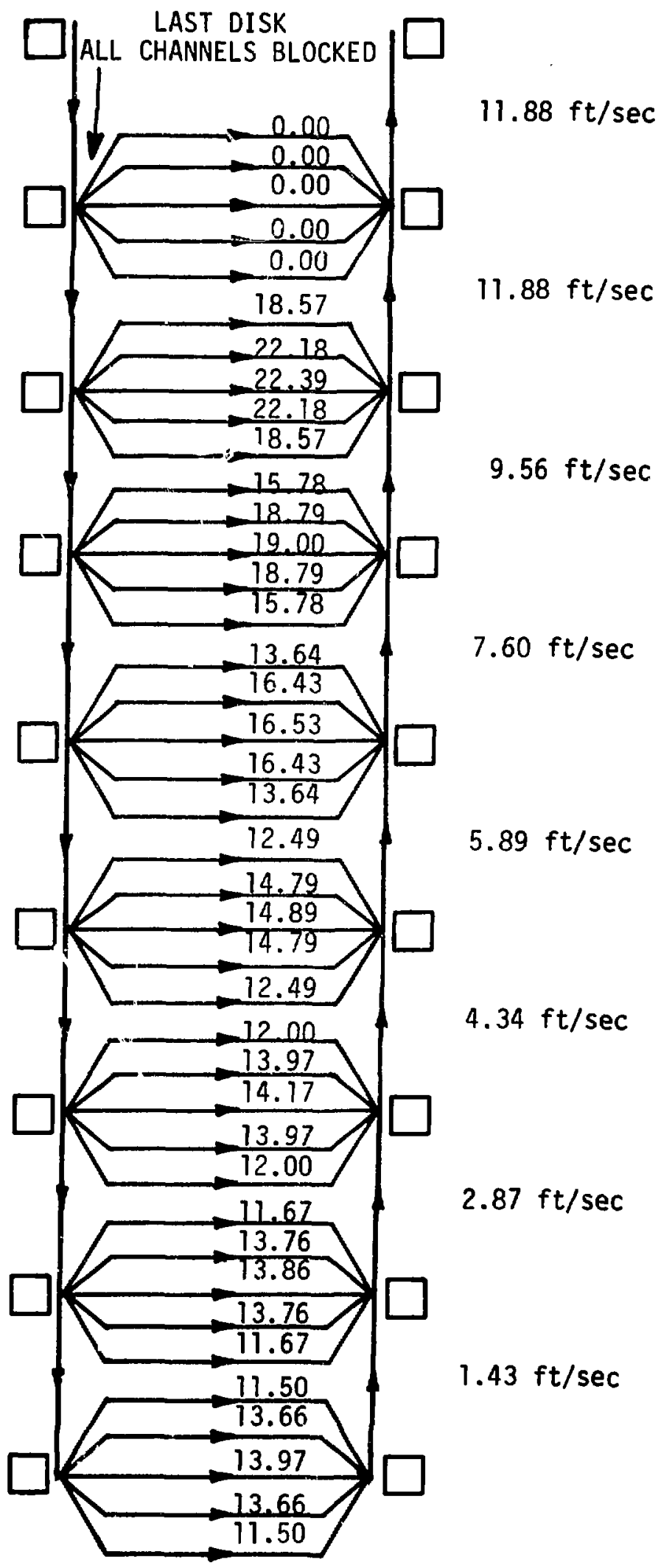

Fig. A.13. Velocity Distribution when All Channels in Last Disc are Blocked. 


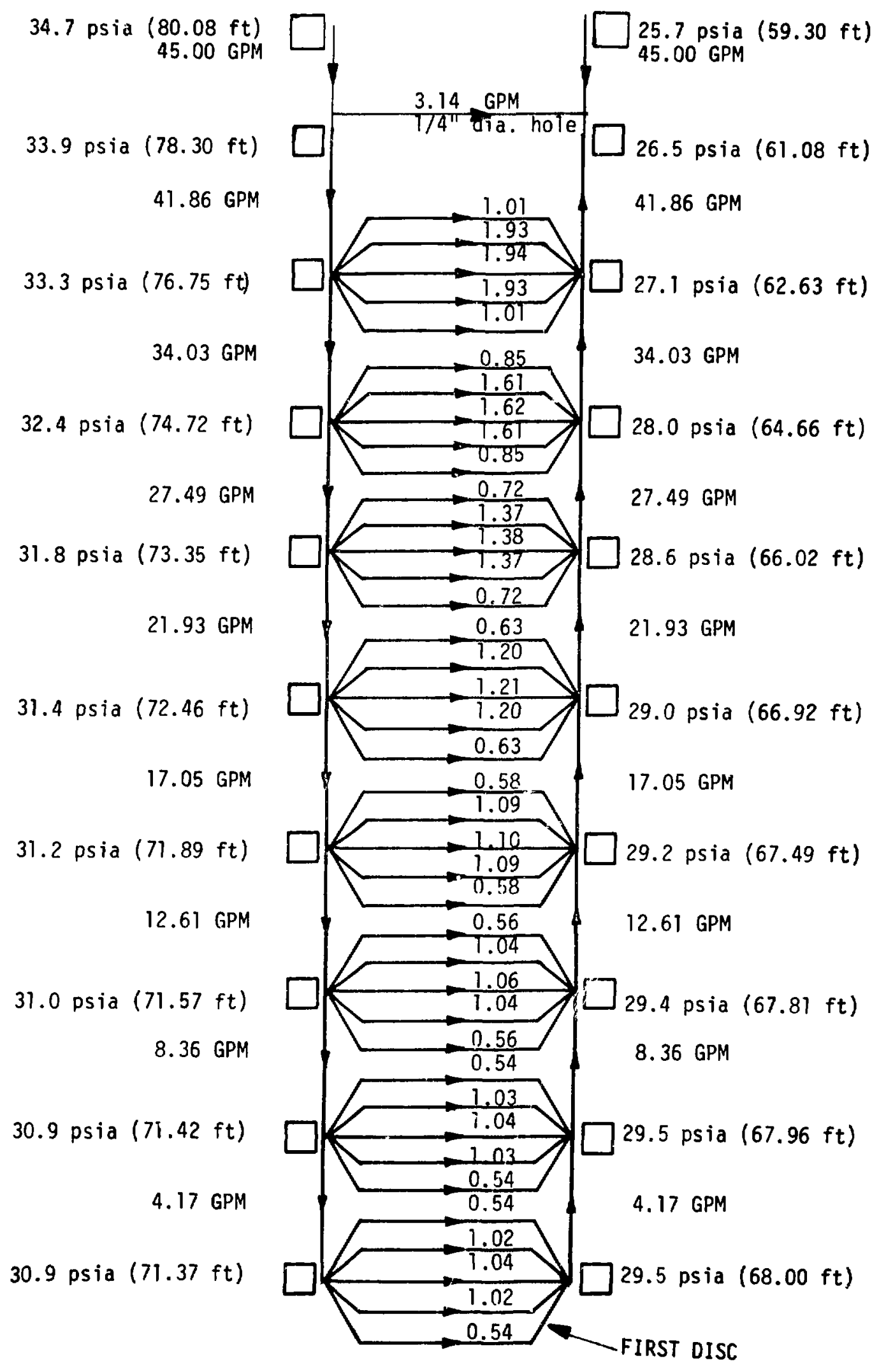

Fig. A.14. Flow and Pressure Distribution with 1/4-in. Diameter Hole between Entrance and Exit Plenums. 


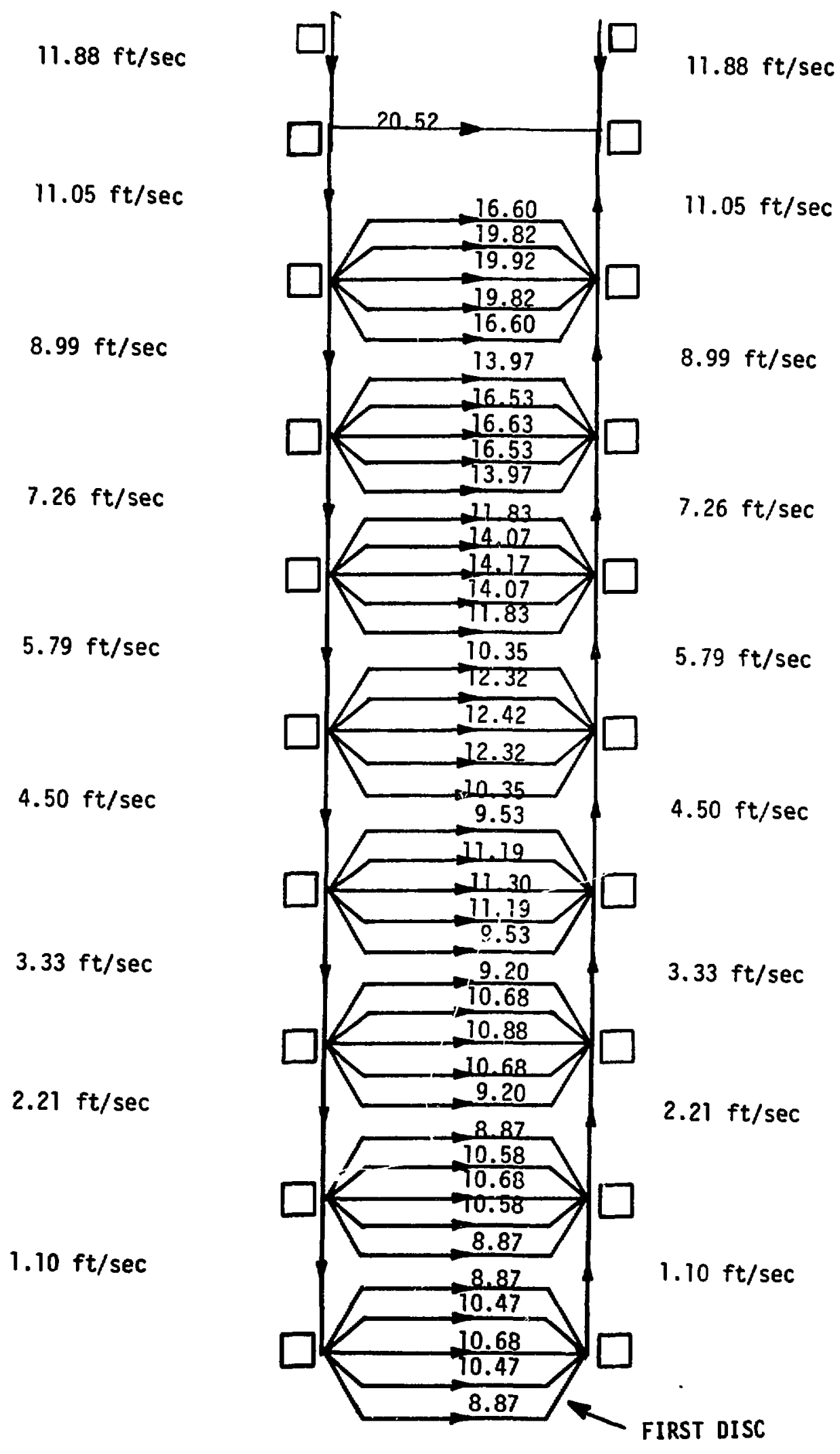

Fig. A.15. Velocity Distribution with 1/4-in.-Diameter Hole between Entrance and Exit Plenums. 
pressure drop $\Delta H$ are related by

$$
v=C_{1} \sqrt{2 g \Delta H}
$$

and choosing the coefficient $C_{1}$ as 0.6 , we obtain

$$
V=4.815 \sqrt{\Delta \mathrm{H} \text {. }}
$$

Different values of $C$ were tried in the HYNAL program. If $C=100$, we obtain $\Delta H=15 \mathrm{ft}$ and $V=38.26 \mathrm{ft} / \mathrm{sec}$, which does not satisfy Eqn. A4. If $C=83$, we get $\Delta H=14.7 \mathrm{ft}$ and $V=32.5 \mathrm{ft} / \mathrm{sec}$, which again does not satisfy Eqn. A4. If $C=50$, we obtain $\Delta H=17 \mathrm{ft}$ and $V=20.5 \mathrm{ft} / \mathrm{sec}$, which satisfied Eqn. A4 and was finally chosen as the Hazen-Williams coefficient for the pipe simulating the short circuit from inlet to outlet as a result of the broken spring.

The flow and pressure profiles are shown in Fig. A.14 and the velocity distribution in Fig. A.15. It is seen that $3.14 \mathrm{gpm}$ flow through the hole at a velocity of $20.52 \mathrm{ft} / \mathrm{sec}$. The cross-sectional araa of the gap is shown in Fig. A.16.

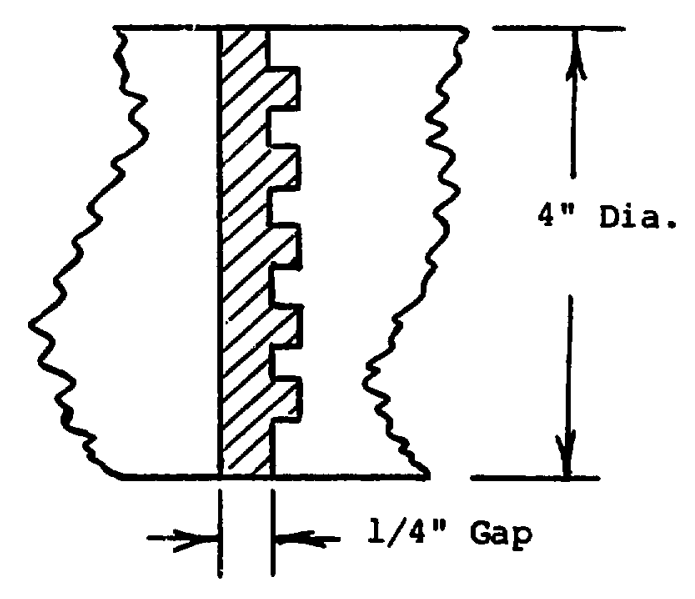

Fig. A.16. Cross-Sectional Area of Gap.

For this channel we obtain the following parameters:

Flow area $=1.10156 \mathrm{in.}^{2}=0076497 \mathrm{ft}^{2}$.

Perimeter $=8.875 \mathrm{in}$.

Hydraulic diameter, $D_{H}=0.49648 \mathrm{in} .=0.04137 \mathrm{ft}$. 
The Reynolds number is in the neighborhood of $6.7060 \times 10^{4}$, and the friction factor is $f=0.023$. The Hazen-Williams coefficient was calculated as $C=907$.

The results when the gap is in front of the first disc are shown in Figs. A.17 and A.18. The results when the gap is in front of the eighth (1ast) disc are given in Figs. A.19 and A.20. The HYNAL program calculated the pressure to the first decimal place in psia and to the second decimal place in feet. However, when a small amount of flow passes through a channel of small length, the pressure drop is small and better accuracy is desirable. In Figs. A.17 and A.19 the circled pressures in feet are the computer results and have been corrected from the knowledge of pressure drops in the appropriate pipes.

The cases of the gaps in front of the first and last discs are the two extremes. When the gap is in front of any other disc, the flow and velocity profiles will have values between the two extremes.

A set of reduced flow cases was also calculated. The flow and pressure profiles for the $40 \%$ flow are given in Fig. A.21, and the corresponding velocity distribution is given in Fig. A.22. The flow and pressure profiles for the $20 \%$ flow are given in Fig. A.23, and the corresponding velocity distribution is given in Fig. A.24. 


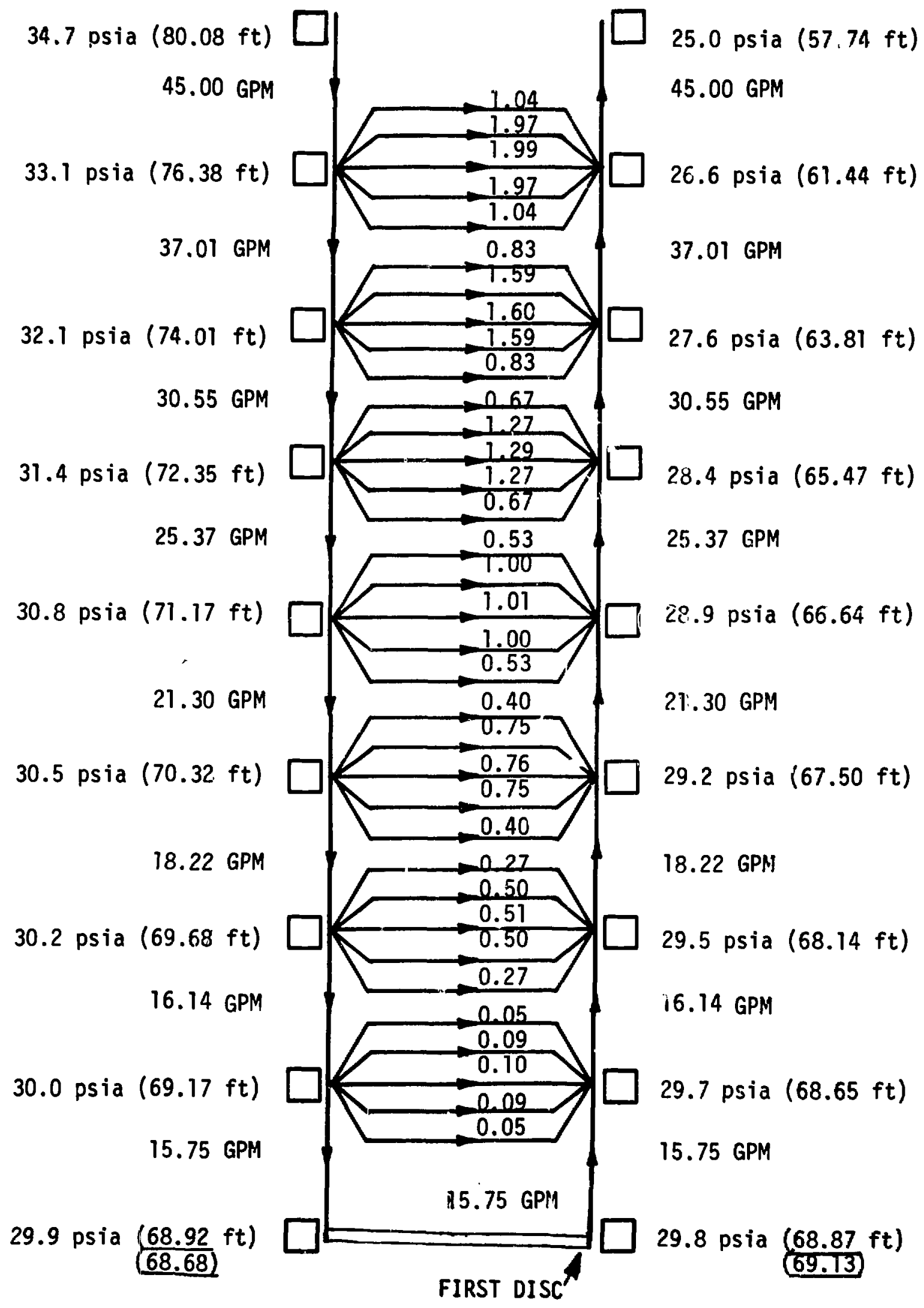

Fig. A.17. Flow and Pressure Distribution with 1/4-in. Gap at Front of First Disc. 
$11.88 \mathrm{ft} / \mathrm{sec}$

$9.77 \mathrm{ft} / \mathrm{sec}$

$8.07 \mathrm{ft} / \mathrm{sec}$

$6.70 \mathrm{ft} / \mathrm{sec}$

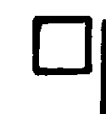

$\square$

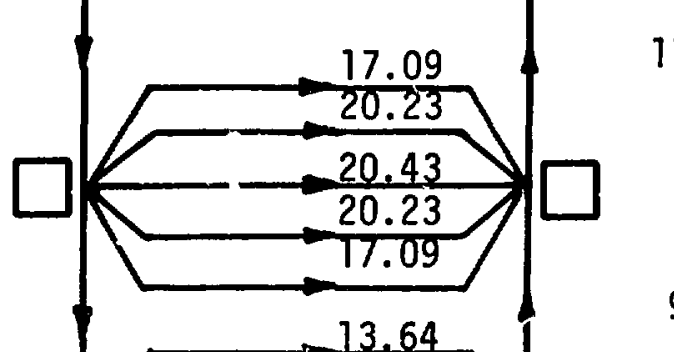

$11.88 \mathrm{ft} / \mathrm{sec}$

$9.77 \mathrm{ft} / \mathrm{sec}$

$8.07 \mathrm{ft} / \mathrm{sec}$

$5.63 \mathrm{ft} / \mathrm{sec}$

$4.81 \mathrm{ft} / \mathrm{sec}$

$4.26 \mathrm{ft} / \mathrm{sec}$

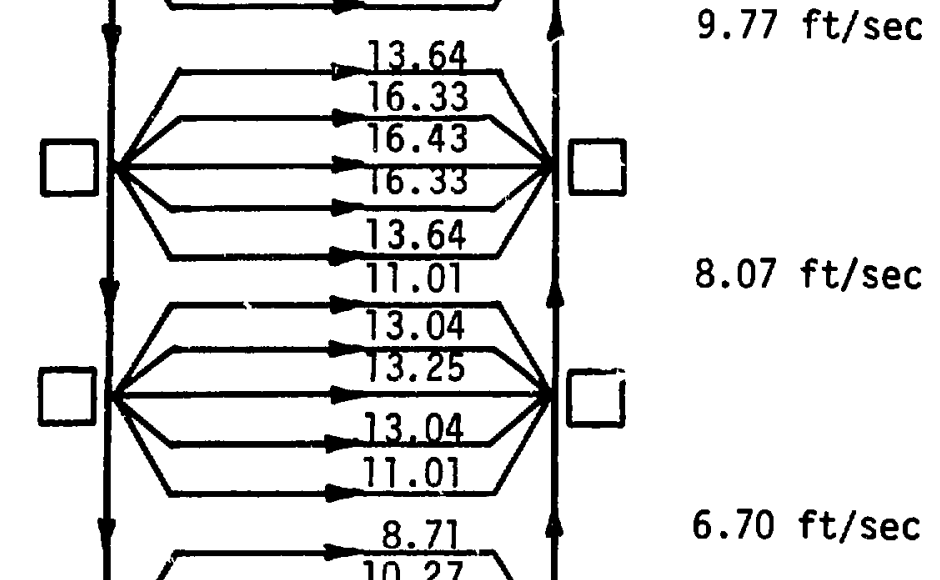

$5.63 \mathrm{ft} / \mathrm{sec}$

$4.81 \mathrm{ft} / \mathrm{sec}$

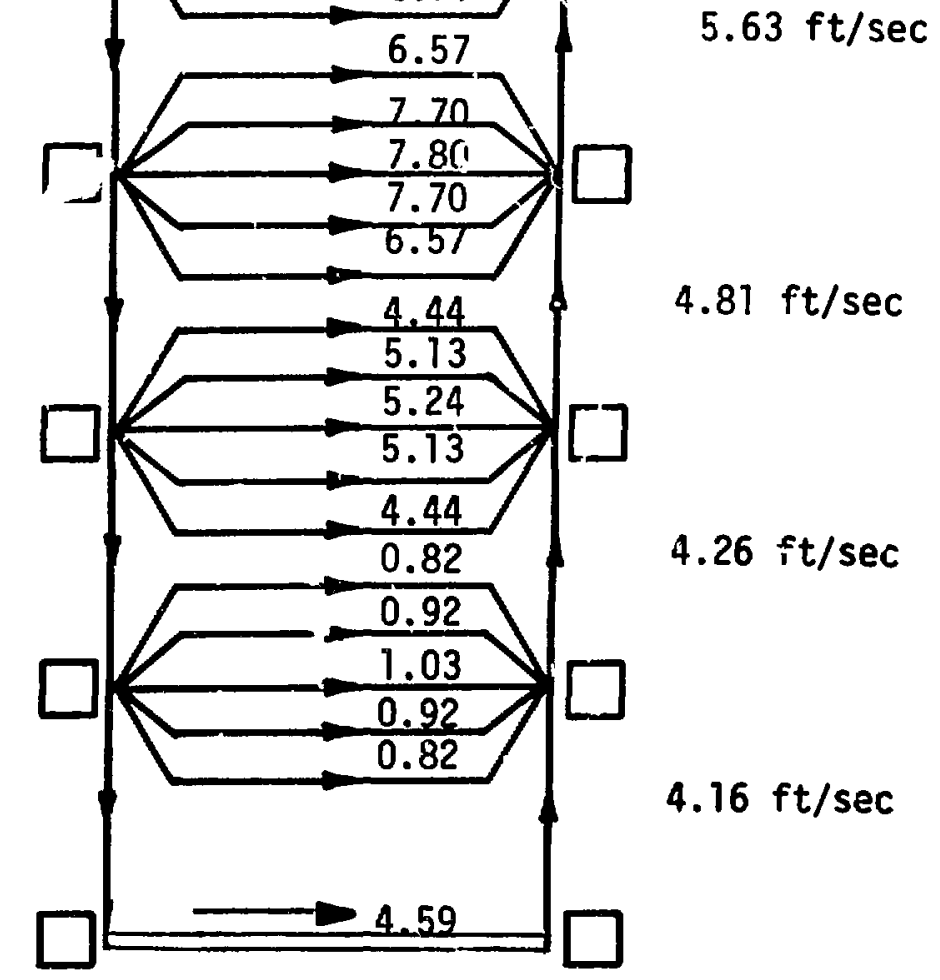

$4.26 \mathrm{ft} / \mathrm{sec}$

$4.16 \mathrm{ft} / \mathrm{sec}$

Fig. A.18. Velocity Distribution with 1/4-in. Gap at Front of First Disc. 


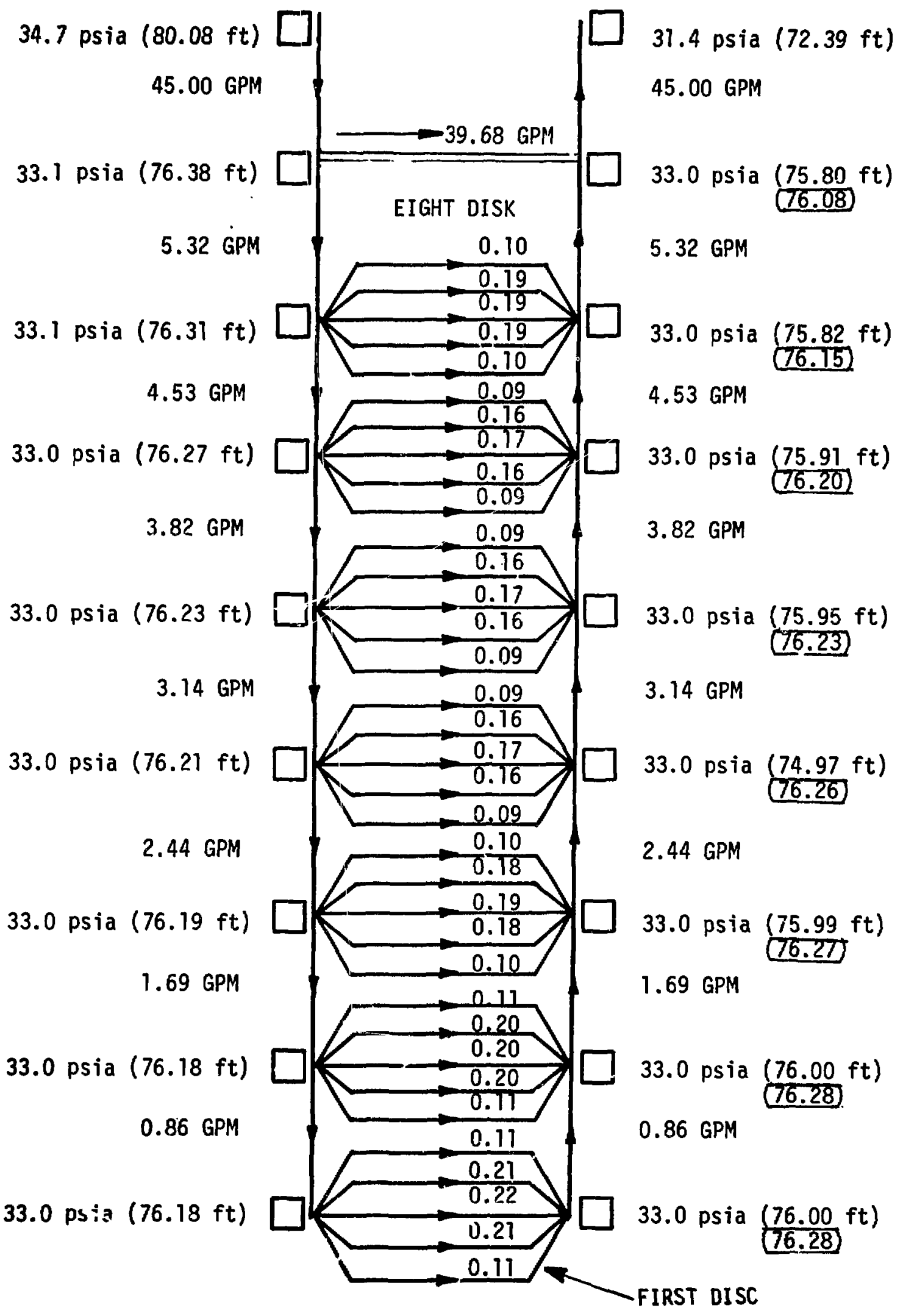

Fig. A.19. Flow and Pressure Distribution with 1/4-in. Gap at Front of Eighth Disc. 
$11.88 \mathrm{ft} / \mathrm{sec}$

$1.40 \mathrm{ft} / \mathrm{sec}$

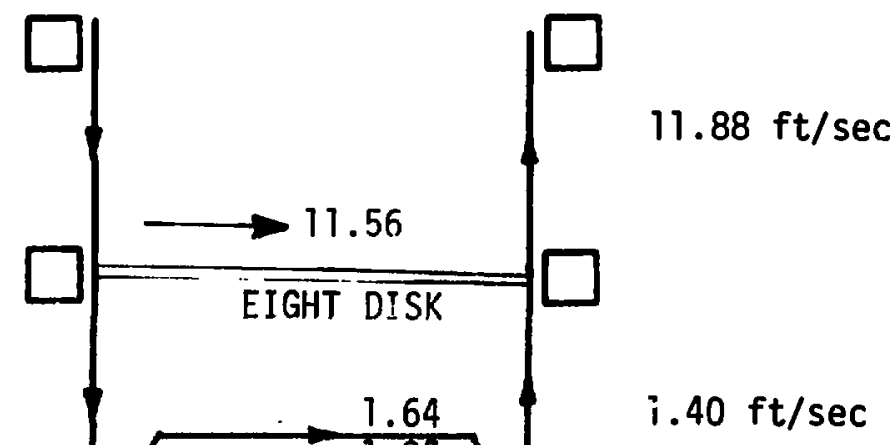

$1.20 \mathrm{ft} / \mathrm{sec}$

$1.01 \mathrm{ft} / \mathrm{sec}$

$0.83 \mathrm{ft} / \mathrm{sec}$

$0.64 \mathrm{ft} / \mathrm{sec}$

$0.45 \mathrm{ft} / \mathrm{sec}$

$0.23 \mathrm{ft} / \mathrm{sec}$

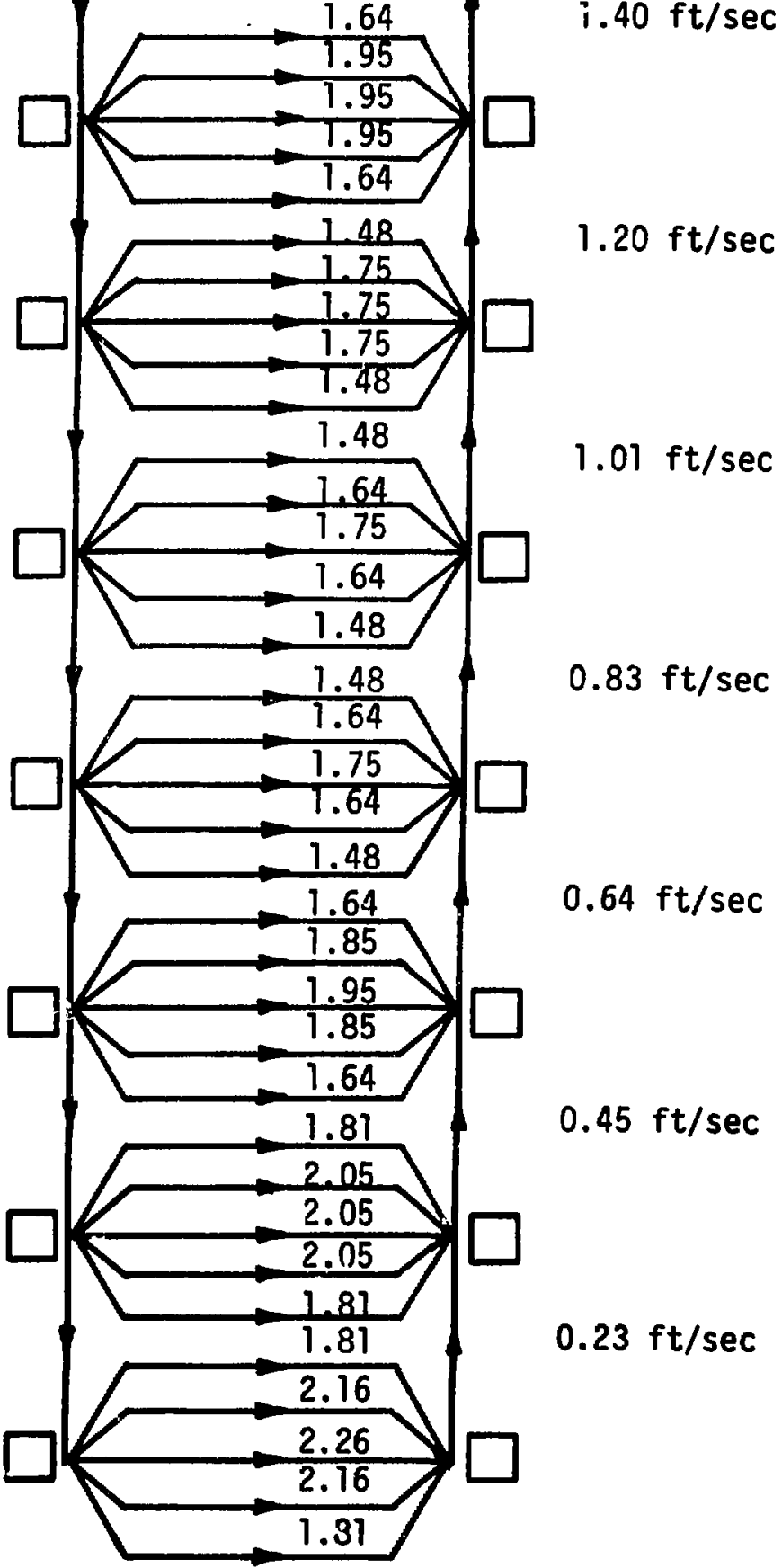

Fig. A.20. Velocity Distribution with 1/4-in. Gap at Front of Eighth Disc. 


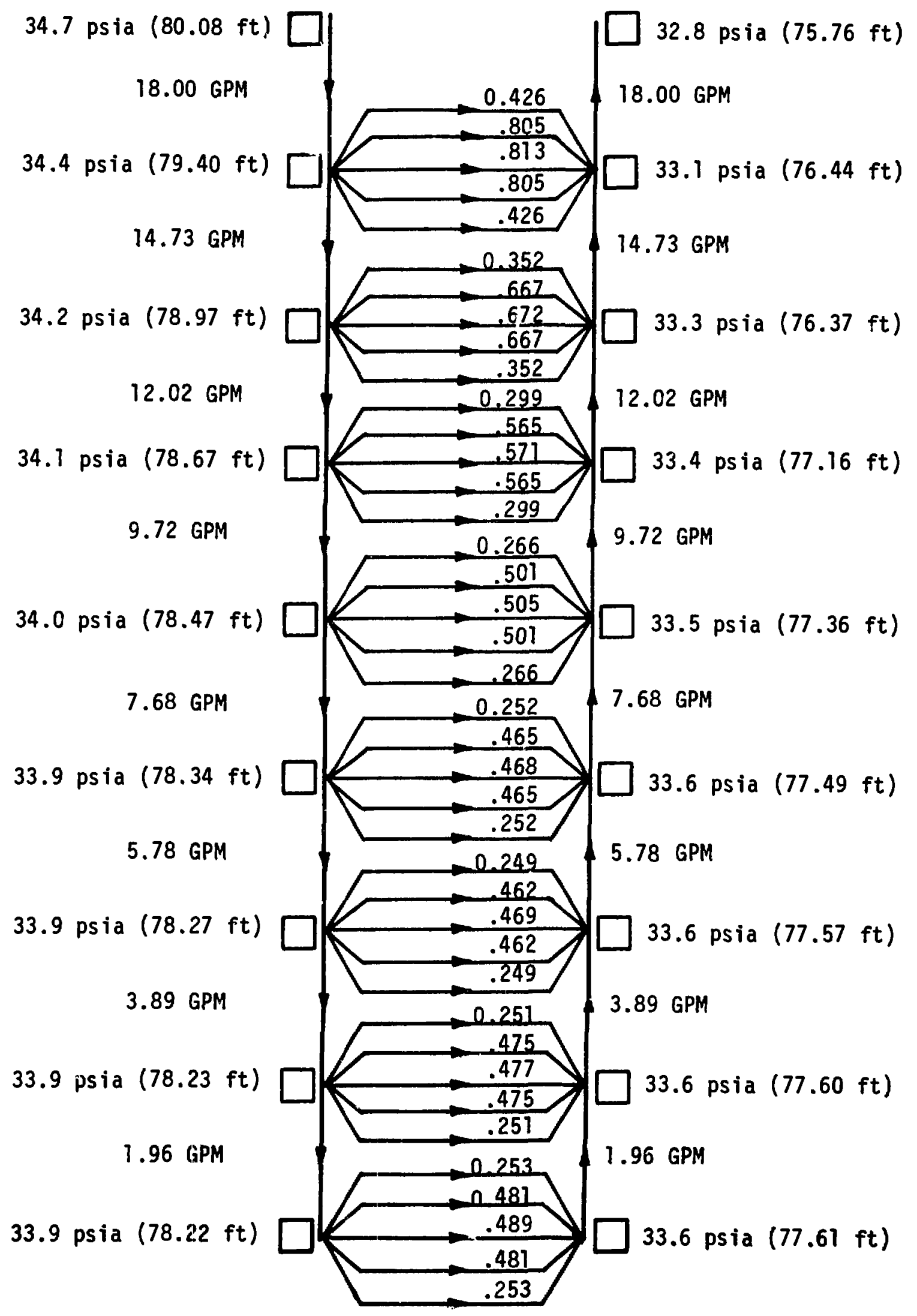

Fig. A.21. Flow and Pressure Profile for $40 \%$ flow. 


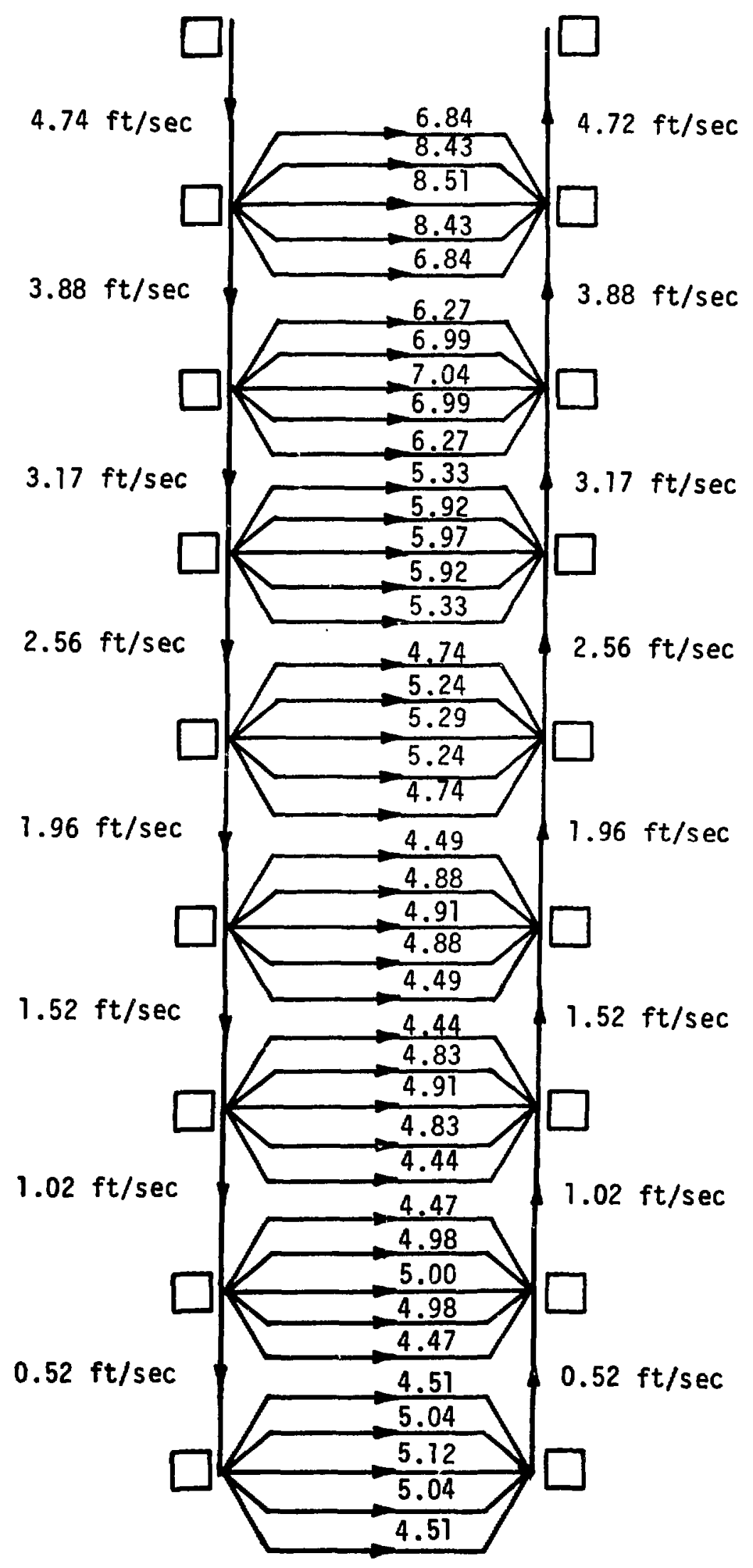

Fig. A.22. Velocity Distribution for $40 \%$ Flow. 


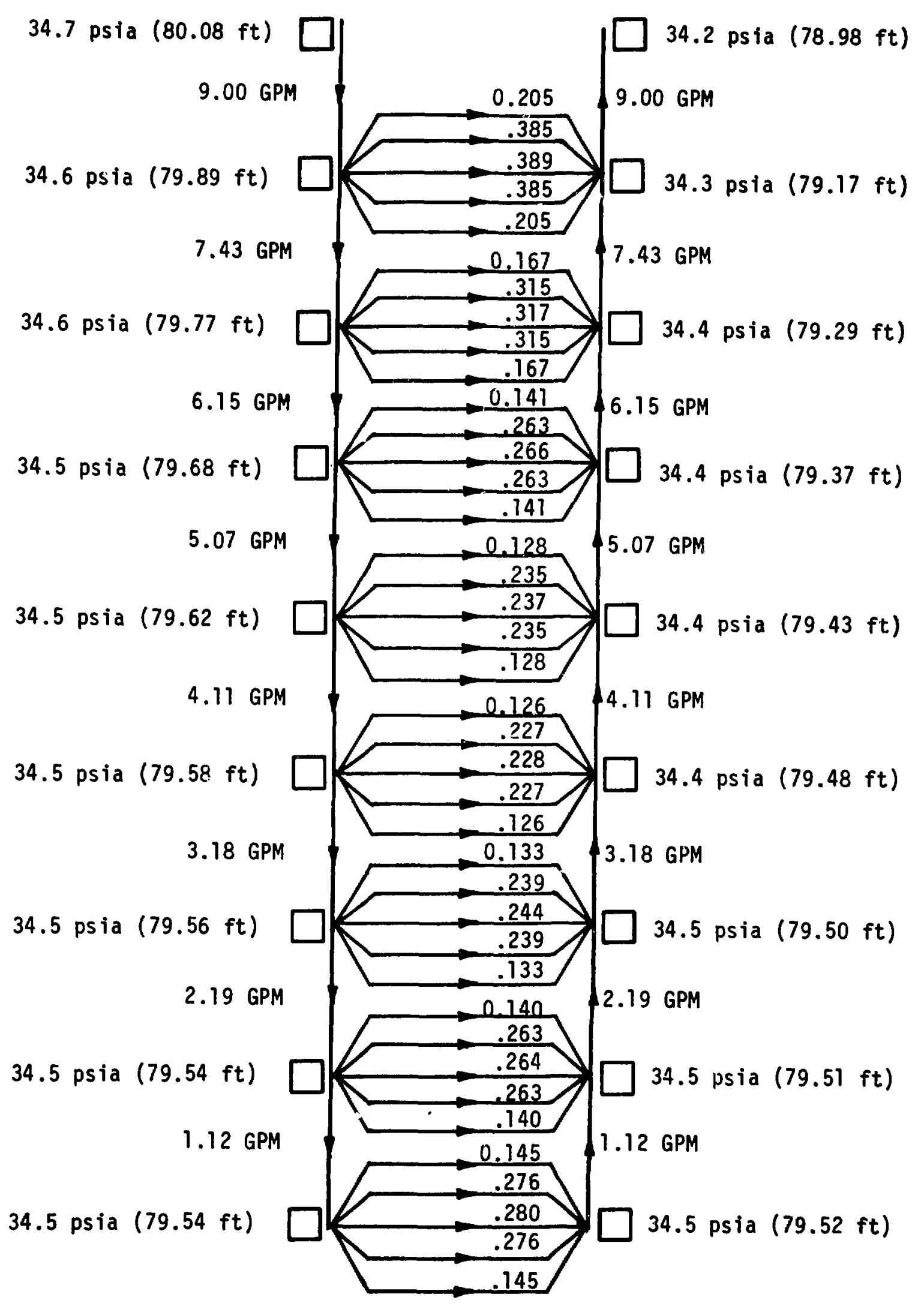

Fig. A.23. Flow and Pressure Profile for $20 \%$ Flow. 


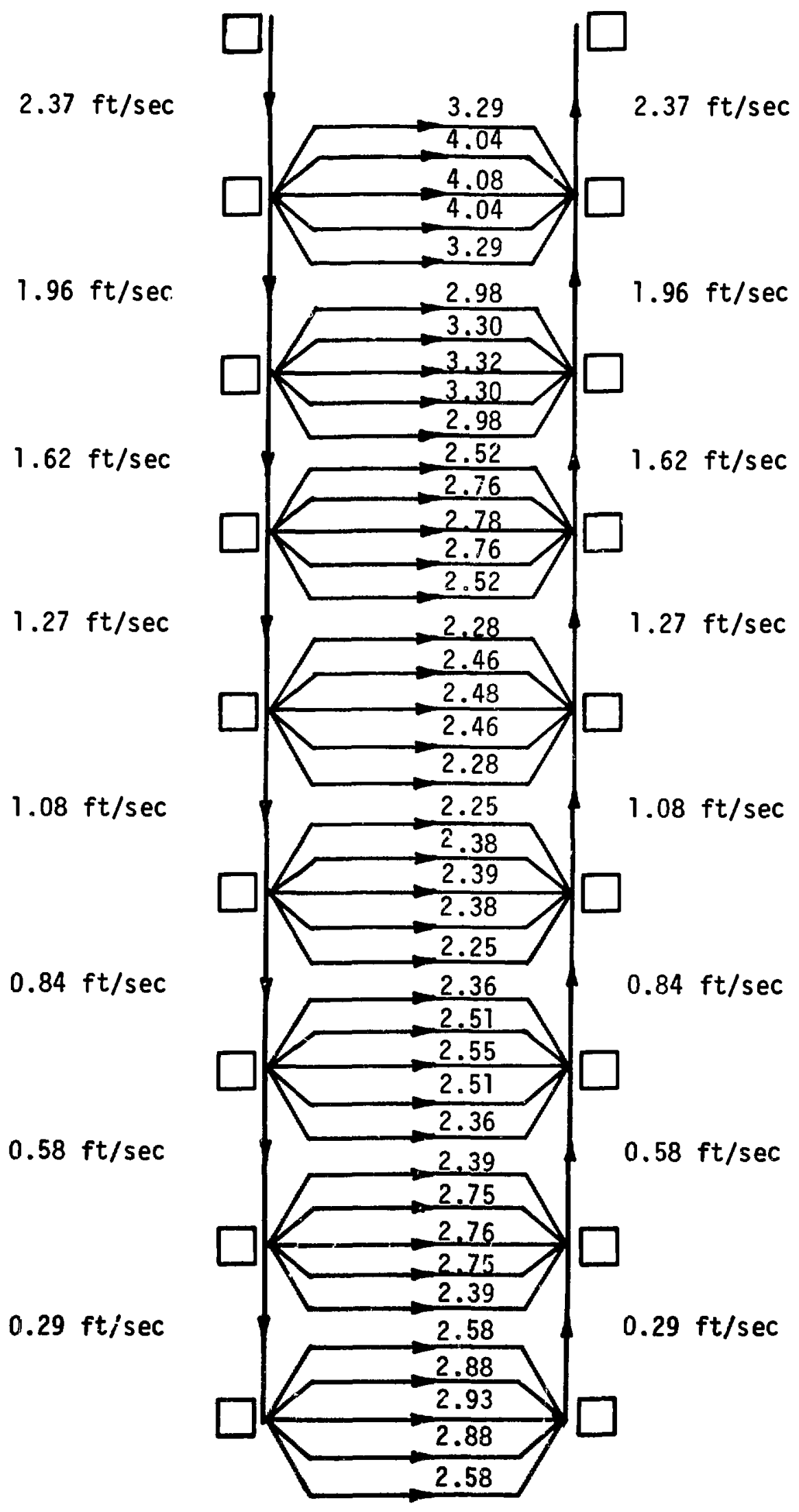

Fig. A.24. Velocity Distribution for $20 x$ Flow. 


\section{References}

[A.1]. Hydraul ic Network Analysis (HYNAL), User Manual, Logicomp Corporation. [A.2]. Flow of Fluids, Engineering Data, Crane Company. 


\section{Appendix B}

Two-Phase Flow Instability in IPNS-1 Target

The IPNS-1 target is designed to operate with a total of 45-gpm coolingwater flow and 35-psia system pressure. Each face of the eight discs contains eight flow channels. The maximum flow in each target disc is estimated at $5 \mathrm{gpm}(15 \mathrm{ft} / \mathrm{sec})$ channel velocity. Hydraulic calculations presented in Appendix A provide information on the flow distribution in various size channels and various flow rates to the target discs for normal operation and accidental events. The first disc in the target, which sees the most severe heat-transfer conditions, is used here for assessing two-phase flow instability.

Based on the set of design calculations shown in Tables B.1 and B.2 and the equilibrium theory of Ishii [B.1 and B.2] together with the nonequilibrium theory of Saha, Ishii, and Zuber [B.3], the onset of the two-phase flow instability in the IPNS-1 target was investigated. It is concluded from the calculations presented in this appendix that the IPNS-1 target will have stable coolant flow conditions under all specified operating conditions.

According to the equilibrium theory of Ishii and Zuber, no significant vapor generation starts until the liquid bulk temperature reaches the saturation value, and beyond that, all the heat added to the system goes to generate vapor. In reality, however, due to a themal-boundary layer near the surface, significant vapor generation is possible, even if the liquid bulk temperature is below saturation. This, in effect, inireases the length of the region occupied by the two-phase mixture, but at the same iime reduces the local rate of vapor generation, because part of the heat added is used to increase the bulk temperature of the liquid. In the nonequilibrium model this important aspect of two-phase flow is included, and it allows the determination of the significance of thermal nonequilibrium in predicting the onset of flow instability. 
Table B.1 Calculated Values of Physical Constants

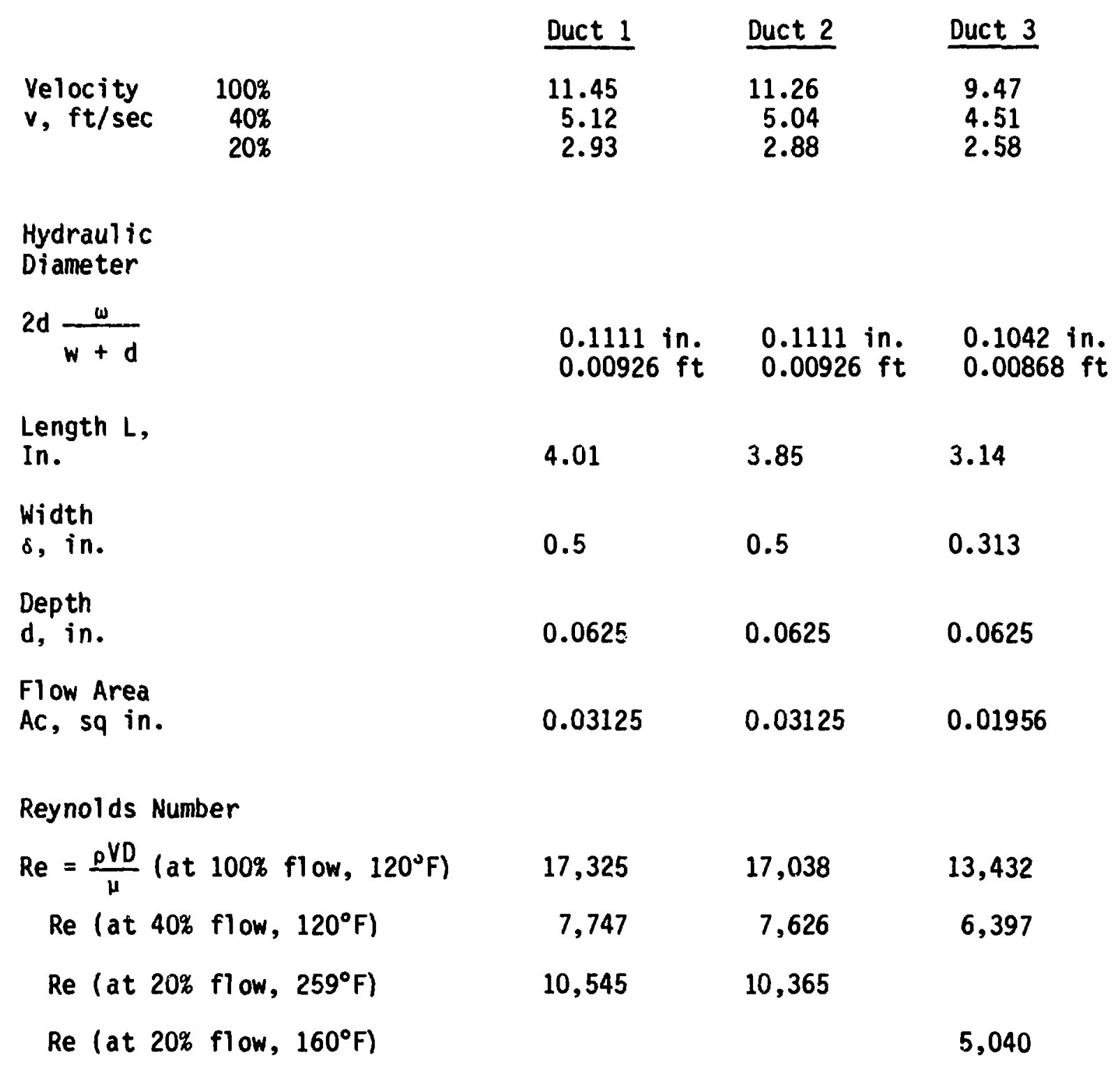

Prandte Number

$\begin{array}{ll}\mathrm{Pr} \text { at } 120^{\circ} \mathrm{F} & 3.64 \\ \mathrm{Pr} \text { at } 160^{\circ} \mathrm{F} & 2.535 \\ \mathrm{Pr} \text { at } 259^{\circ} \mathrm{F} & 1.39\end{array}$


Table B.2 Calculated Values of Physical Constants

\begin{tabular}{llll}
$D^{*}=\frac{D_{H}}{L}$ & Duct 1 & Duct 2 & Duct 3 \\
$\begin{array}{l}\text { Heated } \\
\text { perimeter, in. } \\
\varepsilon=2 \text { (w+d) }\end{array}$ & 0.0276 & 0.0288 & 0.0331 \\
$\begin{array}{l}\text { Friction Factor } \\
f_{s}=\frac{0.184}{\text { (Re) }^{0.2}}\end{array}$ & 1.125 & 0.02722 & 0.02855 \\
$\begin{array}{l}\text { Two-phase } \\
\text { flow friction } \\
\text { Coefficient } \\
C_{m}\end{array}$ & 0.02711 & 0.2722 & 0.02855 \\
$\Delta P=K_{j} \rho_{f} V_{f}^{2}$ & $1.5-2$ & $1.5-2$ & $1.5-2$ \\
$\Delta P=K_{0} \rho V_{f}^{2}$ & 0.25 & 0.25 & 0.25 \\
\hline
\end{tabular}

1. Instability Criteria due to Ishii Theory

Thermal equilibrium is given by

$$
r_{g}=\frac{q_{w}^{\prime \prime} \varepsilon}{A_{c} \Delta i_{f g}}
$$

and the characteristic frequency of the phase change is given by

$$
\Omega=\frac{r_{g} \Delta \rho}{\rho g \rho f}=\left(\frac{q^{\prime \prime} w}{A_{c}{ }^{i} f g}\right)\left(\frac{\Delta \rho}{\rho g \rho f}\right),
$$

where $\quad q_{w}^{\prime \prime}=$ heat flux, Btu/hr $\mathrm{ft}^{2}$,

$A_{C}=$ flow area, $\mathrm{ft}^{2}$,

$\Delta i_{f g}=$ latent heat of vaporization, Btu/lb,

$p f=$ density of liquid, $1 \mathrm{~b} / \mathrm{ft}^{3}$

$p g=$ density of vapor, $1 \mathrm{~b} / \mathrm{ft}^{3}$

and

$\Delta p=$ density change, $1 \mathrm{~b} / \mathrm{ft}^{3}$

$$
\varepsilon=\text { heated perimeter, } \mathrm{ft} \text {. }
$$


As shown in Table B.3, the calculated values of the characteristic frequency $\&$ are so small that the expected oscillations (if any) in the IPNS-1 target will be "Density Oscillations" or "Void-Fraction Oscillations." These types of oscillations are commonly encountered in two-phase media and post no hydraulic-instability problems. Flow excursions are possible, however, when the characteristic frequency is high. The criterion for instability in a two-phase medium as given by Refs. $B 1$ and $B 2$ is

$$
N_{\text {sub }}=\frac{\Delta i_{\text {sub }}}{\Delta i_{f g}} \frac{\Delta \rho}{\rho g},
$$

where $N_{\text {sub }}=$ subcooling number,

$$
\Delta i_{\text {sub }}=i_{f, s a t}-i_{i}=C_{p}\left(T_{\text {sat }}-T_{i}\right)
$$

\begin{tabular}{|c|c|c|c|}
\hline & Duct 1 & Duct 2 & Duct 3 \\
\hline $\begin{array}{l}\text { Two-Phase Flow Friction Factor } \\
f_{m}=C_{m} f_{s}\end{array}$ & 0.05156 & 0.05276 & 0.05322 \\
\hline Liquid Bulk Temperature & $120^{\circ} \mathrm{F}$ & $120^{\circ} \mathrm{F}$ & $120^{\circ} \mathrm{F}$ \\
\hline $\begin{array}{l}\text { Duct Wall Temperature at } \\
\text { Centerl ine }\end{array}$ & $272^{\circ} \mathrm{F}$ & $232^{\circ} \mathrm{F}$ & $166^{\circ} \mathrm{F}$ \\
\hline $\begin{array}{l}\text { Density of Steam } \\
{ }^{\circ} \mathrm{g}, 1 \mathrm{~b} / \mathrm{cft}\end{array}$ & 0.085 & 0.085 & 0.085 \\
\hline $\begin{array}{l}\text { Density of Liquid } \\
\rho_{f}, 1 \mathrm{~b} / \mathrm{cft}\end{array}$ & 61.71 & 61.71 & 61.71 \\
\hline$\lambda=\frac{\Delta \rho}{\rho f^{\rho} g}$ & 11.746 & 11.746 & 11.746 \\
\hline $\begin{array}{l}\text { Characteristic Frequency } \\
\Omega=\lambda \Gamma_{g}\end{array}$ & 3.33 & 3.7 & 1.76 \\
\hline Density Ratio & & & \\
\hline$N_{p}=\frac{\rho g}{p f}$ & 0.00137 & 0.00137 & 0.00137 \\
\hline
\end{tabular}

Table B.3. Two-Phase Flow Physical Properties 
Phase-change number

$$
N_{n c h}=\frac{q_{w}^{\prime \prime}}{A_{c} v_{f} \Delta i f g} \frac{\Delta \rho}{{ }^{\rho} g p_{f}},
$$

where several terms are defined in Table B.3 and B.4. The criterion of stability is [B1, B2].

$$
N_{p c h}-N_{s u b}<\frac{2 K_{i}+\frac{f_{s} C_{m}}{2 D^{\star}}+K_{e}}{1+\frac{1}{2} \frac{{ }_{s} C_{m}}{2 D^{\star}}+2 K_{e}}
$$

From Table B. 2 computations,

$$
\begin{aligned}
& N_{p c h}-N_{\text {sub }} \frac{2 K_{i}+\frac{f_{s} C_{m}}{2 D^{\star}}+2 K_{e}}{1+\frac{1}{2} \frac{f_{s} C_{m}}{2 D^{\star}}+2 K_{e}}=1.74 \\
& \text { or } \quad N_{p c h}-N_{\text {sub }}<1.74 \\
& N_{p c h}<\left(1.74+N_{\text {sub }}\right)
\end{aligned}
$$

\begin{tabular}{|c|c|c|c|}
\hline & Duct 1 & Duct 2 & Duct 3 \\
\hline Surface Tension $\sigma, 1 \mathrm{~b} / \mathrm{ft}$ & $3.65 \times 10^{-4}$ & $3.65 \times 10^{-4}$ & $2.65 \times 10^{-4}$ \\
\hline Standard gravity $\mathrm{g}_{\mathrm{c}}, \mathrm{ft} / \mathrm{sec}^{2}$ & 32.174 & 32.174 & 32.174 \\
\hline Local gravity $\mathrm{g}, \mathrm{ft} / \mathrm{sec}^{2}$ & 32.2 & 32.2 & 32.2 \\
\hline $\begin{array}{l}\text { Liquid-vapor enthalpy difference } \\
h_{f g}, B t u / l b .\end{array}$ & & 939.2 & 939.2 \\
\hline $\begin{array}{l}\text { Liquid heat capacity cf, Btu/lb }{ }^{\circ} F \\
\text { Heat flux, ( } q / A)\end{array}$ & 1.0 & 1.0 & 1.0 \\
\hline $\begin{array}{l}\text { Boiling } \\
\text { BTU/hr in. } 2\end{array}$ & & & \\
\hline \multicolumn{4}{|l|}{$(q / A)$} \\
\hline $\begin{array}{l}\text { Conv., } \\
\text { Btu/hr in. } 2\end{array}$ & & & \\
\hline$q_{w}^{\prime \prime}, B t u / h r$ in. 2 & 580 & & \\
\hline
\end{tabular}

Table B.4. Heat Transfer Properties of Fluid 
The criterion of stability defined above is applicable to large subcooling numbers. From Table B.3, the calculated value of $\Omega$ is 3.33. From Table B.5, the calculated value of $N_{\text {sub }}=108$. From Tables B.4 and B.5, calculations of the phase-change numbers show that for each of the ducts at the three flow conditions in Table B.1,

$$
\text { Nocg Nub, }
$$

and the system is stable as long as the right-hand side of inequality B.6 is positive. As long as inequality $B .9$ is satisfied, the assumed values in inequality $B .6$ do not create a problem. Hence, it is not necessary to calculate the two-phase flow pressure drop in order to predict a better value of two-phase flow-friction coefficient. The length of the nonboiling region is given by

$$
\lambda^{*}=\frac{\lambda}{\ell}=\frac{N_{\text {sub }}}{N_{\text {pch }}}=1.579
$$

2. Instability Criterion due to Saha Theory

According to the nonequlibrium model,

$$
N_{\text {sub } c r}=\frac{\Delta i g}{\Delta i f g} \frac{\Delta \rho}{\rho g}
$$

where for

$$
\begin{aligned}
& P E \leq 70000 \\
& \text { and } \Delta i=0.0022 \frac{q_{w H}^{\prime \prime} D_{p f} C_{p f}}{k_{f}}
\end{aligned}
$$

$\mathrm{Pe} \geq 70000$

$$
\Delta i=154 \frac{q \phi}{\rho_{f} V_{f}} \text {. }
$$

From Table B.5, the Peclet numbers in all ducts are greater than 7000; therefore Eq.. B.12 is applicable.

Since $\Delta i_{\text {sub }}=140$ from Table B.5 and the calculated value of $\Delta i_{\lambda}$ is much smaller,

$\Delta i_{\text {sub }} \ll \Delta i_{\lambda}$. 
Table B.5. Two-Phase Flow Properties

Duct 1

$C_{p}, \mathrm{Btu} / 1 \mathrm{~b}^{\circ} \mathrm{F}$

1.0

Duct 2

Duct 3

$\Delta i_{\text {sub }}$, Btu $/ 1 b=$

$C_{p} T_{\text {sat }}{ }^{-T}$ i

140

140

140

$N_{\text {sub }} \frac{\Delta i_{\text {sub }}}{\Delta i_{f g}} \cdot \frac{\Delta \rho}{P_{g}}$

108

110

108

$N_{p c h}=\frac{q_{w} E \ell}{A_{c} V_{f} \Delta^{i}{ }_{i g}} \cdot \frac{\Delta \rho}{\rho g^{\rho} f}$

$1.88 \frac{q k}{v_{f}}$

$1.97 \frac{\mathrm{ght}}{\mathrm{V}_{\mathrm{f}}}$

$1.765 \frac{q^{4 t}}{v_{f}}$

$K_{f}, B t u / h r f^{\circ} \mathrm{F}$

0.370

0.370

0.370

$P e=\frac{\rho f V_{f} D_{H} C_{p}}{K_{f}}$

82300

$73 i 21$

69971

Nonboiling length

$\lambda^{*}=\frac{\lambda}{l}=\frac{N_{\text {sub }}}{N_{\text {pch }}}$

1.5799

Therefore the boiling boundary (the point where significant vapor generation starts) is given by

$$
\begin{aligned}
& \lambda=\frac{\rho f V_{f} A_{c} \Delta s u b-\Delta i_{\lambda}}{\dot{q}_{w h}^{\prime \prime} \xi_{h}} \\
&=94, \\
& \text { and } \\
& N_{\text {sub }}>N_{\text {sub }}=66.5 . \\
& \text { Since } \\
& N_{\text {sub }}>N_{\text {sub }},
\end{aligned}
$$

the system is stabilizing. 
Thus the stability of the IPNS-I system has been demonstrated based on equilibrium as well as nonequlibrium theory. However, the calculation of the nonboiling length $(x)$ indicaltes that Ishij's criterion is more reasonable to apply; this is the case for large subcooling numbers.

\section{Limitations of the Application.}

1. Boiling heat-transfer calculations are based on averaging heattransfer coefficients calculated in two zones of the surface and are believed to be conservative.

2. Ishij's criterion as applied here is itself considered conservative.

3. Two-phase flow pressure drop was not calculated. Rather, a reasonable two-phase friction coefficient of 2 was assumed.

\section{Conclusions and Recommendations}

Based on the calculations presented in Tables B.1-B.5, Ishii's criterion establishes the stability of the IPNS-1 target coolant flow by a margin of at least 1.59:1. As a result, no flow oscillations are expected. The indicated margin of stability can be greater if some undue conservatism is removed from the boiling-heat-transfer calculations.

Ishii's work indicates that any increase in the frictional pressure drcp in liquid region has a stabilizing effect, whereas the increase in the two-phase region has a destabilizing effect. When the channel geometry is fixed, an increase in the inlet velocity has a significant stabilizing effect for a given heat flux. On the other hand, increased heat flux always results in a smaller stability margin or greater flow instabilities. An increase in the system pressure is a stabilizing effect in terms of improved quality, since at higher pressure the density change due to phase change is less significant. The effect of parallel channels is generally stabilizing compared with that of an identical single channel. Unless all channels are oscillating in phase there will be a damping effect of one channel with respect to others. 


\section{keferences}

[B.1]. M. Ishii, Thermally Induced Flow Instabilities in Two-Phase Mixtures in Thermal Equilibrium, PhD Thesis, Georgia Institute of Technology, June 1971.

[B.2]. M. Ishii, Study on Flow Instabilities in Two-Phase Mixtures, ANL75-23, March 1976.

[B.3]. P. Saha, M. Ishii, and N. Zuber, An Experimental Invest igation of the Thermally-Induced Flow Oscillations in Two-Phase Systems, ASME Paper 75-HT/-6, January 1976. 


\section{Appendix C. Heat-Transfer Coefficients}

\section{Zing-P' Target}

The Zing-P' urarium target is cooled by four parallel, helical flow channels each measuring $1 / 8 \times 1 / 4 \mathrm{in.}$ (set Fig. 3.1). The design flow rate in the Zing- $P$ ' tarqet is $10 \mathrm{gpm}$, which corresponds to a channe 1 velocity of $25.67 \mathrm{fps}$ in each channel. The minimum operable flow rate is designed to be $3 \mathrm{gpm}$.

The convective heat-transfer coefficient may be estimated using the Dittus-Boelter correlation [C. 1] which, for the special case of water, may be expressed in the temperature-dependent form.

$$
h=0.0107(t+100) \mathrm{v} 0.8 / \mathrm{D}^{0.2} \mathrm{Btu} / \mathrm{hr} \text { in. }{ }^{\circ} \mathrm{F} \text {, }
$$

Where $t\left(F^{\circ}\right)$ is the average film temperature $\left(t_{\text {bulk }}+t_{\text {wal }}\right) / 2$, $D$ is the hydraulic diameter (in.), and $V$ is the flow velority (fps).

In the present case, the equivalent hydraulic diameter is $1 / 6 \mathrm{in.;}$ hence, for $10 \mathrm{gpm}$ flow to the target and assuming $t_{f i l m}=t_{b u l k}=86^{\circ} \mathrm{F}$,

$$
\begin{aligned}
h & =0.0107(186)(25.67)^{0.8 /(1 / 6)^{0.2}} . \\
& =38.2 \mathrm{Btu} / \mathrm{hr}-i n .2^{2}{ }^{\circ} \mathrm{F} .
\end{aligned}
$$

Fron the computed Zing- $P^{\prime}$ temperature distributions (see Figs. 5.2 and 5.3), the cooling channel wall is essentially held at the fluid bulk temperature. The target temperatures are thus expected to be largely insensitive to the flow rate (or convective coefficient), provided the flow is adequate to maintain the wall temperature near the bulk temperature. This has been confirmed by computation for the 3-gpm case ( $h=$ $14.6 \mathrm{Btu} / \mathrm{hr}$ in. ${ }^{2 \circ} \mathrm{F}$ ), where it is found that the peak temperature differs by only $1 \%$ from the $10-\mathrm{gpm}$ result.

\section{IPNS-1 Target}

Because of the higher proton beam power density used with the IPNS-1 target as compared with ZING-P', the film temperature is not equal to the 
bulk coolant temperature as in the Zing-P' case. As a result, the IPNS-1 target temperatures are sensitive to flow variations. Moreover, since the film temperature is not known in advance, an iterative approach is necessary to compute a thermally consistent convective coefficient.

\subsection{One-Convective Zone Model}

In the one-zone model, the average film temperature can be deduced from the target energy deposition rate.

From Table 5.3, the energy deposition rate for a 1- $\mu \mathrm{A}$ beam at the target face is $121.2 \mathrm{~W} / \mathrm{in}$. target thickness. For a 1.1-in.-thick target disc, the total power is thus

$$
\begin{aligned}
121.2 \times 1.1 & =1.33 .3 \mathrm{~W} \\
& =455 \mathrm{3tu} / \mathrm{hr} .
\end{aligned}
$$

At full beam power $(22 \mu \mathrm{A})$ and applying the $1.7 / 1.1$ correction factor developed in Sec. 5.2,

$$
P=455 \times 22 \times 1.545=15470 \mathrm{Btu} / \mathrm{hr} .
$$

The area of the two-target disc faces is

$$
2 \times_{\pi}(2.06)^{2}=26.66 \text { in. }{ }^{2} \text {, }
$$

hence, the average heat flux through the face is

$$
q^{\prime \prime}=15470 / 26.66=580 \mathrm{Btu} / \mathrm{hr}-\mathrm{in} .^{2} \text {. }
$$

Since $q=h\left(t_{\text {wall }}-t_{\text {bulk }}\right)$, the average wall temperature $\left({ }^{\circ} \mathrm{F}\right)$ may be computed from

$$
\text { avg. } t_{\text {wall }}=\frac{q}{h}+t_{\text {bulk }}=\frac{580}{h}+120\left({ }^{\circ} \mathrm{F}\right),
$$

and the average film temperature obtained from

$$
\text { avg. } \begin{aligned}
t_{f i l m} & =\left(t_{w a 11}+t_{b u l k}\right) / 2 \\
& =\frac{290}{\hbar}+120\left(F^{\circ}\right),
\end{aligned}
$$

where $h$ is the effective zone convective coefficient in units of Btu/hr-in. ${ }^{\circ}{ }^{\circ} \mathrm{F}$.

Given an initial estimate for the film temperature, the convective 
coefficient $h$ is evaluated from Eq. C.1. The resulting $h$ value is substituted into Eq. C.3 to compute an improved estimate of the film temperature, which in turn is used to recompute $h$. The iterative process is repeated until $h$ and $t_{f i l m}$ converge to thermally consistent values.

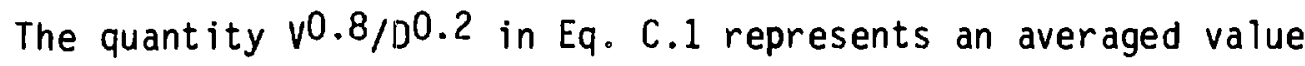
over the face of the target and is computed by summing the values of v0.8/00.2 for each channel, weighted by the ratio of the channel area to the target face area. Tables $C .1$ and $C .2$, respectively, summarize the averaging procedure and the iterative computational scheme to compute $h$, for the five and seven channel cases. Channel areas for the two channel geometries in the one-zone model are summarized in Fig. C.1.

\subsection{Two-Convective-Zone Model}

In the two-zone scheme, the target disc face is divided into two concentric regions: an inner circular zone of 1 -in. radius, and the remaining annular-shaped outer zone (see Fig. C.2). A separate convective coefficient is computed for each zone, based on the averaged channel properties and film temperature for the zone. Again, the average film temperature of each zone is not known in advance; hence, an iterative procedure is required to compute $h$. Unlike the one-zone case, however, an analytic iterative procedure is not possible, since the heat flux in each zone is unknown. It is therefore necessary to initially assume values of $h$ for the inner and outer zones, compute the corresponding target temperature distributions, and reevaluate the zone-convective coefficients. A second and possibly third iteration is usually necessary to converge to acceptably consistent zone film temperatures and convective coefficients.

The next several pages present two-zone convection coefficient calculations for the full- and reduced-fl ow cases, based on the final (converged) average film temperatures. 

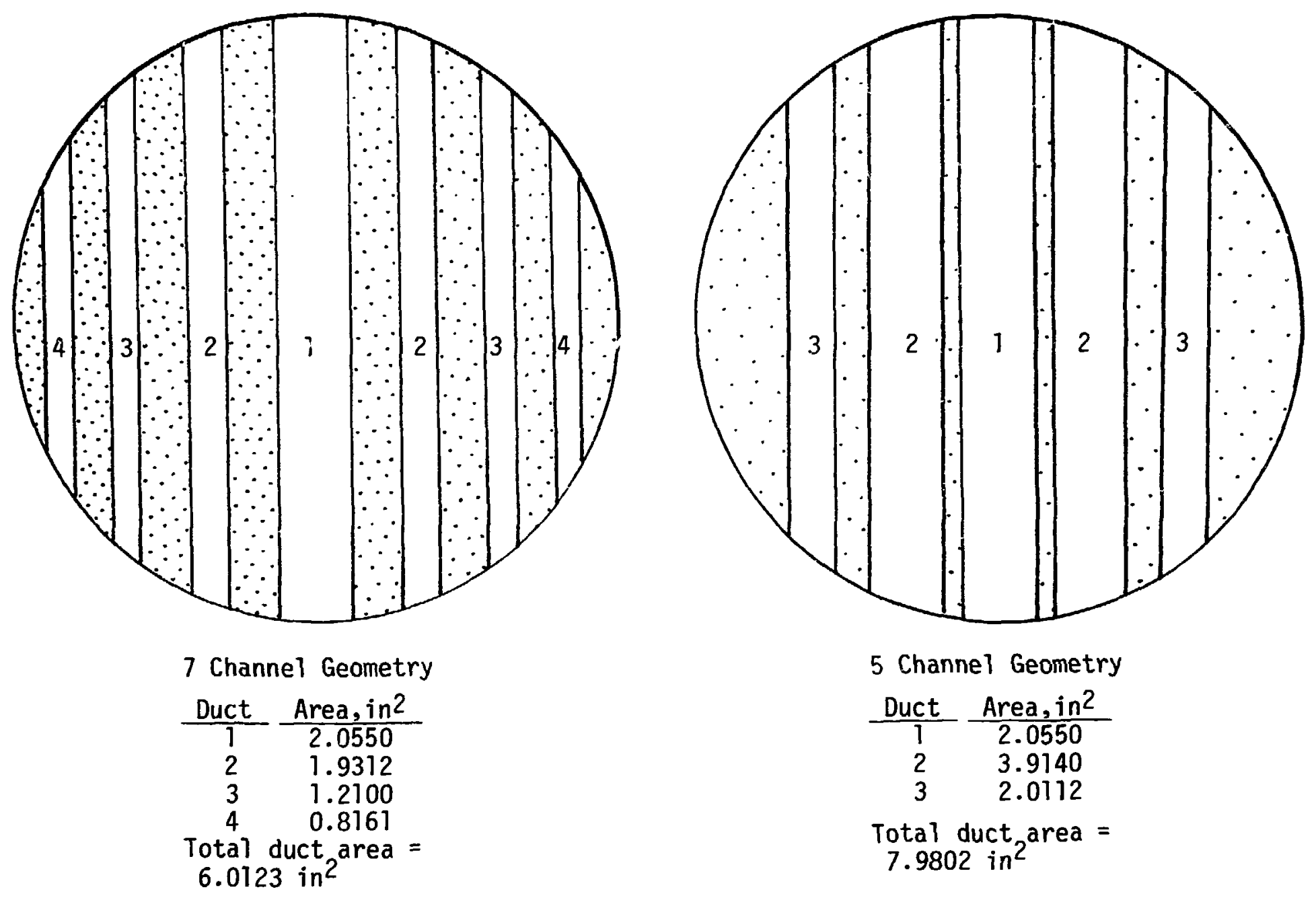

Fig. C.1. One-convective-zone Mode1 (Zone and Duct Areas). 

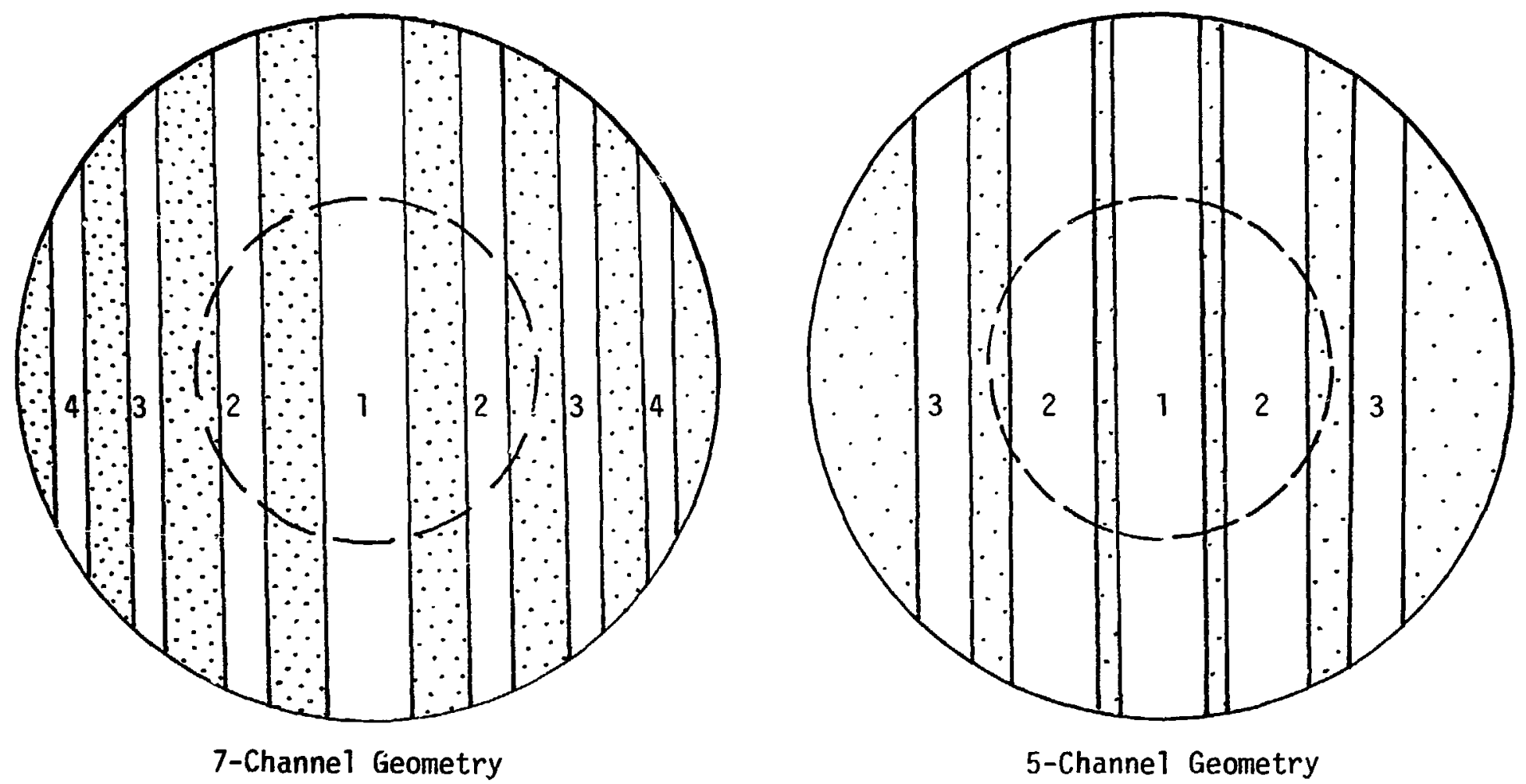

INNER ZONE

Total zone area

$=3.14759$ in 2

OUTER ZONE

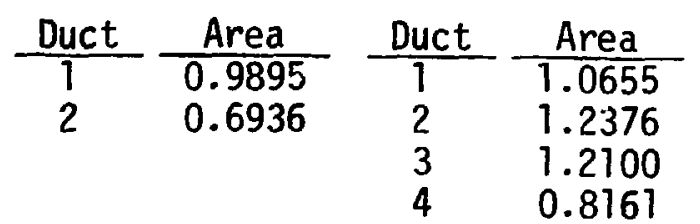

INNER ZONE

Total zone area Total zone area

$=3.14159 \mathrm{in}^{2}=10.19007 \mathrm{in}^{2}$

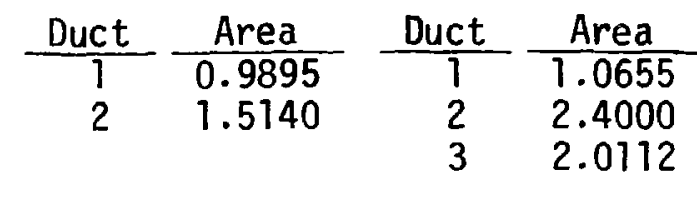

Fig. C.2. Two-convect ive-zone Model (Zone and Duct Areas). 
Table C.1. Five-Channel Geometry; One-Convective-Zone Model

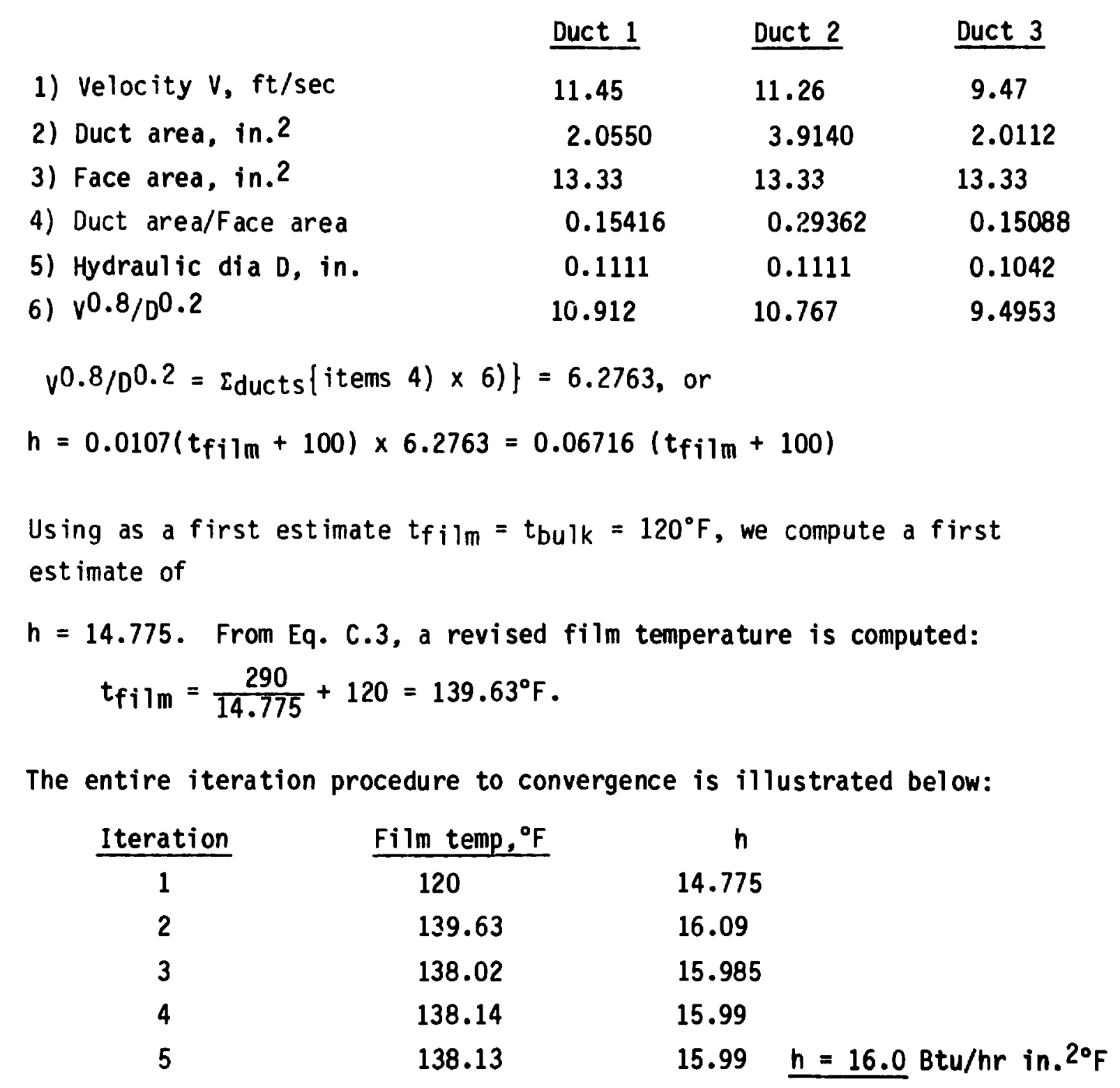


Table C.2. Seven-Channel Geometry; One-Convective-Zone Model

\begin{tabular}{|c|c|c|c|c|}
\hline & Duct 1 & Duct 2 & Duct 3 & Duct 4 \\
\hline 1) Velocity $v, \mathrm{ft} / \mathrm{sec}$ & 13.2 & 13.2 & 13.2 & 13.2 \\
\hline 2) Duct area, in.2 & 2.0550 & 1.9312 & 1.2100 & 0.8161 \\
\hline 3) Face area, in.2 & 13.33 & 13.33 & 13.33 & 13.33 \\
\hline 4) Duct area/Face area & 0.15416 & 0.14488 & 0.090773 & 0.061223 \\
\hline 5) Hydraulic dia $D$, in. & 0.1111 & 0.1001 & 0.09384 & 0.09384 \\
\hline 6) $v 0.8 / 0^{0.2}$ & 12.227 & 12.485 & 12.647 & 12.647 \\
\hline$h=0.0107\left(t_{f i 1 m}+100\right)$ & $\times 5.6160=0$ & $6009 / t_{f}$ & $100)$ & \\
\hline Iteration & Film temp, ${ }^{\circ} \mathrm{F}$ & & & \\
\hline 1 & 120 & & & \\
\hline 2 & 141.94 & & & \\
\hline 3 & 139.95 & & & \\
\hline 4 & 140.11 & & & \\
\hline 5 & 140.10 & & $h=14.4$ & $\mathrm{hr}$ in. $2^{\circ} \mathrm{F}$ \\
\hline
\end{tabular}


Table C.3. Five-Channel Geometry; Two-Convective-Zones, Full-Flow Model Inner Zone $\quad$ Outer Zone

Duct 1 Duct 2 Duct 1 Duct 2 Duct 3

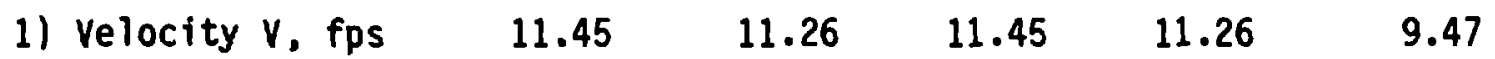

2) Duct area, in. ${ }^{2} \quad 0.9895 \quad 1.5140 \quad 1.0655 \quad 2.4000 \quad 2.0112$

3) Face area, in.2 $\quad 3.1416 \quad 3.1416 \quad 10.190 \quad 10.190 \quad 10.190$

4) Duct area/Face area $0.31497 \quad 0.48192 \quad 0.10456 \quad 0.23553 \quad 0.19737$

5) Hydraulic dia $D$, in. $0.1111 \quad 0.1111 \quad 0.1111 \quad 0.1111 \quad 0.1042$

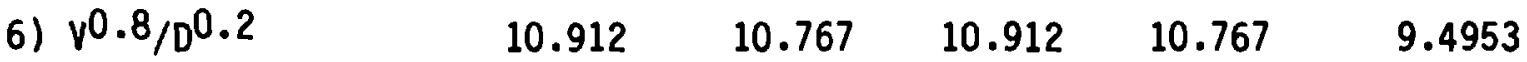

$\left\langle\left(0.8 / 0^{0.2}\right\rangle=\Sigma\right.$ ducts $\{$ items 4) $\left.\times 6)\right\}=8.6258$ (inner zone), 5.5510 (outer)

h Inner zone

avg $T_{\text {wall }}=180$, hence $t_{\text {film }}=(180+120) / 2=150^{\circ} \mathrm{F}$

$h=0.0107 \times(150+100) \times 8.6258=23.1$ Btu $/ \mathrm{hr}$ in. ${ }^{2}$

h outer zone

avg $T_{\text {wall }}=150$, hence $t_{f i l m}=(150+120) / 2=135^{\circ} \mathrm{F}$

$h=0.0107(135+100) \times 5.5510=\underline{14.0} \mathrm{Btu} / \mathrm{hr}$ in. ${ }^{2}$ 
Table C.4. Seven-Channel Geometry; Two-Convective-Zones, Flow Model

\begin{tabular}{lccccccc} 
& \multicolumn{3}{c}{ Inner Zone } & & \multicolumn{3}{c}{ Outer Zone } \\
& Duct 1 & Duct 2 & Duct 1 & Duct 2 & Duct 3 & Duct 4 \\
1) Velocity V, fps & 13.2 & 13.2 & 13.2 & 13.2 & 13.2 & 13.2 \\
2) Duct area, in.2 & 0.9895 & 0.6936 & 1.0655 & 1.2376 & 1.2100 & 0.8161 \\
3) Face area, in.2 & 3.1416 & 3.1416 & 10.190 & 10.190 & 10.190 & 10.190 \\
4) Duct area/Face area & 0.3150 & 0.2208 & 0.1046 & 0.1215 & 0.1187 & 0.0801 \\
5) Hydraulic dia D, in. & 0.1111 & 0.1001 & 0.1111 & 0.1001 & 0.0938 & 0.0938 \\
6) V0.8/D0.2 & 12.227 & 12.485 & 12.227 & 12.485 & 12.647 & 12.647
\end{tabular}

$\left\langle v^{0.8} / 0^{0.2}\right\rangle={ }^{2}$ ducts $\{$ items 4$\left.\left.) \times 6\right)\right\}=6.6082$ (inner zone), 5.3101 (outer)

h Inner zone

avg $T_{\text {wall }}=200^{\circ} \mathrm{F}$, hence $t_{f i 1 m}=(200+120) / 2=160^{\circ} \mathrm{F}$

$h=0.0107 \times(160+100) \times 6.6082=18.4 \mathrm{Btu} / \mathrm{hr}$ in. 2

h Outer zone

avg $T_{\text {wall }}=150^{\circ} \mathrm{F}$, hence $t_{f i 1 m}=(150+120) / 2=135^{\circ} \mathrm{F}$

$h=0.0107(135+100) \times 5.3101=13.4 \mathrm{Btu} / \mathrm{hr}$ in..$^{\circ} \mathrm{F}$ 
Table C.5. Five-Channel Geometry; Two-Convective-Zones, Flow Model (40\% flow)

Inner Zone

Outer Zone

Duct 1 Duct 2 Duct 1 Duct 2 Duct 3

1) Velocity $V$, fps

5.12

5.04

5.12

5.04

4.51

2) Hydraulic dia $D$, in.

0.1111

0.1111

0.1111

0.1111

0.1042

3) $v 0.8 / D^{0.2}$

5.7316

5.6598

5.7316

5.6598

5.2453

4) Duct area, in. 2

0.9895

1.5140

1.0655

2.4000

2.0112

5) Zone area, in. 2

3.1416

3.1416

10.190

10.190

10.190

6) Duct area/Zone area

0.31497

0.48192

0.10456

0.23553

0.19737

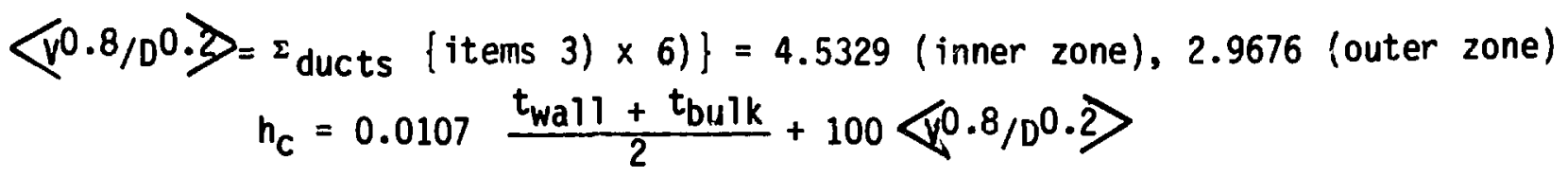

The inner zone is the central area with a 1-in. radius and the outer zone is the area surrounding this central zone. The bulk temperature $t_{b u l k}$ is assumed to be $120^{\circ} \mathrm{F}$, but iterations are required to determine the wall temperature. Only the results of the final iteration are given in the following.

Inner Zone. After iterating, the average wall temperature for the inner zone is obtained as $t_{\text {wall }}=230^{\circ} \mathrm{F}\left(\right.$ Max. $\left.\mathrm{T}_{\text {wall }}=259.5^{\circ} \mathrm{F}\right)$. We then get $h=13.19 \mathrm{Btu} / \mathrm{hr}-\mathrm{in} .2^{\circ} \mathrm{F}$.

Outer Zone. After iteration, the average wall temperature for the outer zone is obtained as $t_{w a 11}=174^{\circ} \mathrm{F}$. Hence,

$$
\mathrm{h}=7.81 \mathrm{Btu} / \mathrm{hr}-\mathrm{in} .2^{\circ} \mathrm{F} \text {. }
$$


2.3 Five-Channel Geometry; Two-Convective Zones, Reduced Flow Model (20\% Flow)

The area is divided into two zones. The inner zone is the central area with a 1-in. radius, and the outer zone is the area surrounding this central zone. The objective here is to study the flow boiling in the central zone and compare the heat flux to the critical heat flux. The boiling process may be classified as either pool boiling or flow boiling. Pool boiling involves natural convection, and the formation of vapor is due to heat added to the liquid by a surface in contact with or submerged within the liquid. Flow boiling involves forced convection and is applicable to our case.

Both pool boiling and flow boiling have nucleate boiling and film boiling regimes and a transition zone from nucleate to stable film boiling. Different correlations must be used in the nucieate-boiling and film-boiling regimes.

For nucleate flow boiling, as long as the liquid wets the wall, the empirical equation of Davis and David [C.5] may be used. This equation is given by

$$
\frac{h D}{K \ell}=0.06 \frac{\rho \ell}{\rho V}^{0.28} \frac{\mathrm{DGX}}{\mu \ell}^{0.87} \operatorname{Pr}_{\ell}^{0.4} \text {, }
$$

where $x$ is the quality. Another correlation for nucleate flow boiling is that of Chen [0.2]. For film flow boiling, Bromley's correlation [C.2] is recommended. All the flow boiling correlations require knowledge of the quality or void fraction, wich is not available in our case unless the two-phase flowconservation equations are solved. Hence, the procedure followed here is given below.

It is assumed that the heat flux is less than the critical value, and hence nucleate flow bolling exists. Whether this assumption is satisfied is verified later. Following the method of Rohsenow [C.3], the total heat flex is separated into two parts, one a boiling flux $q_{B} / A$ and the other a convective flux $q_{c} / A$. Then the total heat flux is given by

$$
q_{\text {total }}=q_{c}+q_{b} \text {, i.e., } h=h_{c}+h_{b} \text {. }
$$


For the convective coefficient $h_{c}$, the Dittus-Boelter [C.1] correlation is used. This correlation is given by

$$
\mathrm{Nu}=0.023 \mathrm{Re}^{0.8 \mathrm{Pr}} 0.4 \text {. }
$$

For water, the physical properties may be combined into one temperature-dependent expression as

$$
h_{c}=0.0107\left(\frac{t_{\text {wall }}+t_{\text {bulk }}}{2}\right)+100 \frac{v^{0.8}}{0^{0.2}} B t u / h r-i n .{ }^{\circ} \mathrm{F},
$$

where $V$ is in $\mathrm{ft} / \mathrm{sec}, D$ is in inches, and the temperature is in ${ }^{\circ} \mathrm{F}$. It is assumed that in the central zone, $t_{b u l k}$ is the saturation temperature $T_{s}$ of water at a pressure of 35 psia $\left(t_{b u l k}=T_{s}=259^{\circ} \mathrm{F}\right)$.

To obtain the boiling flux, the nucleate pool boiling correlation is used. This correlation is given by Eq. (C.5)

$$
\frac{q_{b}}{A}=\left(\frac{C_{\ell} \Delta}{C_{s} h_{f g}{ } p_{l}^{1.7}}\right)^{3.03} \mu_{\ell} h_{f g} \frac{g\left(\rho_{\ell}-\rho_{v}\right)}{g_{c} \sigma}
$$

where the properties evaluated at $259^{\circ} \mathrm{F}$ are given in the following:

$$
\begin{aligned}
& C_{\ell}=\text { specific heat of saturated liquid }=1.0165 \mathrm{Btu} / 1 \mathrm{~b}_{\mathrm{m}}{ }^{\circ} \mathrm{F} \text {, } \\
& \Delta T:=T_{W}-T_{s} \text {, where } T_{W} \text { and } T_{S} \text { are the wall and saturation temperatures, } \\
& C_{s f}=\text { empirical constant, which depends upon the nature of the } \\
& \text { heating surface-fluid combination } \\
& =0.0132 \text { for water on mechanically poilished stainless steel, } \\
& H_{f g}=1 \text { atent heat of vaporization }=939.2 \mathrm{Btu} / 1 \mathrm{~b}_{\mathrm{III}} \\
& \mathrm{Pr}_{\ell}=\text { Prandtl number of saturated liquid }=1.39 \text {, } \\
& \mu_{\ell}=\text { viscosity of } 1 \text { iquid }=0.5421 \mathrm{~b}_{\mathrm{m}} / \mathrm{hr}-\mathrm{ft} \text {, } \\
& \mathbf{g}=\text { gravitational acceleration }=32.3 \mathrm{ft} / \mathrm{sec}^{2} \text {, } \\
& g_{c}=\text { conversion factor }=32.21 b_{m} \mathrm{ft} / 1 b_{f} \sec ^{2} \text {, } \\
& \rho_{\ell}=\text { density of saturated } 1 \text { iquid }=58.514 \mathrm{lb}_{\mathrm{m}} / \mathrm{ft}^{3} \text {, } \\
& \rho_{V}=\text { density of saturated vapor }=0.084 \mathrm{lbm} / \mathrm{ft}^{3} \text {, }
\end{aligned}
$$

and

$$
\begin{aligned}
\sigma & =\text { surface tension of liquid to vapor interface } \\
& =35.95 \times 10^{-4} 1 \mathrm{~b}_{\mathrm{f}} / \mathrm{ft}
\end{aligned}
$$




$$
\begin{aligned}
& \text { Hence, we obtain } \\
& \qquad \begin{aligned}
\frac{q_{b}}{A} & =\left(\frac{1.0165 \Delta T}{0.0132 \times 939.2 \times 1.391 .7}\right)^{3.03}(0.542 \times 939.2) \\
& \times\left(\frac{32.2(58.514-0.084)}{32.2 \times 35.95 \times 10^{-4}}\right)^{1 / 2} \\
& =6.0855076\left(T_{W}-T_{s}\right)^{3.03} \mathrm{Btu} / \mathrm{hr}-\mathrm{ft} .2 \\
& =0.0422605\left(\mathrm{~T}_{\mathrm{W}}-\mathrm{T}_{\mathrm{s}}\right)^{3.03 \mathrm{Btu} / \mathrm{hr}-\mathrm{in} .2}
\end{aligned}
\end{aligned}
$$

The area $A$ in the foregoing equation is the area of ducts 1 and 2 in the inner zone (i.e., $A=2.5035$ in. $^{2}$ ). However, the total area of the inner zone is $3.1416 \mathrm{in.}^{2}$. Hence, for the inner zone

$$
\begin{aligned}
n_{b} & =\frac{q_{b}}{T_{w}-T_{s}} \frac{2.5035}{3.1416} \\
& =0.033677\left(T_{W}-T_{s}\right) 2.03 \mathrm{Btu} / \mathrm{hr}-\mathrm{in} .{ }^{2 \circ} \mathrm{F},
\end{aligned}
$$

where $T_{S}=259^{\circ} \mathrm{F}$ and the wall temperature $T_{W}$ is not known and is to be determined iteratively. The determination of $h_{c}$ is given in Table C.6.

\section{Blocked Center Channel Accident}

This accident condition assumes no coolant in the hottest (center) channel of the five-channel geometry. The calculation uses essentially a three-zone model, with the convective coefficient set to zaro in a 0.75-in.-dia. circle centered in the disc face (see Fig. C.3). The calculation of zone convective coefficients for the blocked center channel case is summarized in Table C.7.

For critical heat flux in flow boiling, the Westinghouse correlation and the General Electric correlation are available, but they require knowledge of quality that is not available in our case. Lowdermilk, Lanzo, and Siegel [C.3] reported measurements of burnout heat fluxes for water at pressures between 1 and $7 \mathrm{~atm}$ in tubes of 0.051 to $0.88-\mathrm{in}$. diameter, length-todiameter ratios 25 and-250, and velocities of $0.1-98 \mathrm{ft} / \mathrm{sec}$. Inlet conditions ranged from a liquid subcooled $140^{\circ} \mathrm{F}$ to a saturated liquid. Burnout heat fluxes were observed in the range between $1 \times 10^{6}$ and $13 \times 10^{6} \mathrm{Btu} / \mathrm{hr}^{-\mathrm{ft}^{2}}$. 
Table C.6. Five-Channel; Two-Convective Reduced Fl ow Model (20\% flow)

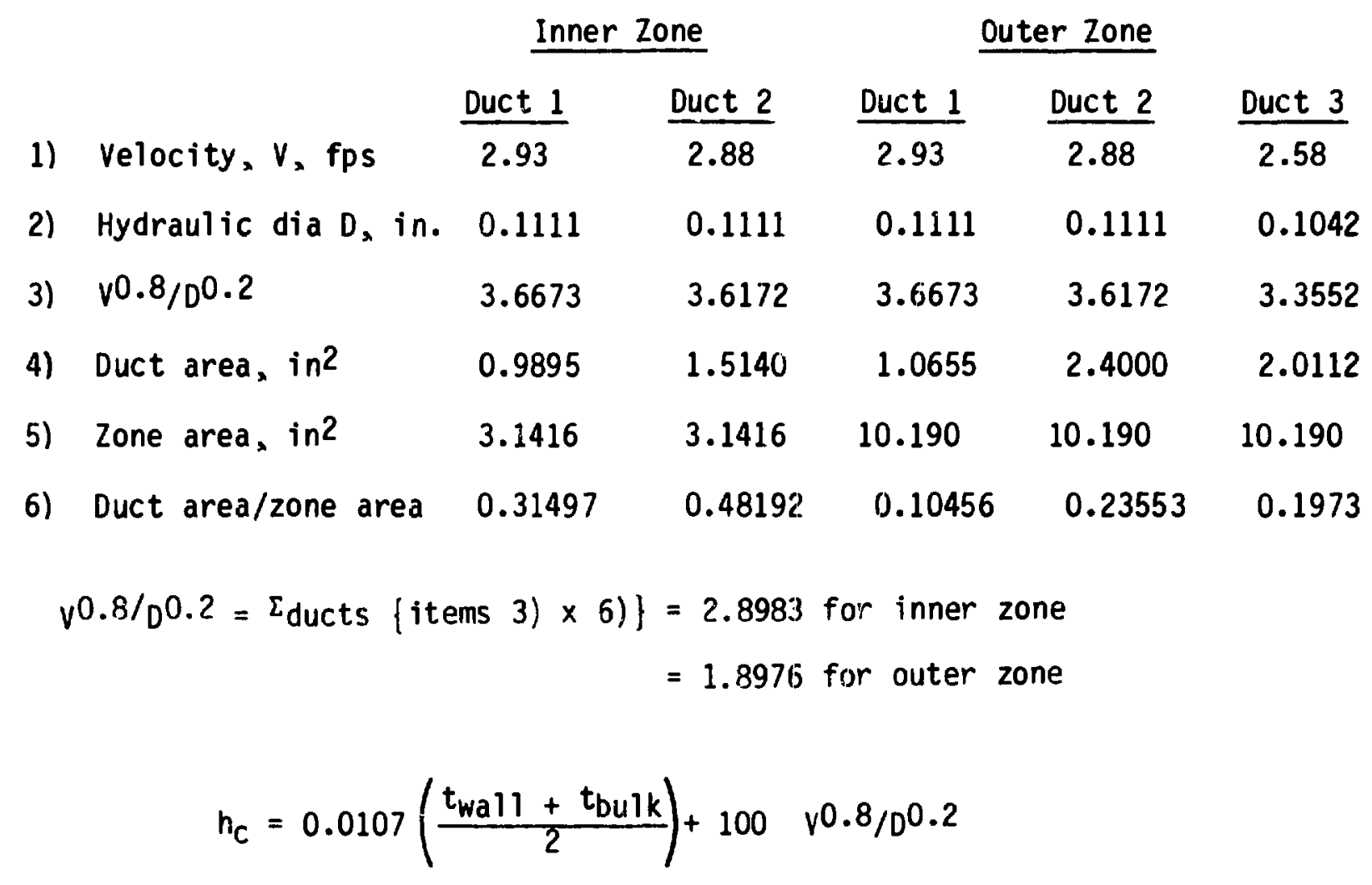

Inner Zone. After iterating, the average wall temperature for the inner zone is obtained as $t_{w a 11}=290^{\circ} \mathrm{F}$. Since $t_{b u l k}$ is assumed as saturation temperature of $259^{\circ} \mathrm{F}$, we obtain

$$
\begin{aligned}
& h_{c}=11.6 \mathrm{Btu} / \mathrm{hr}-i n .2^{\circ} \mathrm{F} . \\
& h_{b}=35.9 \mathrm{Btu} / \mathrm{hr}-i n .2^{\circ} \mathrm{F} .
\end{aligned}
$$

and $h=h_{c}+h_{b}=47.5$ Btu $/ \mathrm{hr}$ in..$^{\circ} \mathrm{F}$

Outer Zone. for this zone $t_{\text {bulk }}$ is assumed as $160^{\circ} \mathrm{F}$ and boiling heat transfer is not considered. After iterating, we obtain $t_{\text {wall }}=233^{\circ} \mathrm{F}$.

Hence,

$$
h=h_{c}=6.0 \mathrm{Btu} / \mathrm{hr} \text { in. }{ }^{\circ} \mathrm{F} \text {. }
$$




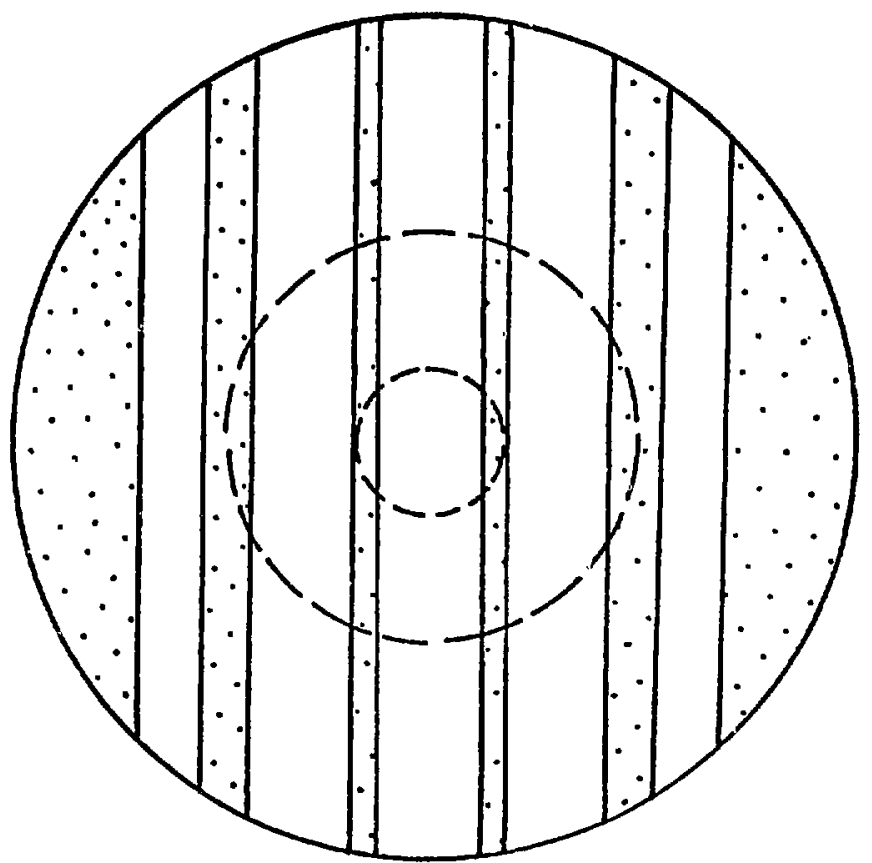

Inner zone: $\mathrm{h}=0$

Total zone area $=0.4418$ in. 2

$r=0.375$

Channel area $=0.3450 \mathrm{in.}$ ?

Middle zone:

Total zone area $=2.6998$ in. 2

$r=1 \mathrm{in}$.

Center channel area $=0.6445$ in. 2

Next channel area $=1.5140$ in. 2

Outer zone:

Same as two-zone model.

Fig. C.3. Blocked Center Channel Case; Three-zone Geometry. 
Table C.7. Seven-Channel; Biocked Center Channel

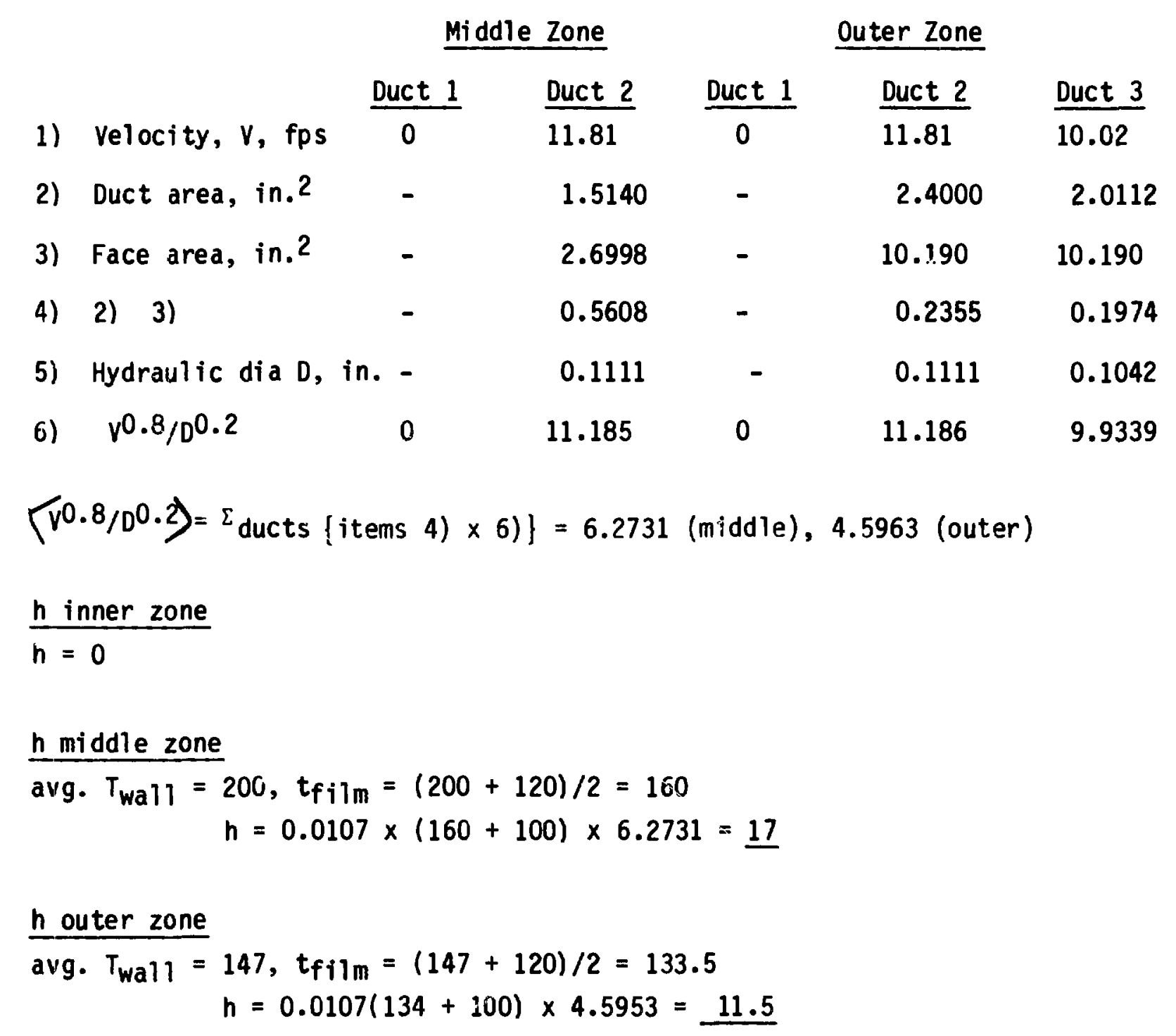


Their correlation is as follows:

$$
\begin{aligned}
& \left(\frac{q}{A}\right)_{\text {crit }}=\frac{270 G 0.85}{D^{0.2}\left(\frac{L}{D}\right)^{0.85}} \text { for } 1 G /\left(\frac{L}{D}\right)^{2} 150 \\
& \left(\frac{G}{A}\right)_{\text {Crit }}=\frac{1400 G 0.5}{D^{0.2}\left(\frac{L}{D}\right)^{0.15}} \text { for } 150 G /\left(\frac{L}{D}\right)^{2} 10,000,
\end{aligned}
$$

where $\left(\frac{q}{A}\right) \begin{aligned} & \text { is the critical heat flux in } B t u / h r \\ & \text { crit }\end{aligned}$ diameter in feet and $G$ is the mass flux in $1 b / h_{r}-f^{2}$. For the central duct, letting $L=2 \mathrm{in}$, $D=0.1111 \mathrm{in}$, and $V=2.93$ for $20 \% \mathrm{flow}$, we get

$$
G /\left(\frac{L}{D}\right)^{2}=\frac{2.93 \times 3600 \times 58.514}{\left(\frac{2}{0.1111}\right)^{2}}=1,904.95
$$

Hence, the correlation we use is

$$
\left(\frac{q}{A}\right)_{\text {crit }}=\frac{1400 G 0.5}{0^{0.2}\left(\frac{L}{D}\right)^{0.15}}
$$

Hence, for the central duct $::$ obtain

$$
\begin{aligned}
& \left(\frac{\mathrm{q}}{\mathrm{A}}\right)_{\mathrm{crit}}=\frac{1400 \mathrm{G} 0.5}{\left(\frac{0.1111}{12}\right)^{0.2}\left(\frac{2}{0.1111}\right)^{0.15}} \\
& \quad=2,314.9 \mathrm{G} 0.5
\end{aligned}
$$

where $G=\rho V, l b / h r-f^{2}$

Using the corresponding values of densities and velocities for the central duct in the inner zone, we get the following results:

Full flow: $\left(\frac{9}{A}\right)_{\text {crit }}=3.6925 \times 10^{6} \mathrm{Btu} / \mathrm{hr} \mathrm{ft}^{2}=25,643 \mathrm{Btu} / \mathrm{hr}$. in.2. 


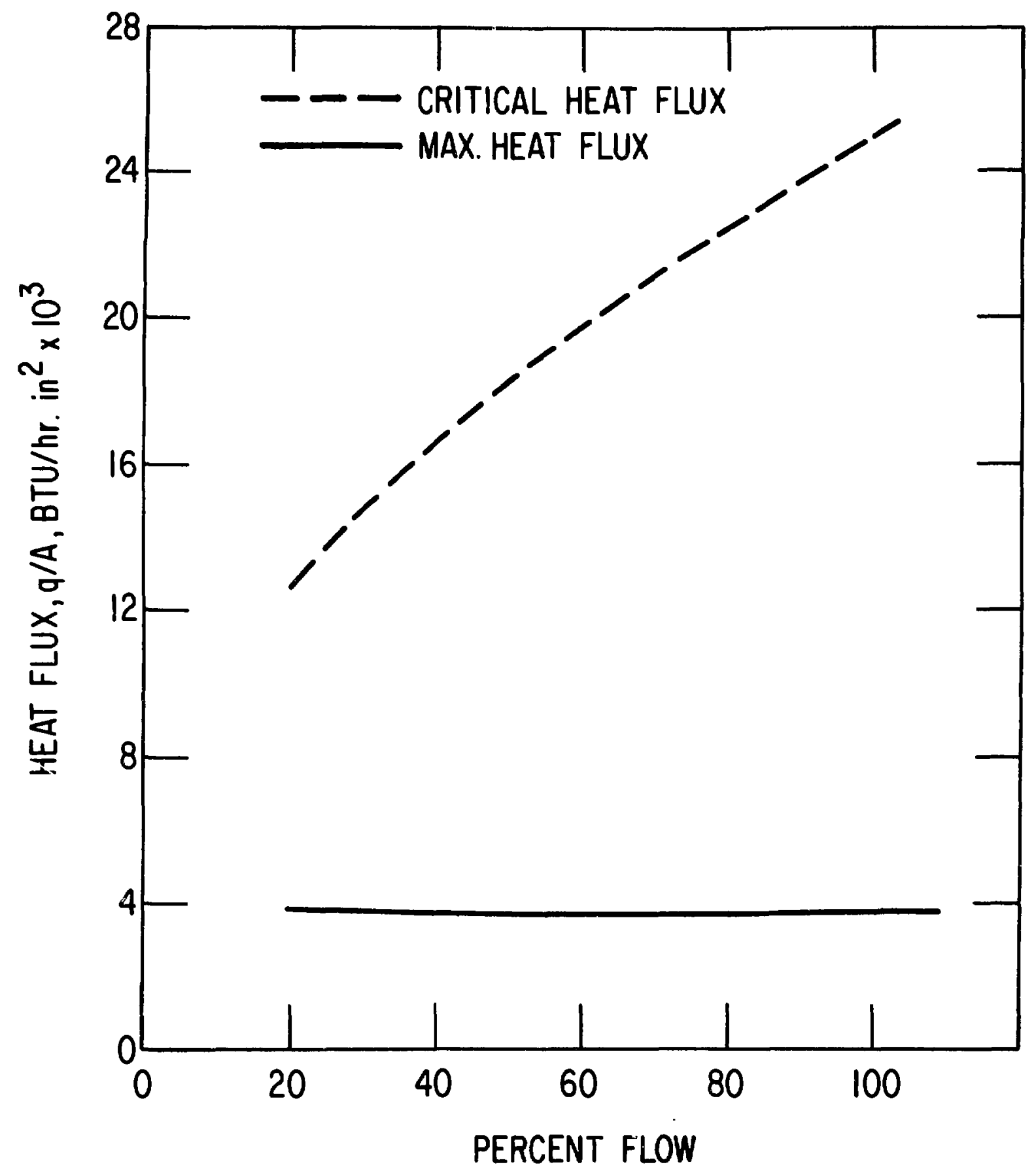

Fig. C.4. Critical Heat Flux in IPNS-I Target with Reduced Flows. 


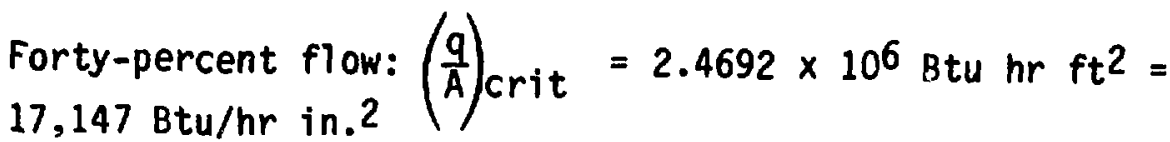
Twenty-percent flow: $\left(\frac{\mathrm{q}}{\mathrm{A}}\right)_{\text {crit }}=1.8186 \times 10^{6} \mathrm{Btu} / \mathrm{hr} \mathrm{ft}^{2}=$
$12,629 \mathrm{Btu} / \mathrm{hr}$ in. 2

These values of the critical heat flux are considerably higher than the maximum heat flux for all flow conditions. These results are shown in Fig. C.4.

The critical heat flux in flow boiling is shown in Fig. C.5. It is noted that $\frac{\mathrm{q}}{\mathrm{A}}$ ranges from $1 \times 10^{6} \mathrm{Btu} / \mathrm{hr} \mathrm{ft}^{2}$ to $13 \times 10^{6} \mathrm{Btu} / \mathrm{hr} \mathrm{ft}^{2}$ depending upon the subcooling and flow velocity. For our case, the velocity is $2.93 \mathrm{ft} / \mathrm{sec}$ and the critical heat flux is about $1 \times 10^{6} \mathrm{Btu} / \mathrm{hr} \mathrm{ft}^{2}$. For the central zone, the maximum heat flux is

$\left(\frac{q}{A}\right)=1942.3 \mathrm{Btu} / \mathrm{hr}$ in. ${ }^{2}=0.279693 \times 10^{6} \mathrm{Btu} / \mathrm{hr}-\mathrm{ft}^{2}$.

Since this flux is less than the critical flux, it is confirmed that any boiling is nucleate boiling.

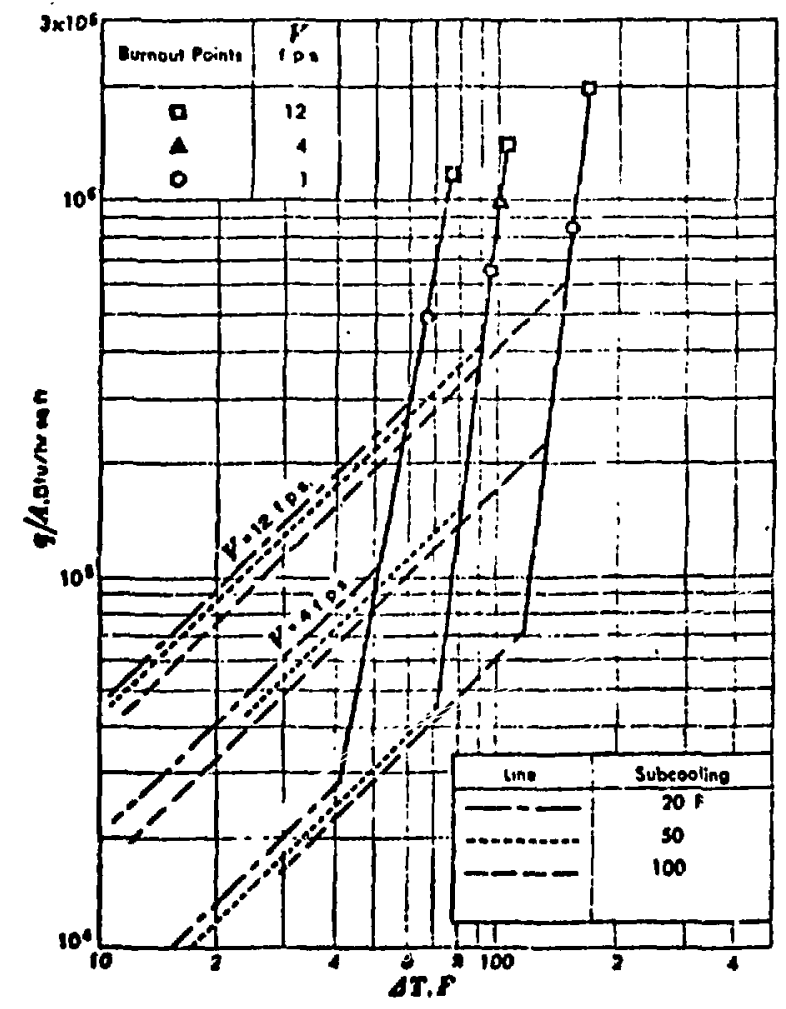

Fig. 0.5

Typical boiling data for subcooled forced convection--heat flux vs. temperature difference between surface and fluid bulk [C.4]. 


\section{References}

[C.1]. F. W. Dittus and L. M. K. Boelter, Univ. of Calif. (Berkeley) Pub. Eng., Vol 2, p. 443, 1930.

[C.2]. F. Kreith, Principles of Heat Transfer--3rd Ed., Harper and Row, New York, 1973.

[C.3]. M. M. Wakil, Nuclear Heat Transport, International Text Book Co., Scranton, Pennsylvania.

[C.4]. W. M. McAdams, W. E. Kennel, C. S. Minden, R. Carl, P. M. Picarnell, and J. E. Drew, "Heat Transfer at High Rates to Water with Surface Boiling," Ind. Eng. Chemistry, Vol. 41, 1945.

[C.5]. E. J. Davis and M. M. David, "Two-Fhase Gas-Liquid Convection Heat Transfer," I. and E. C. Fundamentals, Vol. 3, pp. 11-118, 1964. 
Appendix D. Materials Physical and Mechanical Properties

1. Uranium
a. Melting point $-2066^{\circ} \mathrm{F}$
b. Allotropic structures
Orthohombic $(\alpha) .<1222^{\circ} \mathrm{F}$
Tetragonal $(\beta), 1222$ to $1416^{\circ} \mathrm{F}$
Body-centered cubic $(\gamma),>1416^{\circ} \mathrm{F}$
c. Heat Capacity, C
$0^{\circ} \mathrm{F} \quad 200^{\circ} \mathrm{F} \quad 400^{\circ} \mathrm{F} \quad 600^{\circ} \mathrm{F} \quad 800^{\circ} \mathrm{F}$
(Btu/1b. $-{ }^{\circ} \mathrm{F}$ )
0.0270
0.290
0.0313
0.0340
0.0371

d. Thermal conductivity, $K$

$0^{\circ} \mathrm{F} \quad 200^{\circ} \mathrm{F} \quad 400^{\circ} \mathrm{F} \quad 600^{\circ} \mathrm{F} \quad 800^{\circ} \mathrm{F}$

$$
\left(\mathrm{Btu} / \mathrm{hr} \cdot \mathrm{cm} \cdot{ }^{\circ} \mathrm{F}\right)
$$
$\begin{array}{lllll}1.217 & 1.292 & 1.383 & 1.496 & 1.625\end{array}$

e. Modulus of elasticity, $E$

$E(p s i)=29.04 \times 10^{6}-1.08 \times 10^{4} \mathrm{~T}^{\circ} \mathrm{F}$

f. Poisson's ratio, $v$

$$
v=0.2087
$$

g. Shear modulus, $G$ *

$$
G(p s i)=12.01 \times 10^{6}-4.48 \times 10^{3} \mathrm{~T}^{\circ} \mathrm{F}
$$

h. Density, $p$

$$
\rho\left(1 \mathrm{~b} / \text { in. }{ }^{3}\right)=0.6902-2.203 \times 10^{-5} \mathrm{~T}^{\circ} \mathrm{F}
$$

\begin{tabular}{|c|c|c|}
\hline Temperature & Yield Strength & Tensile Strength \\
\hline$\left({ }^{\circ} \mathrm{F}\right)$ & (psi) & (psi) \\
\hline 70 & 48,400 & 123,000 \\
\hline 700 & 21,300 & 31,400 \\
\hline
\end{tabular}

i. Thermal expansion coefficient, $\alpha$

$$
a\left(\text { in./in. }-{ }^{\circ} \mathrm{F}\right)=8.17 \times 10^{-6}+1.7 \times 10^{9} \mathrm{~T}
$$

j. Tensile properties 


\section{Zirconium}

a. Heat capacity, C

$$
c\left(\mathrm{cal} / \mathrm{g} /{ }^{\circ} \mathrm{C}\right)=0.070+3.6 \times 10^{-5} \mathrm{~T}
$$

b. Thermal conductivity, $k$

$K\left(B t u / h r\right.$. in. $\left.{ }^{\circ} \mathrm{F}\right)=8.0+0.0032 T$

c. Modulus of Elasticity, $E$

$E(p s i)=13.9 \times 10^{6}\left(70^{\circ} \mathrm{F}\right)$

d. Poisson's ratio, $v$

$\nu=0.33$

e. Shear Modulus, $G^{*}$

$G(p s i)=5.24 \times 10^{6}$

f. Density, $\rho$

$$
\rho\left(1 b / \text { in. }{ }^{3}\right)=0.23
$$

g. Thermal expansion coefficient, $\alpha$ $\alpha\left(\right.$ in. $/$ in. $\left.-^{\circ} \mathrm{F}\right)=3.19 \times 10^{-6}+17.0 \times 10^{-10 \mathrm{~T}}$ 
3. Zircaloy-2*

a. Heat capacity, C

$\begin{array}{llll}0^{\circ} \mathrm{F} & 200^{\circ} \mathrm{F} & 400^{\circ} \mathrm{F} & 600^{\circ} \mathrm{F} \\ & \left(\mathrm{Btu} / 1 \mathrm{~b}-{ }^{\circ} \mathrm{F}\right) & \\ 0.0695 & 0.0748 & 0.0785 & 0.0810\end{array}$

b. Thermal conductivity, $K$

$K\left(\right.$ Btu $\cdot$ hr $\cdot$ in. $\left..0^{\circ} \mathrm{F}\right)=8.0+0.0032 \mathrm{~T}$

c. Modulus of Elasticity, $E$

$E(p s i)=14 \times 10^{6}-5.5 \times 10^{3} \mathrm{~T}^{\circ} \mathrm{F}$

d. Poisson's ratio, $v$

$$
v=0.31
$$

e. Shear modulus, $G \star \star$

$$
G(p s i)=5.344 \times 10^{6}-2.107 \times 10^{3} \mathrm{~T}^{\circ} \mathrm{F}
$$

f. Density, $\rho$

$$
\rho\left(1 \mathrm{~b} / \text { in. }^{3}\right)=0.235-3.72 \times 10^{-6} \mathrm{~T}^{\circ} \mathrm{F}
$$

g. Thermal expansion coefficient, $\alpha$

$$
\alpha\left(\text { in. } / \text { in. }-{ }^{\circ} \mathrm{F}\right)=3.11 \times 10^{-6}+9.5 \times 10^{-10} \mathrm{~T}
$$

* Zircaloy-2 is a zirconium alloy containing 1.2-1.7 wt\% Sn and a total iron, chronium, and nickel content of 0.18-0.38 wt\%.

$\star * G=E / 2(1+v)$ 


\section{Distribution for ANL-83-14}

Internal:
H. U. Ahmed
R. Avery
J. L. Bailey
E. S. Beckjord
E. F. Bennett
S. K. Bhattacharyya
L. Burris
J. M. Carpenter (20)
I. Charak
C. A. DeLorenzo
T. Ewing

G. L. Fogle

B. P. T. Frost

G. K. Rusch

A. G. Hins

M. A. Kirk

K. L. Kl iewer

J. H. Talboy

C. E. K10:2

A. E. krox

K. E. Kuczen

B. D. LaMar

L. G. LeSage (2)

R. A. Lewis

B. A. Loomis

F. A. Nichols

H. R. Thresh

C. E. Till

E. Van Berkum

R. W. Weeks

H. Wiedersich

R. S. Zeno

ANL Patent Dept.

ANL Contract File

ANL Libraries

TIS Files (6)

\section{External:}

DOE-TIC, for distribution per UC-34C (121)

Manager, Chicago Operations Office, DOE

G. S. Bauer, KFA Institute fur Festkoperforschung, Julich, West Germany (2)

B. G. Chidley, Chalk River Nuclear Labs., Chalk River, Ont., Canada (2)

A. F. D'Souza, Illinois Institute of Technology, Chicago

W. E. Fischer, Swiss Institute for Nuclear Research, Villigen, Switzerland (2)

F. H. Hammad, American University, Cairo, Egypt

Y. Ishikawa, Tohoku University, Sendai, Japan (2)

G. U. Russe11, Los Alamos National Laboratory (2)

H. Sasaki, National Laboratory for High Energy Physics, Ibaraki-ken, Japan (2)

G. C. Stirling, Rutherford and Appleton Laboratory, Chilton, England (2)

I. M. Thorson, Simon Fraser University, Burnaby, B.C., Canada (2)

J. E. Vetter, Kernforschungs zentrum, Karlsruhe, West Germany (2) 